Aston University

Some pages of this thesis may have been removed for copyright restrictions.

If you have discovered material in AURA which is unlawful e.g. breaches copyright, (either yours or that of a third party) or any other law, including but not limited to those relating to patent, trademark, confidentiality, data protection, obscenity, defamation, libel, then please read our Takedown Policy and contact the service immediately 
B R U S H P I T I N G O F

B E A R I G A L L O Y S ON

A L U M I N I U A I L O Y S H E L L S

MICHAEL TURNER

A Thesis submitted for the degree of Doctor of Philosophy

THE UNIVERSITY OF ASTON IN BIRMINGHAM

SEPTEMBER 1986

This copy of the thesis has been supplied on condition that anyone who consults it is understood to recognise that its copyright rests with its author and that no quotation from the thesis and no information derived from it, may be published without the author's prior, written consent. 
TITLE

AUTHOR'S NAME

DEGREE

\section{BRUSH PLATING OF BEARING ALLOYS ON ALUMINIUM ALLOY SHELLS}

MICHAEL TURNER

PhD

1986

\section{S U M M A R Y}

The turbocharging of diesel engines has led to increase in temperature, load and corrosive attack of plain bearings. To meet these requirements, overlay plated aluminium alloys are now preferred. Currently, lead-tin alloys are depositted using a zincate layer and nickel strike, as intermediate stages in the process. The nickel has undesirable seizure characteristics and the zincate can give rise to corrosion problems. Consequently, brush plating allows the possible elimination of these stages and a decrease in process time together with greater automation.

The effect of mode of application, on the formation of zincate films, using film growth weight measurements, potential-time studies, peel adhesion testing and scanning Electron Microscopy was studied, for both SIC and ASIS aluminium alloys. The dịrect plating of aluminium was also successfully achieved.

The results obtained indicate that generally, although lower adhesion resulted when a brush technique was used, satisfactory adhesion for fatigue testing was achịeved.

Both lead-tin and tịn-cobalt overlays were examined and a study of the parameters governing brush plating was carried out using various electrolytes. An experimentally developed small scale rig, was used to produce overlay plated bearings that were fatigue tested until failure. The bearings were then examined and an analysis of the failure mechanisms undertaken.

The results indicated that both alloy systems are of the regular codeposition type. Tin-cobalt overlays were superior to conventional lead-tin overlays and remained in good condition, although the lining (substrate) failed. Brush plated lead-tịn was unsatisfactory.

Sufficient understanding has now been gained, to enable a larger scale automated plant to be produced. This will allow a further study of the technique to be carried out, on equipment that more closely resembles that of a full scale production process. 
The author wishes to thank the science and Engineering Research Council for providing overall project funding, the Glacier Metal Co. Itd. for financial assistance and the provision of equipment. The author also wishes to thank the academic and technical staff of the Department of Mechanical and Production Engineering at the University of Aston in Birmingham for their continuous support throughout the research.

In particular the author wishes to thank his supervisor Dr. J.K. Dennis for his considerable guidance throughout the work and Dr. D.R. Eastham for all the helpful discussions. 
Page

TITLE PAGE

SUMMARY

ACKNOWLEDGEMENTS

LIST OF CONTENTS

LIST OF FIGURES

LIST OF TABLES

1. INTRODUCTION 21

2. BRUSH PLATING 24

2.1 Introduction to Brush Plating 24

2.2 Process Development 25

2.3 Brush Plating - Its Advantages and $\begin{array}{ll}\text { Disadvantages } & 26\end{array}$

2.3.1 Advantages 26

2.3.2 Disadvantages 29

2.4 Materials and Equipment 30

2.4.1 Special Electrolytes 30

2.4.1.1 Temperatures 31

2.4.1.2 Variable Concentration 31

2.4.1.3 Current Density 31

2.4.2 Anodes 31

2.4.3 Power Supply 33

3. ELECTROCHEMICAL ASPECTS. OF HIGH SPEED PLATING 35

4. ALLOY PLATING - 47 
4.1 Introduction to Alloy Plating 47

4.2 Classification of Codeposition of Alloys ' 49

4.2.1 Regular Codeposition 49

4.2.2 Irregular Codeposition 49

4.2.3 Equilibrium Codeposition 50

4.2.4 Anomalous Codeposition 50

4.2.5 Induced Codeposition 50

4.3 Electrodeposition of Lead-Tin Alloys 51

4.3.1 Types of Bath 52

4.3.1.1 Fluoborate 52

4.3.1.2 Pyrophosphate 53

4.3.1.3 Sulphamate 54

4.4 Tin-Cobalt Alloy Plating 55

4.4.1 Plating Variables 56

4.4.2 Effect of plating Variables on

the Structure of Electro-

deposited Cobalt $\quad 57$

5. ELECTRODEPOSITION ONTO ALUMINIUM ALLOYS 59

5.1 Methods used for Electrodeposition

onto Aluminium 60

5.1.1 Anodic Oxidation 61

5.1.2 Chemical oxidation 62

5.1.3 Mechanical Roughening 62

5.1.4 Chemical Roughening 63

5.1.5 Immersion Films 63

5.1.5.1 Tin Immersion Process 65

5.1.5.2 Theory of Immersion

Films Developed from

zincate Solutions 
5.1.5.3 Development of Zincate

Solution Formulations $\quad-67$

5.1.6 Direct Plating

6. BEARINGS

6.1 Properties of an Ideal Bearing Material 78

6.2 Historical Review of Bearings 82

6.3 Bearing Overlays 86

6.3.1 Plating Process Cycle 95

$\begin{array}{ll}\text { 7. ASPECTS OF WEAR } & 97\end{array}$

7.1 Types of Wear 99

7.1.1 Abrasive Wear $\quad 99$

7.1.2 Adhesive Wear 99

7.1.3 Erosive Wear 100

:7.1.4 Chemical Wear 100

7.1.5 Fretting Wear 101

7.1.6 Fatigue Wear 101

7.2 Wear of Plain Bearings 102

$\begin{array}{ll}7.2 .1 \text { Dirt } & 103\end{array}$

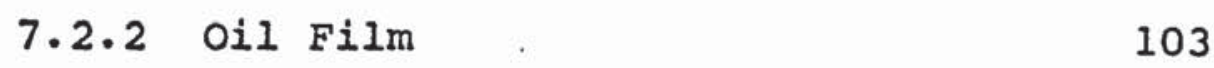

7.2.3 Cavitation Erosion 104

7.3 Fracture and Fatigue 105

7.3.1 Overlay Fatigue 109

$\begin{array}{lll}7.4 & \text { Lubrication } & 110\end{array}$

8. EXPERIMENTAL PROCEDURE 113

8.1 Brush Plating Equipment and Technique 113

8.1.1 Selection of stylus Holder 113

8.1.2 Stylus Preparation 113

8.1.3 Power Supply 115

8.1.4 Brush Plating Technique 116 
8.2 Substrate Material

8.3 Pretreatment and Plating procedure 119

8.3.1 Sequence Al Simple Immersion 120

8.3.2 Sequence A2 120

8.3.3 Sequence BI Electrolytic Immersion $\quad 120$

8.3.4 Sequence B2 120

8.3.5 Sequence Cl Simple Brush. 121

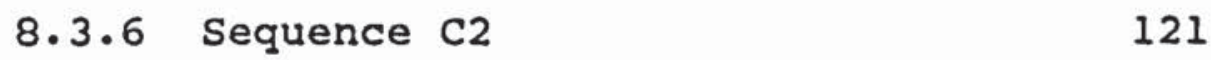

8.3.7 Sequence DI Electrolytic Brush 121

$\begin{array}{lll}\text { 8.3.8 Sequence D2 } & 121\end{array}$

8.3.9 Sequence E Direct Pretreatment

Sequence

8.4 Study of zinc Alloy Film Morphology

8.5 Determination of the Film Weight of the zinc Alloy Coatings

8.6. Potential-Time Measurements in a Zinc Alloy Solution

8.7 Peel Adhesion Testing 126

$\begin{array}{lll}8.8 \text { Examination of Peeled Panels } & 127\end{array}$

$\begin{array}{lll}8.9 & \text { Brush plating Solutions } & 127\end{array}$

8.9.1 Commercial Solutions 127

8.9.2 Preparation of Tin-Cobalt Electrolytes

8.10 Analysis of Deposit Composition 129

8.10.1 Atomic Absorption

$\begin{array}{cc}\text { Spectrophotometry (AAS) } & 130 \\ 8.10 .1 .1 \text { Tin-Cobalt Overlays } & 130 \\ 8.10 .1 .2 \text { Lead-Tin Overlays } & 130 \\ 8.10 .2 \text { Energy Dispersive X-ray Analysis } & 131\end{array}$


8.11 Effect of Speed, Load and Solution Flow on Deposit Characteristics

8.11.1 Calculation of Cathode Current Efficiency of Alloy Solutions

8.12 x-ray Diffraction

8.13 Fatigue Testing

8.14 Corrosion Testing of the overlaySubstrate Bond

8.15 Metallographic Sample Preparation and Examination

9. EFFECT OF MODE OF APPLICATION ON THE FORMATION OF ZINC ALLOY FILMS

9.1 On SIC Aluminium

9.1.1 Using 'Bondal' as the Zinc Alloy Solution

9.1.2 Using 'Alumseal' as the Zinc Alloy Solution

9.2 On ASI5 ( $\mathrm{Al}-208 \mathrm{Sn}-18 \mathrm{Cu})$

9.2.1 Using Nitric ACid

9.2.2 Using Hydrogen Peroxide-Sulphuric Acid

10. DISCUSSION ON THE EFFECT OF MODE OF APPLICATION ON THE FORMATION OF ZINC ALLOY FIIMS

10.1 on SIC Aluminium

10.2 on AS15

11. OVERLAY PLATING OF AS15 BEARING SHELLS 184

11.1 Direct Plating Pretreatment (Sequence E) 184

11.2 Lead-Tin Overlays. 
11.2.1 Effect of Speed, Load and Solution Flow on Deposit Characteristics

188

11.3 Tin-Cobalt Overlays

11.3.1 Effect of Speed, Load and

Solution Flow on Deposit

Characteristics

202

11.3.2 Microstructure of Tin-Cobalt

overlays

12. DISCUSSION ON THE OVERLAY PLATING OF ASI5

BEARING SHELLS

226

12.1 Direct Plating Pretreatment 226

12.2 Lead-Tin Overlays 228

12.3 Tin-Cobalt Overlays 233

13. RESULTS FROM SAPPHIRE FATIGUE TESTS 244

13.1 Manual Brush Plating 244

13.1 .1 AlA 244

13.1 .2 AlB 247

$\begin{array}{ll}13.1 .3 \text { A4 } & 247\end{array}$

$\begin{array}{lll}13.1 .4 \text { B5 } & 247\end{array}$

$\begin{array}{ll}13.1 .5 \text { В6 } & 249\end{array}$

13.2 Semi-Automatic Brush Plating

(Small Anode) $\quad 249$

13.2 .1 MT2 249

$\begin{array}{ll}13.2 .2 \mathrm{MT} 3 & 250\end{array}$

$\begin{array}{ll}13.2 .3 \text { MT4 } & 250\end{array}$

13.2.4 MT5 251

13.3 Semi-Automatic Brush Plating

(Large Anode 'Selvyt' Pad) 252

13.3.1 MT6 252 
$13.3 .3 \mathrm{MT8} \quad 254$

$\begin{array}{ll}13.3 .4 \text { MT9 } & 254\end{array}$

$\begin{array}{ll}13.3 .5 ~ M T 10 & 255\end{array}$

13.3 .6 MTII 255

13.4 Semi-Automatic Brush Plating

( 3 Pairs of Bearings) 255

13.4.1 MT15 259

$\begin{array}{ll}13.4 .2 M T 16 & 259\end{array}$

$\begin{array}{ll}13.4 .3 \operatorname{MT} 17 & 259\end{array}$

13.4.4 MT18 259

13.4 .5 MT19 262

13.4 .6 MT20 262

13.4.7 MT21 262

13.4 .8 MT22 263

$\begin{array}{ll}\text { 14. DISCUSSION } & 264\end{array}$

15. CONCLUSIONS 274

16. SUGGESTIONS FOR FURTHER WORK 278

17. REFERENCES 280 
FIG. 1

FIG. 2

FIG. 3

FIG. 4

FIG. 5

FIG. 6

FIG. 7

FIG. 8

FIG. 9

FIG. 10

FIG. 11

The effect of relative anode-cathode motion and current density on deposit characteristics $(3)$

The relationship between $E$ and $i$ for $a$ cathode and anodic electrode process(15)

The relationship between cathode current density and cathode potential(15)

Schematic representation of metal deposition at low and high overpotentials(19)

Cylinder pressure diagrams for naturally aspirated and turocharged diesel engines (115)

Effect of overlay on the apparent fatigue strength of the lining material determined on the Sapphire test machine (116)

The effect of overlay thickness on fatigue strength(117)

Corrosion of overlays in medicinal white oil at $120^{\circ} \mathrm{C}(117)$

Typical oil film pressure contours over the surface of an automotive engine bearing at the instant of minimum oil film thickness(116)

The relationship of friction in a journal bearing to the viscosityspeed-load criterion $\mathrm{ZN} / \mathrm{P}(133)$ 
FIG. 13 Styli holders used in this investigation

FIG. 14 Materials involved in preparation of the stylus

FIG. 15 Semi-automated brush plating equipment

FIG. 16

Schematic diagram of the Sapphire fatigue testing machine(116)

FIG. 17

Scanning electron micrographs of SIC surfaces prior to the final alloy zincate stage for : (a) Sequence Al

(b) Sequence A2 (c) Sequence $\mathrm{Cl}$

(d) Sequence C2

FIG. 18(i) Scanning electron micrographs of SIC surfaces after a 10 second immersion in 'Bondal' solution for : (a) Sequence Al

(b) Sequence A2 (c) Sequence $\mathrm{Cl}$

(d) Sequence C2

FIG. 18(ii) Scanning electron micrographs of SIC surfaces after a 10 second immersion in 'Bondal' solution for : (e) Sequence $\mathrm{Cl}$

(f) Sequence C2 (g) Sequence DI

(h) Sequence D2

FIG. 19(i) Scanning electron micrographs of SIC surfaces after a 60 second immersion in 'Bondal' solution for : (a) Sequence A1 (b) Sequence A2 (c) Sequence Cl (d) Sequence C2

FIG. 19(ii) Scanning electron micrographs of SIC surfaces after a 60 second immersion in 'Bondal' solution for : (e) Sequence Cl (f) Sequence C2 (g) Sequence DI (h) Sequence D2 
FIG. 20

Scanning electron micrographs of SIC surfaces after brushing with a 'Selvyt' covered stylus using 'Bondal' solution for (a) 10 seconds (b) 60 seconds

FIG. 21

Relationship between zincate time and film growth weight on SIC using

'Bondal' solution

FIG. 22

Relationship between zincate time and film growth weight on SIC for nylonpolpropylene covered styli using 'Bondal' solution

FIG. 23

Relationship between zincate time and film growth weight on SIC for 'Selvyt' covered styli using 'Bondal' solution

FIG. 24a Relationship between immersion time and the change in surface potential of SIC in a 'Bondal' solution

FIG. 24b

Relationship between immersion time and the change in surface potential of SIC in a 'Bondal' solution

FIG. 25

Scanning electron micrograph of SIC (sequence A2) after peel adhesion testing and the corresponding aluminium $\mathrm{X}$-ray map

FIG. 26

Scanning electron micrographs of SIC surfaces after brushing with an 'Alumseal' solution for (a) $10 \mathrm{~s}$ Sequence $\mathrm{Cl}$ (b) $60 \mathrm{~s}$ Sequence $\mathrm{Cl}$ (c) 10s Sequence C2 (d) 60 s Sequence C2

FIG. 27

Relationship between zincate time and film growth weight on SIC for nylonpolypropylene covered styli using 'Alumseal' solution

FIG. 28

Scanning electron micrographs of AS15 surfaces prior to the final alloy zincate stage for : (a) sequence AI (b) Sequence A2 and (c) after a 60s immersion in 'Bondal' solution using Sequence AI 
FIG. 29

Relationship between zincate time and film growth weight on ASI5 using

'Bondal' solution

164

FIG. 30

Relationship between immersion time and

the change in surface potential of

ASl5 in a 'Bondal' solution

166

FIG. 31 Scanning electron micrographs of AS15

surfaces prior to the final alloy

zincate stage for : (a) Sequence $\mathrm{Cl}$ (b)

Sequence C2 (c) after a 30 s brushing

with 'Bondal' solution using Sequence Cl 167

FIG. 32 Relationship between zincate time and film growth weight on ASI5 using 'Bondal' solution for : (a) Sequence $A l(G)$ (b)

Sequence A2(G) (c) Sequence $\mathrm{Cl}(\mathrm{G})$ (d)

Sequence $\mathrm{C2}(\mathrm{G})$

FIG. 33

Relationship between immersion time and

the change in surface potential of AS15

in a 'Bondal' solution for sequences

$A I(G), A 2(G), C l(G)$ and $C 2(G)$

170

FIG. 34 Scanning electron micrographs of the surface of (a) ASI5 and (b) SIC after pretreatment prior to overlay plating using sequence $E$.

FIG. 35

Relationship between plating voltage and deposit composition for lead-tin brush plating solutions, using 0.34 $\mathrm{ms}^{-1}, 0.1 \mathrm{ml} \cdot \mathrm{s}^{-1}$ and $22 \mathrm{~g}$

FIG. 36 Relationship between plating voltage and deposit composition for lead-tin fluoborate solution, using $0.34 \mathrm{~ms}^{-1}$, $0.1 \mathrm{ml} \cdot \mathrm{s}^{-1}$ and $22 \mathrm{~g}$

FIG. 37a(i) Relationship between relative anodecathode motion and deposit composition for lead-30v/o tin brush plating solution, using $15 \mathrm{~V}, 0.1 \mathrm{ml} \cdot \mathrm{s}^{-1}$ and $22 \mathrm{~g} 190$ 
FIG. 37a(ii) Relationship between relative anodecathode motion and cathode solution efficiency for lead-30v/o tin brush plating solution, using $15 \mathrm{~V}, 0.1 \mathrm{ml} \cdot \mathrm{s}^{-1}$ and $22 g$

FIG. 37b(i) Relationship between applied anode load and deposit composition for lead-30 $/ 0$ tin brush plating solution, using $15 \mathrm{~V}$, $0.34 \mathrm{~ms}^{-1}$ and $0.1 \mathrm{ml} \cdot \mathrm{s}^{-1}$

FIG. 37b(ii) Relationship between applied anode load and cathode solution efficiency for lead-30v/o tin brush plating solution, using $15 \mathrm{~V}, 0.34 \mathrm{~ms}^{-1}$ and $0.1 \mathrm{ml} \cdot \mathrm{s}^{-1}$

FIG. 37c(i) Relationship between solution flow rate and deposit composition for lead-30 $/ 0$ tin brush plating solution, using 15V, $0.34 \mathrm{~ms}^{-1}$ and $22 \mathrm{~g}$

FIG. 37c(ii) Relationship between solution flow rate and cathode solution efficiency for lead $-30 \mathrm{v} / 0$ tin brush plating solution, using $15 \mathrm{~V}, 0.34 \mathrm{~ms}^{-1}$ and $22 \mathrm{~g}$

FIG. 38

Relationship between solution make-up and deposit composition for tin-cobalt brush plating solutions using $15 \mathrm{~V}, 0.34$ $\mathrm{ms}^{-1} 0.1 \mathrm{ml} \cdot \mathrm{s}^{-1}$ and $22 \mathrm{~g}$

FIG. 39

Relationship between plating voltage and deposit composition for $t i n-25 \mathrm{v} / 0$ cobalt brush plating solution, using $0.34 \mathrm{~ms}^{-1}, 0.1 \mathrm{ml} \cdot \mathrm{s}^{-1}$ and $22 \mathrm{~g}$

FIG. 40

Relationship between plating voltage and deposit composition for Aston solutions 1,2 and 4 using $0.34 \mathrm{~ms}^{-1}, 0.1 \mathrm{ml} \cdot \mathrm{s}^{-1}$ and $22 \mathrm{~g}$

FIG. 41

Scanning electron micrograph showing the effect of the pad material on overlay morphology for (a) nylonpolypropylene pad and (b) 'Selvyt' pad 200 
FIG. 42

The effect of pad material on deposit composition for tin-cobalt brush plating solution, using $15 \mathrm{~V} 0.34 \mathrm{~ms}^{-1}$, $0.1 \mathrm{ml} \cdot \mathrm{s}^{-1}$ and $22 \mathrm{~g}$ 201

FIG. 43a(i) Relationship between relative anodecathode motion and deposit composition for tin-25V/o cobalt brush plating solution, using $15 \mathrm{~V}, 0.1 \mathrm{ml} \cdot \mathrm{s}^{-1}$ and $22 \mathrm{~g} 203$

FIG. 43a(ii) Relationship between relative anodecathode motion and cathode solution. efficiency for tin-25v/o cobalt brush. plating solution, using $15 \mathrm{~V}, 0.1 \mathrm{ml} . \mathrm{s}^{-1}$ and $22 \mathrm{~g}$

FIG. 43b(i) Relationship between applied anode load and deposit composition for $\operatorname{tin}-25 \mathrm{v} / 0$ cobalt brush plating solution, using $15 \mathrm{~V}, 0.34 \mathrm{~ms}^{-1}, 0.1 \mathrm{ml}^{-1} \mathrm{~s}^{-1}$

FIG. 43b(ii) Relationship between applied anode load and cathode solution efficiency for tin-25v/o cobalt brush plating solution, using $15 \mathrm{~V} 0.34 \mathrm{~ms}^{-1}$ and $0.1 \mathrm{ml} \cdot \mathrm{s}^{-1}$

FIG. 43c(i) Relationship between solution flow rate and deposit composition for tin-25v/o cobalt brush plating solution, using $15 \mathrm{~V} 0.34 \mathrm{~ms}^{-1}, 22 \mathrm{~g}$

FIG. 43c(ii) Relationship between solution flow rate and cathode solution efficiency for tin-25v/o cobalt brush plating solution, using $15 \mathrm{~V}, 0.34 \mathrm{~ms}^{-1}, 22 \mathrm{~g}$

FIG. 44a(i) Relationship between relative anodecathode motion and deposit composition for Aston solution 3 , using $15 \mathrm{~V}$, $0.1 \mathrm{ml} \cdot \mathrm{s}^{-1}$ and $22 \mathrm{~g}$

FIG. 44a(ii) Relationship between relative anodecathode motion and cathode solution efficiency for Aston solution 3, using $15 \mathrm{~V}, 0.1 \mathrm{ml} \cdot \mathrm{s}^{-1}$ and $22 \mathrm{~g}$ 
FIG. 44b(i) Relationship between applied anode

load and deposit composition for Aston

solution 3 , using $15 \mathrm{~V} 0.34 \mathrm{~ms}^{-1}$,

$0.1 \mathrm{ml} \cdot \mathrm{s}^{-1}$

FIG. 44b(ii) Relationship between applied anode

load and cathode solution efficiency

for Aston Solution 3, using $15 \mathrm{~V}, 0.34$

$\mathrm{ms}^{-1}$ and $0.1 \mathrm{ml} \cdot \mathrm{s}^{-1}$

FIG. 44c(i) Relationship between solution flow rate and deposit composition for Aston

solution 3 , using $15 \mathrm{~V} 0.34 \mathrm{~ms}^{-1}, 22 \mathrm{~g}$

FIG. 44c(ii) Relationship between solution flow rate and cathode solution efficiency for Aston solution 3 , using $15 \mathrm{~V} 0.34 \mathrm{~ms}^{-1}$, $22 \mathrm{~g}$

FIG. 45

'Spot' E.D.X.A. results obtained by traversing an overlay cross-section of bearings MT $3, \mathrm{MT} 4$ and MT 5

FIG. 46

'Spot' E.D.X.A. results obtained by traversing an overlay cross-section of bearings MT 6, MT 7, MT 9 and MT 11

FIG. 47

'Spot' E.D.X.A. results obtained by traversing an overlay cross-section of bearings MT 15 and MT 17

FIG. 48

'Spot' E.D.X.A. results obtained by traversing an overlay cross-section of bearings plated at $10 \mathrm{~V}, 15 \mathrm{~V}, 20 \mathrm{~V}$ and by using an initially hot solution $\left(70^{\circ} \mathrm{C}\right)$

FIG. 49a,b Optical micrographs indicating the distribution of phases and corresponding cobalt elemental line concentration profiles for bearings : (a) AIB

(b) MT 2

FIG. 49c Optical micrographs indicating the distribution of phases and corresponding cobalt elemental line concentration profiles for bearings : (c) MT 3 
FIG. 50

Optical micrographs indicating the distribution of phases and corresponding cobalt elemental line concentration profiles for bearings : (a) MT 4 (b) MT 5

FIG. 51 Optical micrographs indicating the distribution of phases and corresponding cobalt elemental line concentration profiles for bearings : (a) MT 6 (b) MT 7

FIG. 52 Optical micrographs indicating the distribution of phases and corresponding cobalt elemental line concentration profiles for bearings : (a) MT 9 (b) MT 11

FIG. 53

Cobalt elemental line concentration profiles of an overlay plated bearing (a) before and (b) after heat-treatment at $180^{\circ} \mathrm{C}$ for 100 hours

FIG. 54

Optical micrographs of bearing AlA showing cavities within the overlay

FIG. 55

Optical micrographs of bearing A4 showing catastrophic failure of the As15 lining

FIG. 56

Optical macrographs of bearings MT 2 MT 5 exhibiting the variation in the amount of the overlay removed

FIG. 57 Weight loss data obtained during the fatigue tests of bearings MT 2 - MT 5

FIG. 58

Optical macrograph of bearing exhibiting the variation of overlay deposit quality from edge to centre

FIG. 59a Optical macrograph of bearing MT 15 after Sapphire fatigue testing, showing no evidence of fatigue 
FIG. 59b Optical micrograph of bearing MT 15 after Sapphire fatigue testing indicating the presence of a 'light blue' phase at the substrate-coating interface

FIG. 60

Optical micrograph of bearing MT 17 , exhibiting fatigue of the ASI5 lining

261 
$\underline{\text { Page }}$

TABLE 1 Comparison of Metal Concentration of Brush plated and Conventional Electroytes

TABLE 2 Processing Sequence for Nickel Plating on Aluminium using the Stannate Immersion Process

TABLE 3 Processing Sequence for Nickel Plating on Aluminium using the Simple zincate Immersion Process 70

TABLE 4 Processing Sequence for Nickel Plating on Aluminium using the Direct Plating process

TABLE 5 Adhesion of Watts Nickel Electrodeposits to SIC and AS15 after various pretreatment Sequences

TABLE 6 Typical 'd spacings' obtained by X-ray Diffraction of a Tin-Cobalt Overlay, Together with the Theoretical 'd spacings' for the possible phases 
Many millions of bearings have been produced for the automotive industry over the years and many types of bearing materials have been used, some of which have been overlay plated to improve the friction characteristics, corrosion resistance, fatigue strength, embeddability and conformability of the substrate.

In recent years, a greater power output and higher speeds have been sought from automotive engines, but without a pro rata increase in engine weight. This general trend has lately been slowed down for petrol. engines but, has proceeded apace for diesel engines. Haulage operators compete to reduce journey times and operating costs, over routes which are a mixture of fast motorways and winding second class roads. In order to achieve high average speeds under such varying condition, increased mid-range engine torque is required together with the freedom to run for periods at high speeds during overrun on downhill slopes. Diesel engine designers are meeting these requirements, often by turbocharging for high mid-range torque and by accommodating high mechanical stresses in rotating and reciprocating components.

The effect on engine bearings is twofold. A high load imposed for a comparatively short time at medium speed upon the bearing surface, introduces critical fatigue stresses 
in the bearing material. The high speed overrun condition however, generates thin hydrodynamic oil films and this leads to a requirement for a high resistance to seizure and wear in the same bearing material. Extremes of fatigue strength and resistance to seizure tend to be mutually incompatible and a bearing material compromise is always necessary .

High engine speeds also lead to high lubricant temperatures and in long life engines running at high temperatures, materials are exposed to the possibility of corrosive attack from acidic and degraded lubricants. In addition to an ability to carry very high loads and still retain good surface properties therefore, bearings require to be highly resistant to corrosion.

In order to meet these operating conditions, overlay plated aluminium alloys are now preferred. The present industrial practice is for lead-tin alloys to be electrodeposited onto the alloy shells, using the well known zinc alloy immersion process, as an intermediate stage in the sequence. This is currently necessary, due to the reactive nature of aluminium and consequent rapid formation of an oxide film, which prevents the addition of a conventional electrodeposited coating. It has also proved necessary to deposit a nickel strike coating onto the zinc alloy plating. However, the nickel has undesirable seizure characteristics and its omission from the sequence is preferred. 
In this current investigation, brush (selective) plating techniques were used as a novel way of electrodepositing overlays onto plain bearings. The successful brush plating of these overlays, would have several advantages over the conventional process. Brush plating operates at very high current densities hence, reducing the process time. The operation can be carried out with a reduction in plant size and requires fewer operators, as it can be automated. The possibility exists with brush plating, for the successful direct deposition of overlays onto the aluminium alloy substrates. This eliminates the zinc alloy film and the nickel strike layer. Hence the process becomes simpler and cheaper to operate, environmentally cleaner, by removing the stage using a cyanide solution and produces an overlay plated bearing that does not contain a nickel layer, that is prone to seizure. 


\subsection{Introduction to Brush Plating}

Brush plating is one of a number of names given to the process in which an absorbent pad, wrapped around an anode is soaked with electrolyte and rubbed over the surface to be plated. The process is also known as selective area, tampon or swab plating. The area to be plated, at any one instant, is only small, but it can be assumed that at that particular area, the process is one of high speed plating. Control of the process is exercised by means of voltage and ampere-hour measurement and only to a limited extent by current density as in the case of vat plating. No immersion of the component in a vat is necessary and selected areas can be plated.

The plating tool is not a flexible brush, but consists of an inert anode covered with a suitable absorbent material to hold the electrolyte hence, the term brush plating is a misnomer. The system is designed such that the inert electrode can be made either the cathode or the anode, depending on the treatment being carried out. The time required to deposit a particular coating is dependent on the thickness required, the area to be plated and the efficiency of the solution. However, the rectifier capacity necessary, is much lower than for conventional 
plating and in consequence, the rectifier unit is relatively small and portable. A selected area can be plated with a minimum of stopping-off, adhesive tape around the area to be plated is normally sufficient.

\subsection{Process Development}

The first reported use of brush plating as a technique was as far back as $1899(1)$. The original use was a 'touch-up' to plate areas unplated by conventional methods, or to cover over surface defects. The technique employed was to hold the component against a bus bar, whilst it was rubbed with an electrolyte soaked rag connected to the other bus bar.

Hughes(2) reported a further development into a low voltage technique (6-8 v) using solutions from which deposits could be obtained easily. A later improvement arose with the concept of a 'brush' to retain' the electrolyte. The brush consisted of an insulated handle terminating in a fan shaped brush of fine wires. The electrolyte was in the form of a thick paste and since it was only the viscosity of the paste that prevented anode-cathode shorting, severely burned deposits could be produced.

Initially, control of the process was poor and with only a small area being plated at any instant, many burned 
deposits were produced. Significant developments were achieved in the early $1950^{\prime} \mathrm{s}$, when research work produced a controlled and workable industrial brush plating system, capable of depositing metallic coatings of uniform thickness which were metallurgically sound. Fig. 1 shows the relationship between anode-cathode motion and the current density required to produce sound deposits(3). These deposits had extremely high adhesion and good mechanical properties. The first commercial instruction manual was published in $1950(4)$ and the first technical paper on the subject was presented by Rubinstein(5) in 1954. Further development work, carried out by the Selectron organisation(6) and Metadalic Ltd,(7), resulted in soundly engineered brush plating equipment capable of achieving satisfactory results.

\subsection{Brush Plating - Its advantages and its disadvantages}

The advantages and disadvantages of brush plating have been listed in detail by the majority of workers in the field, particularly Rubinstein and ogden(8) however, some of the more important ones are listed below.

\subsubsection{Advantages of Brush Plating}

(a) Touching-up. Defective areas of an electrodeposit can be readily activated and replated by this 


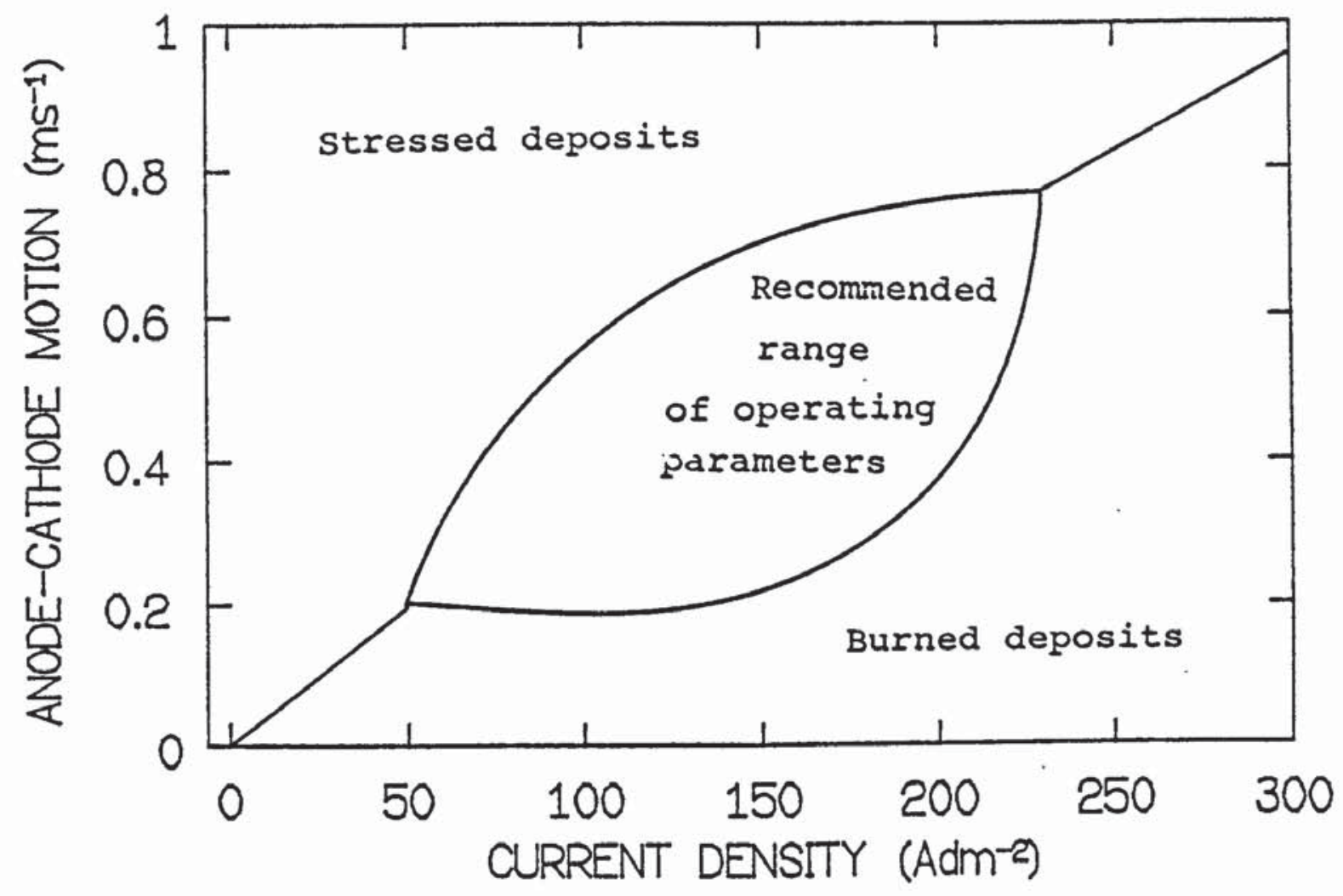

FIG. 1 The effect of relative anode-cathode motion and current density on deposit characteristics $(3)$ 
technique. This may occur immediately after plating; or a considerable period later, when a component may be in service and not readily accessible.

(b) Portability. Components can be plated in-situ. This is very useful in the aerospace industry, where it is costly and time consuming to dismantle components. Brush plating may also be of value where components are too large for conventional vat plating .

(c) Selective plating . Considerable expense and difficulty can-be involved in stopping-off areas of the workpiece on which the deposit is not required. Brush plating reduces the need for such elaborate operations.

(d) Adhesion. It has been reported by Rubinstein that adhesion can be as good as or even better than that achieved by equivalent bath plating.

(e) Repair of Worn Components. Worn aluminium engine blocks have been repaired by building up with copper(9). Plastic moulding dies have also been repaired by the use of multilayer brush coatings $(10)$ 
(f) Platịng Diffịcult Materịals. Some degree of success has been achịeved when platịng metals that cannot be vat electroplated easily. It has been suggested that on aluminium and refractorary metals, adhesion is far superior to that achieved by conventional plating(15). This is claimed to be due to the high current densities used in the cleaning procedure followed by immediate deposition of the required material.

\subsubsection{Disadvantages of Brush Plating}

(a) Labour Intensịve. Some expertise is needed to enable good results to be achieved by this technique. Manual brush plating is also laborious and tịme consuming. In certaịn cịrcumstances mechanisation of symmetrical components can be achieved, however close supervịition is still required. It may now be possible, with the advent of microprocessors, to achịeve thịs automatically.

(b) Expensive Solutions. Solution costs are high due to the hịgh concentration of metal salts used. For some applications the solution is not re-used but fortunately the volume of solution used per unit area is not too great. Large scale mechanised brush platịng plants require large volumes of solutions, hence spent solutions are re-used. Solution 
maintenance is then required.

(c) Absorbent Materials for the Anodes. The material chosen must be resistant to the solutions employed, which may either be acid or alkaline. It must be able to withstand the appropriate solution at the high temperatures present in brush plating and must not contaminate the solutions. It must be abrasion resistant, thus preventing shorting of the workpiece and the electrode and must not be detrimental to the deposit produced. This is of particular importance when depositing very soft layers.

\subsection{Materials and Equipment}

\subsubsection{Special Electrolytes}

The electrolytes developed for use in brush plating have a much higher metal content than those used for conventional plating. This is necessary if the high deposition rates are to be achieved. Since precise control is difficult when brush plating, the solutions must be capable of producing a sound deposit over a wide range of plating variables. 
2.4.1.1 Temperatures. The temperature of the electrolyte in the immediate vicinity of the anode may reach its boiling point. In these cases, anode design is important, as rapid heat dissipation may prevent such an increase in temperature. Constituents which give rise to toxic fumes, under such conditions, should be avoided in the make up of brush plating solutions.

2.4.1.2 Variable Concentration. Rapid metal ion depletion of the electrolyte takes place around the anode, due to the high deposition rate in brush plating. The solution should be capable of reasonably uniform deposition over a wide range of metal ion concentrations.

2.4.1.3 Current Density. A wide range of current densities is experienced during plating, due to the small area of contact with the workpiece and the movement of the anode. Consequently, the solution must be able to produce sound deposits under widely differing conditions. of current density.

\section{4 .2 Anodes}

The earliest brush plating electrodes consisted of a metal 
anode wrapped with a rag however, this technique has been superceded by more sophisticated anodes. Soluble anodes inside nylon bristles or brushes were also an early development. This however, gave rise to problems due to the intense anode polarisation at the high current densities used. Inert anodes overcame this problem. The early inert anodes were graphite, as this was easily machined to various shapes and sizes. Initially, commercial carbon was used, but this tended to become heavily contaminated with metals such as zinc or copper which resulted in contamination of the solutions. Special high density carbon is now preferred which can withstand the stress of the stylus movement and the ingress of impurities. Other materials have been used; these include platinised titanium, tantalum, platinum-iridium and stainless steel. However stainless steel, due to its vulnerability with respect to attack by chlorides and other chemicals and subsequent contamination of the electrolyte, has not proved very successful. Anodes made out of the same material as that being brushed plated have been used $(11,12,13)$, but these proved to be inefficient due to intense anode polarisation caused by the formation of anode films and the consequent reduction in plating rate. 
The earliest method of retaining the electolyte was to wrap the anode with an acid resistant cloth. Subsequently, a large number of materials have been tried with the object of providing a chemically inert, abrasion resistant and absorbent pad. For most brush plating purposes, long fibre sterịle cotton battịng is claimed to be most suitable, but may be difficult to obtain. Other wrappings have also proved successful, such as nylon-polypropylene which provịdes much better wear resistance and prevents snagging or rough edges.

\subsubsection{Power Supply}

It is necessary to have a power supply capable of providing a varịale voltage over a required range. For most brish plating operations thịs range is $8-30$ Volts. It is a consequence of the nature of the technique that the current fluctuates rapidly between zero and a given maximum. This is due to the anode being removed and replaced onto the workpiece, consequently ammeters are of less value as a means of control than they are in conventional vat plating. It should be noted that the time taken to produce a deposit of a given thickness can differ significantly depending on the proportion of time spent passing current as opposed to replenishing the stylus with solution. Consequently, in the present work, control of the process is exercised by means of a constant voltage and ampere-hour measurements. 
The equipment should also provide the facility of current reversal. This enables the working tool to be made cathodic with respect to the workpiece, as this situation may be necessary during the pretreatment procedure. Due to the nature of the current involved, it is important that some form of safety cut-out should be incorporated. The current being stopped immediately there is a short circuit or a breakdown in rectification. This protects both the operator and workpiece from serious damage. 
Theoretical aspects of fast rate deposition must be considered with respect to the brush plating technique, in order to understand the mechanisms concerned. Consequently, the electrochemical requirements for high speed plating, together with examples of how these are achieved in practice are outlined below.

Where an electrode process occurs at an electrode, its potential departs from its equilibrium value, the cathode becomes more negative and the anode more positive hence the electrode is said to be polarised. The term overpotential may be used to describe all effects that result in the departure of the potential of the electrode from its unpolarised value. Hence, a change in potential due to concentration is referred to as concentration overpotential(14). When an external electromotive force (emf) is applied and a current flows at a finite rate, the potentials of the two electrodes change from their unpolarised values and are said to be polarised, Fig. 2 hence, the polarised potential of the electrode is due to the overpotential associated with one or more electrode processes that are proceeding at the electrode under consideration. Therefore polarisation is the departure of the potential of the electrode, from its equilibrium value, when a reaction occurs at a finite rate. 
The various types of overpotential that result in polarịsation can be classified as follows :

(a) Concentration overpotential - due to the change in concentration of metal ịons in the vicinity of the electrode. Thịs accounts for a considerable proportion of polarisation at industrial plating current densịties.

(b) Actịvation overpotential - associated wịth the process occuring at the electrodes which require activation energy in order to make them proceed. Typical processes involved include hydration or dehydration of ions, discharge of ịons at electrodes and the formation of crystals or molecular gases from absorbed atoms.

(c) Ohmic overpotentịal - additional polarisation effects may be caused by the presence of ionically conducting films, whịch do not cause changes in reversịle equịlibrium potentials. These effects may be caused by the oxịdation or reduction of organic addịtịon agents.

(d) Resịstance overpotentịal - due to $I-R$ drop across the main bulk of the solution.

The Nernst equation ( $i$ ), although relevant to equilịbrịm conditions, can be used to demonstrate the effect of 
concentration on the deposition process as follows :

$$
E=\frac{E_{m}^{0} z \pm}{m}+\frac{R T}{z F} \quad \ln a_{m} z+
$$

$$
\begin{aligned}
& \text { where } \mathrm{E}=\text { Electrode potential at } 25^{\circ} \mathrm{C} \text { (V) } \\
& E^{\circ}=\text { Standard electrode potential at } 25^{\circ} \mathrm{C}(\mathrm{V}) \\
& R=\text { Gas Constant }=8.314 \mathrm{~J}^{\circ} \mathrm{C}^{-1} \mathrm{~mol}^{-1} \\
& \mathrm{~F}=\text { Faraday's constant }=96,486 \mathrm{c} \\
& z \quad=\text { valency } \\
& \mathrm{a}_{\mathrm{m}} \mathrm{z}+=\text { Activity of charge ions in solution. }
\end{aligned}
$$

Hence, the electrode potential of a metal in a solution of its ions, varies logarithmically with the activity of the ions in solution.

As a metal is deposited, the solution adjacent to the cathode becomes depleted of the metal ions and as more metal is deposited further deposition becomes more difficult. At equilibrium, the electrode reactions are reversible $i . e$. the rate of metal dissolution being exactly equal to the rate of deposition. This balance is disrupted when the solution around the cathode becomes depleted of metal ions hence, the potential becomes more negative. The greater the current density, the lower is the metal ion concentration near to the cathode and hence the greater the polarisation. By reference to equation (i) it can be seen that as the metal ion concentration approaches zero, the 
potential becomes more negative and eventually approaches infinity, Fig. 2(15). The current density at which this occurs is known as Limiting Current Density (LCD) and it is the raising of this which constitutes the basis of high speed plating. An increase in current above the limiting current density, cannot result in higher deposition rates, as metal ions have insufficient time to diffuse through the cathode film. These areas of localised concentration variations are called diffusion films and a concentration gradient exists across the film consequently, a second process occurs, usually hydrogen evolution.

The change of current density with electrode potential is shown in Fig. 3. Region $A B$ represents the discharge of metal ions at the cathode. BC represents an increase in the rate of discharge as the potential becomes more negative hence, current density is increased. Eventually, the stage is reached where metal ions are discharged as soon as they arrive at the cathode consequently, a further increase in potential cannot lead to an increase in current density. At this point the process is diffusion controlled and the current is termed the limiting current density. Stage CD represents a further cathode process, this occurs when the potential has reached a sufficiently negative value. 


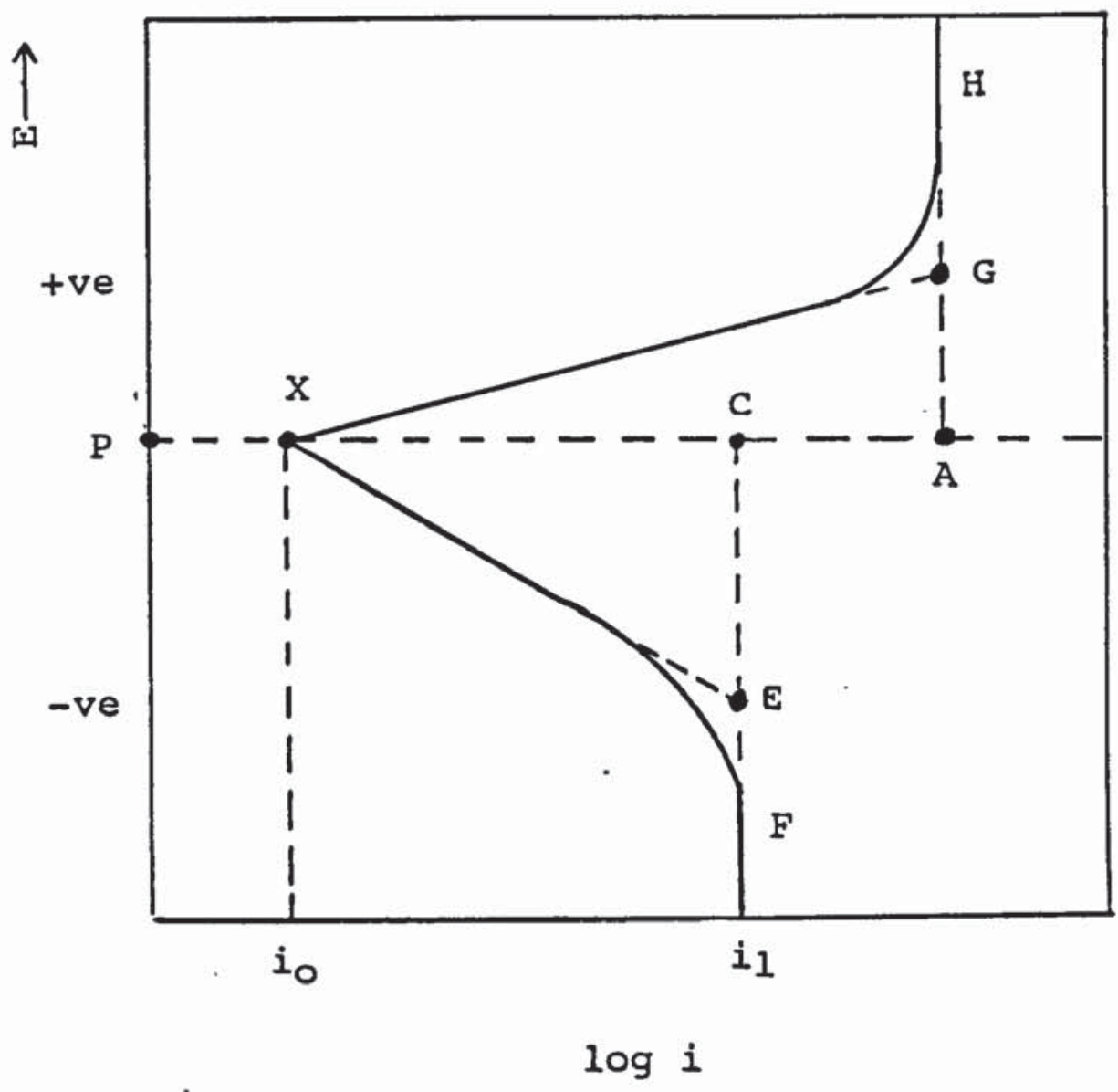

Point $X$ gives the reversible potential $P$ of the electrode and the corresponding exchange current density $i_{0}$. Cathodic polarisation gives the linear Tafel line $\mathrm{XE}$ which is then affected by diffusion phenomena, so that the curve departs fromlinearity and attains the limiting current density $i_{1}$ at $F$. Similar considerations apply to the anodic curve XG and its anodic limiting current density $H$.

FIG. 2 The relationship between $E$ and $i$ for a cathode and anodic electrode process(15) 


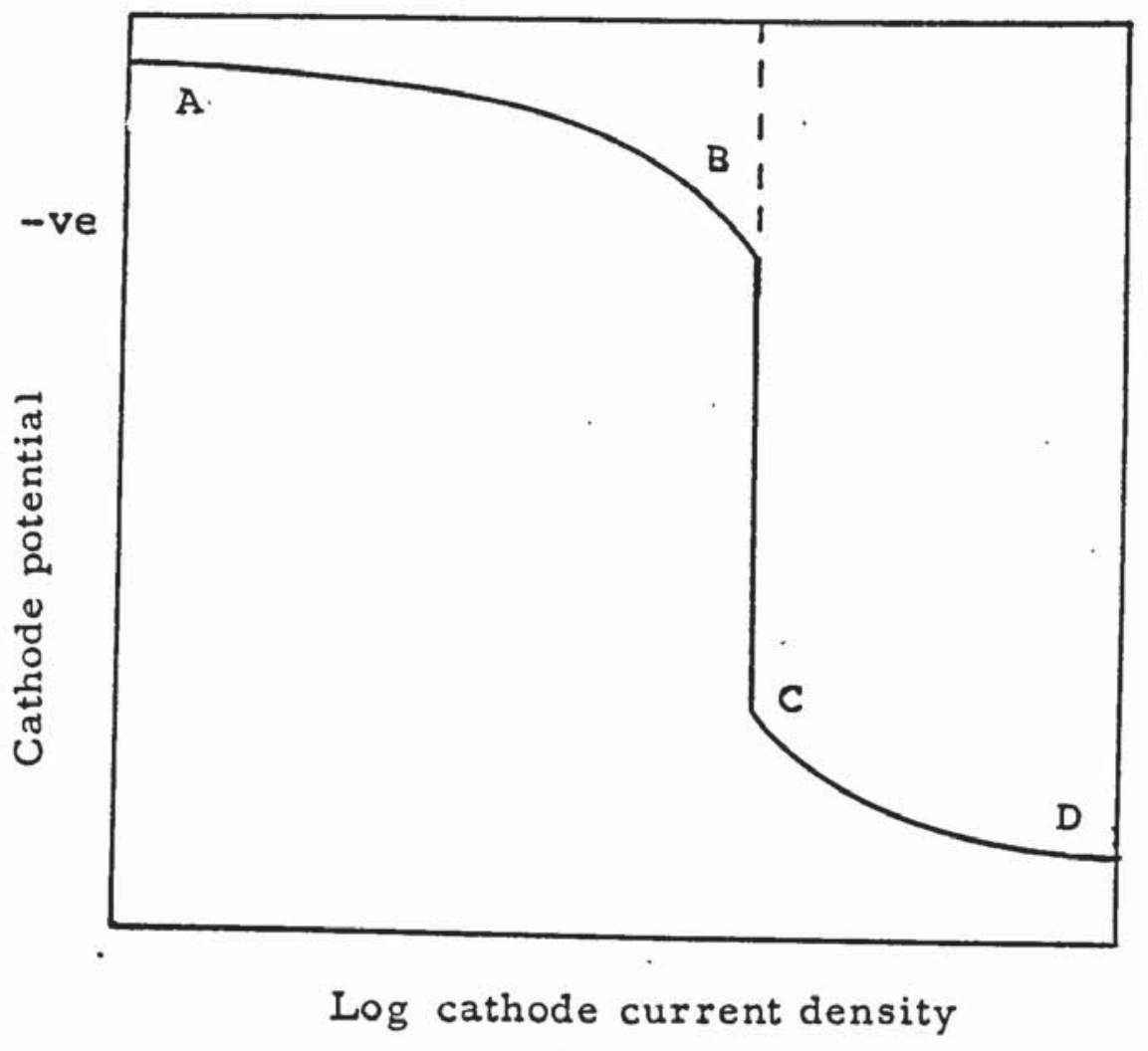

FIG. 3 The relationship between cathode current density
and cathode potential(15)

The diagram indicates the limiting current density for metal discharge $B C$ and the onset of a second process such as hydrogen evolution at $c$. 
For a diffusion controlled process(16), it can be shown that :

$$
i_{L}=\frac{D_{\mathrm{m}^{2+} \cdot 2 \mathrm{Fa} \mathrm{m}^{2+}}}{(1-\mathrm{t}) \mathrm{s}}
$$

where ì $=$ Lịmiting current density $\left(\mathrm{A} \cdot \mathrm{cm}^{-2}\right)$

D = Diffusion coefficient of metal ions $\left(\mathrm{cm}^{2} \mathrm{~s}^{-1}\right)$

$a_{m} z^{+}=$Bulk concentration of metal ịons (g.ịon.1-1)

$\mathrm{s} \quad=$ Thickness of diffusion film (cm)

$t=$ Transport number of metal ịons

$z \quad=$ Valency

$F=$ Faraday's constant

From equation ( $i$ ) it can be seen that if the limiting current densịty is to be raịsed, wịth a resultant increase in rate of deposition, there are three possibilities :

1) Increase Diffusion Coefficient D

2) Increase actịvity of metal ịons $a_{m} z+$

3) Decrease thickness of the diffusion film s

Dịffusịon Coeffịcịent (D). Can be raịsed by ịcreasịng the temperature of the electrolyte. In brush plating this is unnecessary as the electrolyte often boils, due to the high current densities involved and the relatively small volumes of solution used. An increase in temperature however, can gịve rise to problems, such as decomposition of organic 
additions, if present and greater costs for bath plating.. The use of an alternative anion can also increase-the diffusion coefficient e.g. Nickel ions diffuse faster in the presence of chloride ions ( $\mathrm{Cl}^{-}$) than they do in the presence of sulphate ions $\left(\mathrm{SO}_{4}{ }^{2-}\right)$.

Activity of metal ions $\left(a_{m} z+\right)$. This may be raised by increasing the metal ion concentration. An example of this is the Ni-Speed process, developed in the early 1960's by Kendrick and Watson(17,18), where $600 \mathrm{gl}^{-1}$ of nickel sulphamate electrolyte was used to produce a sound deposit at current densities up to $50 \mathrm{Adm}^{-2}$. High concentrations of metal ions are used in brush plating solutions to enable a satisfactory plating rate to be achieved, Table $1(1)$.

-1 Table 1

COMPARISON OF METAL CONCENTRATION OF BRUSH PLATED AND CONVENTIONAL ELECTROLYTES

Solutions

\begin{tabular}{lcc}
\hline & Conventional & Brush \\
\cline { 2 - 3 } & $20-50$ & 60 \\
Copper (Alkaline) & $4-12$ & 100 \\
Gold & $35-80$ & 100 \\
Nickel (Acid) & $60-100$ & 70 \\
Nickel (Low Stress) & $60-80$ & 75 \\
Nickel (Semi bright) & $1.3-2.0$ & 20 \\
Rhodium & $30-95$ & 190 \\
Silver & $-42-$ &
\end{tabular}


Thickness of the diffusion films (s) can be reduced by vigorous agitation. This can take place in the form of electrode movement, air agitation, ultrasonics, turbulent flow of electrolyte over the cathode surface, or by mechanical scrubbing of the diffusion layer.

The most effective method of decreasing the cathode film, recognised by Dennis and Such(15), Hart(19) and others, is by rapid movement of the cathode or the solution or both.

It is important that deposition processes take place below the limiting current density, otherwise the deposits produced become progressively rougher and more nodular as electrocystallisation can take place perpendicular to the substrate $(19,20)$, Fig. 4. This occurs as more energy is available and the growth of the deposit is not confined to the direction parallel to the substrate surface(20). In processes such as brush plating, these surface asperities (nodules) may be removed during the mechanical scrubbing action of the cathode surface. However, in other techniques, employing different methods of diffusion layer reduction, the maximum operating current density may be limited due to deposit roughness.

Furthermore, if sufficient potential is applied so that the diffusion limiting current density is exceeded, then some other cathodic process, most usually the reduction of hydrogen ions takes place simultaneously with the metal deposition process. This leads to an increase in $\mathrm{pH}$ near 
Low Overpotentials

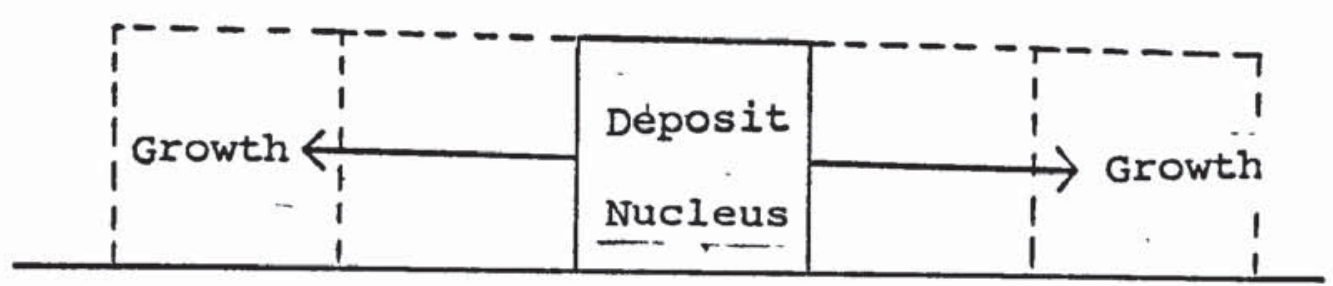

Metal substrate

High overpotentials

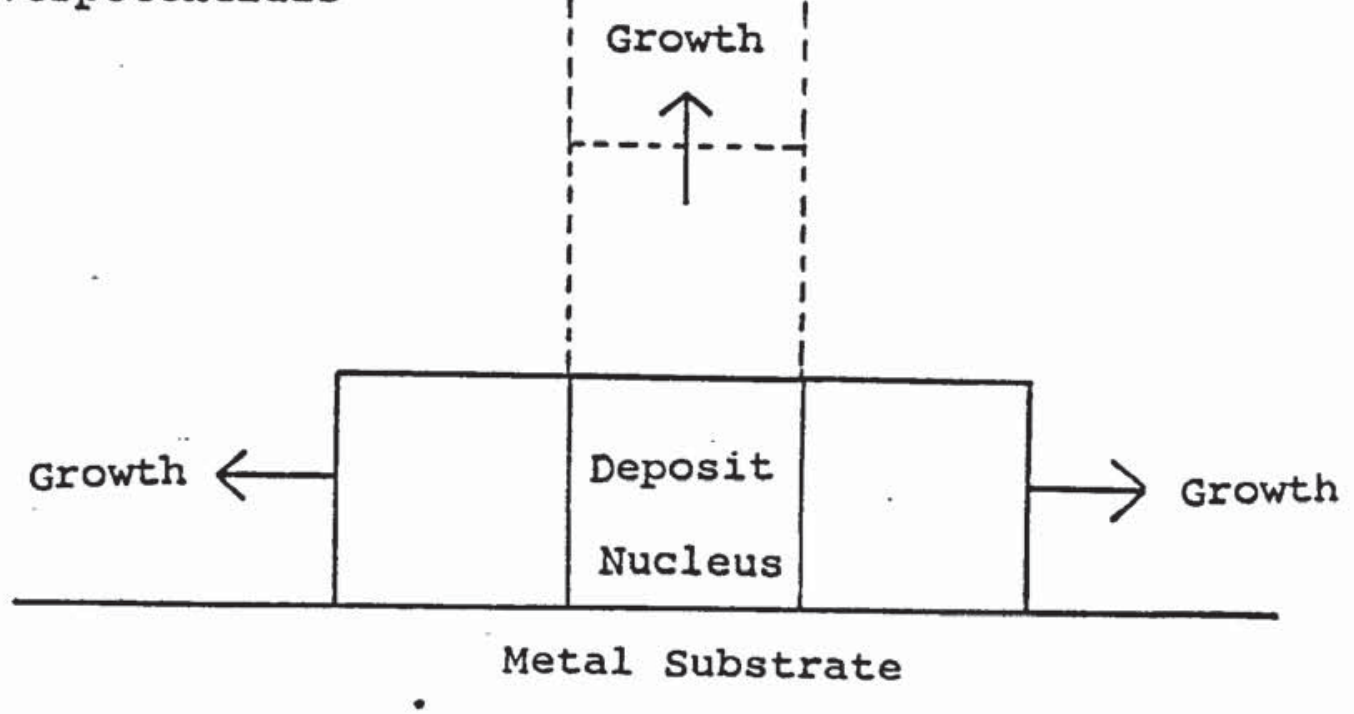

FIG. 4 Schematic representation of metal deposition at low and high overpotentials (19) 
to the cathode surface which can cause precipitation of oxides and hydroxides of the metal. This produces the characteristic rough and burnt deposits that are observed on the high current density areas of plated components, when too high a current density is used.

The main aim of any high speed plating operation is to reduce the thickness of the cathode film. High speed electrodeposition has been a target for many researchers in the last few decades. The majority of work in this area requires very high flow rates of electrolyte past the cathode surface, these techniques are well documented by Wesley et al (21) and Safranek and Layer(22).

Other techniques of breaking-up the cathode film have been investigated. One such method has been published by Eisner(23) and involves the previously reported high flow rates of electrolyte, but differs from previous work in that it also depends on the activation of the cathode during electrodeposition. 'This is achieved by contact with moving hard particles and is known as abrasive plating.

Brush plating can also be considered in this way. Dennis and Jones(24) reported that for the deposition of cobaltmolybdenum and cobalt-tungsten alloys, cotton wool by itself proved unsatisfactory as an absorbent cover for the anodes and consequently, the cover used in their investigation was one of mixed polypropylene-nylon felt, bonded with acrylic resin. This felt had a scouring action 
on the plated surface which promoted a smooth finish and disrupted the cathode film in a manner very similar to that reported by Eisner(23).

Consequently, results obtained from the high speed plating technique can be compared with those from brush plating. Eisner(25) produced a list of the effects of the abrasive plating method :

a) Smaller grain size than vat plating was achieved.

b) No twinning within the grains.

c) High dislocation density.

d) Equiaxed crystals were produced.

e) Crystals were randomly orientated.

f) Harder deposits than conventional plating resulted.

g) Parallel striations were noted on the deposit.

h) A brighter finish than conventional plating was obtained.

i) Good adhesion was achieved.

Further to this list, Safranek and Layer(22) indicated that brush plating gives directional properties, particularly if undesirable inclusions were present and would exhibit layer like characteristics. Some of these phenomena have also been observed by Hughes(25) and Rubinstein(26). 
A review of the relevant litterature revealed a great deal of information on the conventional vat plating of many alloy systems, but very little has been published on brush plating. Consequently, little is known of the effect of conditions encountered in brush plating on the electrochemical aspects of alloy deposition. The lead-tin and tịn-cobalt systems beịng ịvestịgated are reported to be of the regular codeposition type(27) and consequently, particular emphasis is gịven to this classification of codeposition. Consideration of the possible effects of brush plating on these alloys is also included.

\subsection{Introduction to Alloy Plating}

The main reason for producịng alloy electrodeposits is to obtain properties superior to those of single metals e.g. strength, hardness, wear resịstance or magnetic properties. Lowenheim(28) and Gabe(29) have indicated problems associated with alloy depositition and they suggest that only a few of the large number of systems investigated have any commercịal potential, as control is difficult even on a very small scale. A major problem is the control of the deposit composition. Alloy plating systems are inherently more complex than single metal systems and are susceptable to even small fluctuations in current density, temperature and $\mathrm{pH}$. 
Commercial control of alloy systems is further complicated by replenishment of the metal content of the bath. "For example, the metals must be added to the bath in the same proportions as they are deposited. Some of the techniques used for metal replenishments are listed below :
a) Alloy anodes of the same composition as the deposit.
b) Inert anodes and chemical additions.
c) Anodic replenishment of one metal, chemical additions of the other.
d) Separate anodes of the two metals.
e) Alternative use of the two metals as an anode.

\begin{abstract}
All the above have various disadvantages consequently, there is no single method of metal ion replenishment used for every alloy system.
\end{abstract}

Problems of control increase proportionally with the number of elements in the system hence, binary alloy deposits have received most attention $(30)$ and appear to offer the best prospect of commercial exploitation.

In brush plating, problems associated with metal ion replenishment are generally avoided, as in the majority of cases deposition takes place from a concentrated electrolyte which is then discarded. Recovery of brush plating solutions is seldom practised as the quantity involved, in typical operations is relatively small hence, 
replenishment is not viable. However, if the process is to . be used on a large production scale, recovery would be necessary and some form of metal ion replenishment carried out.

In most cases, the alloys produced by electrodeposition can be considered as true metallurgical alloys as they contain phases which appear on the phase diagram relevant to their temperature of formation. However, there are exceptions, two of which are the alloys of 60-40 copper-tin $(31,32)$ and 63-37 tin-nickel $(33,34)$ both of these systems produce phases that are thermally unstable.

\subsection{Classification of Codeposition of Alloys}

Brenner(27) divided the codeposition of alloys into five alloy plating processes.

4.2.1 Regular Codeposition : Deposition is diffusion controlled and as such the effect of plating variables on the metal ion content of the diffusion film can be predicted from diffusion theory. Examples of this system are lead-tin and tin-cobalt.

4.2.2 Irregular Codeposition : Codeposition is normally controlled by the characteristics of the potentials of metal against the solution rather than by diffusion. Such solutions contain complex ions and 
are markedly affected by the concentration of free complexing agents within the baths. ITin-nickel- and copper-zinc are two examples of irregular codeposition.

4.2.3 Equilibrium Codeposition : Such solutions are in chemical equilibrium with both parent metals and the ratio of the metals in the deposit is similar to their ratio in the bath. Lead-tin acid baths of 70-30\% composition exhibit this phenomenon.

4.2.4 Anomalous Codeposition : This type is rare and contains one or more of the iron group metals. It is referred to as anomalous as the less noble metal deposits preferentially. Examples are iron-zinc, iron-tin and iron-lead.

4.2.5 Induced Codeposition : This type is characterised by the deposition of alloys containing molybdenum, tungsten and germanium, which cannot be deposited alone from aqueous solution, such as tungsten-cobalt and molybdenum-nickel.

Prediction of alloy deposition behaviour is difficult in the controlled conditions of conventional vat plating. During brush plating, the anode and cathode are constantly being separated for solution replenishment and as such there are wide variations in current density. Boiling of 
the electrolyte is not uncommon and introduces a further complication in a system already difficult to investigate.

\subsection{Electrodeposition of Lead-Tin Alloys}

As there is little or no published literature available on the process of brush plating from alloy solutions, it is difficult to predict the effect of plating variables on the systems under consideration. The following discussion of behaviour in conventional plating may give some indication when attempting to make such predictions, but it should be noted that the unfamiliar conditions encountered in brush plating may lead to incorrect suppositions.

The electrodeposition of lead-tin alloys has several features of interest. The standard electrode potentials of the two metals differ by only $10 \mathrm{mV}$ and due to the closeness of the potentials, deposition of these alloys is one of the simplest of the alloy plating processes. Furthermore, since the potentials of lead and tin are only slightly less noble than that of hydrogen and since the metals have a high hydrogen overpotential, the alloy deposits from acid solution with a cathode current efficiency of $100 \%$.

The first published information on lead-tin alloys was in two patents dealing with the plating of the interior of 
torpedoes $(35,36)$. However, the first basic study of the electrodeposition of the alloy was carried out by Blum and Haring(37) in 1921. A systematic study of the effects of the plating variables on the composition of the alloy deposits was published 30 years later $(38)$. Although the study was concerned with fluoborate solutions, the results can be considered as a useful guide for other acid solutions.

\subsubsection{Types of Bath}

Lead-Tin alloys may be electrodeposited from many different solutions. Literature can be found for baths based on fluoborate, sulphamate, pyrophosphate etc.. with fluoborate being the most common bath for commercial applications.

4.3.1.1 Fluoborate. Fluoborate solutions are considered to have many advantages over other solutions; these include high conductivity, high deposition rate, high stability and fine grain size(39). However, there are also disadvantages such as difficulty in preparation, toxicity and high cost. Fluoborate baths consist of lead fluoborate, stannous fluoborate, fluoboric acid and various addition agents. The free acids are present in the bath in order to minimise the hydrolysis of the fluoborates and improve the solution stability and conductivity. The addition agents improve the deposit quality by suppressing dendritic growth. Air agitation must not be used as this 
oxidises the stannous tin to stannic (II $\longrightarrow$ IV) and this cannot easily be reversed.

The lead-tin alloy system is of the regular type, as classified by Brenner(27). A large variation in the composition of the deposits with plating variables is therefore expected however, this is not found to occur. Much smaller variations are exhibited due to the potentials of the metals being so close. The study of the plating variables by Du Rose and Hutchinson(38) showed that any increase in current density increased the tin in the deposit, an increase in temperature of $3^{\circ} \mathrm{C}$, decreased the tin content of the deposit by $1 \%$. IThe increase in metal content in the bath decreased the amount of tin in the deposit.

4.3.1.2 Pyrophosphate. This is the only alkaline bath which has been investigated in any depth(40) and promising results have been claimed. The bath usually consists of stannous pyrophosphate, lead nitrate and sodium or potassium pyrophosphate. The sodium or potassium pyrophosphate is usually added for the purpose of complexing the stannous ion. Additions of gelatine or $\beta$ naphthol(4l) yield smooth deposits. Initially the bath produced deposits containing 2-15\% tin(42) however, more recent work(43) has resulted in some modifications in its composition to secure a wider range of alloys. 
Discounting the effect of agitation, the variation of the deposits composition with respect to the plating variables, is that of a regular alloy system. The tin content of the deposit increases with an increase in addition agents, current density and tin content in the bath(42).

4.3.1.3 Sulphamate. In the 1930s Piontelli and Giulatto(44) carried out an investigation into the electrodeposition of many metals including lead and tin from sulphamate solutions and followed up the work with a study of the deposition of alloys also from sulphamate solutions(45). Their findings were not encouraging, the solution hydrolysed after two days consequently, the solutions have had little practical importance. Cliftor (46) and Du Rose(47) however, both patented sulphamate solutions capable of depositing a lead-tin alloy of up to $30 \% t i n$. More recently Indira and Udupa(48) claimed sulphamate baths could be used to produce high quality deposits with excellent covering and throwing power.

Sulphamate baths consist mainly of lead sulphamate, tin ions, free sulphamic acid and addition agents to improve deposit quality.

The effects of the plating variables on the composition of the deposits was said to be similar to their effect on fluoborate baths (44). 
It can be seen from the brief description given above that the mechanisms involved in the conventional bath deposition of alloys are complicated and not fully understood. With regard to the process of brush plating with all its complexities of variable current densities, severe agitation and temperature of the electrolyte rising from ambient to boiling during plating, little information has been published with respect to deposition of alloys. Work carried out on the brush plating of alloys has always been highly commercially orientated and as such is seldom published.

\subsection{Tin-Cobalt Alloy Plating}

Electrodeposited alloys of these two metals have gained interest commercially in recent times as an alternative to chromium especially in decorative finishes. The appearance of these alloys can be similar to that of chromium but its hardness and wear resistance are significantly lower.

Little has been published in the literature concerning this alloy system and many baths are referred to only in patents. The earliest reference to the alloy was in a patent issued to the Du Pont Company(49) and the work concerned the deposition of $0.35 \%$ cobalt from a stannate bath containing cobalt cyanide. Deposition of tin-cobalt from an alkaline bath was mentioned in a patent by Jennison and Bradley (50). The possibility of electrodepositing the 
alloy from fluoride based solutions was claimed in a patent by Ireland and Parkinson(51). and Sree and Rama Char-(52) have suggested a pyrophosphate bath. Clarke, Elborne and Mackay(53) reported the electrodeposition of an alloy containing $33 \%$ cobalt from a fluoride-chloride based solution. The alloy was said to exhibit passivating properties, similar to the one investigated by Thomas and Sharma(54), the deposit obtained was an intermetallic compound of CoSn. Hemsley and Roper(55) carried out a detailed study on the codeposition of an alloy containing 208 cobalt from a mildly alkaline sulphate based solution. The corrosion behaviour of the alloy from baths similar to these, has been studied by spanchak and O'Grady(56).

\subsection{1 plating Variables}

Work carried out by sree and Rama Char(52) indicates that cobalt is much less readily deposited than tin. They also show that the higher the current density the more cobalt will be present in the deposit. IThis indicates that the cobalt-tin plating system is of the regular type with tin functioning as the more noble metal. This is consistent with the behaviour of the regular plating systems, the tin content of the deposit increasing with elevation of the temperature of the bath and with agitation. Sree and Rama Char(52) also stated that organic additions decrease the amount of cobalt in the deposit and $\mathrm{pH}$ has little effect. The cathode current efficiency was about $95 \%$ at a current 
density of $0.7 \mathrm{Adm}^{-2}$ but fell to $50 \%$ at current densities above $5 \mathrm{Adm}^{-2}$.

The above findings of course, apply specifically to conventional plating methods and not for brush plating. Brush plating has its own unique set of problems, high temperatures, high current densities etc consequently, many of the stated findings would be in conflict when applied to brush plating.

4.4.2 Effect of Plating Variables on the Structure of Electrodeposited Cobalt

Electrodeposited cobalt can exist in three forms, facecentred-cubic ( $f c c$ ), hexagonal-close-packed (hcp) or as a mixed fcc/hcp structure. No information relating to these phenomena has been found in the literature for tin-cobalt alloys consequently, a brief description of the effects of plating variables on other cobalt alloys has been given.

The microstructure of cobalt electrodeposits is usually columnar or fibrous. Fibrous structures can be typically obtained from sulphate solutions and those containing 17 or 228 nickel(57). A banded structure can also be obtained for alloys containing 53,73 or 758 nickel $(58,59)$. A mixed structure was observed in phosphorus $(60,61)$ and tungsten alloys $(62)$. 
A mixture of $\mathrm{hcp}$ and fcc lattice structures has been observed by several investigators, whereas the fcc structure is characteristic of cobalt alloys containing more than 308 nickel $(63,64)$. A low $\mathrm{pH} 2.5$ favours the cubic form for cobalt, whereas a high $\mathrm{pH}$ or high temperature increases the proportion of hcp cobalt in deposits produced from sulphate baths with addition agents(65). With no organic additions, the hcp form was predominant. The hcp form was also approached for alloys deposited from sulphate baths containing no additions at $\mathrm{pH}$ 2.9. The application of magnetic field during deposition also favours the hcp form $(66)$. This may be of benefit in conditions where sliding wear is an important consideration, as the hcp form of cobalt has a lower coeficient of friction. A high deposition temperature also induces the hcp structure for cobalt deposited from a chloride bath(67). High current densities favour the fcc form from sulphamate solutions(68). A high degree of preferred orientation has been observed for cobalt alloys deposited from sulphate baths $(67)$ but cobalt deposited from chloride solutions was randomly orientated. High current densities also give a random distribution(64). 
The alloys of aluminium have a number of useful engineering properties e.g. low density, high specific strength and reasonable corrosion resistance. Hence, the considerable incentive to use aluminium and its alloys in a variety of applications. This range of applications can be widened still further by electrodeposition to alter the surface characteristics.

In 1913 information was published(69) on some improved methods for plating onto aluminium and since that time many new techniques have been introduced. The pretreatment operations required for the numerous alloys remain complex, due to the wide variety of surface characteristics. The following difficulties associated with electrodeposition of aluminium were listed by West(70) :

a) The presence of an oxide film.

b) Its amphoteric nature.

c) The position of aluminium in the electrochemical series, giving rise to immersion deposits in plating solutions.

d) The wide range of aluminium alloys used in practice.

e) The expansion coefficient of aluminium relative to other metals. This can lead to bond rupture between substrate and electrodeposit. 
f) The presence of a 'Beilby' layer of flowed or amorphous material, incorporating grease or oil impregnated oxide on the surface of polished aluminium.

Aluminium is an extremely reactive element and has a high affinity for oxygen. It has a rapidly self-healing oxide film that when electroplated, reduces adhesion between coating and substrate. Using conventional pretreatments however, preventing exposure of the oxide free surface to the atmosphere is difficult. Aluminium is amphoteric and as such readily dissolves in most acids and alkalis and is strongly electropositive. Hence, aluminium is attacked in many plating solutions and undesirable immersion deposits are often formed by metallic displacement. Consequently, Jongkind(71) recognised that it was necessary to modify the aluminium surface prior to electrodeposition.

\subsection{Methods used for Electrodeposition on to Aluminium}

There are three distinct operations common to commercial . electroplating processes :

1) Cleaning

2) Surface preparation

3) Electrodeposition 
The pretreatment processes for plating onto aluminium can be classified broadly as follows :

1) Preparation by anodic and chemical oxidation

2) Mechanical Roughening

3) Chemical Roughening

4) Use of Immersion Films

5) Direct plating

\subsubsection{Anodic Oxidation}

There are several commercial techniques involving thickening the oxide by anodising prior to electrodeposition. Electrolytes including phosphoric acid and oxalic acid(72,73) are used. In conventional plating the oxide on aluminium is a disadvantage. However, an anodic coating formed under controlled conditions can provide a sound base for electrodeposition. The oxide consists of the 'barrier' and 'porous' layers. Pores act as keys for the electrodeposit and are preferably large, this depends on electrolyte and operating conditions. There are many problems when electroplating from strongly alkaline solutions, if the anodic layer dissolves before being totally covered with the deposit(74). This may be solved by applying a copper strike prior to the main electrodeposition operation. 
- Different electrolyte concentrations, pretreatment and operating conditions are often recommended for each ailoy type. The technique is suitable only for a few sandcast and no common diecasting alloys. The anodic coating characteristics are influenced by current density and so large and complex shaped components are awkward to process. Additionally, formation of an anodic coating requires a relatively high voltage power source and this increases process cost and complexity.

\subsubsection{Chemical Oxidation}

Cheaper alternatives to anodic oxidation are aluminium oxides produced by chemical oxidation, a typical example of this is the MBV process(75). This involves a post-plating heat treatment to develop adhesion and is not commercially important. The process involves immersing the work in a mixture of sodium carbonate and sodium chromate at about $90^{\circ} \mathrm{C}$ for 5 minutes. A grey coating is produced which forms a suitable base for further finishing operations.

\subsubsection{Mechanical Roughening}

The first common operation of preparing aluminium for electroplating. was sandblasting. However, the surfaces produced are generally too rough and this may also cause distortion particularly of thin sheet. It has been reported that sub-standard bonding and hence low adhesion 
levels also occur(76). A commercial process involving blasting the workpiece with a"slurry of quartz crystals has been used prior to hard chromium plating(77). The component is placed into the plating bath still covered in the slurry to prevent reoxidation.

\subsubsection{Chemical Roughening}

This can be used as an alternative to the mechanical methods previously mentioned. Solutions were developed commercially in the 1930s based on acid dips containing varying amounts of a metal ion e.g. nickel, iron and manganese. The high proportion of metal in the dips causes a metallic immersion film to form. These solutions also cause etch pits having the correct undercut shape, in order to key the deposit to the substrate. Most alloys have a recommended procedure to obtain the required etch pit, as each alloy type usually poses specific problems. A postplating heat treatment may increase bond strength.

Both chemical and mechanical roughening have similar disadvantages, as the surface produced may be too rough to be smoothed by typical thicknesses of decorative levelling nickel.

\subsubsection{Immersion Films}

These immersion films, used as a pretreatment prior to 
plating aluminium, are deposited by means of a displacement reaction. For instance, chemically active aluminium dipped into a copper sulphate solution tends to establish a potential, relative to the solution, greater than the potential required to deposit copper. Thus, aluminium has displaced copper ions from the solution and aluminium has dissolved from sub-microscopic regions. After a few minutes, action essentially ceases when the substrate is covered by a film of copper.

Aluminium has such a high negative potential that when placed in most plating solutions, immersion deposits are formed. Typically these are non-adherent and unlikely to provide a suitable base for further plating. However, under favourable conditions satisfactory films can be deposited from various solutions. The immersion processes for producing adherent metallic films, must incorporate two essential constituents; a salt of a metal which is more noble than aluminium and an aggressive anion capable of removing the oxide layer without dissolving the underlying metal $(80)$. The two anions that dissolve the oxide at a suitable rate are hydroxyl $\left(\mathrm{OH}^{-}\right)$and fluoride $\left(\mathrm{F}^{-}\right)(81)$.

Several metal salts have been used as the basis for immersion films(82) but present proprietary formulations are based on either sodium zincate (zinc salt) or sodium stannate (tin salt) solutions. 
The most important tịn immersion preparatory process is the stannate based 'Alstan*' treatment(83,89). A typical processing sequence is shown in Table $2(71)$. The acid dip ịs crucial as it should produce a unịform oxide layer. This ịs therefore, often formulated specially for specific alumịnịm alloys. A major difference between the stannate and the zincate processes is that the work is not rinsed following the stannate immersion treatment. The function of the stannate dịp, is to remove the oxide layer and 'activate' or condition the surface and then protect the bare metal, as the part is transferred 'live' into the electrolytic bronze bath.

Whille the stannate process is reported to be used widely in the USA, the zịncate process is preferred in the UK.

\subsubsection{Theory of Immersion Films Developed from Zincate} Solutions

Bullough and Gardam(90) stated that when pure aluminium is immersed in pure sodịum zincate the following chemical reactịon occurs:-

$3 \mathrm{Na}_{2} \mathrm{ZnO}_{2}+2 \mathrm{Al}+2 \mathrm{H}_{2} \mathrm{O} \longrightarrow 2 \mathrm{NaAlO}_{2}+3 \mathrm{Zn}+4 \mathrm{NaOH} \ldots$ (

* Proprietary solution of Mand $\mathrm{T}$ Chemicals Ltd. 
1. Degrease.

2. Alkali soak clean at $60^{\circ} \mathrm{C}$ for $1 \mathrm{~min}$.

3. Water rinse.

4. Dip in 308 nitric acid at room temperature for $30 \mathrm{~s}$.

5. Water rinse.

6. Dip in stannate tin solution at $30^{\circ} \mathrm{C}$ for $30 \mathrm{~s}$.

7. Plate (load-live) in special bronze alloy deposition solution at $30^{\circ} \mathrm{C}$ for $3 \mathrm{~min}$. at $5 \mathrm{Adm}^{-2}$.

8. Water rinse.

9. Nickel plate. 
This means that for every two aluminium atoms dissolved there are three zinc atoms deposited. Ideally a monomolecular layer of zinc should form. However, this behaviour was not observed on typical hetrogeneous alloys which contain surface imperfections and in practice this reaction proceeds rapidly and there is a great tendency to form zinc dentrites or large crystals.

The initial formation characteristics of the immersion deposit are important because the adhesion between the zinc and aluminium surface will influence the adhesion of any subsequent electrodeposit. - Bullough and Gardam(90) suggested adhesion between the zinc film and aluminium was affected by the degree of epitaxy between the deposit and substrate although, no experimental evidence was reported. Lashmore $(91,92)$ found that dissolution of pure aluminium in a zincate solution, is a sensitive function of the crystallographic orientation of the substrate. However, the highly deformed surface usually present on polished or machined components, was found to interfere with epitaxial phenomena.

\subsubsection{Development of Zincate Solution Formulations}

Keller and Zelley(93) found that if small deposits of iron and sodium potassium tartrate were added to the sodium zincate solution, adhesion of the subsequent coatings was substantially improved. It was discovered that equation 
(iii) above, is no longer true for the more complicated electrolyte and that substantially more aluminium has to be dissolved before the zinc alloy will deposit. The atom ratio of aluminium to zinc deposited is about $9: 1$.

Further additions to the zincate solution were examined by various workers. West $(70)$ indicated that copper ions reduced the rate of zinc deposition and made the process more controllable. Such and Wyszynski(94), found the presence of nickel in the zincate solution, beneficial in promoting adhesion of nickel plated directly onto the zincate immersion film and that excess quantities of copper in the solution cause unsatisfactory adhesion. Bengston(95) obtained improvements when zinc sulphate was used as the zinc salt.

The work of Such and Wyszynski(94) resulted in the formation of the proprietary alloy zincate solution 'Bondal*'(96). This complexed solution yields a zinc alloy film comprising of approximately $86 \%$ zinc, $8 \%$ copper and $6 \%$ nickel and a small amount of iron. The nickel content of the film increases with time. The small amounts of iron present inhibit the growth of acicular crystals and gives rise to grain refinement $(97)$.

* Proprietary solution of $\mathrm{W}$ Canning Materials Ltd. 
An important development to the zincate process, was the 'double-dip' technique devised by Korpiun(98). This is used for most aluminium alloys where inhomogeneity can result in a considerable variation of activity over the surface during zincating. This results in the formation of a non-uniform immersion deposit that when overlay plated may produce a coating prone to blisters (71). The first zincate deposit is stripped in 508 nitric acid(99) and a further zincate film deposited by re-immersion. It is believed the first zincate dip reacts selectively with the most active region of the aluminium substrate. Removing this film, exposes a surface of more uniform activity upon which during re-zincating, a thinner uniform deposit forms. A typical processing sequence is shown in Table 3.

Lashmore(91) studied the morphology of zincate pretreatments on aluminium alloys as well as pure aluminium and found that on an alloy containing magnesium and iron (total 3\%), the zincate film deposited principally at the grain boundaries. However on 99.9998 aluminium the zincate film showed no preferential growth. Using Rutherford Backscattering, Lashmore also showed that 99.9998 aluminium, zincated for 60 seconds and then dipped in nitric acid for 20 seconds, maintained a zincate film, as zinc and iron were detected.

Work by Kampert et al(100) showed that in many environments, the zincate film is anodic to both the electro- 
TABLE 3 : PROCESSING SEQUENCE FOR NICKEL PLATING ON

ALUMINIUM USING THE SIMPLE ZINCATE IMMERSION'

\section{PROCESS}

1. Degrease.

2. Alkali soak clean at $65^{\circ} \mathrm{C}$ for $2 \mathrm{~min}$.

3. Water rinse.

4. Dip in $50 \%$ nitric acid at room temperature for $30 \mathrm{~s}$.

5. Water rinse.

6. Dip in simple zincate solution at room temperature for 2 min.

7. Water rinse.

8. Copper plate using Rochelle cyanide.

9. Water rinse.

10. Nickel plate. 
deposited coating, as well as the aluminium substrate. Thus, if the electrodeposit is ruptured to the substrate, undermining corrosion can occur. To avoid this, the tradịtional copper cyanịde strike layer should be replaced by a neutral nickel layer. The zịncated aluminium is placed in a nickel bath and when the potential, measured against the nickel electrode, drops $200 \mathrm{mV}$ below the original value, the nickel plating should be started. Galvanịc dịplacement of nickel from the solution by zincate contịnues untịl the zịncate layer dịsappears.

Recent work by Monteịo and Ross(101) has shown the elemental dịtrịbution through the thịckness of the zincate fịlm. On average, the thịckness of the sịgle dipped film was $0.20 \mu \mathrm{m}$ whịle the double dịpped fịm was $0.15 \mu \mathrm{m}$. It was concluded that certain elements, such as copper, in the zincate solution, tend to be concentrated at the substrate/fịlm ịterface and reịnforce bondịng strength. Initially, the concentration of copper exceeds that of $z$ inc in the film hence, the initial layer has a composition somewhat likke brass. As the film thickens, the copper concentration falls and that of zinc predominates. It was also found, that the zincate film produced during the second immersion contained the hịghest proportion of oxygen just below the surface and not at the surface as is the case wịth the sịngle dịp fịlms. It should also be noted that the proportion of nickel in the film remained constant at 1-2 at. 8 throughout the 90 second immersion and did not 
ịncrease wịth ịmersịon time as suggested by Wysynski(97).

\subsubsection{Direct Plating}

Many metals including copper(102), nickel(103), chromịu(104) and tịn(105) have all been electroplated dịrectly onto alumịnịum from specịalịsed baths. Work(106) reported a direct zinc plating method in 1931 and Asada(107) used an alternating current, in a solution contaịning nịckel ịons, to produce a layer of alumịnịum oxịde and nickel oxide. The film was then reduced cathodịcally and followed by nịckel platịng .

In the U.K. however, the process whịch gaịned the greatest commercịal success was the Vogt process $(108,109)$. Thị had an advantage over immersion, ịn that a unịform zịnc coating can be applịed electrolytịcally ịn spịte of varịations ịn surface composition of the substrate. If the surface of the basịs metal is not homogeneous, an immersion coating of dịfferent thịcknesses wịll be obtaịned on the matrịx, from that on intermetallịc constịtuents. In the vogt process, the thin zinc layer is followed by a thin brass electrodeposit prịor to final electroplating. Good adhesịon ịs achịeved only if plated artịcles are stoved for 30 mịnutes at $230^{\circ} \mathrm{C}$, to allow interdịfusion to occur. For this reason the process became largely obsolete in the 1960s. 
Information on several direct plating systems, using the brush plating tẹchnique has been published. One system developed by Selectron Ltd(110) claims to permit several metals to be deposited directly onto aluminium, with a bond strength that approaches the inherent strength of the substrate material. The aluminium is anodised with an activating solution in order to replace the original oxide with a softer porous form, subsequent plating can then be carried out. A period of 15-30 seconds elapses prior to the deposit being observed on the substrate. It is claimed that the very soft oxide layer is brushed away or electrochemically reduced or both, prior to the flash layer becoming adherent. Once the flash coating has been applied successfully, any other metal may then be electrodeposited. A modification to enable silicon containing alloys to be more successfully plated, involves an alkaline desmutting stage(9), prior to the flash layer being applied.

Rubinstein(9) states that microscopic examination shows that the deposited metal bonds directly to the aluminium with only a 'spiderweb' network of oxide remaining. There is not enough oxide to inhibit adhesion or reduce conductivity. Rubinstein(9) also noted the following points :

1) The standard zincate or stannate solutions can be brushed onto the aluminium prior to brush plating although the resulting adhesion is not as high as 
the brush anodising process(110) mentioned above.

2) Stannate and zincate immersion films result in the highest adhesion on relatively pure aluminium with a loss of adhesion on alloys, particularly those containing large amounts of silicon and/or copper. However, the reverse is true when the activation system(110) is used for brush plating.

Techniques for direct electroplating onto aluminium reported by Wasserman(111-113), do not require the plating of flash layers, but rely on converting the surface of the aluminium to a meta-stable form. It is reported that electrochemically the process reverses aluminium's anodic potential in all of the most common electroplating solutions. The process enables the electrodeposit to bond directly to the aluminium by converting the meta-stable aluminium compound to a metal-to-metal bond during heat treatment. Low temperature, about $104^{\circ} \mathrm{C}$, is satisfactory for this heat treatment stage. One advantage is that no low melting point metals such as zinc or tin are involved in bonding thus, the plated aluminium can be used at higher temperatures without risk of blistering or flaking. Brush plating techniques are used for the preparatory stage. Once the surface has been prepared by use of the activating solution, both conventional or brush electroplating processes may be used. Acid solutions are preferred, but excellent results have been achieved using a cyanide 
plating solution(111).

The precleaning is accomplished in a low caustic alkaline or a phosphoric acid based cleaner, if the work piece can be immersed. For selective plating operations a $10 \%$ sodium hydroxide-starch paste can be applied to the areas to be plated(112). The second operation involves applying a microetch by means of an electrolytic brush. The electrolyte being a dilute acid. This is followed by an activation or aluminium hydride forming stage(112). This again is achieved by electrolytically brushing a dilute acid electrolyte over the aluminium surface. It should be noted, that in the case of the microetch step, the workpiece is anodic, while the activation stage is carried out with the workpiece cathodic. After rinsing, the component is ready for electroplating. A typical processing sequence can be seen in Table 4 .

\section{TABLE 4 : PROCESSING SEQUENCE FOR NICKEL PLATING ON} ALUMINIUM USING THE DIRECT PLATING PROCESS (111)

1. Alkaline clean

2. Water rinse

3. Immerse in $0.5 \%$ fluoboric acid (silicon alloys only)

4. Water rinse

5. Activate, using proprietary brush plating technique

6. Water rinse

7. Chromium plate. 
Wasserman postulates(113) that microetchịng and cathodic activation convert the aluminium surface layer to metastable alumịnịm hydrịde and shift the electrode potential of the surface from the anodic to the cathodic condition. When nickel is deposited onto the activated surface the following reaction occurs :
$\mathrm{Al}+3 \mathrm{H}$
$\mathrm{AlH}_{3}$
.... (iv)
$\mathrm{AlH}_{3}+\mathrm{Ni}$
$\mathrm{Al} / \mathrm{Ni}+1.5 \mathrm{H}_{2}$
$\ldots(v)$

This reaction is accelerated when the temperature is raised to $100^{\circ} \mathrm{C}$ or above. The result of the reaction is a metalto-metal bond that provides excellent adhesion. The adhesion of electrodeposits to aluminịm is obtained by chemịcal treatment whịch ịmparts a fịne graịn dịspersed etch and forms a surface layer of alumịium hydride. The author also claịms the deposịt, ịn thịs case nickel, can be heated to the melting point of aluminium without forming blịsters. 
A bearịng assembly may be defịned as a region in a machine where a force is transmitted between two members moving relatively to one another. The two moving surfaces will wear rapidly unless they are separated. Separation can be achịeved in a number of ways. oịl can be pumped in between the surfaces to provide hydrostatịc lubrication as in the use of jacking-oịl for turbo-generators. The assembly can be designed to operate wịth hydrodynamị lubrication i.e. by making use of the separating forces generated in a film of oịl, which is being dragged by the journal into a dịmịnịhịng clearance space. The surfaces may be separated mechanically by means of balls or rollers, but even in this case the rollers and theịr matịng surfaces are stịl likely to wear rapidly, unless the materials from whịch they are made are suittably chosen and some lubrịcation provịded.

An alternative method of dealing with the problem in some instances, is to tolerate wear and select bearing materịals that wịl reduce wear rates and frictional forces to a minimum. The 'dry bearings' based on materials such as PTFE and Graphịte provịde examples of thịs type.

The classes of bearings outlined above meet very different requirrements and their applications do not overlap. plain bearings for example, can be produced at a reasonable cost and are particularly suited to carrying hịh loads at high 
speeds. Roller bearings, on the other hand, are more expensive to manufacture, but can withstand high loads at low speeds. 'Dry' bearings enable machinery lubrication systems to be simplified and they are often used in systems where a lubricant would be an undesirable contaminant. As the bearings used in this investigation are lubricated plain bearings, the following discussion is concerned directly with their specific applications and requirements.

\subsection{Properties of an Ideal Bearing Material}

When the two moving surfaces are completely separated by a film of. lubricant, The nature of the bearing alloy itself is not of great importance. It must however, have sufficient strength to withstand the maximum pressure and temperature generated in the oil film. If this is all that is needed, the bearing could be made of the same material as the shaft. However, experience has shown that such combinations cause, at best, high wear rates.

High wear rates may occur when the bearing and the journal surfaces come into contact, as commonly happens when the two surfaces are at rest or moving slowly. The actual contact areas are small and therefore local pressures are correspondingly high. These pressures may cause local welding and later movement will cause fracture, generally in the journal or the bearing and not in the weld itself. Repetition of this process gives rise to wear of both 
bearing and journal or even to seizure in extreme cases. The bearing material must therefore, be chosen to resist wear due to this cause.

Excessive wear may arise through an alternative mechanism, that of abrasion by dirt particles carried in the lubricant. Although, this type of wear can be controlled by clean assembly and filtration of the oil, it cannot be eliminated altogether. It is therefore, an advantage if the bearing material is able to absorb this type of contaminant and so remove it from the system.

The ideal bearing material would be expected to accomodate such non-ideal load patterns, as those imposed by a misaligned shaft. What is required, is a material that can yield plastically, in order to redistribute local high loads. Bearings have to withstand chemical attack by the lubricant. Degredation products of the oil and the products of combustion of the fuel, are the likely sources of corrosive agents, especially if water is present. It is also desirable that the bearing should be capable of manufacture at reasonable cost.

To sum up the bearing material should :

1) Withstand high loads at the appropriate temperatures, 
2) Operate for short periods with only boundary lubrication,

3) Absorb solid contaminant from the lubricant,

4) Redistribute high local loads,

5) Resist corrosion by the lubricant.

These are conflicting requisites. The need for high strength, can be met only by using materials that cause a high rate of wear of the shaft, but in theory at least, a material can be chosen which gives the best compromise between these two factors. In practice, the choice of material is often determined by the load that has to be carried, although the use of hardened shafts with greater wear-resistance increase the range of possibilities.

Work carried out by Duckworth and Forrester(114), indicated that in lubricated journal bearings, the wear of the journal was generally greater than that of the bearing, in spite of its much greater hardness. It therefore, appeared unlikely that either the formation and rupture of local welds or the mechanical interlocking of asperities could be the main cause of wear. Poor correlation between the wear rates and the known chemical behaviour of the oxides involved, also caused this theory to be discounted. The evidence therefore, indicated that contamination of the 
lubrịcant, partịcularly by ferrous particles was the single most important factor.

The bearing surface can be scoured by particles of contaminant small enough to pass through the clearance space, but these particles are likely to come into contact with the bearing and journal for only a short time, before beịng removed by filtration. Particles smaller than the clearance space wịll become embedded in the bearịng and cause wear of the journal. The mechanism of wear between the embedded particle and the journal, may well be that of the interlocking of asperities, or the rupture of local welds. If the bearing cannot readịly accomodate foreign partịcles, they are lịkely to remaị above the surface and abrade the journal. If the particles are completely embedded, abrasịon ị lịkely to be reduced. If embedded particles escape, they may be permanently removed from the system, or become embedded elsewhere where they wịll continue to cause wear. The type of action that occurs with a given contaminant will depend upon the properties of the bearing alloys.

Low hardness and a low elastic modulus encourage deep embeddịng and so reduce wear. Low tensile and shear strengths may encourage the release of entrapped particles. A low meltịng poịnt, whịch usually ịmplịes a low softenịng temperature, should also favour deep embedding of foreign partịcles. Weak chemical affinity between the bearịng and 
ferrous material, the most widespread contaminant, should mean that ferrous particles are more easily detached.

\subsection{Historical Review of Bearings}

An outline of the metallurgical developments serves to reduce a complex range of materials, to an oversimplified system based on tin and lead. Of the materials available at the beginning of the 19th century, only tin and lead were found to have adequate bearing properties for light loads. They were soft and had low melting points, which enabled the materials to absorb abrasive dirt particles, operate with poor lubrication without seizing and be easily cast into bearing form. The additions of antimony and copper to tin based, alloys and antimony and tin to lead based alloys in the 1830s, improved the strength of the alloys. The strength of these bearings is proportional to the amount of alloying present, but there is a limit to the extent that this can be achieved. The greater their strength the harder the bearing becomes consequently, the wear rate of the shaft increases. A further more important concern, is that the ductility of the bearing alloy decreases and its ability to conform to misalignments of the journal is diminished.

For further specific load-carrying capacity a different approach was used. Lead was used as a dispersion in a stronger matrix such as copper. These alloys were 
introduced in the 1930 s however, high shaft wear rates were incurred, resulting in the need for the shaft to be hardened. The copper-lead alloys in particular, suffered from corrosive attack by the oxidation products of the type of lubricating oil then in use, the lead phase being easily removed. Additions of antimony normally made to lead, to improve its corrosion resistance, was of little benefit as in this case they mainly dissolved in the copper matrix. The problem was overcome by electroplating the copper-lead alloy with a lead-tin or, lead-indium overlay, both of which have good corrosion resistance. These overlays introduced in the 1940 s have a greater mechanical strength than might be expected, due to their thinness and they have an additional advantage of causing little wear of the shaft.

As the possibility of forming a two-phase system based on tin and copper does not exist, work was carried out on alternative combinations. Aluminium-tin was found to be successful. Reference to these alloys had been made early in the century, but it was not until a satisfactory manufacturing technique for large scale production was developed, in the 1950s, that extensive use of the system was made. The aluminium-tin alloys, typically $20 \%$ tin, can be used unplated and have better corrosion resistance than copper-lead. 
The compromise of fatigue strength and surface properties offered by this alloy, represents a satisfactory bearing specification for naturally aspirated engines and the economics of production make it very marketable. However, even moderately turbocharged diesel engines have increased cylinder pressures, Fig. 5, which impose higher loads on the bearing surface than are generally found in naturally aspirated engines. In addition, oil film thicknesses are reduced, although this is predominantly an effect in main bearings at overspeed conditions. For reasons of overall engine size and cost, designers are reluctant to compensate for this, by increases in bearing size and there is now a general acceptance of higher bearing duty, made possible by higher standards of bearing environmental design and by the development of bearing materials to suit the more arduous operating conditions. The present requirements are beyond the capability of copper-lead and 208 tin-aluminium alloys to provide an acceptable fatigue 1ife. This is especially true in connecting rod big end bearings, where calculated loads for some engines approach $50 \mathrm{MPa}$ and even for main bearings are as high as $40 \mathrm{MPa}$ (115).

High strength bearing materials, are therefore required in these highly stressed engines, which are not only capable of providing an acceptable fatigue life but which are also able to operate without seizure and excessive wear when oil films are thin and temperatures are high. An aluminium-6\% tin alloy bearing in unplated form, has virtually an 


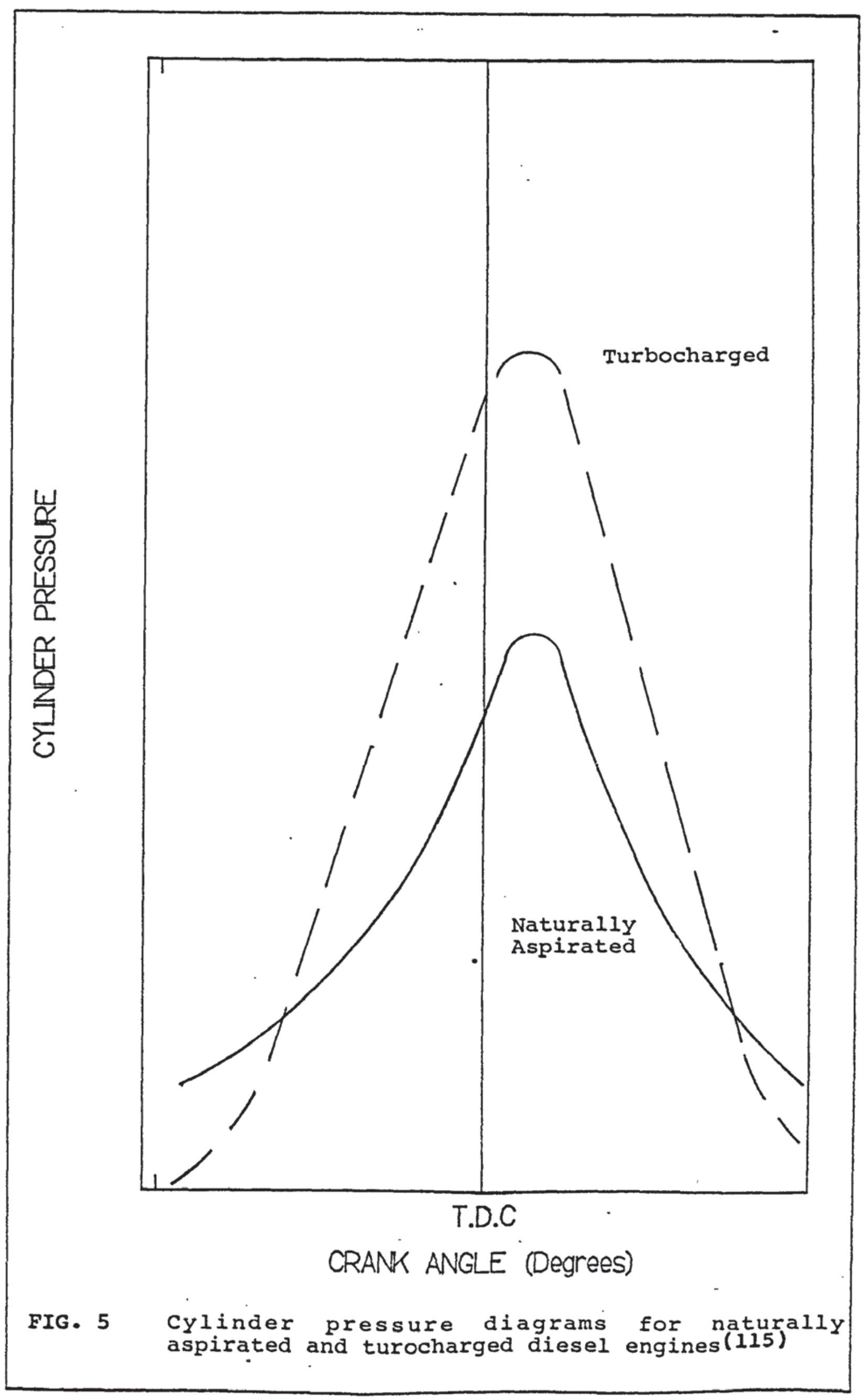


identical fatigue strength to alumịnịm-20\% tinn, however, the presence of the overlay increases fatigue strength of the lining material by $10 \%$ and hence can be used under more arduous conditions. The relative fatigue strength, as measured on a hydraulically loaded bearing test machine, for various materials and overlays ịs shown in Fig.6. A recent development in the hịgh strength field, is an aluminium based 118 silicon, lo copper alloy, which constịtutes a bearịng material with a hịgh resistance to fatịgue and ịs currently used in turbocharged engịnes(116). Thịs alloy has a very different metallurgical structure, consịstịng of fịnely dịvịded sịlịcon ịn an alumịnịm-copper matrix, from the typical cast alloys of similar compositicion. However, the hardness, the relatịvely poor dịt embeddabịlịty and poor conformabilitty, require that the bearings are overlay plated for satisfactory engine performance.

\subsection{Bearing overlays}

The requirement for hịg fatigue strength in a bearing material is in opposition to the equally important requịrement for good surface properties, since fatigue strength is generally proportional to hardness. Materials such as aluminium-sịlịcon possess a level of resistance to fatigue which makes them generally unsuitable in terms of their surface properties unless they are used in conjunction wịth an overlay. Thịs ịs not to suggest that 


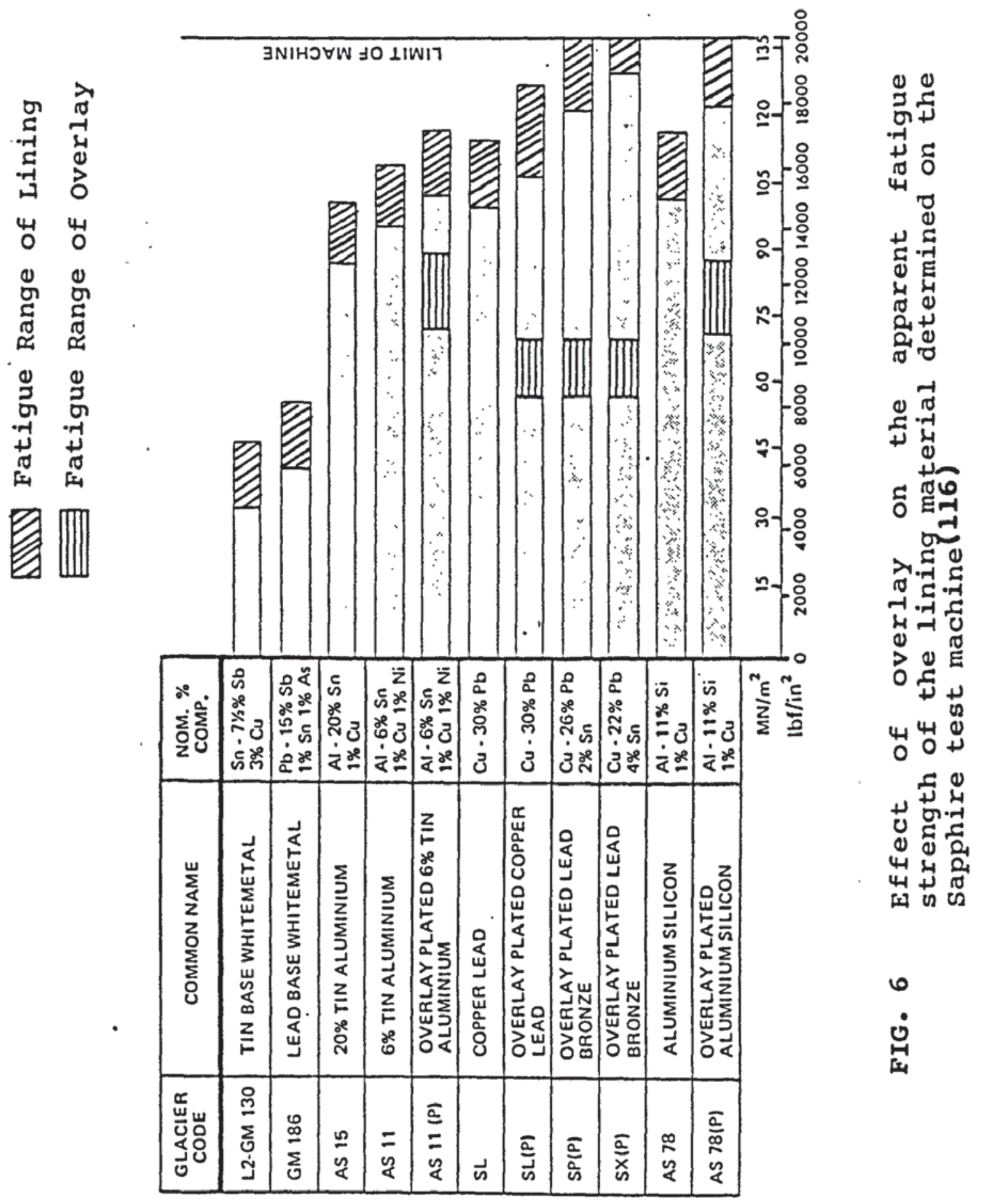


once an overlay is removed by gradual wear, the lining is incapable of performing satifactorily. It is common in some engines where oil films are very thin, for local wear of the overlay to occur and because the transition to part exposure of the harder lining has been gradual i.e. practical local oil films have been established, the wear rate reduces and satisfactory behaviour is obtained.

The purpose of an overlay, be it lead-tin, lead-indium, lead-tin-copper or any other material, is to provide good surface properties where they are lacking in hard, strong interlayers. The overlays have the function of :

1) Preventing corrosive attack of the bearing alloy by oxidised lubricating oils, which are acidic.

2) Reduce the tendency towards seizure, galling and scoring caused by solid phase welding between the sliding surfaces without localised melting. This resistance to seizure is dependent upon three basic factors namely :

( i) Compatibility - the ability of the combination of materials to resist solid phase welding and thus adhesive wear. This is particularly important if the oil film between the bearing and the shaft is disrupted. 
(ii) Conformability - fatigue strength is increased by reason of a greater degree of conformability i.e. a soft overlay will wear or yield against a deflecting crankshaft, so spreading the applied load across a wider surface area, reducing the effective unit load and increasing the practical film thickness.

(iii) Embeddability - this is the capability of the overlay to cover small foreign particles with a thin layer of deposit, hence preventing harmful abrasion and scoring of both the shaft and the bearing lining.

The thickness of the overlay is a compromise between optimum embeddability, which increases with thickness and fatigue strength, which is at a maximum at low overlay thickness(117), Fig.7.

A strong, hard bearing material with a steel backing and an overlay plated surface is hence, very well suited to the modern uprated diesel engine, where firing loads are high and also where inertia loads are high and unrelieved at overrun speeds. These temperatures, 90-1700 C, accelerate the tin and indium diffusion that occurs in the overlays and intermetallic compounds form at the interface between the overlay and the nickel interlayer. A consequence of a 


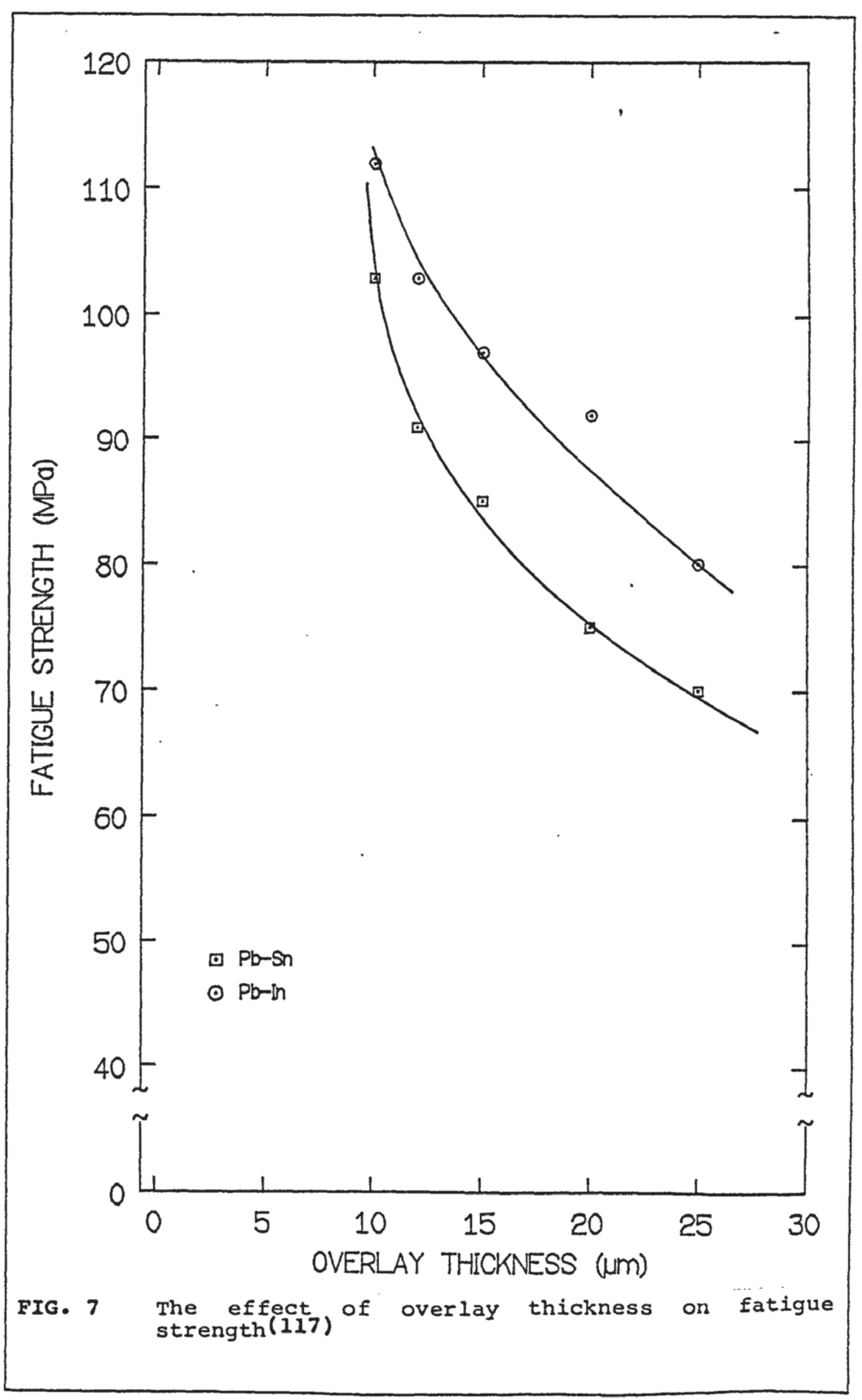


high rotational speed is high lubricant temperature and if this aproaches $140^{\circ} \mathrm{C}$, the overlay alloys suffer from diffusion to form compounds at the interface between the overlay and the interlayer.

The initial composition of the overlays, lead $10 \%$ tin or lead 108 indium will resist corrosion, but if the levels fall to 38 for tin or 58 for indium(116), corrosion is likely in the presence of degraded lubricants. No practical solution has yet been found and work is being carried out on various barrier materials, to see if an improvement could be made. Work by Semlitsch(118) has shown that a nickel barrier at the interface, deposited to prevent diffusion of the overlays to the copper-lead lining, does not inhibit diffusion of tin; nickel-tin compounds form instead. Indium diffuses in a similar way.

The corrosion resistance of an overlay is dependent on the presence of the alloying metal and if the correct levels are not maintained, the corrosion becomes a serious problem. Fig.8. shows the effect of heating at $120^{\circ} \mathrm{C}$ in medicinal white oil (MWO), Al-6z Sn linings, overlay plated with lead-tin-copper and having a nickel barrier. The results shows that lead-tin-copper is more corrosion resistant than lead-tin. A further series of corrosion tests have been carried out by Eastham and Crooks(117) on different linings, Fig.9. It is apparent that the nickel is of considerable importance in acquiring high corrosion 


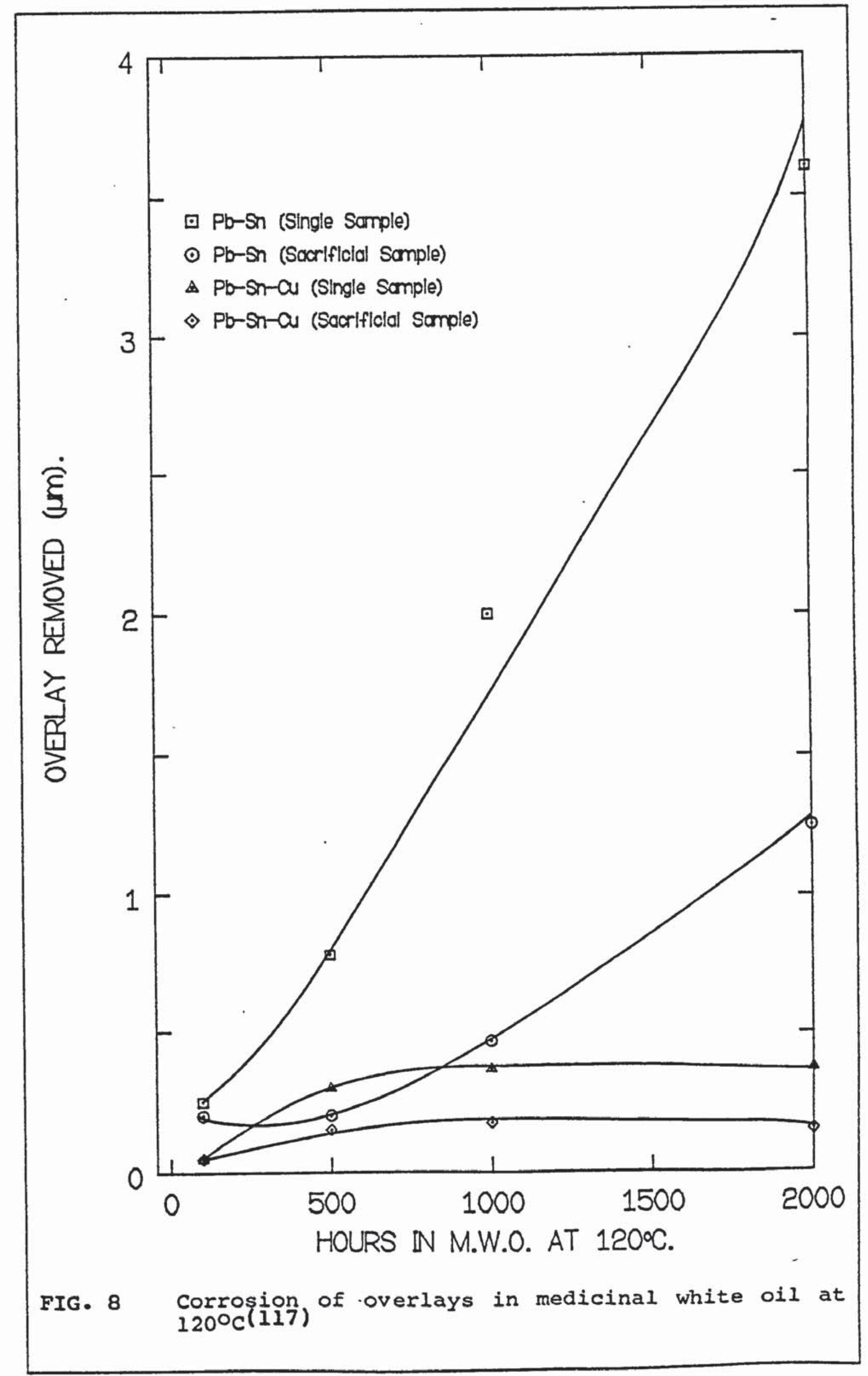




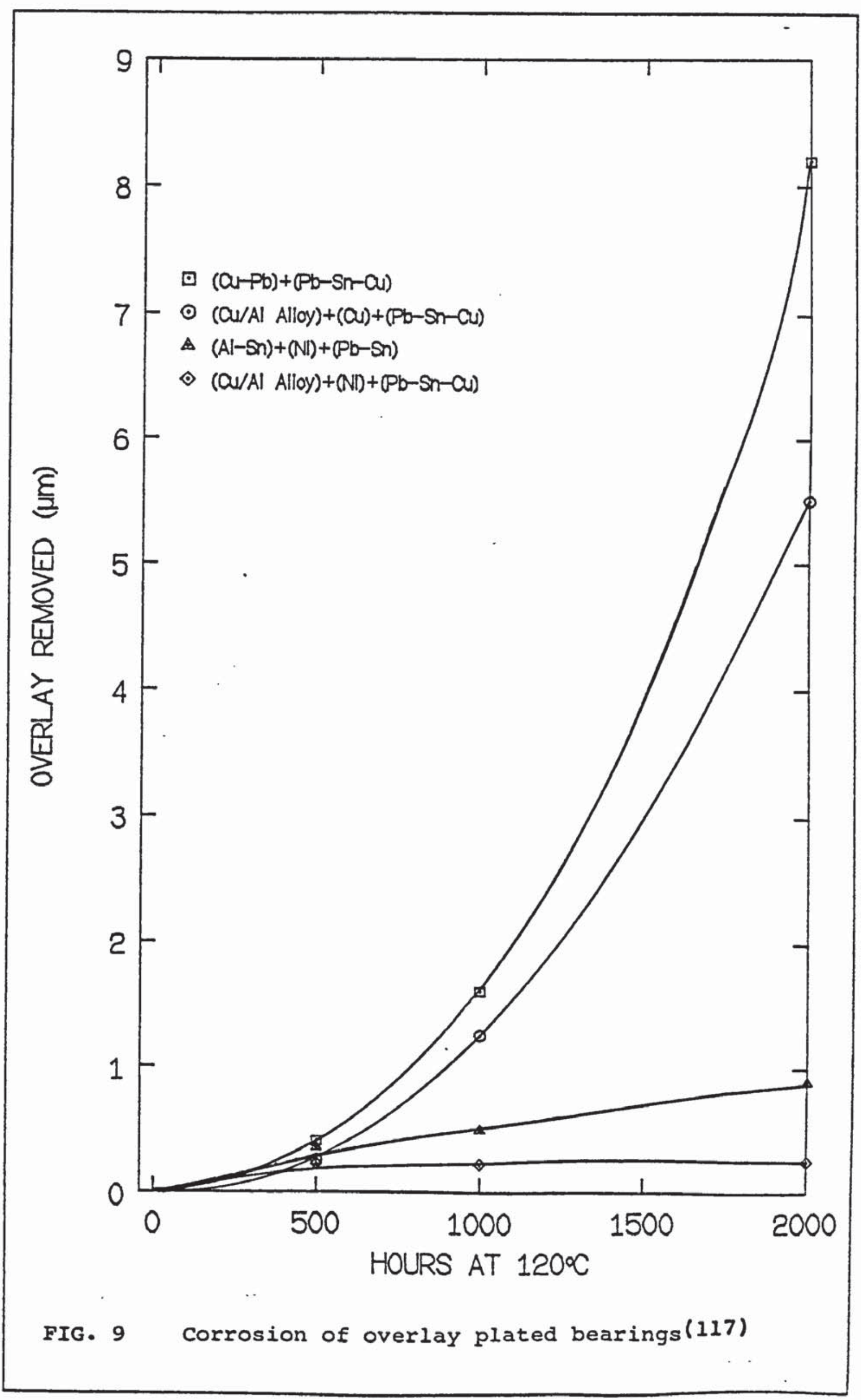


resistance, by reducing the rate of tin loss by diffusion.

It should be noted that lead-indium plating does not constitute alloy plating in the same way as lead-tin, but the sequence is one of depositing a thin layer of indium over previously deposited lead. The coating is then subjected to a temperature of $150^{\circ} \mathrm{C}$ in an oil bath to allow interdiffusion to occur. This however, produces a nonuniform coating composition.

The wear resistance of the lead-tin overlay is higher than that for lead-indium, although they have the same as-plated hardness, 8-10 HV. Both hardness, 13-15 HV and wear resistance for lead-tin-copper overlays are higher than those for the other overlays(117). The addition of copper tends to behave as an improving factor, but excess can cause a reduction in strength, the optimum is said to be 1$3 \%(119)$.

Many hundreds of millions of bearings have been overlay plated, since the introduction of a precision mass production plating technique in the 1950s(120). The process for plating the bearings has changed over the years, but a typical technique has been described by Beebe (121). 


\subsubsection{Plating Process Cycle $(121)$}

\section{(i) Aluminium etch}

Thịs etch, usịng sodịum hydroxịde and sodịum sulphịde is reported to remove $4-5 \mu m$ of alumịnium from the bearing surface. The sodịum sulphịde continuously purifies the etch solution by precipitating the lead drag-in from the plating racks, otherwịse the etch rate and the bonding becomes erratic.

\section{(iị) Pickle}

Thịs removes the residual smut of heavy metals left on the aluminium. surface after the etch. This must be carried out without significant attack on the steel bearing backs. Ammonịum persulphate is used electrolytically.

\section{(iii) Zinc Strike}

Concentrated zincate solution is used. In order to ensure that the zinc plate is of sufficient thickness in the portion of the aluminium immediately adjacent to the steel, a combination of replacement plating and electroplating is used. The sequence uses 10 seconds immersion without current, followed by 20 seconds at 0.1 $\mathrm{Adm}^{-2}$. The introduction of current into zincate deposition allows the aluminium close to the steel at the edges to be 
coated. The steel impresses a potential on the aluminium, ịnhibiting the normal zinc ịmmersion coating.

\section{(iv) Nickel strike}

Thịs produces a good bond to the zincate layer, however reasonably close control ịs requịred especịally regarding $\mathrm{pH}$ and ịmpurịtịes.

(v) Lead alloy overlay plate

The alloy, typically $\mathrm{Pb}-108 \mathrm{Sn}-28 \mathrm{Cu}$, is deposited from a fluoborate solution with various addition agents at 6 $\mathrm{Adm}^{-2}$.

The alloy must be deposited uniformaly over the entire curved insịde surface of the bearing. None of the alloy must be deposited on the steel backing consequently, extensịve use is made of current shịlds. similarly, the steel should not be attacked during the pretreatment sequences. 
Wear in general, is rarely catastrophic but reduces the operating efficiency by increasing the power losses, oil consumption and the rate of component replacement however, in the case of certain plain bearings, wear can remove an electrodeposited overlay, expose the nickel interlayer allowing seizure to occur. Wear may result whenever there is relative sliding. The rate at which material is removed depends upon working conditions, for example loading, lubrication and environment. The large number of variables involved, in even apparently simple cases makes generalisation difficult, that is each wear study is very much individual in character. Although a considerable amount of work has been done in the study of wear, there is as yet no fundamental theory of wear. The primary objective of most wear studies is to reduce wear, although in some cases, for example running in, some wear may be beneficial.

Surface treatment to reduce wear is a subject of considerable importance. Surfaces may be hardened by various methods to be more resistance to wear, or they may be given special coatings which are wear resistant, for example coatings which in themselves have lubricating properties; coatings which can be sacrificed; or coatings formed and renewed by additives within the lubricant. 
The generally accepted definition of wear is, the progressive loss of substrate from the operating surface of a body, occurring as a result of relative motion of the surface(122). The usual classification of types of wear are abrasive, adhesive, erosive, fretting, wear due to fatigue and wear due to chemical action.

A situation is seldom reached where one of these mechanisms is met in isolation, as most examples are a combination of two or more of the above mechanisms.

Friction and wear are not intrinsic material properties, but are characteristics of the engineering system. Any change in load, speed or environmental conditions, may cause catastrophic changes in the wear rate of one or both of the surfaces in contact(123).

Wear occurs by surface interactions at asperities and components may need replacement after only a relatively small amount of material has been removed, or if the surface has been unduly roughened, for example, piston rings in internal combustion engines. These rings lose efficiency as soon as the surface roughness is sufficient to allow oil and gas seepage, with failure being indicated by a reduction of power and an increase in engine oil consumption. 
The generation and circulation of wear debris, particularly in systems where the clearances are small, relative to the wear particle size, may be more of a problem than the actual amount of wear.

\subsection{Types of Wear}

\subsubsection{Abrasive Wear}

This occurs when hard particles penetrate the surface and displace material in the form of slivers or chips. An otherwise smooth surface becomes roughened with regular grooves. This is usually referred to as scratching, scoring or gouging.

\subsubsection{Adhesive Wear}

When two surfaces come into contact with each other they meet at their asperities. Wear by adhesion occurs when surfaces slide against each other and the pressure between the contacting surface asperities is high enough to cause local plastic deformation and adhesion. The asperities deform, until the real area of contact has increased sufficiently to support this load, thus causing an increase in the area over which adhesion can take place, as sliding continues. Ultimately, these adhesively formed junctions rupture at their weakest points resulting in metal transfer 
from one surface to another.

\subsubsection{Erosive Wear}

Erosịve wear is due to impact of particles. The process is a combination of deformation and cutting. The wear rate is dependant upon the angle of attack and the nature of the materịal ịnolved.

What is termed cavitation erosion, arises when local fluid pressure falls below the vapour pressure of the liquidd. In effect, it is boịling of the liquịd by pressure reduction rather than by an increase in temperature. Damage to solid surfaces may result from the rapid and violent collapse of vaporous cavities, adjacent to the surfaces. The local pressures developed can be as high as $2000 \mathrm{MPa}(129)$, this causes considerable plastic deformation of the surface (130).

\subsubsection{Chemical Wear}

Seldom is one type of wear found in isolation and thị is particularly true of chemical wear. Chemical action plays a preliminary part in a number of processes. For example, acidic lubrication oil degradation products, by preferentially attacking constịtutes of the bearing materịal, may grossly accelerate wear and precipitate bearịng failure. 
Corrosion wear, is a form of chemical wear which results from the interactions of the environment with sliding surfaces, followed by the rubbing off of reaction products. Initially, the chemical attack will be rapid. Usually as a film is formed, the rate of reaction slows down and may cease completely. If the products do not adhere or the film is porous, the chemical reaction proceeds independantly of any sliding and the process is one of pure corrosion.

\subsubsection{Fretting Wear}

This is a wear phenomenon occuring between two surfaces having relative oscillatory motion of small amplitude(124). This probably commences as a form of adhesive wear. If the wear debris cannot escape quickly enough, then a form of abrasive wear may follow, which may be more severe if the wear debris oxidises.

\subsubsection{Fatigue Wear}

There is another form of wear that is dominant, when interfacial adhesion plays an unimportant part in the frictional process. This occurs in well-lubricated sliding systems, where there is repeated encounter of asperities. They may never make direct contact but impose high stresses on one another through the lubricating film. After a few million such encounters, the asperities fatigue and pieces 
of material fall out of the surface. This mode of wear is very important in plain bearings and as such will be discussed later in more detail.

\subsection{Wear of Plain Bearings}

The majority of plain bearings operate under conditions of hydrodynamic lubrication, that is the movement of the mating surface relative to the bearing surface, creates a wedge of oil which causes the two to be separated. If a machine was running continously, it would be possible to ensure than an uninterrupted film of clean oil would be maintained over the surface of the bearings and bearing wear would not occur. Unfortunately, these conditions are never obtained and the bearings must be able to withstand anything from intermittent to continuous contact with the mating surface. The mating surface must also be as tolerant as possible of the dirt in the oil, even when the particles are larger than the oil film thickness.

Wear in a hydrodynamically lubricated bearing, may be the first symptom of an inadequate lubrication condition. This symptom if allowed to persist, may lead to a catastrophic seizure condition, since increased clearance in a bearing can lead to thinner oil films, greater wear etc. More importantly, a rough worn surface can cause progressively greater interruption of the oil film, again leading to eventual seizure. A less drastic, but nevertheless serious 
effect of wear, is an increase in bearing noise, which in an automotive engine may reach an unacceptable level.

\subsubsection{Dirt}

This is the main enemy of bearings. It may be built in dirt, such as machining swarf, it may be wear products generated during running from cylinder liners or piston rings, or it may be extraneous dirt from the environment.

\subsection{2 ill Film}

Another common cause of bearing wear, is an insufficient oil film. If the oil film is thinner than the surface roughness of the mating surfaces, resulting in contact between the bearing and the shaft, wear of the former by the latter will occur. It is of vital importance that the bearing should suffer the greater damage in such encounters, the cost of replacement being much less for the bearing .

Thin films can result from an inadequate oil supply. However, even when the supply is adequate, shaft deflections, imperfect shaft geometry or imperfect assembly can give rise to locally thin or non-existent oil films. Very often the symptoms of wear occur predominantly at the bearing edge(125). Bearing design may also be at fault. A situation could arise which makes it impossible for the oil 
film pressures to support adequately the bearing load. Also, the temperature created in the oil film, may realuce the viscosity, to a level where again the oil film will not support the load applied.

Under these conditions either general or localised wear will take place but, will not usually be associated particularly with the bearing edges. If the condition is not severe, only slight wear or wiping of the bearing surface occurs, the oil film will be re-established in the area concerned and the bearing will operate satisfactorily.

\subsubsection{Cavitation Erosion}

Cavitation erosion damage in engine bearings, is a phenomenon which has assumed increasing significance during the past five to ten years, probably as a result of the design trends towards higher rotational speeds. In many cases the damage is restricted to local attack of the overlay and the performance of the bearing is virtually unaffected. However, in more extreme cases, extensive loss of overlay and interlay material occurs and the consequential adverse affects upon oil film conditions, will reduce the service reliability and the life of the bearings and their associated components.

Cavitation erosion damage is seen predominantly in diesel engine bearings and on the rare occasions damage occurs in 
petrol engines, it is normally a result of operating under conditions of sustained overspeed or with incoriect ignition timing(126). The fact that the diesel engine bearings are more prone to cavitation erosion damage, is attributed to the more severe combustion conditions and the necessity for complex oil feeding arrangements with greater change of flow discontinuities. In order for damage to occur to the bearing lining, it is necessary for vapourous cavities in the lubricant to collapse, in close proximity to the surface.

\subsection{Fracture and Fatigue}

Plain bearing literature in the 1930s, described the cracking failures observed in white metals and concluded that they were due to fatigue under the 'pounding action' of repeated loadings in service. With the exception of MacNaughtan(127) no author has described the origins or mechanisms of bearing fracture and it has not been usefully related to other mechanical properties. In particular, there is no published comparison of this type of damage with cavitation erosion. The common feature, being that they are both manifestations of surface cracking resulting from loadings imposed through a fluid.

Generally, a crack appears in the most highly loaded area of the bearing surface(128), with its long axis parallel to 
the shaft axis. The crack propagates, as a plane crack, towards the alloy/steel bond; but turns to run parallel to the bond interface, when still in the alloy. The position at which the crack turns, to run parallel to the bond is determined by the bearing material. White metal bearings for example, have a crack at some distance from the bond, while in non-white metal bearings the crack almost reaches the interface. To avoid damage caused by detachment of the lining alloy, the bearing designers can either lower peak stress, by changing the bearings environment or to change the lining material, to one with a higher fatigue ranking. Fatigue rankings are obtained using test rigs which provide the bearing with repeated and measured load pulses through an oil film, in an attempt to simulate the loading pattern experienced by a crankshaft, bearing $(116,129)$.

During normal operation of a crankshaft, loads are transmitted between the journal and the bearing through an oil film which separates the surfaces and ensures low friction. These loads vary considerably with crank angle, rising momentarily to a maximum at one part of the cycle. Computer predictions of the oil film pressure contours, in an engine bearing $50 \mathrm{~mm}$ dia. $28 \mathrm{~mm}$ long are shown in Fig.10(128).

Such a pressure pattern in the clearance space is accompanied by compression of the bearing and the shaft and acts only on an element of bearing surface for a few 


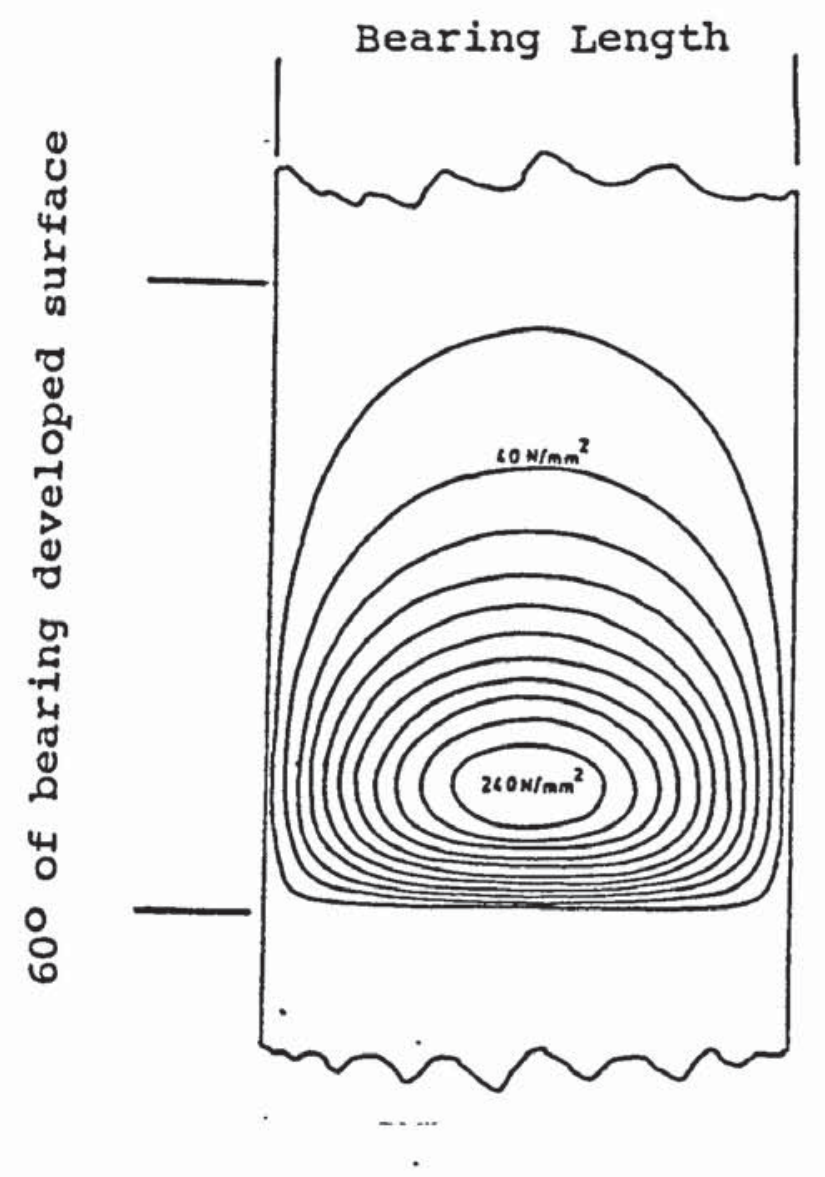

(a)

Shaft Rotation

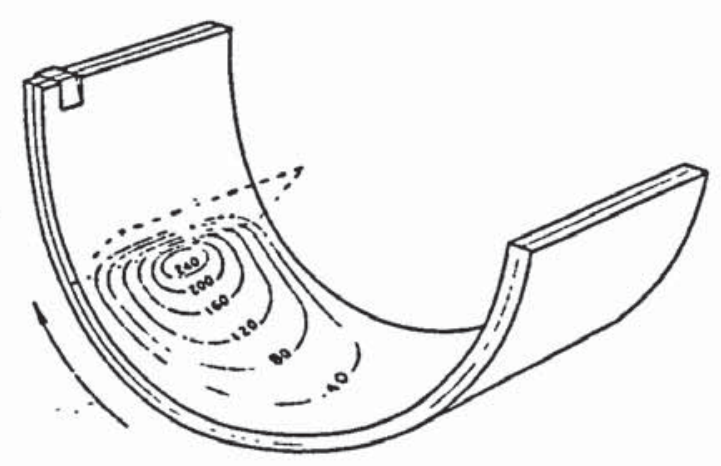

(b)

FIG. 10 Typical oil film pressure contours over the surface of an automotive engine bearing at the instant of minimum oil film thickness(116)

The mean oil film pressure is $40 \mathrm{MPa}$, maximum developed pressure in the oil film is $240 \mathrm{MPa}$. The dotted plane, Fig. $10 \mathrm{~b}$ is that in which there is maximum shear stress. 
milliseconds, at current rotational speeds. If the exịstance of these contours was not so fleeting, they would be less steep, sịnce the oịl pressures would have more tịme to equalise. In the region of the closest packing of the contours, there is a concentration of shear stress, this is the plane ịn whịch the crack fịst appears.

A special consequence of the loading of a bearing through an oil film, ịs that the shear stress becomes high enough to cause fracture because of the cyclic loading. The steep contours, in Fig.10 are not flattened because of the viscous reluctance of the oil to flow, in the few mịllịseconds for whịch the maxịmum pressure is applied. In conventional fatịgue testịng, stress is ịdependant of speed of application and in thịs respect bearing fatigue dịfers.

Computed maximum oịl fịlm pressures, developed over the surface of the test bearing in a test rig, when the load is sufficient to fatigue, can be in the order of $700 \mathrm{MPa}$ for a 208 Sn-Al bearịng alloy. These pressures are far in excess of the yield stress of the lining material, measured conventionally. However, engine bearings consist of a relative thị lịning on a steel backing that enables the lining to carry the heavy fatịgue loads(116).

A further consigderation, is that the maximum oị film pressure is not applied over the whole surface of the 
bearing, but refers only to a mathematical point on that surface. The oil film pressure falls as one moves away from this point, as seen in Fig.10. Thus, the extent of plastic deformation occurring in the lining under the area of maximum oil film pressure is limited, not only by the steel backing, but by the lining alloy outside the area of maximum oil film pressure, the deformation of which is elastic. It is for this combined reason, that the onset of fatigue cracking, as observed in short-term test rigs, is delayed until very high dynamic pressures, of the order of $700 \mathrm{MPa}$ are attained. The exact value of maximum oil film pressure that can be sustained by an engine bearing lining will, of course, depend on the mechanical properties of the lining and its thickness.

\subsubsection{Overlay Fatigue}

Bearing material selection is invariably a compromise of surface properties, strength and corrosion resistance. In the modern highly loaded engines, the normal compromise consists of a lining material having high strength and an electrodeposited overlay having good bearing properties. A consequence of using an overlay is an apparent increase in the fatigue strength of the underlying bearing material, although fatigue of the overlay normally occurs at a lower load than for the substrate material(116). The overlay tends to cushion the lining by lowering the specific load experienced(117). Overlay conformability ensures, that 
after running-in, the geometry is closer to the ideal sịtuation of concentricity for a journal bearing.

\subsection{LUBRICATION}

Optimum conditions of lubrication exist when the sliding surfaces are separated by a fịlm of oịl, thịck enough to prevent any metal-to-metal contact. Thịs means in practice, that the minimum fịlm thịckness should be several times greater than the sum of the individual surface roughnesses of the bearing components. These films can eịther be mạ̣ntaịned by an externally pressurịsed system (hydrostatic lubrication), or be self generated by favourable surface geometry and a relatịve slịdịng velocịty hịg enough to produce laminar flow (hydrodynamic lubrication). The most undesirable condition in lubrịcation, ịs promoted by hịgh loads, low speeds, extreme temperatures or lack of lubricant. In between the two extremes of dry slịdịng and a thịck oịl fịlm, two other dịstinct states of lubrịcation, boundary and thị fịlm, can be ịdentịfịed.

Boundary and thịn fịlm lubrication are states where the lubricant is present, but owing to hịgh loads, low speeds etc.. complete separation of the surfaces does not occur. In journal bearịngs, thịs is found ị starting, stopping and when the shaft passes through zero speed, in reversing. 
In thin film lubrication, surface asperities penetrate and disturb the desirable lamellar conditions of flow, so that only part of the load is carried by hydrodynamic forces, the remainder being metal-to-metal contact. Boundary lubrication occurs only when contact pressures are high enough and sliding velocities low enough for hydrodynamic effects to be completely absent, the entire load is then carried by an extremely thin, multi-molecular layer of boundary lubricant.

Reynolds(130) reviewing the work of Tower(131,132) concluded, that lubrication of the bearings in question depended upon hydrodynamic action and was influenced by the viscous flow properties of the oil. Reynolds suggested that the oil adheres to both stationary and moving surfaces of the bearing and is dragged into the clearance space which, because of the eccentricity of axle and bearing centres, converges in the direction of motion. Thus, a convergent wedge of oil is generated, which builds up sufficient fluid pressure to hold the bearing surfaces apart and carry the applied load.

It can be seen from Fig.1l(133), just how the states of lubrication and frictional resistance in a journal bearing, are influenced by changes in the three main parameters that govern its performance; oil viscosity $(Z)$, load $(P)$ and rotational speed (N). The limiting conditions of a load and speed, which a specific bearing and lubrication situation can successfully accept, are shown in Fig.12(134) 


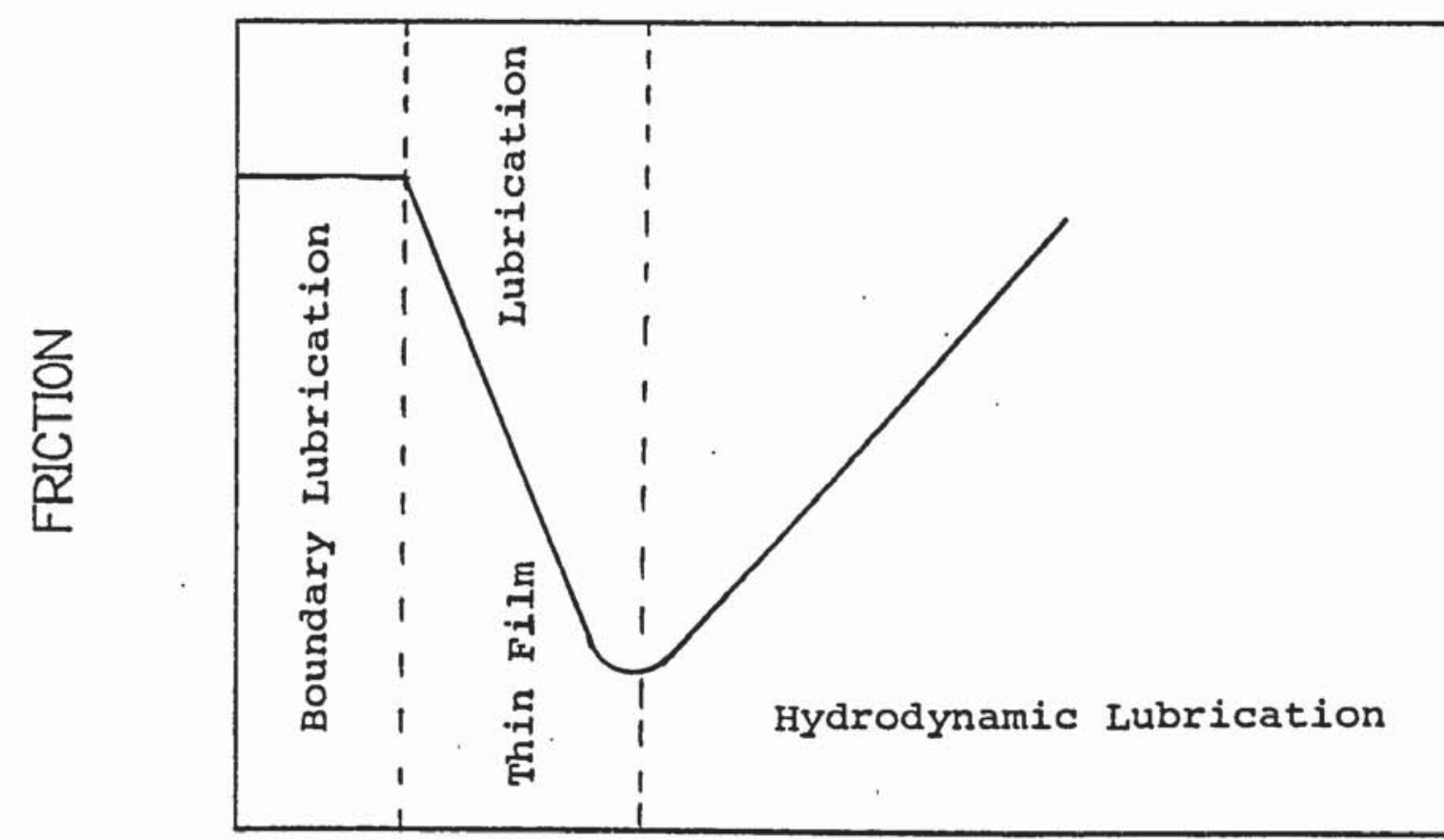

\section{ZN/P}

FIG. 11 The relationship of friction in a journal bearing to the viscosity-speed-load criterion $\mathrm{zN} / \mathrm{P}(133)$

High Bearing Temperature Limit

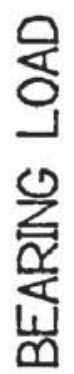

Thin oil Film Limit

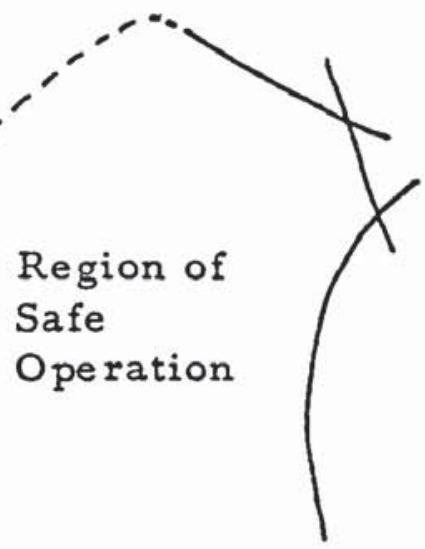

Oil oxidation Limit

Oil Film Whirl Limit

\section{JOURNAL SPEED}

FIG. 12 Limits of safe operation for hydrodynamic journal bearings $(134)$ 


\subsection{Brush Plating Equipment and Techniques}

\subsubsection{Selection of Stylus Holder}

The styli holders used in this investigation, consisted of two that were specially made, the other was a commercially available stylus holder. All three can be seen in Fig. 13. Holder 1 was used for all manual brush plating operations and is the commercially available holder. Holders 2 and 3 were used in conjuction with the Turning Head Sample Holder, for semi-automated brush plating.

\subsubsection{Stylus preparation}

The anode was prepared by inserting a graphite rod into a holder, connected to the power supply. The rod was wrapped in cotton wool and covered by a viscose gauze. A further covering of either a $50 \%$ nylon $50 \%$ polypropylene felt mixture or 'Selvyt' polishing cloth was added by means of rubber bands. These coverings provide some degree of abrasive scrubbing of the cathode surface hence, disrupting the cathode diffusion film. Prior to use, the felt pad and the rubber bands were immersed in $20 \mathrm{~V} / 0$ sulphuric acid for 24 hours, in order that any dyes or other contaminants present were removed. Fig. 14 shows the various materials 


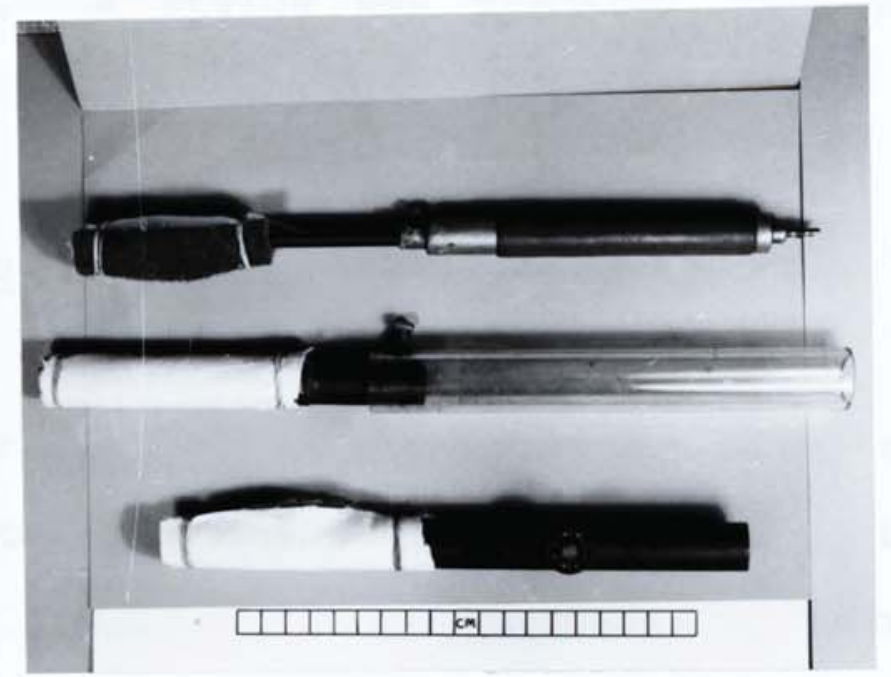

Holder 1

Holder 2

Holder 3

FIG. 13 Styli holders used in this investigation

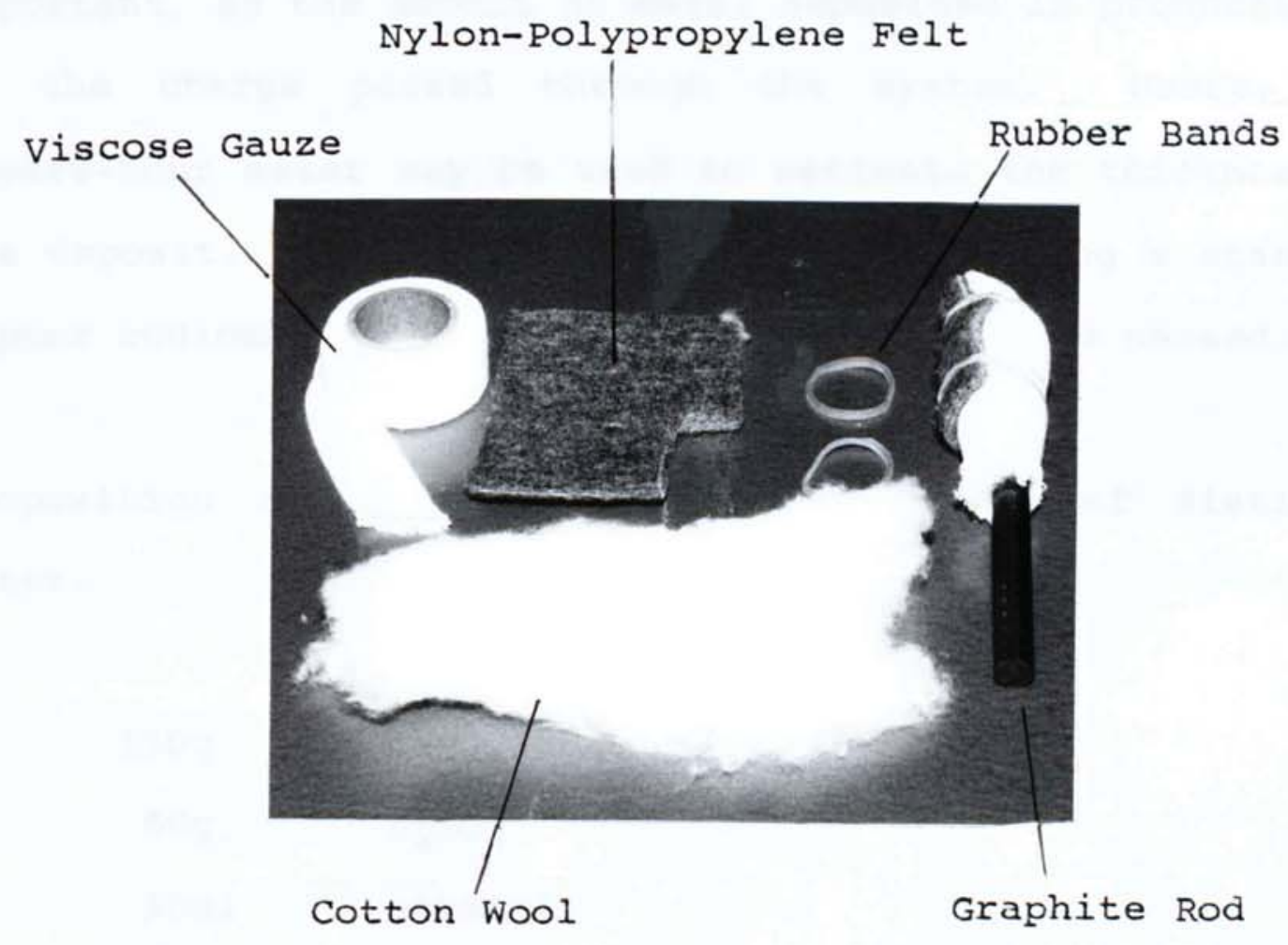

FIG. 14 Materials involved in preparation of the stylus 
involved. A stylus was prepared for each stage of the cleaning and plating operations.

\subsubsection{Power Supply}

The power supply used in this investigation was a commercially produced unit, specifically designed for brush plating. Output voltage can be varied continuously up to $50 \mathrm{~V}$, whilst the maximum current that it is capable of providing is $35 \mathrm{~A}$. Safety cut-outs are incorporated, as is a facility for reversing the polarity of the output and an ampere-hour meter.

In brush plating, the use of the ampere-hour meter is important, as the amount of metal deposited is proportional to the charge passed through the system. Hence, the ampere-hour meter may be used to estimate the thickness of the deposit. The meter was calibrated by using a standard copper coulombmeter to estimate the true charge passed.

Composition of the coulombmeter per litre of distilled water.

$\begin{array}{ll}150 \mathrm{~g} & \mathrm{CuSO}_{4} \cdot 5 \mathrm{H}_{2} \mathrm{O} \\ 50 \mathrm{~g} & \mathrm{H}_{2} \mathrm{SO}_{4} \\ 50 \mathrm{ml} & \text { ethanol }\end{array}$


Recorded charge passed on power supply meter $=1.683 \mathrm{Ah}$ weight deposited at $3 \mathrm{~A}$ in 35.5 minutes $\quad=1.9553 \mathrm{~g}^{-}$ 96,500 coulombs deposit $31.7 \mathrm{~g}$ (assuming $100 \%$ cathode efficiency)

$\therefore$ coulombs required to deposit $1.9553 \mathrm{~g}=$

$$
\underline{96,500} \times 1.9553 \quad=5952.25
$$

31.7

$$
=\underline{5952.25} \quad=1.653 \mathrm{Ah}
$$

3600

$\&$ Error $=$ Meter reading - true reading $\times 100=$ true reading

$1.683-1.653 \times 100=1.82 \%$

1.653

For the purpose of this investigation, this level of error was considered satisfactory, as comparative and not absolute values of charge passed were of more importance.

\subsubsection{Brush Plating Technique}

Two different brush plating techniques were employed, one was manual the other semi-automated. The manual technique 
was used in conjunction with the work on commercial purity (S1C) aluminium panels and the very early work on the Asls bearing shells. This technique is totally operator dependent however, a standard technique was used throughout.

1. The time stated was the total time taken for the operation, including time taken to replenish the stylus with solution and not just the anode contact time.

2. Solution replenishment was carried out every 15 seconds and usually took 2-3 seconds to achieve.

3. The substrate was inclined, in order that excess solution would run away hence, allowing no immersion of the cathode to occur.

In the semi-automated technique, the solution was pumped from a reservoir onto the rotating cathode by means of a peristaltic pump. The equipment can be seen in Fig. 15 . This technique does not require the anode to be removed to enable solution replenishment to be carried out hence, the time stated is the total time taken for the cleaning or plating process of at least two half shell bearings, symmetrically arranged. 


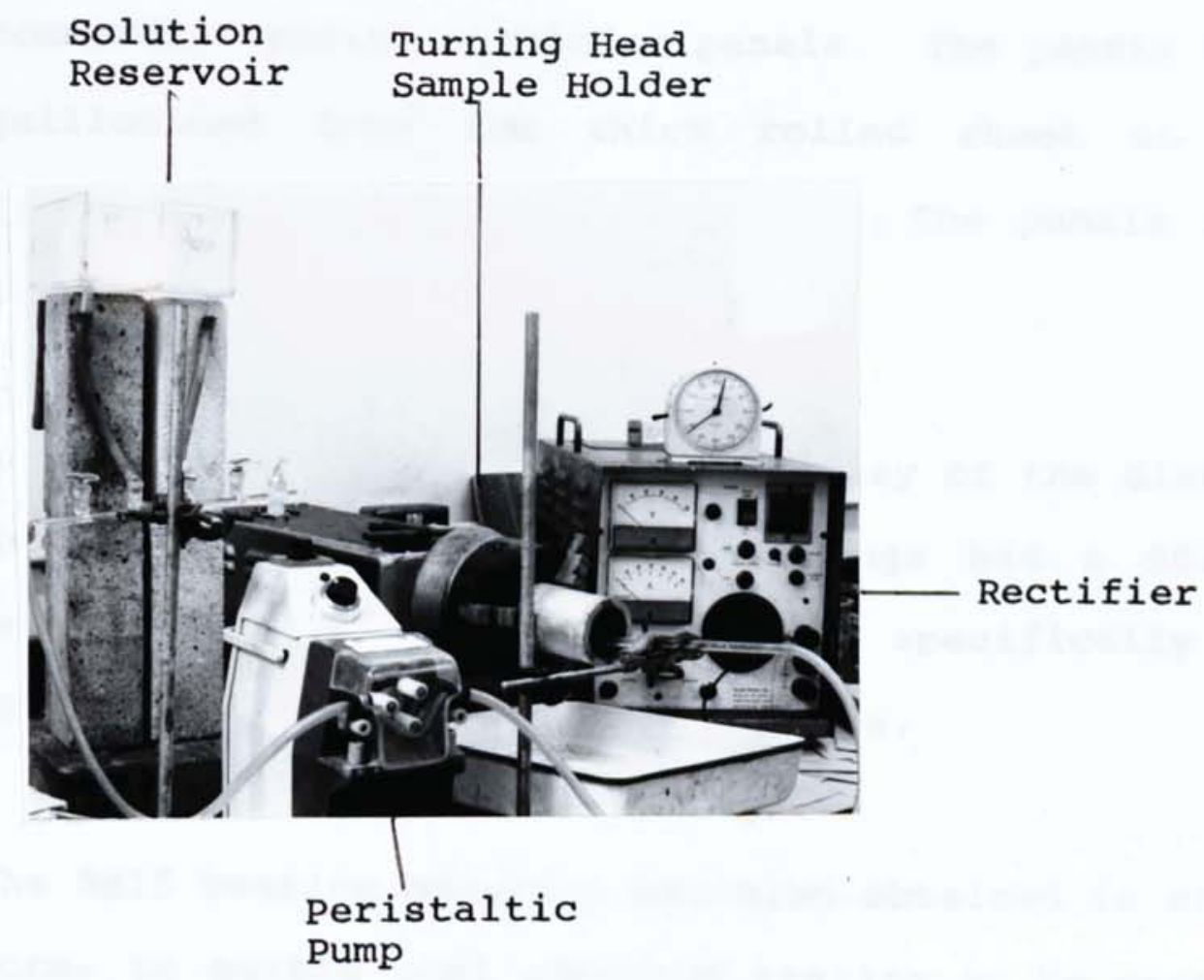

FIG. 15 Semi-automated brush plating equipment

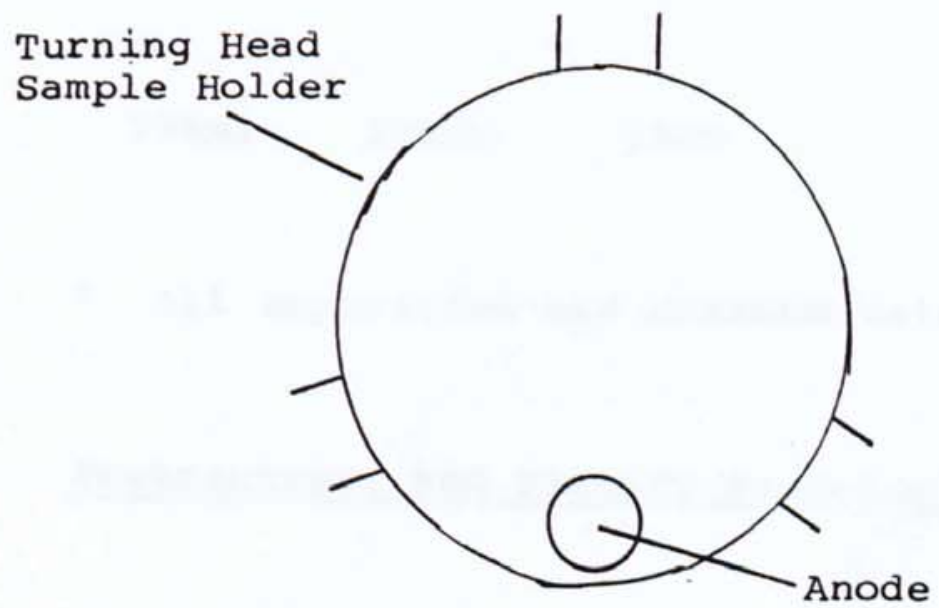

Relative position of Anode and Shell Bearings 


\subsection{Substrate Materials}

The materials used in this investigation were:

S1C commercial purity aluminium panels. The panels were guillotined from $5 \mathrm{~mm}$ thick rolled sheet to the required size, typically $90 \times 40 \mathrm{~mm}$. The panels were ground to a p 240 grit finish.

AS15 steel backed bearing shells, courtesy of the Glacier Metal Co. Itd. The shell bearings had a $50.8 \mathrm{~mm}$ bore, were $28.6 \mathrm{~mm}$ long and designed specifically for the Sapphire Fatigue Testing machine.

The AS15 bearing material was also obtained in strip form, to enable peel adhesion testing to be carried out. The strip was prepared in a manner already described for the SIC material.

SlC $98.68 \mathrm{Al} 0.7 \% \mathrm{Fe} 0.5 \% \mathrm{Si} 0.18 \mathrm{Mn} 0.18 \mathrm{Zn}$ *

AS15 79\%Al 20\%Sn $1 \% \mathrm{Cu}$

* All impurities are maximum values.

\subsection{Pretreatment and plating procedures}

The pretreatment sequences were: 


\subsubsection{Sequence AI Simple Immersion}

1. Acetone degrease

2. Cathodic alkaline clean at $60^{\circ} \mathrm{C}, 2 \mathrm{Adm}^{-2}$ for 2 minutes

3. Water rinse

4. Dip in $50 \mathrm{~V} / 0$ Nitric acid for 1 minute

5. Water rinse

6. Dip in zincate solution

7. Water rinse

8. Electroplate

\subsubsection{Sequence A2}

The double dip equivalent of Al. As Al except that stages 4-6 are repeated.

8.3.3 Sequence Bl Electrolytic Immersion

As Al but stage 6 is carried out electrolytically at a current density of $1 \mathrm{Adm}^{-2}$.

\subsubsection{Sequence B2}

The double dip equivalent of Bl. As Bl but stages $4-6$ are repeated. 
8.3.5 Sequence $\mathrm{Cl}$ Simple Brush

1. Acetone degrease

2. Brush alkaline cleaner, cathodically at $40 \mathrm{~V}$ for two minutes

3. Water rinse

4. Brush with $50 \mathrm{~V} / 0$ Nitric acid for 1 minute

5. Water rinse

6. Brush zincate solution

7. Water rinse

8. Electroplate

\subsubsection{Sequence C2}

The double brush equivalent of $\mathrm{Cl}$. As $\mathrm{Cl}$ but stages 4-6 are repeated.

8.3.7 Sequence Dl Electrolytic Brush

As $\mathrm{Cl}$ but stage 6 is carried out electrolytically at $5 \mathrm{~V}$.

\subsubsection{Sequence D2}

The double brush equivalent of DI. As Dl but stages 4-6 are repeated.

Two proprietary zinc alloy solutions were used in this investigation. 'Bondal' ( $W$. Cannings Ltd) and 'Alumseal' 
$(M+T$ Chemicals Ltd). It can be assumed that the solution used was 'Bondal', unless stated.

If sequences Al - D2 above, are followed by the suffix (G), this refers to the use of a $10 \mathrm{~V} / 0$ Hydrogen Peroxide $/ 10 \mathrm{~V} / 0$ Sulphuric acid solution in the stated process sequence, as opposed to $50 \mathrm{~V} / 0$ Nitric acid.

For example. Sequence $\mathrm{Al}$ (G)

1. Acetone degrease

2. Cathodic alkaline clean at $60^{\circ} \mathrm{C}, 2 \mathrm{Adm}^{-2}$ for 2 minutes

3. Water rinse

4. Dip in $10 \mathrm{~V} / 0$ Hydrogen Peroxide/10 /o Sulphuric acid for 1 minute

5. Water rinse

6. Dip in zincate solution

7. Water rinse

8. Electroplate

For certain applications an extra stage was added to the brush sequences. This was an extra alkaline clean and followed stage 2. Sequences that include this extra stage are referred to as 'extended clean'. 
8.3.9 Sequence E Direct pretreatment Sequence

1. Acetone degrease

2. Anodic etch in $10 \mathrm{v} / 0$ Hydrochloric acid at $9 \mathrm{~V}$ for 2 minutes

3. Cathodic etch in $10 \mathrm{~V} / 0$ Hydrochloric acid at $9 \mathrm{~V}$ for 2 minutes

4. Water rinse

5. Electroplate

NB. Both stages 2 and 3 are carried out by the brush technique.

8.4 Study of zinc Alloy Film Morphology

The morphology and growth characteristics of the zinc alloy films, on both SIC and ASI5 bearing material, was investigated at various stages of formation, for several pretreatment sequences. . The examinations were carried out using Cambridge Instruments 5150 and $2 \mathrm{~A}$ Scanning Electron Microscopes (SEMS). The S150 SEM was fitted with a Link Systems 860 Series 2 Energy Dispersive X-ray Analysis (EDXA) facility. Samples, measuring approximately $10 \mathrm{~mm} \mathbf{x}$ $10 \mathrm{~mm}$ were cut from the treated panels or bearing shells, mounted onto aluminium stubs using double sided adhesive tape. To avoid the possibility of electrical charging in the SEM, the samples were covered with a $25 \mathrm{~nm}$ conductive coating of carbon and were electrically connected to the 
stubs with colloidal silver.

8.5 Determination of the Film Weight of the zinc Alloy Coating

The film weight on the SlC panels was measured using a weight loss technique. The S1C panels were processed according to specific pretreatment routes. Each sample received a final zinc alloy treatment of a different duration. A specific known area was treated, the remainder of the sample was lacquered to prevent erroneous results. After treatment the samples were washed, dried and weighed accurately on a Stanton Instruments Balance, capable of weighing $\pm 0.00001 \mathrm{~g}$. Five readings were taken of each sample and providing the scatter of results was less than $\pm 0.00005 \mathrm{~g}$ the average of the results was calculated. If the scatter was $> \pm 0.00005 \mathrm{~g}$ a further five readings were taken and the sample mean was calculated. The zinc alloy films were then stripped in $50 \mathrm{~V} / 0$ Nitric acid and the panels were washed, dried and reweighed as above. The film weight for a known area could then be calculated.

The weight loss technique described above could not be successfuly used on the ASI5 bearing material as the $50 \mathrm{~V} / 0$ Nitric acid would readily attack the tin present in the AS15 hence, a false result would be obtained. The technique used for the ASIS involved a bearing shell being accurately weighed then lacquered, leaving only a known 
area of the aluminium alloy surface exposed. The bearing shell was then subjected to the necessary pretreatment prior to zinc alloy application. The lacquer was then removed, the bearing reweighed and the amount of metal removed by the pretreatment calculated for a known area. An estimate of any bearings weight prior to zinc alloy application can now be made. Hence, it is possible to calculate film weights by weighing only the test bearing after the zinc alloy film has been applied, providing that a 'standard' bearing has been pretreated and its weight loss calculated, for each pretreatment route and that the subsequent bearings are pretreated under exactly the same conditions.

8.6 Potential - Time Measurements in a zinc Alloy Solution

The variation of surface potential with respect to time, during zinc alloy film build-up, was measured with reference to a Saturated Calomel Electrode and was continuously monitored on a fast response chart recorder. The calomel electrode was connected to the positive terminal of the recorder, a full-scale deflection of $2 \mathrm{~V}$ was selected. The chart recorder was calibrated against a DC voltage calibration unit.

The samples were coated in lacquer as in section $\mathbf{8 . 5}$, allowing only a selected area to be exposed preventing, in 
the case of the AS15, the steel backing from causing a change in potential value recorded, as it is the change in potential of the aluminium alloy surface alone which is to be measured.

The experimental technique used did not lend itself to a replication of all the process sequences used, that is those involving brushing. Consequently, the final stage had to be immersion however, earlier stages in the sequence have an influence on growth rate.

\subsection{Peel Adhesion. Testing}

Paniels, for adhesion testing, were electroplated using a Watts nickel solution under normal conditions of $4 \mathrm{Adm}^{-2}$, pH4, $60^{\circ} \mathrm{C}$, air agitation. Panels were loaded 'live' to avoid dissolution of the zincate film in the plating solution. The duration of electrodeposition was 7 hours.

Peel adhesion was measured using an 'Instron' tensile testing machine in conjunction with a peel test attachment(135). The jig was arranged such that the peeling strip was always at $90^{\circ}$ to the specimen surface. The width of the peeling strip was $25.4 \mathrm{~mm}$, achieved by milling two parallel slits through the coating into the substrate. A tab of deposit was then lifted from the substrate using pliers, an operation made easier by not zincating one end of the panel. The fluctuations of adhesive force, 
monitored by the 'Instron' load cell were displayed on a chart recorder. The area under the curve was then measured using a planimeter to give a measure of the work expended on detaching the foil from the substrate.

\subsection{Examination of Peeled panels}

Sections of failure surfaces and peeled foils were cut from each panel and examined in the SEM. .The method for preparing SEM samples has been detailed in Section 8.4.

\subsection{Brush Plating Solutions}

\subsubsection{Commercial Solutions}

Commercially available brush plating solutions of lead, tin, cobalt and lead-tin alloy were obtained. Alloy solutions were produced from the single metal electrolytes by mixing the solutions in various proportions. The solutions used were :

$\begin{array}{lccc}\text { Lead } & \text { Solution } & \mathrm{pH} & 8.8 \\ \text { Tin } & . . & \mathrm{pH} & 7.5 \\ \text { Cobalt } & . . & \mathrm{pH} & 1.6\end{array}$




$\begin{array}{lll}\mathrm{Pb}-10 \mathrm{~V} / \circ \mathrm{Sn} & \mathrm{pH} & 8.2 \\ \mathrm{~Pb}-23 \mathrm{~V} / \circ \mathrm{Sn} & \mathrm{pH} & 7.9 \\ \mathrm{~Pb}-30 \mathrm{~V} / \circ \mathrm{Sn} & \mathrm{pH} & 7.7 \\ & & \\ \mathrm{Sn}-25 \mathrm{~V} / \circ \mathrm{Co} & \mathrm{pH} & 6.7 \\ \mathrm{Sn}-50 \mathrm{~V} / 0 \mathrm{Co} & \mathrm{pH} & 4.8\end{array}$

A commercially available lead-tin fluoborate vat plating solution was also used. The composition of the bath was :
Lead Fluoborate
$200 \mathrm{gl}^{-1}$
Fluoboric Acid
$84 \mathrm{gl}^{-1}$
Stannous Fluoborate
$33 \mathrm{gl}^{-1}$
Stannic Fluoborate
$5 \mathrm{gl}^{-1}$

In addition to the commercially available solutions, several solutions were prepared at Aston using simple salts. The compositions of these solutions were :

Solution

$\begin{array}{llll}1 & 2 & 3 & 4\end{array}$

$\begin{array}{lrrrr}\text { Stannous Sulphate } & 25 & 50 & 50 & 200 \\ \text { Cobalt Sulphate } & 50 & 100 & 40 & 160 \\ \text { Sodium Heptonate } & 45 & 45 & 50 & 20 \\ \text { Acetic Acid } & 40 & 40 & 40 & 40\end{array}$

All figures are in $\mathrm{gl}^{-1}$ 
Initial preparation of the alloy solutions involved the cobalt sulphate and sodium heptonate being dissolved in distilled water at $70^{\circ} \mathrm{C}$ and purified by means of activated carbon. However, whilst still warm, the $\mathrm{pH}$ of the solution was adjusted to approximately 1.5 to avoid the formation of insoluble cobalt complexes, when the alloying elements were added. Stannous sulphate was dissolved in distillated water and added gradually to the still warm electrolyte. Whilst this procedure was being carried out, a careful check was kept on the $\mathrm{pH}$ of the electrolyte and dilute sulphuric acid was added to bring the $\mathrm{pH}$ back down to 1.5 . On cooling, evaporation losses were made up and the $\mathrm{pH}$ checked after the addition of glacial acetic acid. The brush plating solutions produced were tightly bottled for subsequent use.

\subsection{Analysis of Deposit Composition}

Two methods of determining the composition of the deposit were employed.

i) Atomic Absorption Spectrophotometry

ii) Energy Dispersive X-ray Analysis in the SEM. 
A Perkin-Elmer AAS was used to determine the composition of the electrodeposited alloy. Calibration was carried out using a solution of known metal content.

\subsubsection{Tin-Cobalt Overlays}

Thin foils of the tin-cobalt electrodeposit were weighed, dissolved in 50\% hydrochloric acid then made up to $50 \mathrm{ml}$ in a graduate flask. Further dilutions were carried out by transferring $10 \mathrm{ml}$ of diluted solution to a $100 \mathrm{ml}$ graduated flask and making up the volume with distilled water. The dilutions were continued until a concentration of approximately $5 \mathrm{ppm}$ cobalt resulted. A water blank was run between each sample or standard to verify baseline stability.

\subsubsection{Lead-Tin Overlays}

Approximately $0.05 \mathrm{~g}$ of the lead-tin overlay was dissolved in a mixture of $1 \mathrm{ml}$ of distilled water and $0.2 \mathrm{ml}$ of conc. nitric acid. $8.5 \mathrm{ml}$ of conc. hydrochloric acid was added to redissolve the tin. The solution was transfered to a $50 \mathrm{ml}$ volumetric flask and made up to volume with distilled water. The linear working range for tin is up to $300 \mathrm{ppm}$. 


\subsubsection{Energy Dispersive X-ray Analysis}

Sections of overlay plated panels were cut and prepared prior to SEM examination in a manner similar to that described in section 8.4. Analysis was carried out using the EDXA attachment, which provides the facility for both semi-quantitative or quantitative analysis, using the zAF:4 program. This program corrects the collected $\mathrm{X}$-ray data for atomic number $(z)$, absorbence $(A)$ and fluorescence $(F)$, effects. Deposit composition was determined by either analysing the surface, in which case the electron beam irradiated a volume of material to a maximum depth of approximately $2 \mu \mathrm{m}$ or alternatively a series of 'spot analysis' were carried out traversing a cross-section of the deposit. The cross-sections were prepared in a manner described in section 8.15. The spot size for the SEM in 9$10 \mathrm{~nm}$ however, the irradiated area over which the analysis is carried out is larger.

Elemental line concentration profiles could also be produced, using the EDXA attachment. . These concentration profiles show up more clearly than the analysis, any variations in deposit composition over the cross-section.

The SEM/EDXA method of analysis is much quicker and simpler than the AAS technique. However, it has the obvious limitation of analysing only small volumes of coating. providing this limitation is understood, it is a useful 
technique.

\subsection{Effect of Speed, load and Solution Flows on Deposit Characteristics}

A degree of stylus/substrate movement is required during the brush plating operation. It is therefore of importance to determine the optimum speed of movement of the substrate with respect to the stylus and the effect of variations upon the deposit characteristics.

It was considered equally important to establish the effect of applied load of the stylus and the volume of solution present at the interface on deposit characteristics, if the system is to be successfully automated.

In order to carry out these investigations on speed, load and solution flow rates, a system was devised whereby all three of the parameters could be monitored. The other major brush plating variable, applied voltage, remained constant at $15 \mathrm{~V}$, for all trials. Separate tests, were carried out on the effect of voltage, with a constant speed, load and flow.

Speed, in the form of revolutions per minute of the rotating cathode could be monitored and converted into $\mathrm{ms}^{-1}$. Solution flow rates were measured by calibrating a 
peristaltic pump. A constant load was applied using stylus 3 in Fig. 13. Loads were applied at various points which can be represented by the situation;
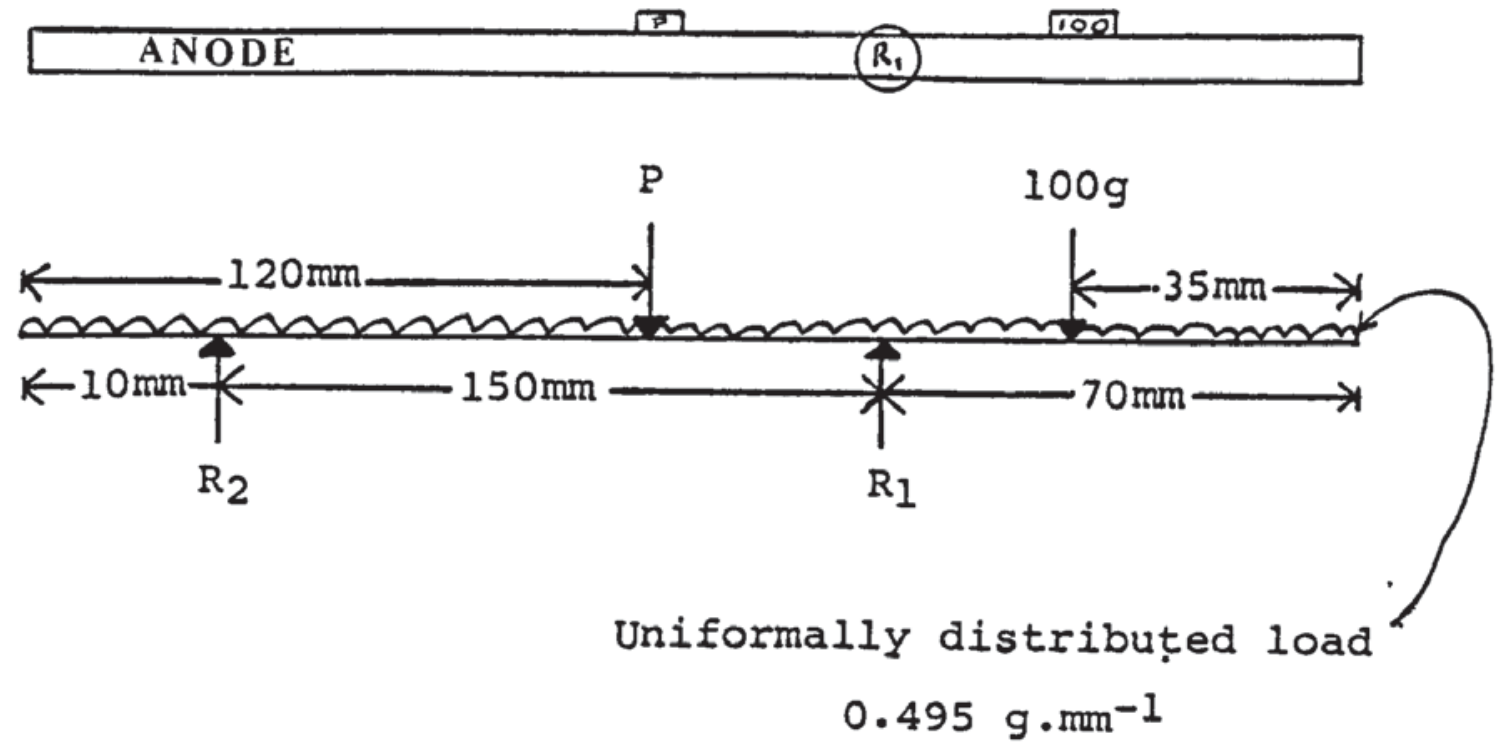

where $R_{1}$ is the pivot

$R_{2}$ is the centre of the pad on the bearing surface.

$\mathrm{p}$ is a variable load

The graphite anode is represented by the uniformally distributed load.

By taking moments about $R_{1}$

$R_{2}=\frac{162.3+4 P}{}$

15

Hence for any value of $P$, the resultant load $R_{2}$ at the centre of the bearing can be calculated. . The height of the stylus holder was adjusted in order that the pad material was parallel to the cathode surface. 
The bearing shells were degreased, dried and weighed in a manner already described, in section 8.5. The bearings were pretreated using sequence $\mathrm{E}$ (Direct) for 0.1 Ah anodically and 0.1 Ah cathodically. A bearing shell was weighed after this pretreatment sequence and the amount of material removed by the cleaning process was calculated. It was assumed that if all the bearings were pretreated under the same conditions, the weight of material removed would also be the same. Hence, the bearing weight prior to brush plating could be calculated. The samples were then brush plated for $0.15 \mathrm{Ah}$ under the conditions of the test. After washing and drying, the bearings were reweighed and the coating weight determined. .. The coating weight together with the deposit composition, analysed using the zAF:4 program on the SEM, were used to calculate the efficiency of the solution for the conditions of the test. All data are the result of duplicate tests.

\subsubsection{Calculation of Cathode Current Efficiency of Alloy}

\section{Solutions}

The calculation involves consideration of the amount of each element deposited by 1 Faraday. ..Thus, the gram equivalent weight deposited by 1 Faraday for each element is :

$\frac{207.19}{2}=103.595 \quad$ lead




$\begin{array}{llll}\frac{58.93}{2} & = & 29.467 \mathrm{~g} \text { coba } \\ \frac{118.69}{2} & =\quad 59.345 \mathrm{~g} \text { tin }\end{array}$

A valency of 2 was used as this was considered to be the valency state of the ions present. The cathode current efficiency for alloy deposition was calculated on the basis of comparing the theoretical number of gram equivalents deposited, with the actual number.

For example, in a brush plating trial :

$0.18524 \mathrm{~g}$ of a lead-tin alloy containing 10.78 tin was deposited after passing 0.3 A.h. 1 Faraday $(96,500$ C) deposits ig equivalent.

$\therefore 0.3 \mathrm{~A}(1080 \mathrm{C})$ deposits $\underline{1080 \mathrm{~g}}$ equivalent. 96500

$=0.01119$

wt. of alloy is $0.18524 \mathrm{~g}$; of $\mathrm{Sn}$ is 10.7

$\therefore$ wt of $\mathrm{Pb}$ in deposit $\quad=0.16542 \mathrm{~g}$

$\therefore$ wt of $\mathrm{sn}$ in deposit $\quad=0.01982 \mathrm{~g}$ 
No. $g$ equivalents of lead $=\underline{0.16542}=1.5968 \times 10-3$ 103.595

No. g equivalents of tin $=\underline{0.01982}=3.340 \times 10^{-4}$ 59.345

Total number of $\mathrm{g}$ equivalents $=1.930810^{-3}$

of Efficiency $=\mathrm{g}$ equivalents deposited $\quad$ x100 Theoretical $\mathrm{g}$ equivalents deposited

$$
\begin{aligned}
& =\frac{1.9308 \times 10^{-3}}{1.119 \times 10^{-2}} \times 100 \\
& =17.28
\end{aligned}
$$

In the case of tin - cobalt alloys, similar calculations were carried out to determine cathode current efficiency, the only difference being the use of $29.467 \mathrm{~g}$ for the gram equivalent weight of cobalt.

\subsection{X-Ray Diffraction}

A Philips X-ray diffractometer was used to determine the structure of the brush plated overlays. Samples were cut from plated bearing shells and placed onto the sample stage by means of double sided adhesive tape. 
Traces were carried out using a chromium $\mathrm{K}$ a source, the least penetrating of the available radiations, this minimised the possibility of obtaining reflections from the AS15 substrate. Where the most intense peaks occurred, the $2 \theta$ angles were noted and by using the Bragg equation.

$$
\mathrm{n} \lambda=2 \mathrm{~d} \cdot \sin \theta
$$

where $\lambda=2.2897$ for $\mathrm{Cr} k a$, the ' $d$ ' spacings of the overlay were calculated. These lattice spacings were subsequently used to index the traces using the ASTM Powder Diffraction File.

\subsection{Fatigue Testing}

Fatigue testing of overlay plated shell bearings were carried out on a Sapphire Fatigue Testing Machine(129). These tests were carried out by the Glacier Metal Co. Ltd. The Sapphire machine is hydraulically loaded with the test bearing mating against an eccentric portion of the test shaft, Fig 16. As the belt driven shaft rotates in the slave bearing, it causes a single acting piston to reciprocate and hence, the maximum load on the test bearing is controlled by an adjustable relief valve. Load is measured by compressive strain of the connecting rod and indicated by electrical resistance strain gauges.

Test are run for periods of 20 hours $\left(3 \times 10^{6} \mathrm{~Hz}\right)$. After each period, the test bearing is examined for signs of fatigue 


\begin{tabular}{|l|}
\hline Aston University \\
Illustration rem oved for copyright restrictions
\end{tabular}

FIG. 16 Schematić diagram of the Sapphire fatigue testing machine(116) 
cracking and if undamaged, replaced and the test continued at an increased load. The machine can test any bearing liner with a bore between $50-75 \mathrm{~mm}$ and length less than $50 \mathrm{~mm}$. Load is controllable up to $1.8 \mathrm{MPa}^{-2}$. Bearing temperature is controlled by the lubricating oil.

\subsection{Corrosion Testing of the overlay - Substrate Bond}

Bearings were overlay brush plated using both the direct, Sequence $E$ and the zinc alloy pretreatment sequences $A I$ and cl. The bearings were then immersed in Medicinal white oil (MWO) at $120^{\circ} \mathrm{C}$ for 24 hours. After immersion, the bearings were removed and cleaned. Adhesion tests were then carried out on these samples. A series of $90^{\circ}$ cross-hatched lines were scribed onto the bearing. Adhesive tape was then applied to the overlay surface and peeled off. If the coating was detached by the adhesive tape, the bearing failed the test.

\subsection{Metallographic Sample Preparation and Examination}

Cross - sections of plated and Sapphire fatigue tested bearings were taken and mounted using a 'Metaserv' automatic mounting press. The samples were then ground and polished to a depth where all surface damage due to the action of the saw had been removed and finally polished to a $1 \mu \mathrm{m}$ finish. 
Examination of the sections was carried out optically using a Reichert - Jung Polyvar microscope. The sections were also examined in the SEM. The microblocks were made electrically conductive by covering them with $25 \mathrm{~nm}$ of carbon in a vacuum coating unit. The Link EDXA attachment fitted to the SEM was used to analyse any interesting features of the sections. 


\section{ZINC ALIOY FILMS}

9.1 On SIC Aluminium

9.1.1 Using 'Bondal' as the Zinc Alloy Solution

Scanning Electron Microscopy revealed that the surface of the slc aluminium, prior to zinc alloy application, responded slightly differently when subjected to brushed pretreatments as opposed to dipped pretreatments. The etch pits resulting from the simple immersion pretreatment (Sequence Al) were larger than those from the equivalent brush pretreatment (Sequence Cl), Fig. 17. This indicated that the dip pretreatment sequencès were more severe than the brushed. The etch pits resulted from preferential attack of the microconstituents and precipitates.

The double treatments, for both brush and immersion sequences had a more severe effect than the single treatments, as during the formation of the first zincate film, dissolution of the aluminium surface occurs causing the chemical activity of the freshly exposed surface to become more uniform $(98)$.

The appearance of zinc alloy films after $10 \mathrm{~s}$ and 60 s are shown in Figs 18 and 19. The series of photographs show clearly the different effects of the immersion and brushing 

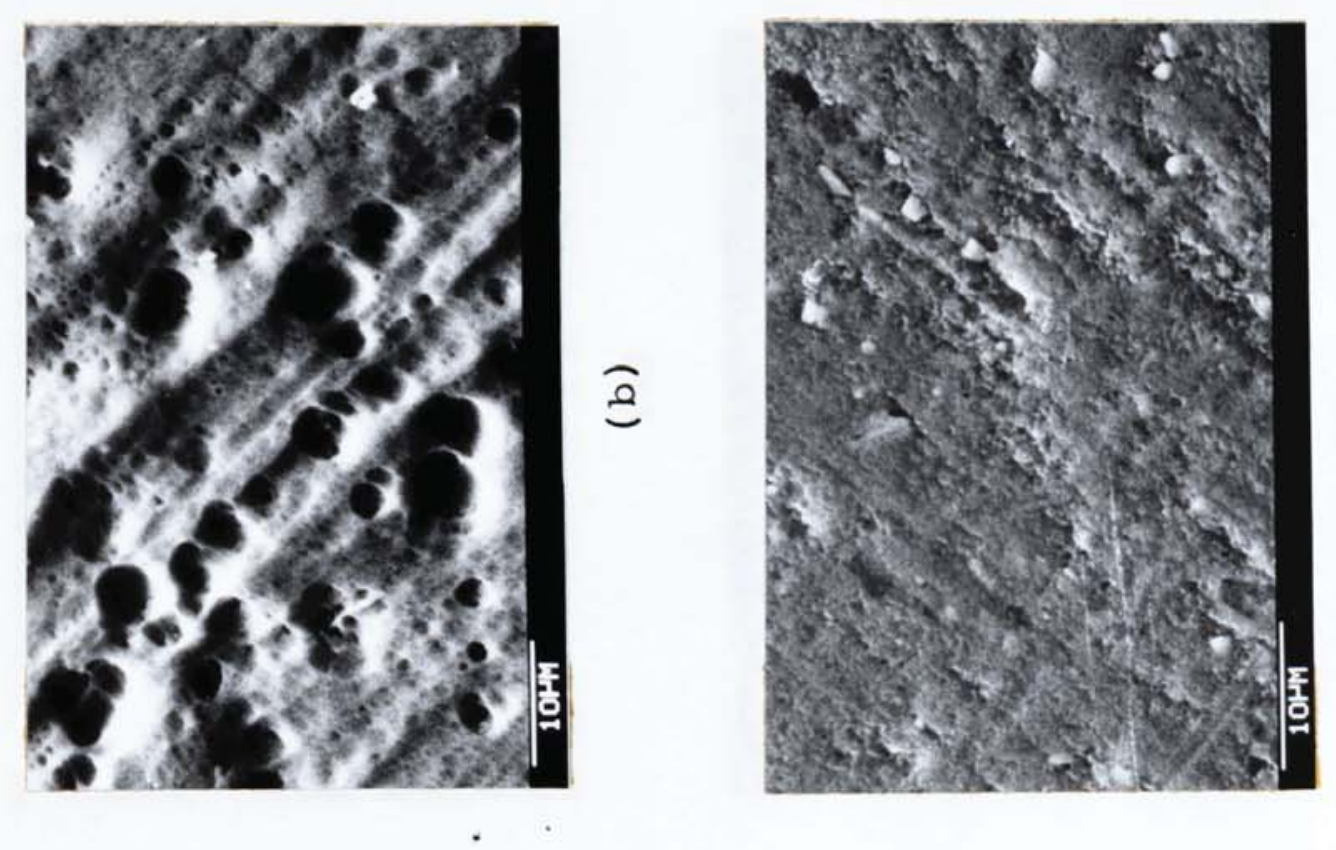

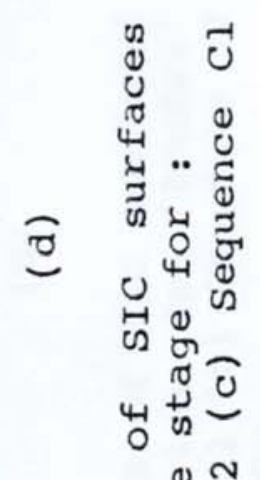

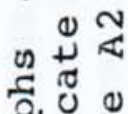

क्ष

कू.

ด $>$ ज

나

㤩

ใิ

द्ञ त्र

过先出
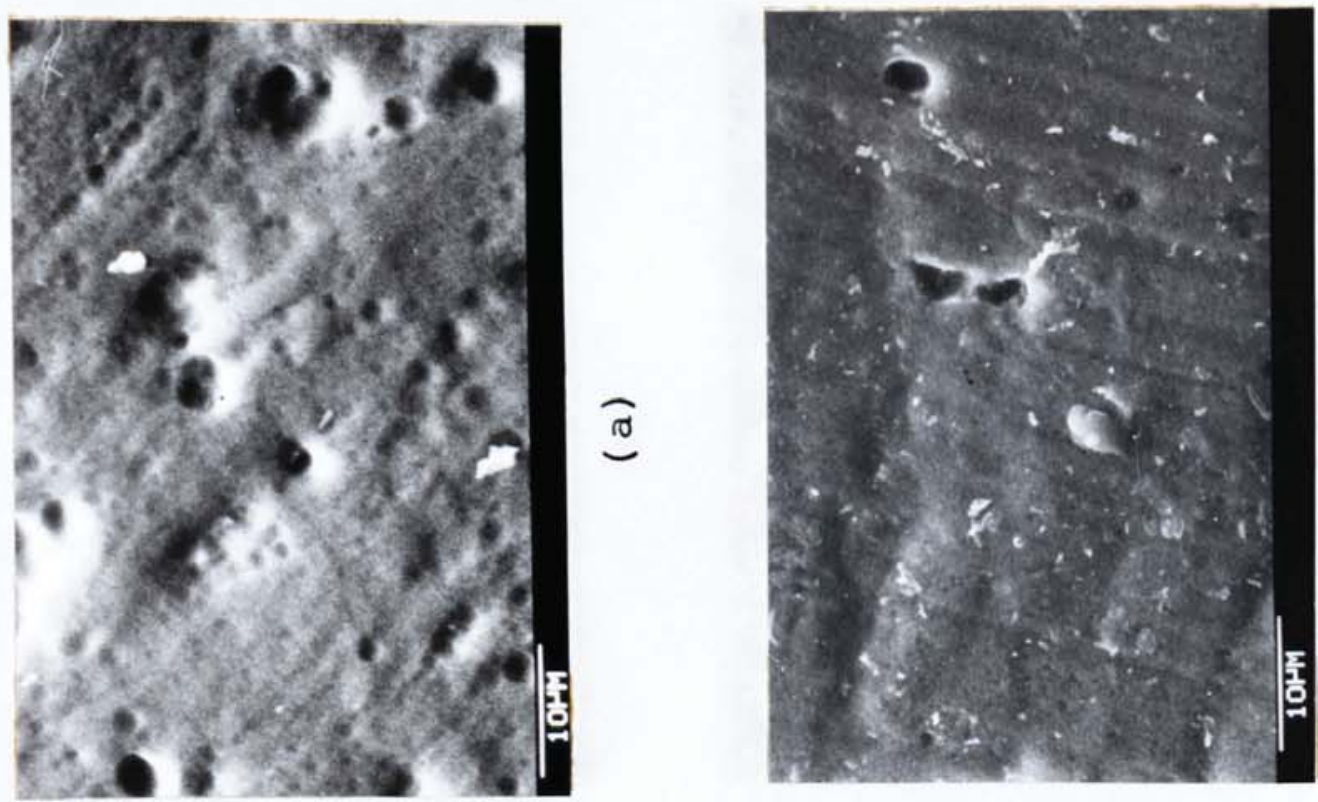

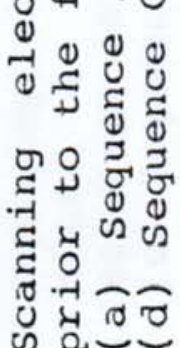

กิ 

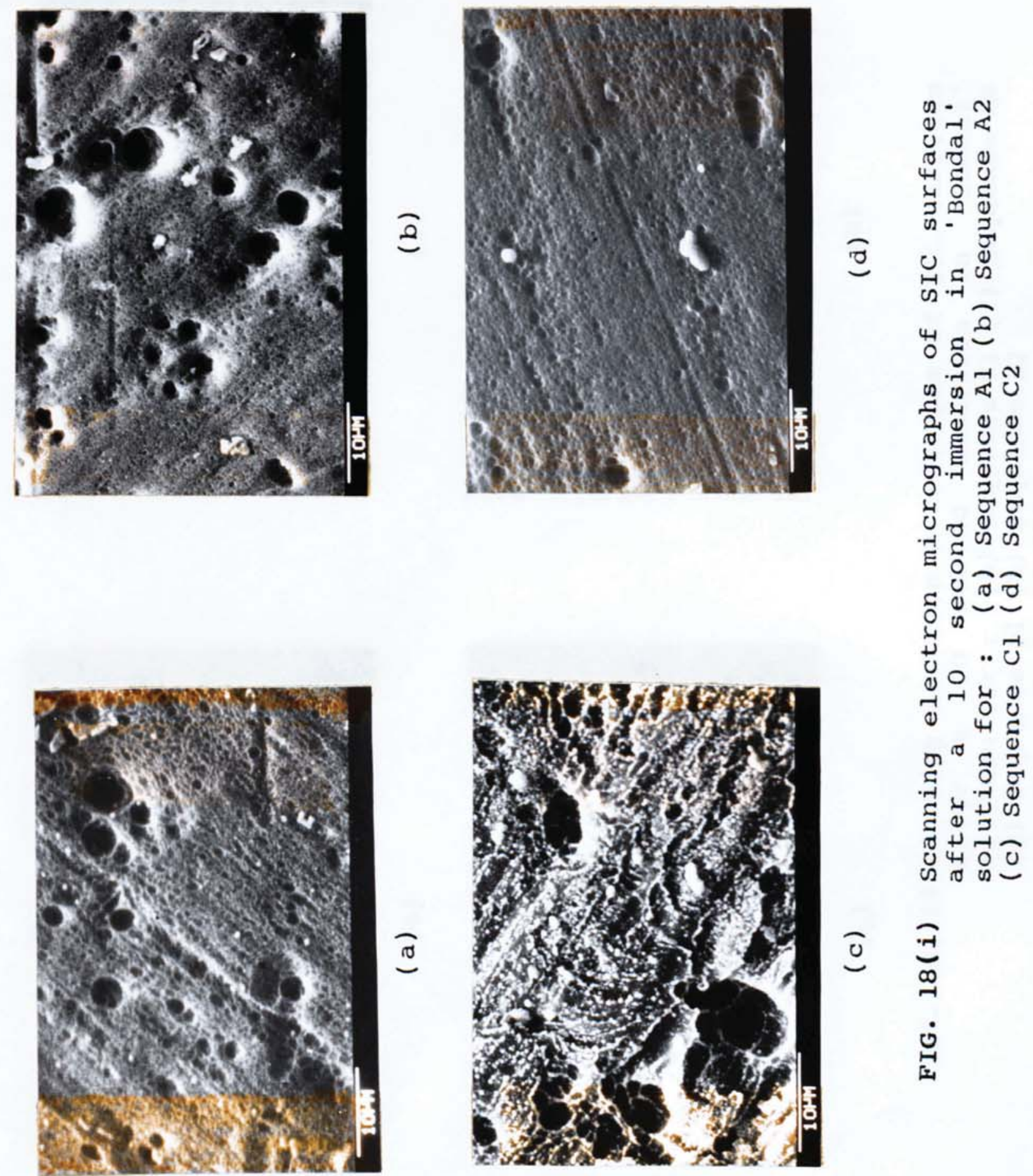

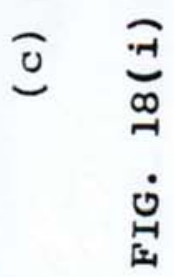



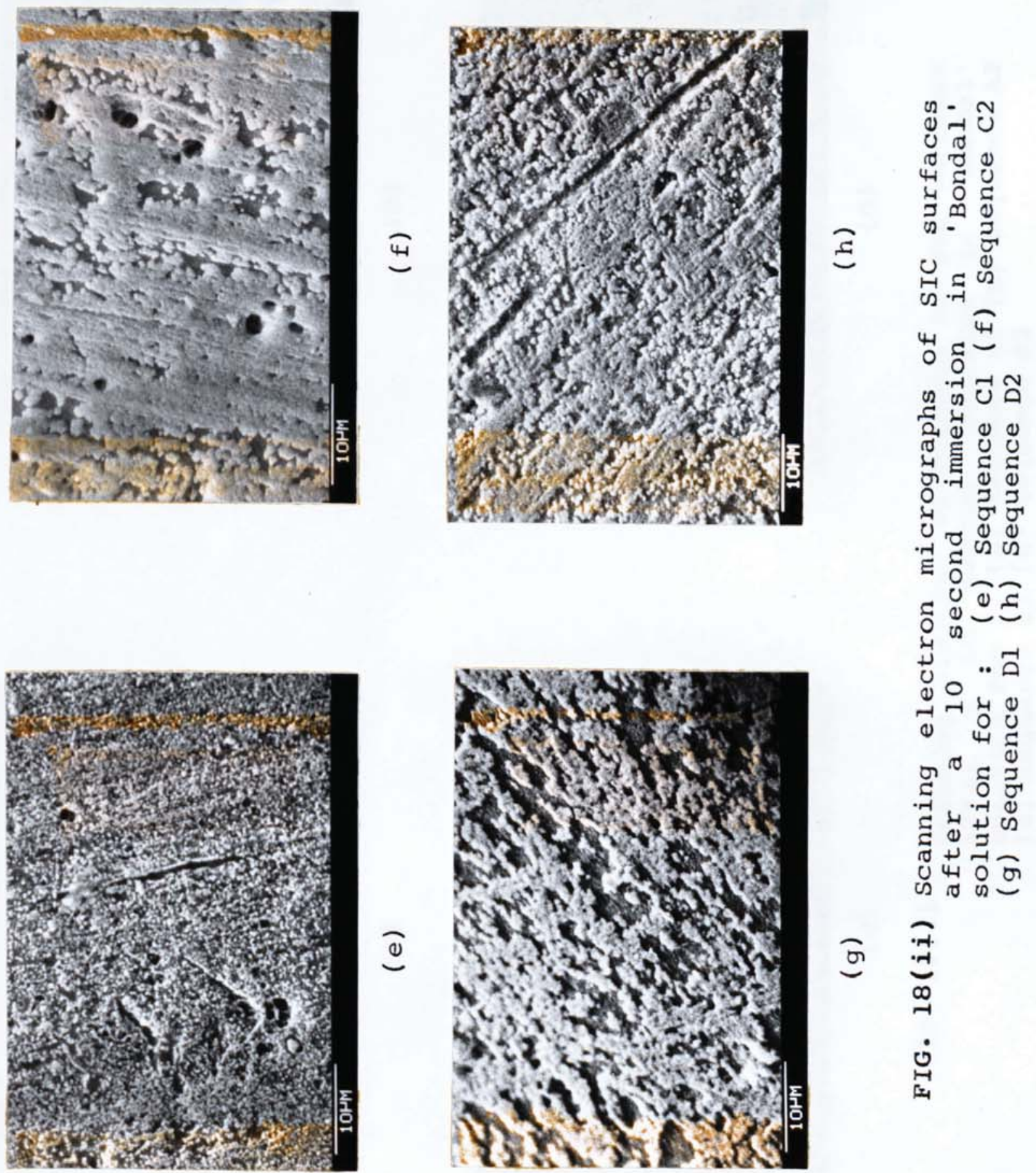

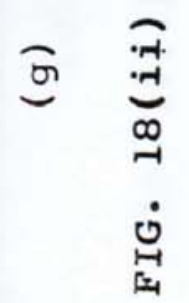



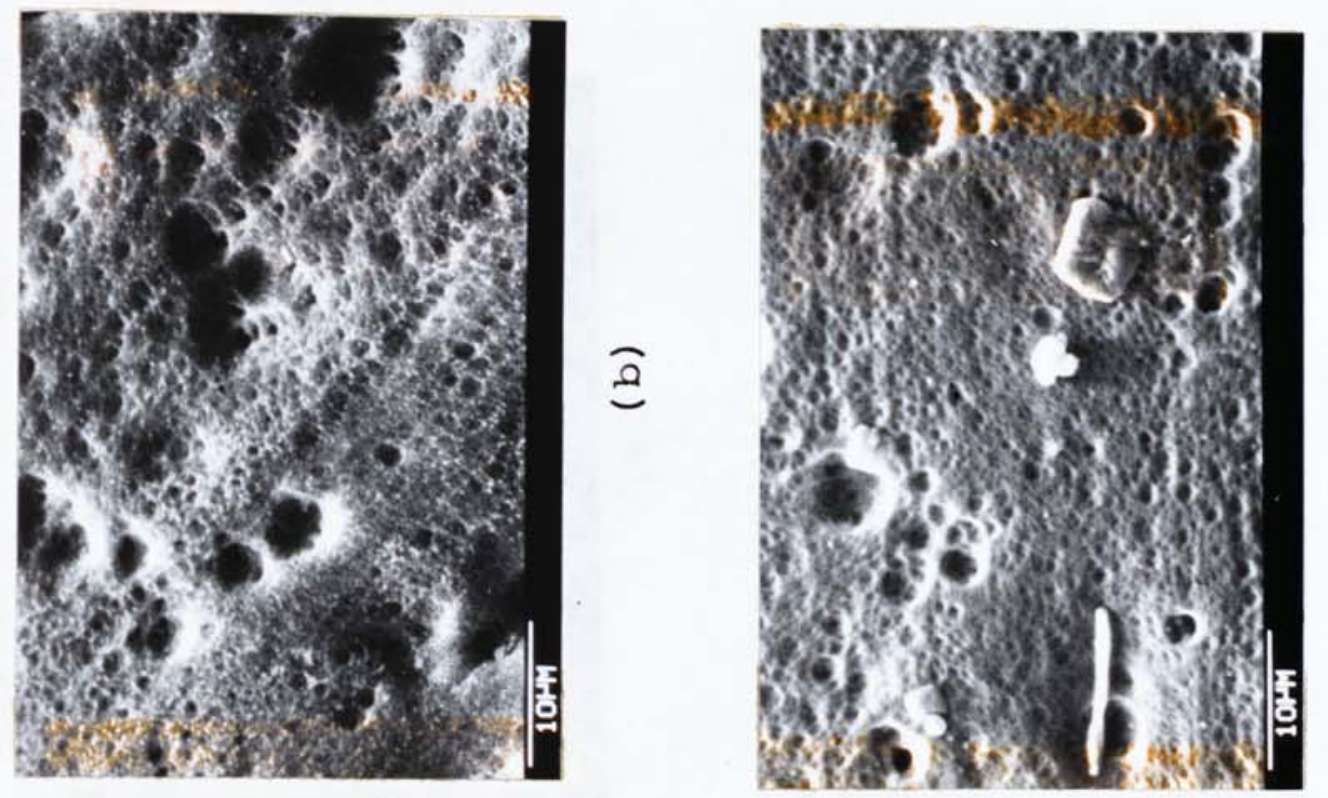

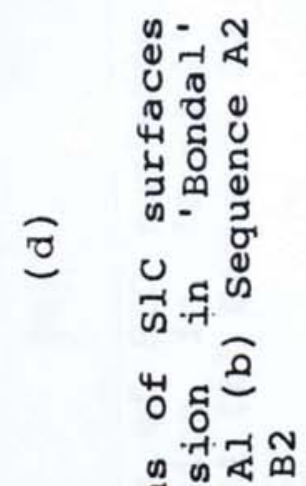

है

내롤

ठ․न ঙ્ ฮ

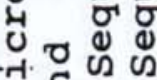

ह

c U

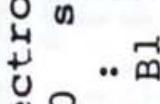

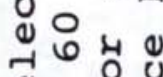

व

ำ 동

त 4

的

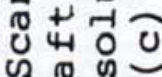
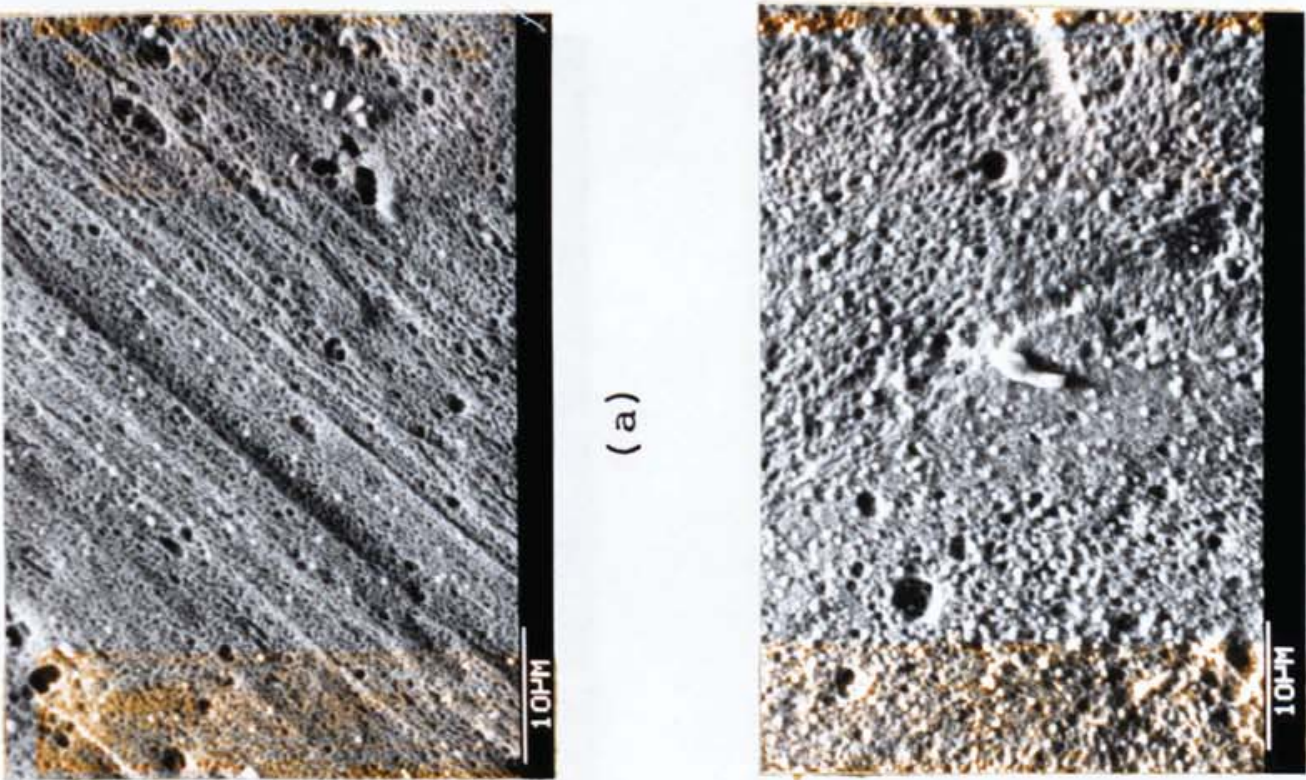

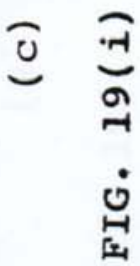



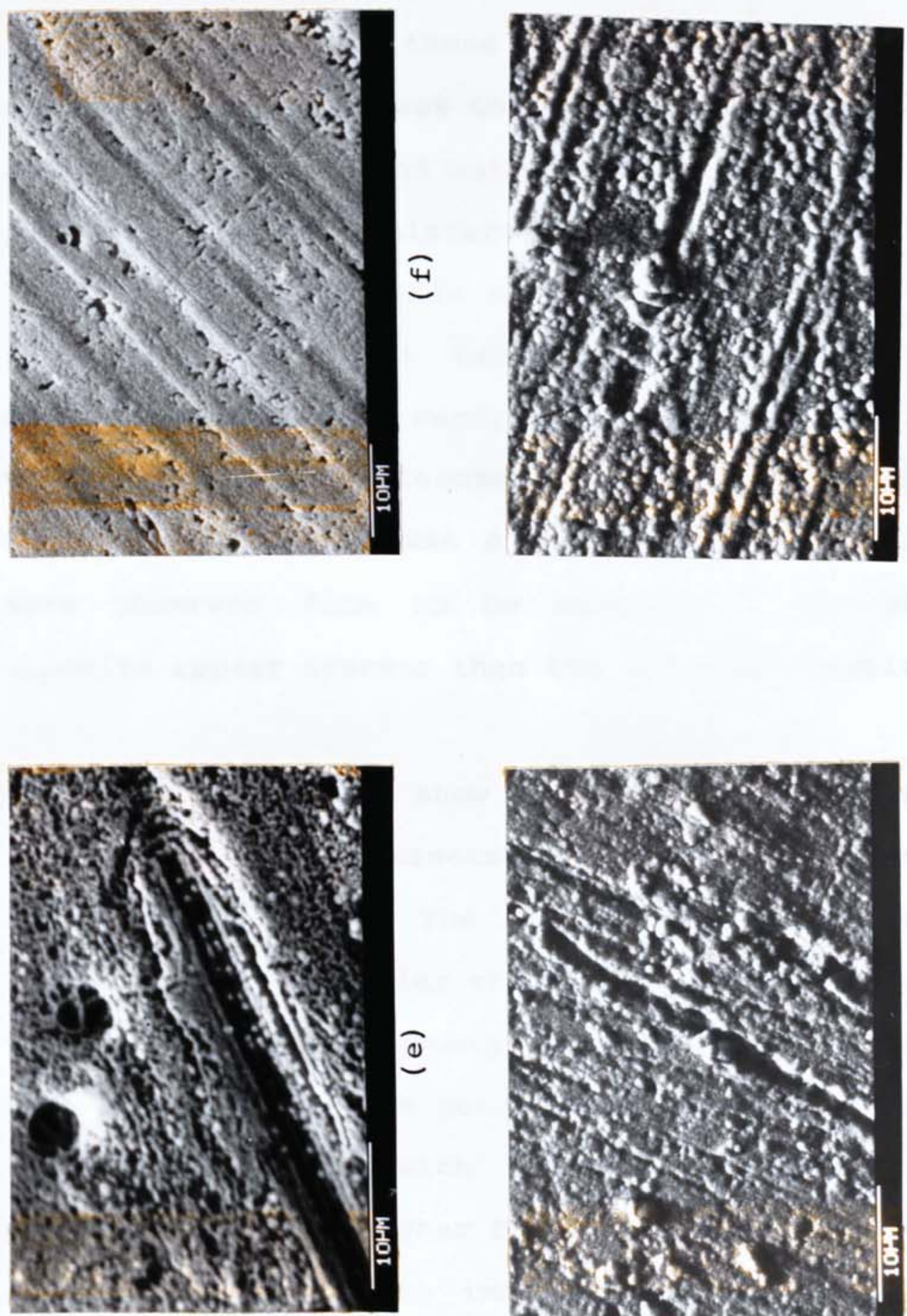

$$
\begin{aligned}
& \stackrel{0}{0}=0 \\
& \text { ( } \\
& \text { 4 } \\
& \text { 느 ติ } \\
& \text { ¿ U ज ज } \\
& \text { 㟧 } \\
& \text { ตู ตี่ } \\
& \text { 总 岂 } \\
& \text { प्र } \\
& \text { ชัन ว } \\
& \text { ป } \\
& \text { 舀 }
\end{aligned}
$$

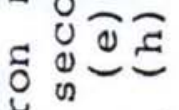

$$
\begin{aligned}
& \text { प्र थ . } \\
& \text { บ일 } \\
& \text { (1) } \\
& \text { ๑ }
\end{aligned}
$$

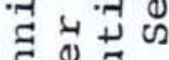

$$
\begin{aligned}
& \text { ฮี } \\
& \text { Uै } \\
& \text { क) न्न }
\end{aligned}
$$


techniques and the electrolytic and the non-electiolytic ones. Initially there are similarities between the immersion and brush sequences, with the zinc alloy film nucleating at a number of sites. When the zinc alloy solution is brushed, these growths continue to increase in size but do not coalesce to form a continuous film. Fig. 20 shows that when the pad material is changed from the nylonpolypropylene felt mixture to the softer less abrasive 'Selvyt' cloth, there is much less of the zinc alloy film on the surface than found when using the other pad material. The growth centres being very obvious. However, when immersed, coalescence does occur. The double treatments whether brush or immersion allow a much finer, more coherent film to be produced. The electrolytic deposits appear coarser than the non electrolytic ones.

Figs. 21, 22 and 23 show the change in film weight with increase in zincate treatment time for all techniques and both pad materials. The curves for the non electrolytic sequences have a similar characteristic shape in that there is a high initial growth rate followed by an extended period where the film weight increases more slowly and is essentially linear with respect to time. The brush sequences produced higher film weights for equivalent times than the corresponding immersion treatments. It appears that the single treatments, whether brush or immersion, produced up to about twice the film weight of their corresponding double treatments. The effect of depositing 

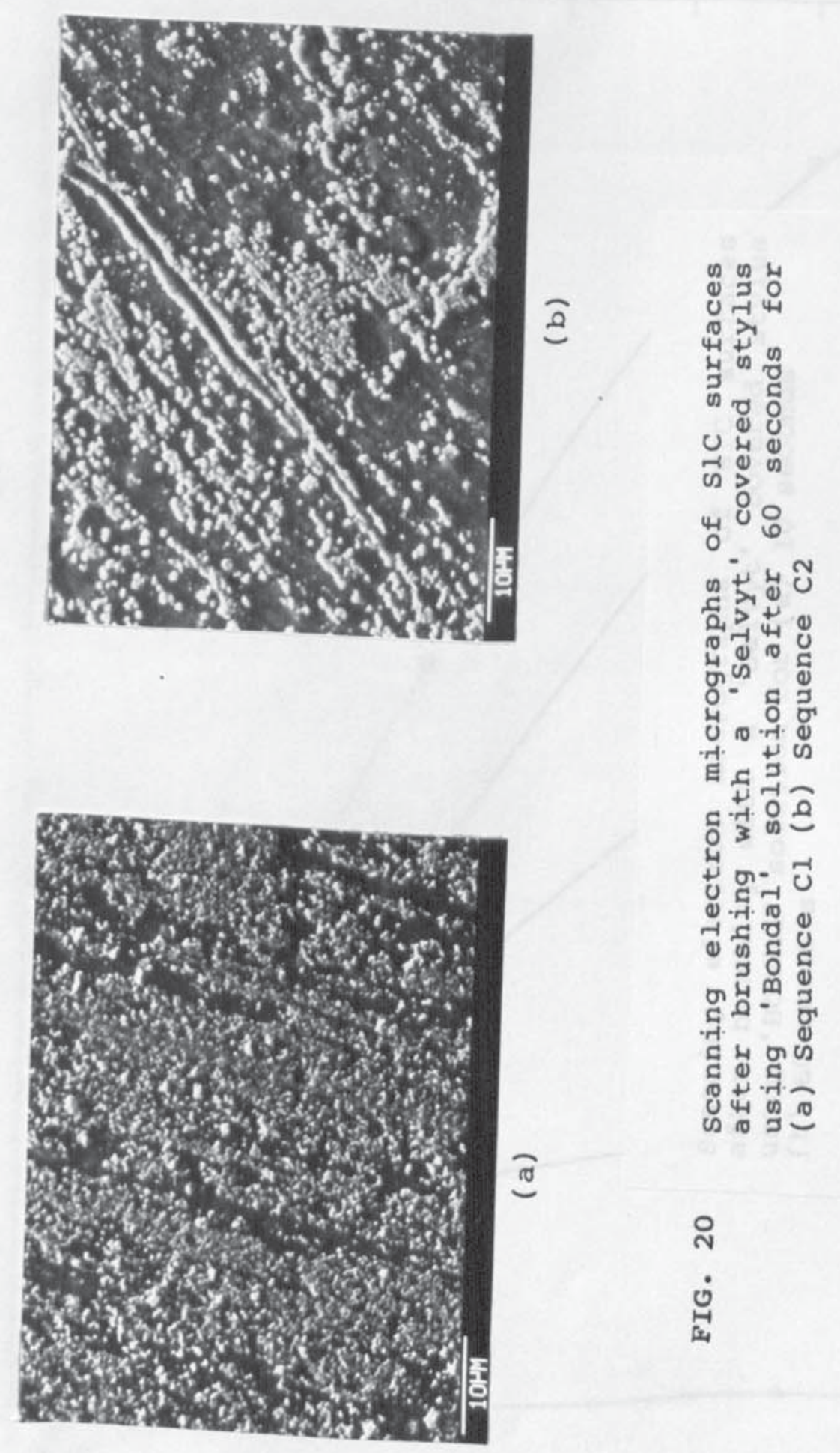

옴 


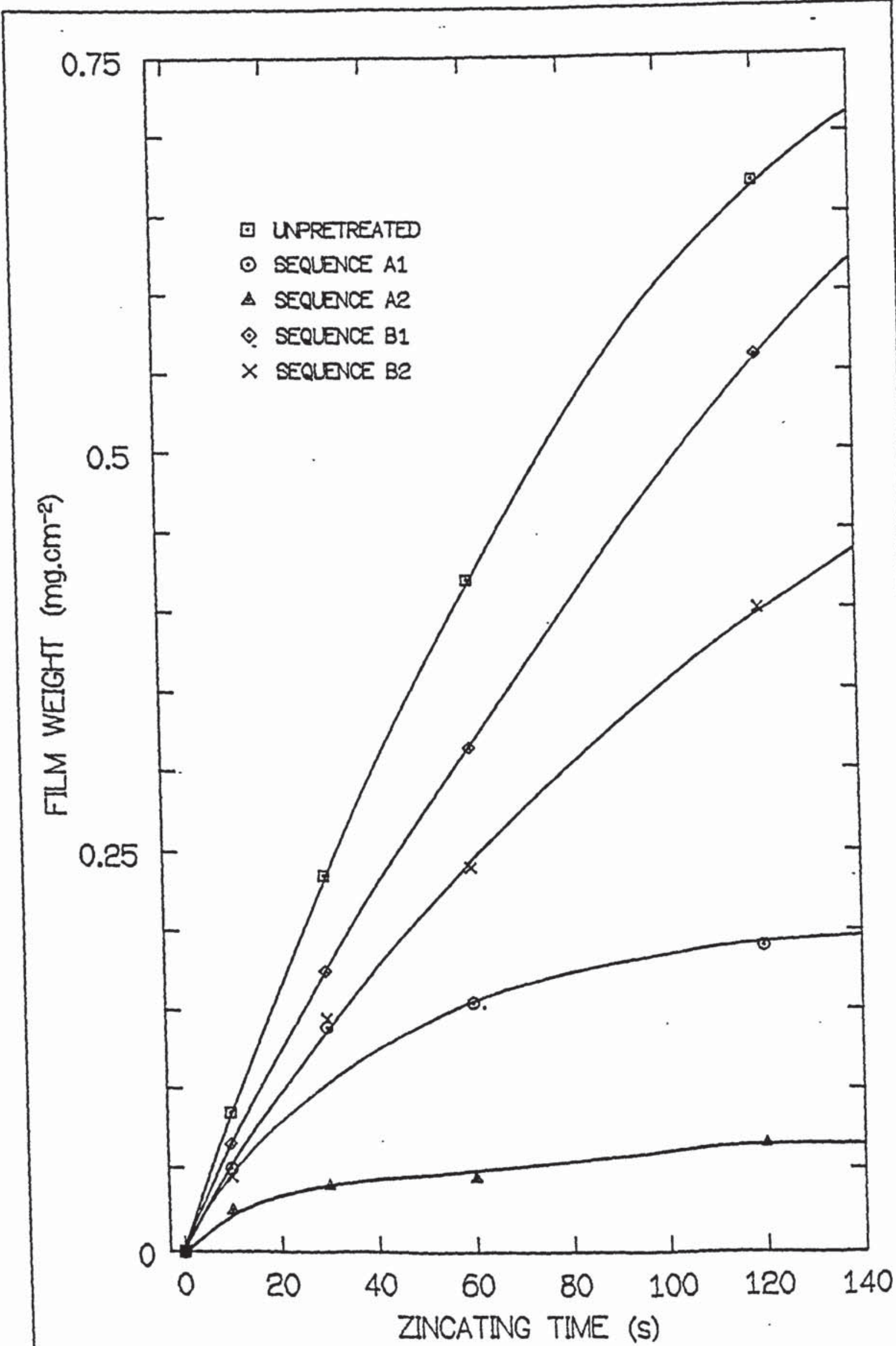

FIG. 21 Relationship between zincate time and film growth weight on SIC using 'Bondal' solution 


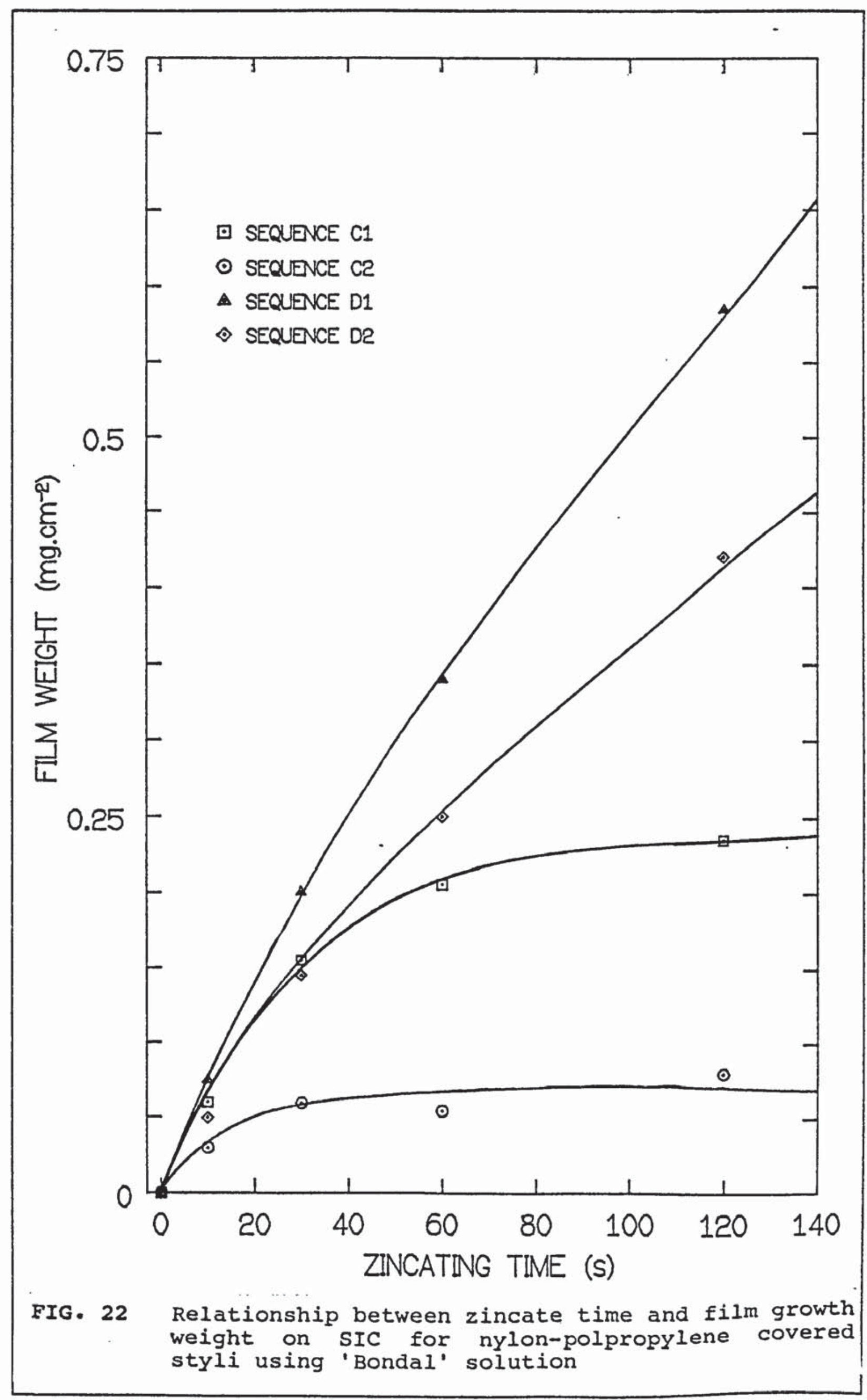




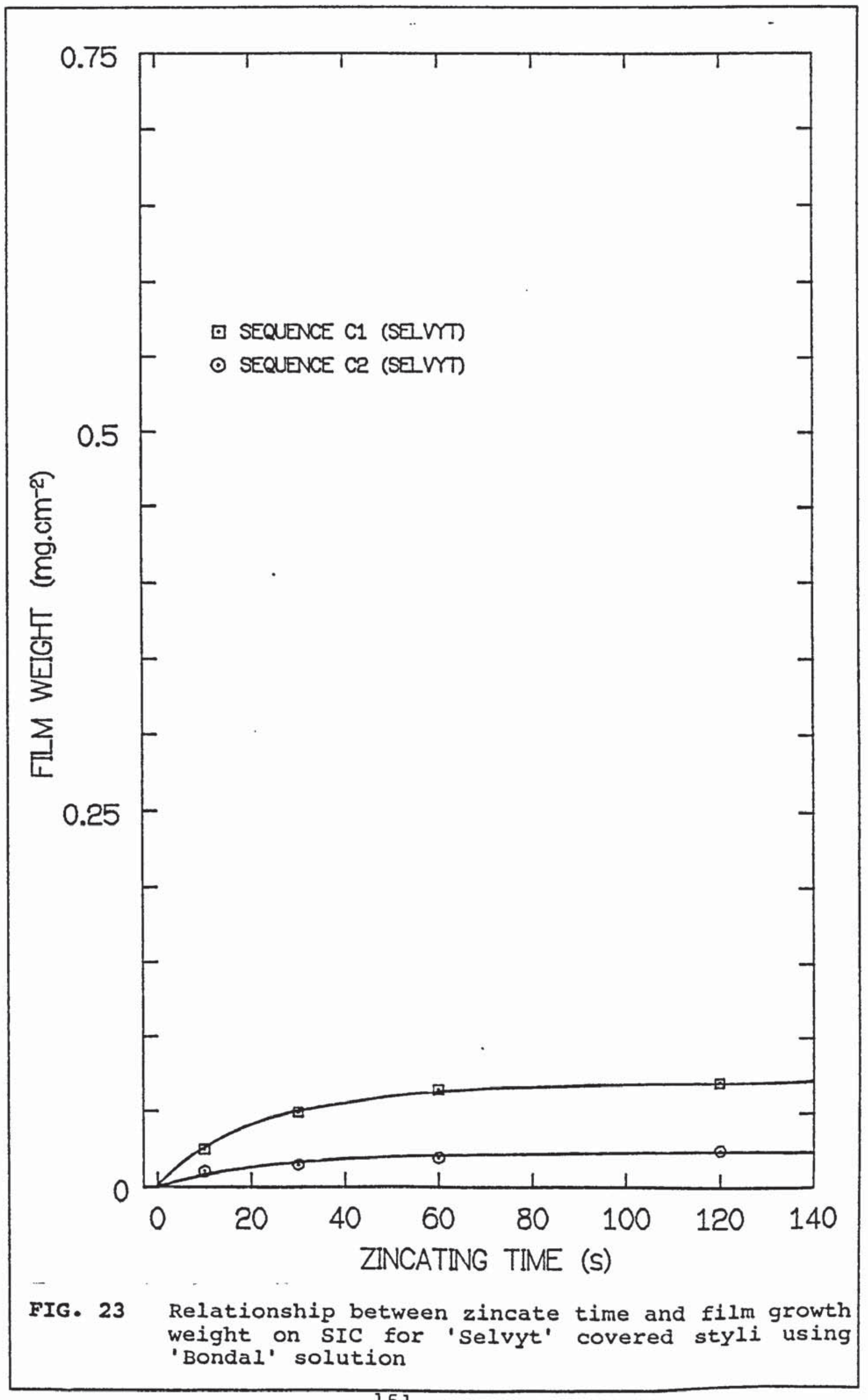

$-151-$ 
the film electrolytically was to increase greatly the film weight of the corresponding non electrolytic treatment. Film weight continued to rise as time increased, whereas with the non electrolytic sequences the film weight levelled off. The films produced when using the 'Selvyt' pad have much lower film weights than those achieved when the more abrasive pad is used. The film weight of an unpretreated panel of SIC was much greater than those of pretreated panels.

From the potential - time curves Fig. 24 a,b, it can be seen that the double dip sequence A2 represents a situation where the aluminium surface, which was more uniform and less reactive by virtue of the double treatment was covered rapidly and uniformally by a thin film. Thus, the equilibrium potential value, indicating coverage of the surface with the zinc alloy deposit, was reached quickly, but the film still continues to grow slowly as discussed previously(136). It is apparent from Fig. 24a that the unpretreated surface of SIC is far more reactive than the surface after pretreatment and for this example, A to B indicates oxide dissolution and exposure of the alloy surface occurs and has the dominant effect. The alloy surface devoid of oxide is then more base. Neither oxide removal, effected by the caustic nature of the zinc alloy solution, nor the total coverage of the surface with the zinc alloy deposit is instantaneous all over the surface. Between $B$ and $C$ the influence of the immersion film growth 


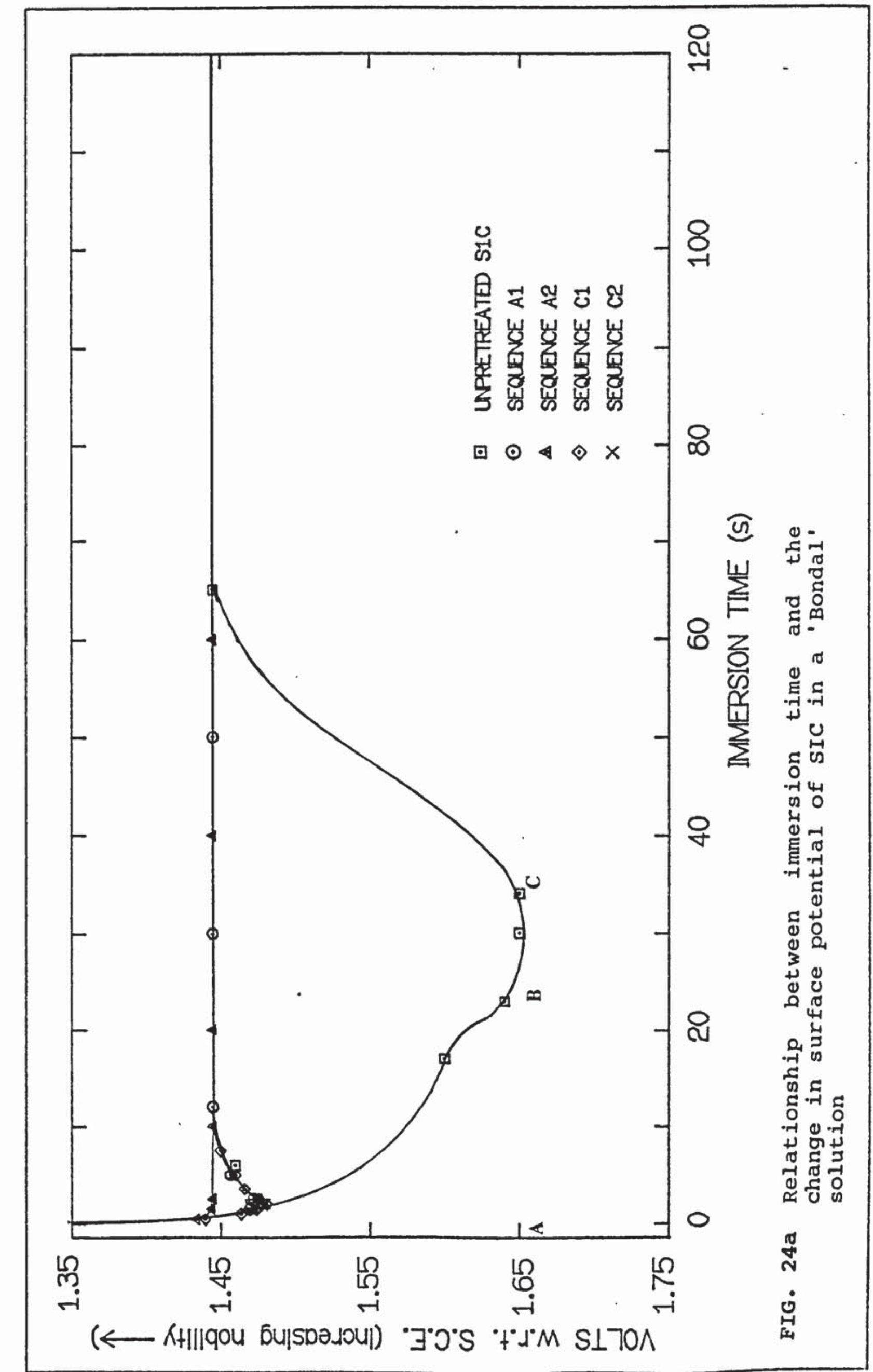




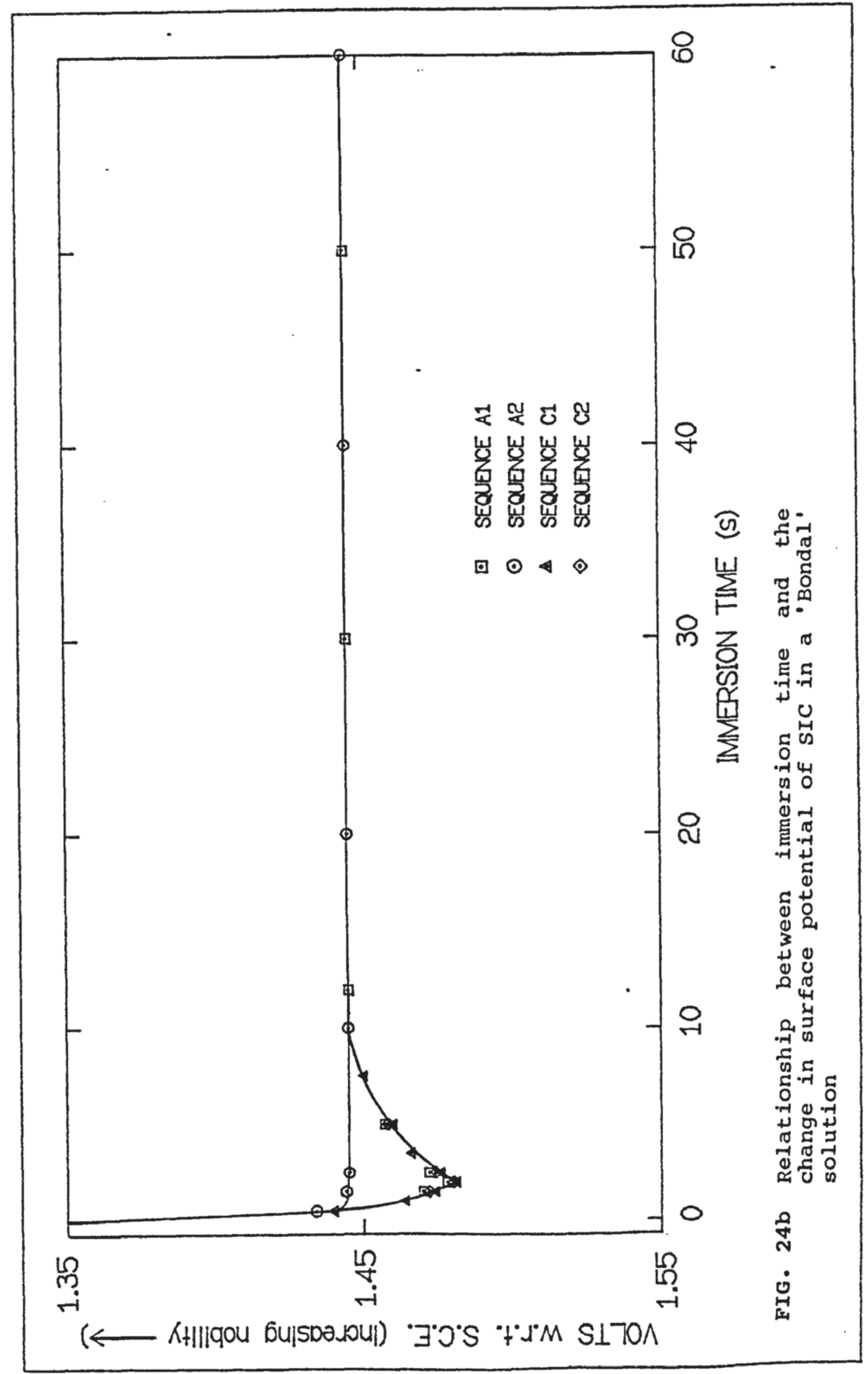


and oxide removal, upon the overall potential, are in balance. From $C$ onwards the build-up of the zinc alloy film begins to have the dominant influence. Once total surface coverage has occurred, the curve becomes flat.

The deposit itself is not pure zinc but is in fact an alloy of zinc, copper, nickel and iron. However, the relative proportions of these alloying elements change as the mode of application and treatment time change. During non electrolytic treatment the proportion of all alloying elements varied with time with the increase in the proportion of copper being the most significant. The effect of brushing the zinc alloy solution caused the film to be relatively high in zinc but low in copper, nickel and iron. Typical film compositions, for 3 minutes of treatment are listed below.

$\begin{array}{lcc} & \text { Immersion } & \text { Brushing } \\ \text { Zinc } & 85.98 & 90.18 \\ \text { Copper } & 8.68 & 6.68 \\ \text { Nickel } & 3.68 & 2.68 \\ \text { Iron } & 1.98^{\circ} & 0.78\end{array}$

During electrolytic treatment however, the amounts of nickel and copper observed in the film were similar. As deposition time increased, preferential growth occurred, these growths had a similar composition to the surrounding film. 
The peel adhesion results are given in Table 5. No difficulty was encountered in covering the surface of the alloys with a zincate deposit but the presence of this film did not always guarantee good adhesion. of the sequences investigated the electrolytic double immersion sequence B2, gave the highest adhesion values. The double brush sequences gave higher values than the single brush, but lower than double immersion. Depending on the adhesion value, differing amounts of substrate were detached on the back of the peeled foil. A number of failure surfaces of various pretreatments and having different levels of adhesion were examined in the SEM. The failure surface indicated that, at the highest adhesion level, failure occurred partly at the slC/electrodeposit interface and partly by ductile cup and cone fracture within the aluminium substrate, Fig. 25. The adhesion values obtained when using the 'Selvyt' pad were low. For sequence $\mathrm{Cl}$, a value of $3.5 \mathrm{Nmm}^{-1}$ was obtained. However, for the double brush sequence $\mathrm{C2}$, the adhesion value was $5 \mathrm{Nmm}^{-1}$, which corresponds to the single brush result of the nylonpolypropylene pad. It is worth noting that all samples, regardless of pretreatment sequence and adhesion level exhibited the phenomenon of aluminium adhering to the back of the detached foil.

similar, but more selective work was undertaken using various pretreatment systems, zinc alloy solutions and substrates. 
Sequence

Peel Adhesion Value

$\left(\mathrm{Nmm}^{-1}\right)$

$\underline{\text { SIC }}$

\begin{tabular}{|c|c|c|}
\hline$A I$ & (120s & Bondal) \\
\hline A2 & (120s & Bondal) \\
\hline Bl & (120s & Bondal) \\
\hline B2 & $(30 \mathrm{~s}$ & Bondal) \\
\hline B2 & ( $60 \mathrm{~s}$ & Bondal) \\
\hline Cl & (120s & Bondal) \\
\hline $\mathrm{Cl}$ & (120s & Bondal 'Selvyt') \\
\hline $\mathrm{Cl}$ & $(60 \mathrm{~s}$ & Bondal) \\
\hline $\mathrm{C} 2$ & $60 s$ & Bondal) \\
\hline $\mathrm{C} 2$ & i $60 \mathrm{~s}$ & Bondal 'selvyt') \\
\hline Dl & ( $60 \mathrm{~s}$ & Bondal) \\
\hline D2 & ( $60 \mathrm{~s}$ & Bondal) \\
\hline
\end{tabular}

8.0

19.5

8.5

27.5

$25 \cdot 5$

5.5

3.5

5.0

9.5

5.0

8.0

12.0

$\begin{array}{llr}\text { A1 } & (120 \mathrm{~s} \text { Alumseal }) & 11.0 \\ \text { A2 } & (120 \mathrm{~s} \text { Alumseal }) & 20.5 \\ \mathrm{C} 1 & (120 \mathrm{~s} \text { Alumseal }) & 7.5 \\ \mathrm{C} 2 & (30 \mathrm{~s} \text { Alumseal }) & 14.5 \\ \mathrm{C} 2 & (60 \mathrm{~s} \text { Alumseal }) & 15.5\end{array}$

E (Brush plated nickel

7.0 applied prior to deposition of Watts Nickel)

$\underline{\text { AS15 }}$
Al (120s Bondal)
A2 (120s Bondal)
Cl (120s Bondal)
C2 (60s Bondal)
$\mathrm{Al}(\mathrm{G})$ ( $60 \mathrm{~s}$ Bondal)
Cl(G) ( $60 \mathrm{~s}$ Bondal)
E (Brush plated nịckel applied prior to deposition of Watts nickel)

$9 \cdot 5$

8.0

$6 \cdot 5$

6.0

9.5

1.5

8.5

All quoted results are an average of four tests. 

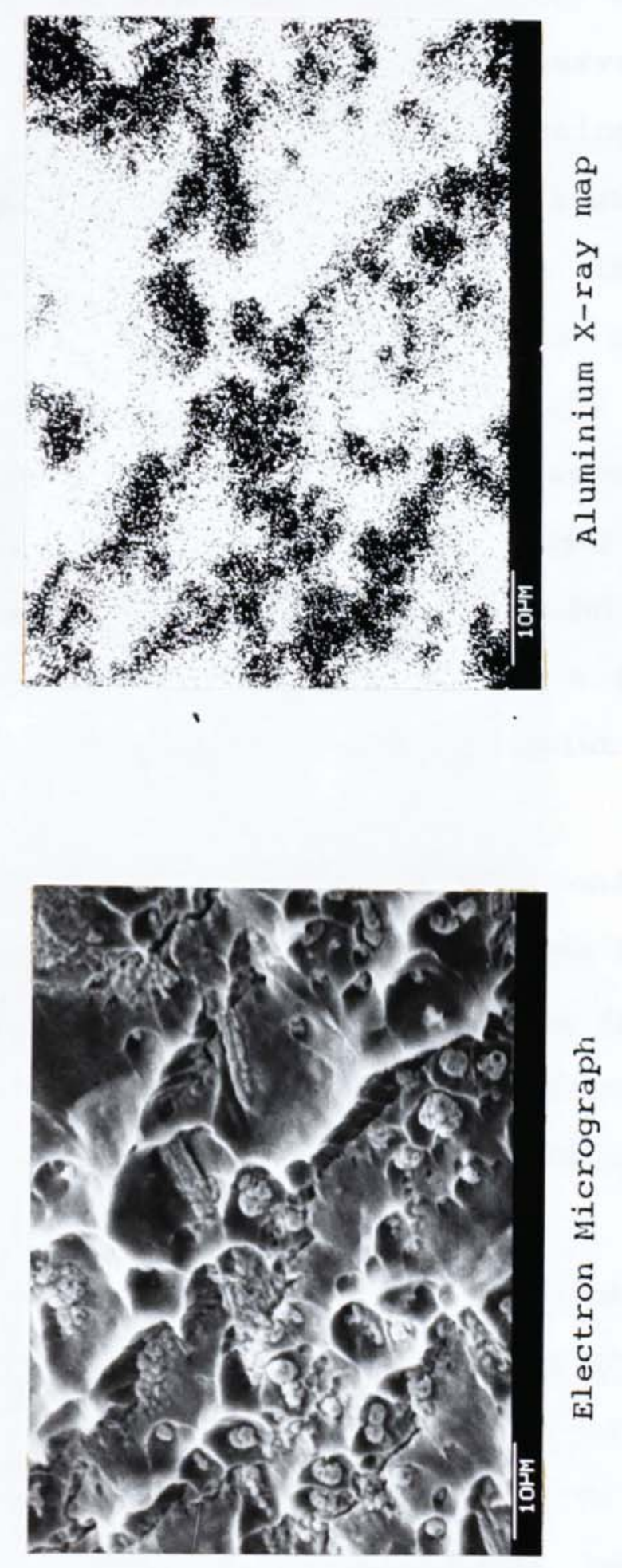

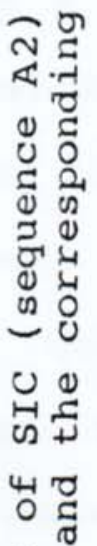

究

ตैं

प्र की

$\rightarrow$

ธ. 융

더에

प्रे त्

บ ซ

-

에

임.

다.

ह ำ

泡出

$\stackrel{\text { ก }}{*}$

通. 
By using the alternative zinc alloy solution 'Alumseal' as opposed to 'Bondal', different observations upon the growth of the film can be made. When using sequences $\mathrm{Cl}$ and $\mathrm{C2}$ the deposits are initially very similar with a number of growth sites, Fig. 26, although the 'Alumseal' growths appear to be larger in size than those that occur when using 'Bondal', Figs. 18 and 19. However, with the 'Alumseal' solution, growth appears to cease after approximatly 30 seconds. At longer treatment times, the 'Alumseal' film remains as a nodular one consisting of numerous growth sites and not as a smooth almost coherent film that results when 'Bondal' solution is used.

The film weight curves, Fig. 27 confirms the observations that essentially film growth ceases after about 30 seconds although, prior to this point, the film growth rate of the 'Alumseal' film is much greater than that of the 'Bondal' film, which slows down after approximatly 60 seconds.

The potential - time curves obtained by using _Alumseal' follow a similar pattern to those obtained using 'Bondal' however, the final potential of the 'Alumseal' film is slightly more negative at $-1.485 \mathrm{~V}$. This is probably due to the compositional difference between the zinc alloy films produced from the two solutions. Typical film compositions for 3 minutes brush treatment are listed 

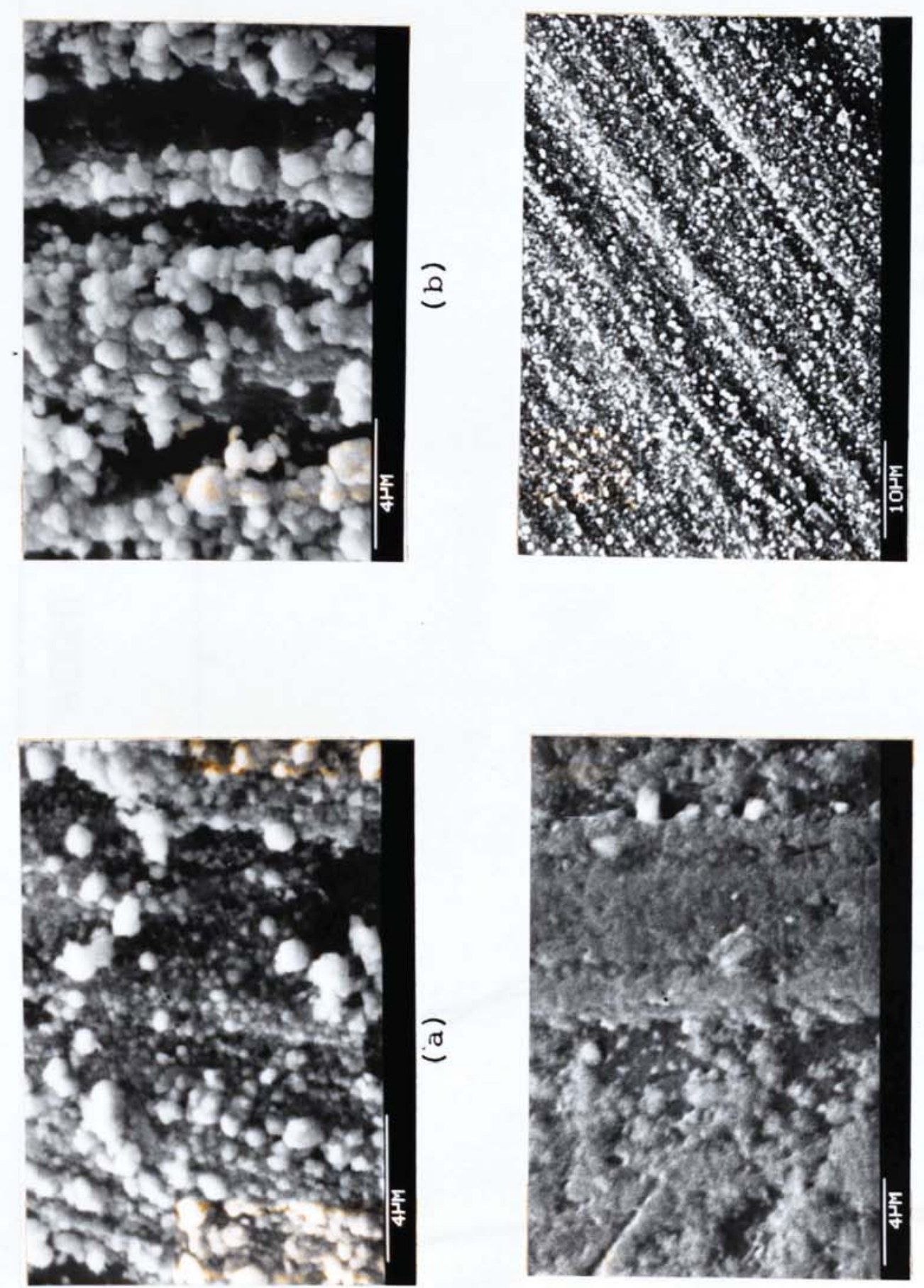

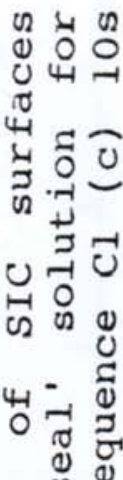

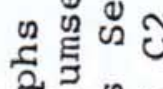

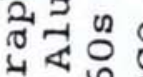

ऊै-

论伺导

छ

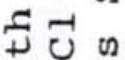

돈

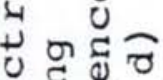

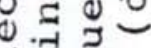

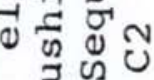

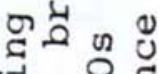

है $4=0$

ब

出两

(2) क⿺辶万

$\stackrel{\circ}{\sim}$

$\underset{0}{0}$ 


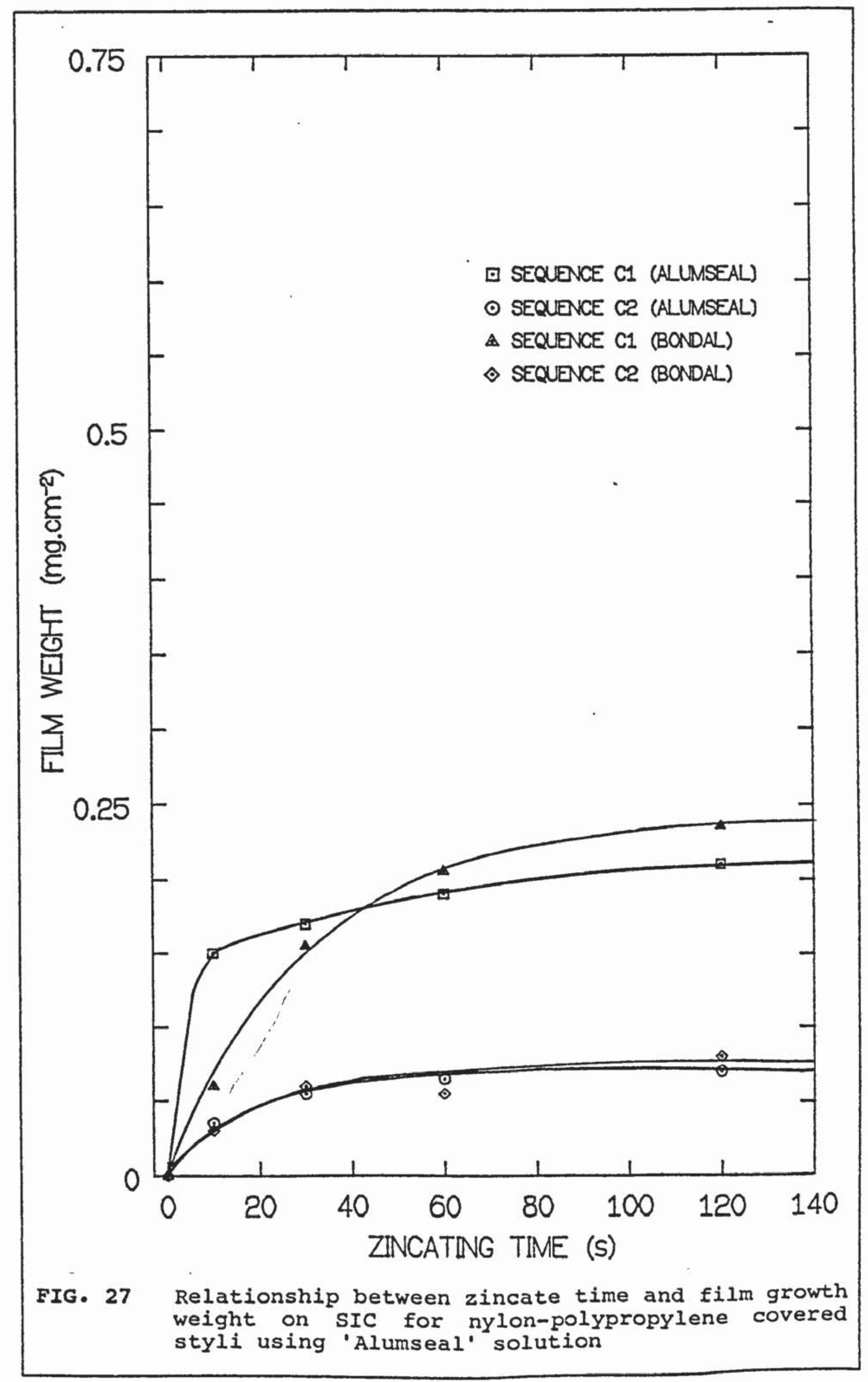


below.

\begin{tabular}{lcc} 
& 'Bondal' & 'Alumseal' \\
\cline { 2 - 3 } Zinc & $90.1 \%$ & $92.5 \%$ \\
Copper & $6.6 \%$ & $2.3 \%$ \\
Nickel & $2.6 \%$ & $4.5 \%$ \\
Iron & $0.7 \%$ & $0.7 \%$
\end{tabular}

The peel adhesion values obtained when using the 'Alumseal' solution, Table 5 are higher than those obtained by using 'Bondal' for the equivalent sequences.

9.2 On AS15 (Aluminium 20\% Tin 18 Copper)

\subsubsection{Using Nitric Acid}

When using either the brush or the immersion pretreatment sequences $(A 1, A 2, C 1, C 2)$ a greater degree of etching is observed prior to zinc alloy application, than occurs with S1C, Fig. 28. This is due to the tin phase of the AS15 being readily attacked by the nitric acid.

When the double treatments are carried out, the second acid stage will readily attack the tin phase again, producing an even greater degree of etching. These etch pits produce a greatly increased effective surface area over which the zinc alloy solution can nucleate and grow causing a much greater film weight to be measured, Fig. 29 although, there is no obvious evidence of such a thick film, Fig. 28. 

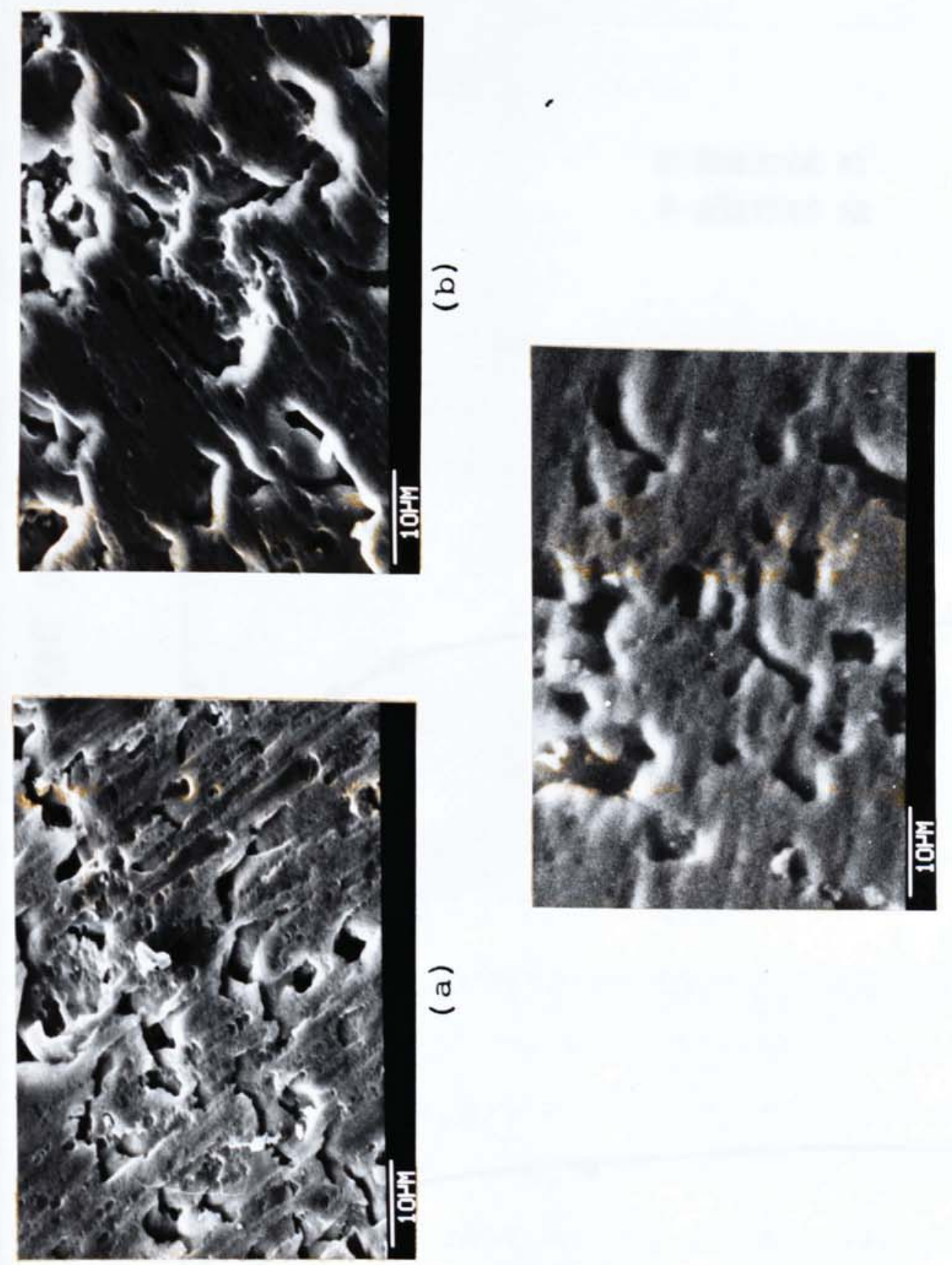

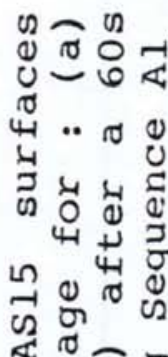

स्षण

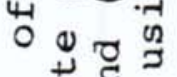
幽 营. 芹 N 대

o

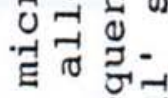

$-10$

ฐ

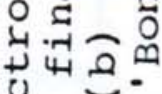

光离

ฮ요

-

ปี

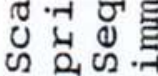

番 


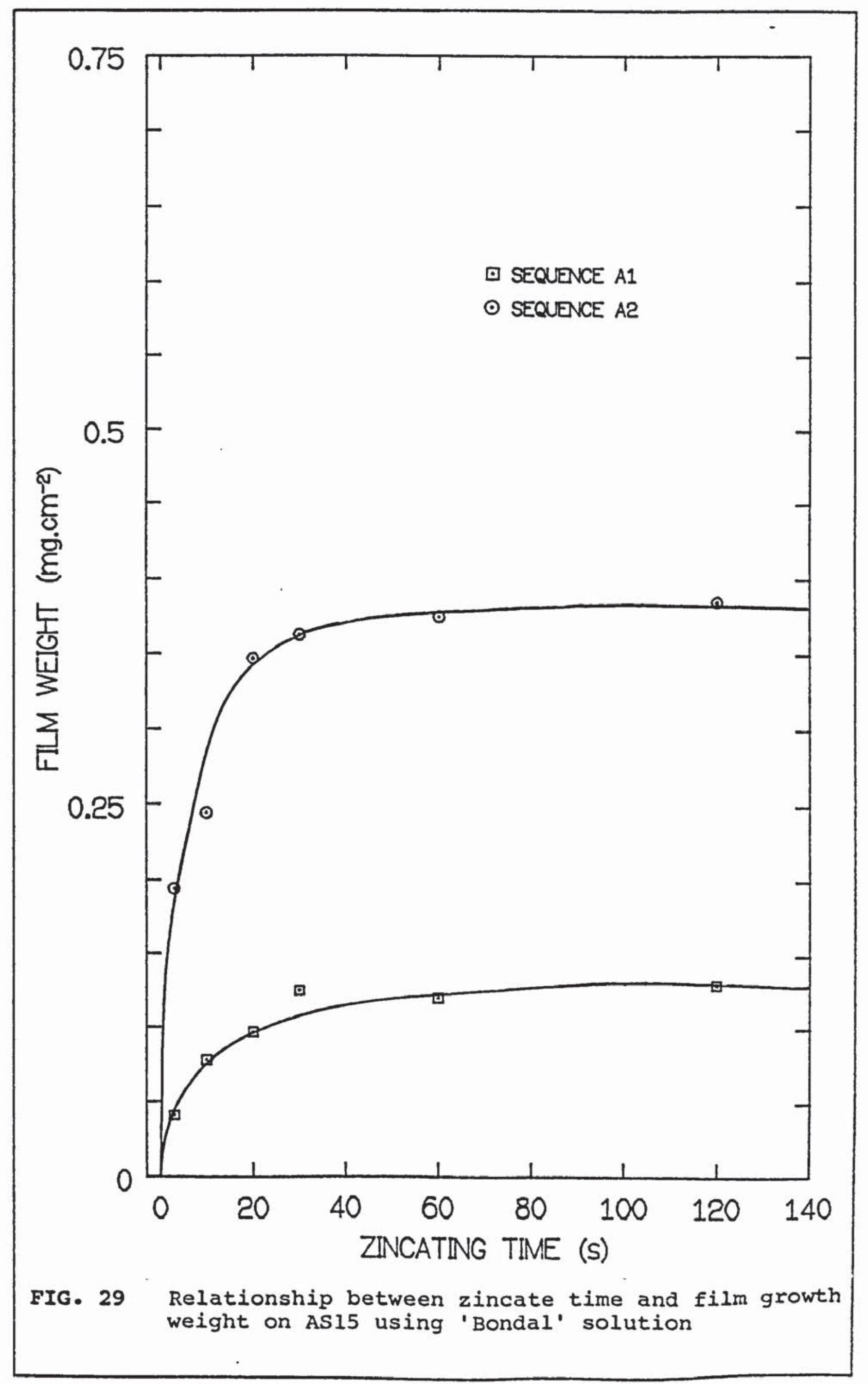


The high degree of activity is reflected in the potential time curves, Fig. 30, where the surface during the second zinc alloy stage is far more reactive than during the first application.

The peel adhesion results give higher values for the single treatments $\mathrm{Al}$ and $\mathrm{Cl}$ but lower values for the double treatments. This is consistant with the greater degree of etching that occurs with this alloy as opposed to SlC allowing more keying. However, when the etch pits become too large, as occurs during the second application of the acid, the adhesion falls.

\subsubsection{Using Hydrogen Peroxide - Sulphuric Acid}

The surface prior to zinc alloy application when using the $\mathrm{H}_{2} \mathrm{O}_{2} / \mathrm{H}_{2} \mathrm{SO}_{4}$ acid desmut, instead of the nitric acid, produces an etched surface, Fig. 31, similar to the surface of SIC when treated with nitric acid, Fig. 17, for the brush sequences. Greater etching is apparent for the immersion sequence. The growth of the zinc alloy film when using the single brush sequence $\mathrm{Cl}(\mathrm{G})$ is similar to that when using sequence $\mathrm{Cl}$ on SIC. There are a few visible growth centres, the number of which increase with time. After 30 seconds many growth centres are still visible, the growths can be seen preferentially around etch pits and scratch lines however, many areas of the substrate are still apparently unaffected by the zinc alloy application. 


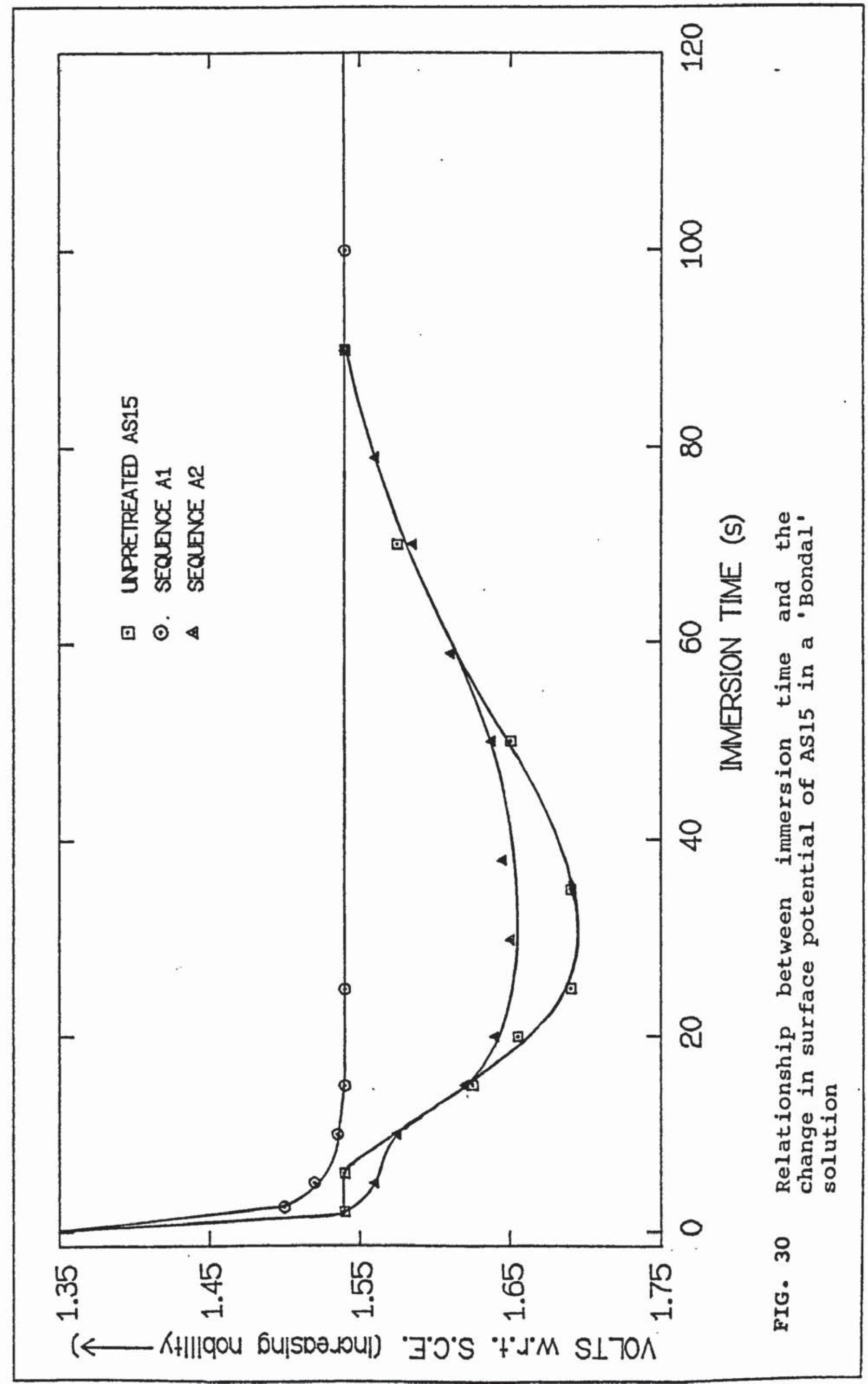




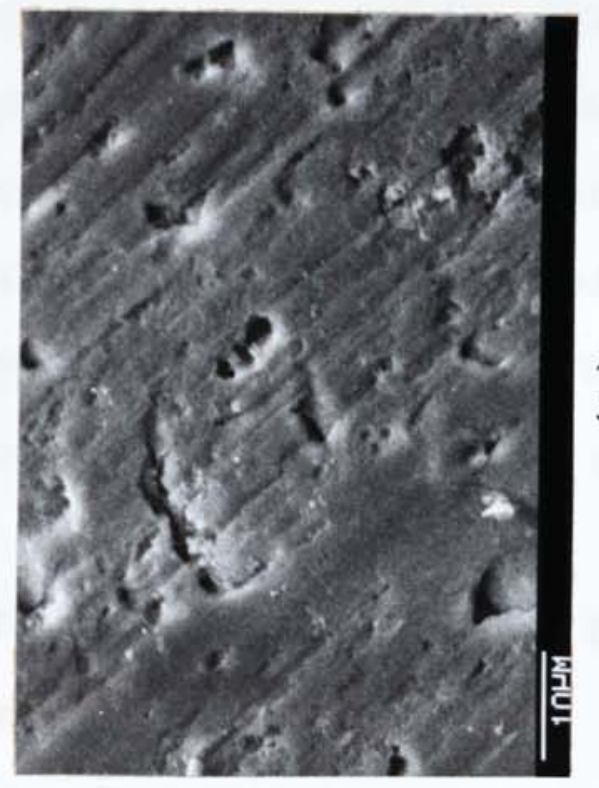

a
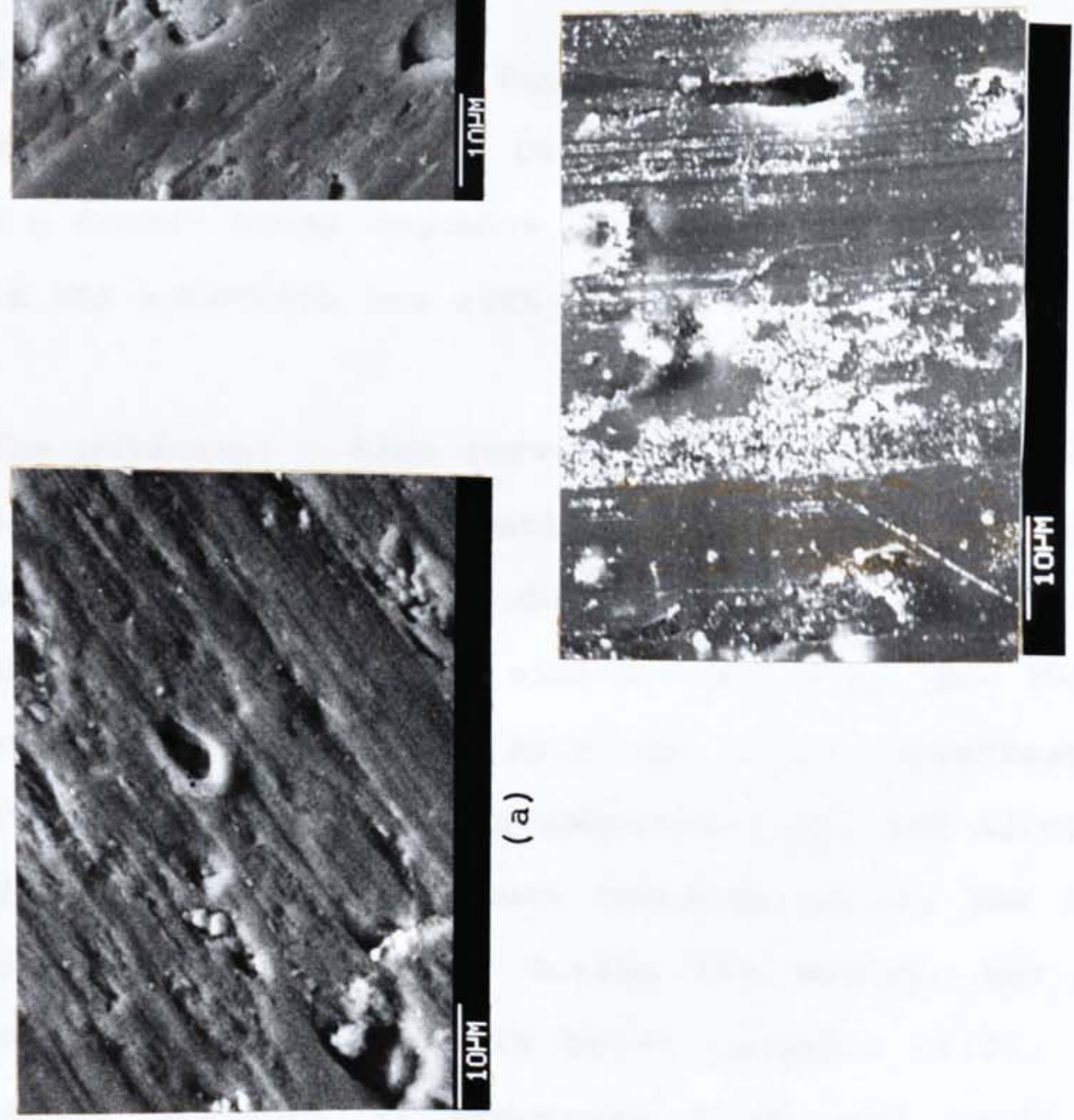

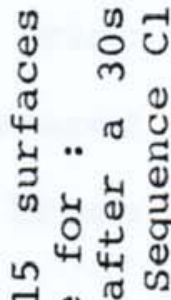

ता ब

ब.

फ

ט

远皆

ब.

प्र $N$ ब

品

प्र 0 Ð

$\therefore$.

O $\quad$ है

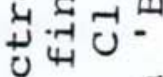

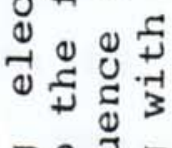

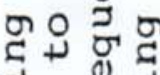

ב

गु.

$\sqrt{\pi}$

m 
Even after 60 seconds much of the surface is covered but individual growth centres can still be observed.

The cleaning treatment prior to the application of the second zinc alloy film using sequence $\mathrm{C} 2(\mathrm{G})$, Fig. 31 produces greater attack of the surface than the single sequence $\mathrm{Cl}(\mathrm{G})$. After a 30 second application of zinc alloy solution, more of the surface appears to be covered by the film than at the same stage of the single brush sequence, although the growths appear smaller.

The film weight curves Fig. 32 correspond with the electron micrographs, showing a relatively low film weight and that the double brush sequence produces a film which covers more of the substrate but with smaller growths.

The potential - time curves Fig. 33, show that the surface during the first application of the zinc alloy solution, is much more reactive than during the second application. The surface is also of similar activity to that of an unpretreated sample of AS15 and to an unpretreated sample of S1C, Fig. 24a. When sequence $A 1(G)$ and $A 2(G)$ are used the surface is again more reactive during the first zinc alloy application than during the second, but much less reactive than the single brush sequence $\mathrm{Cl}(\mathrm{G})$. The film weight produced by sequences $A 1(G)$ and $A 2(G)$ are also higher than for the brushed samples. 


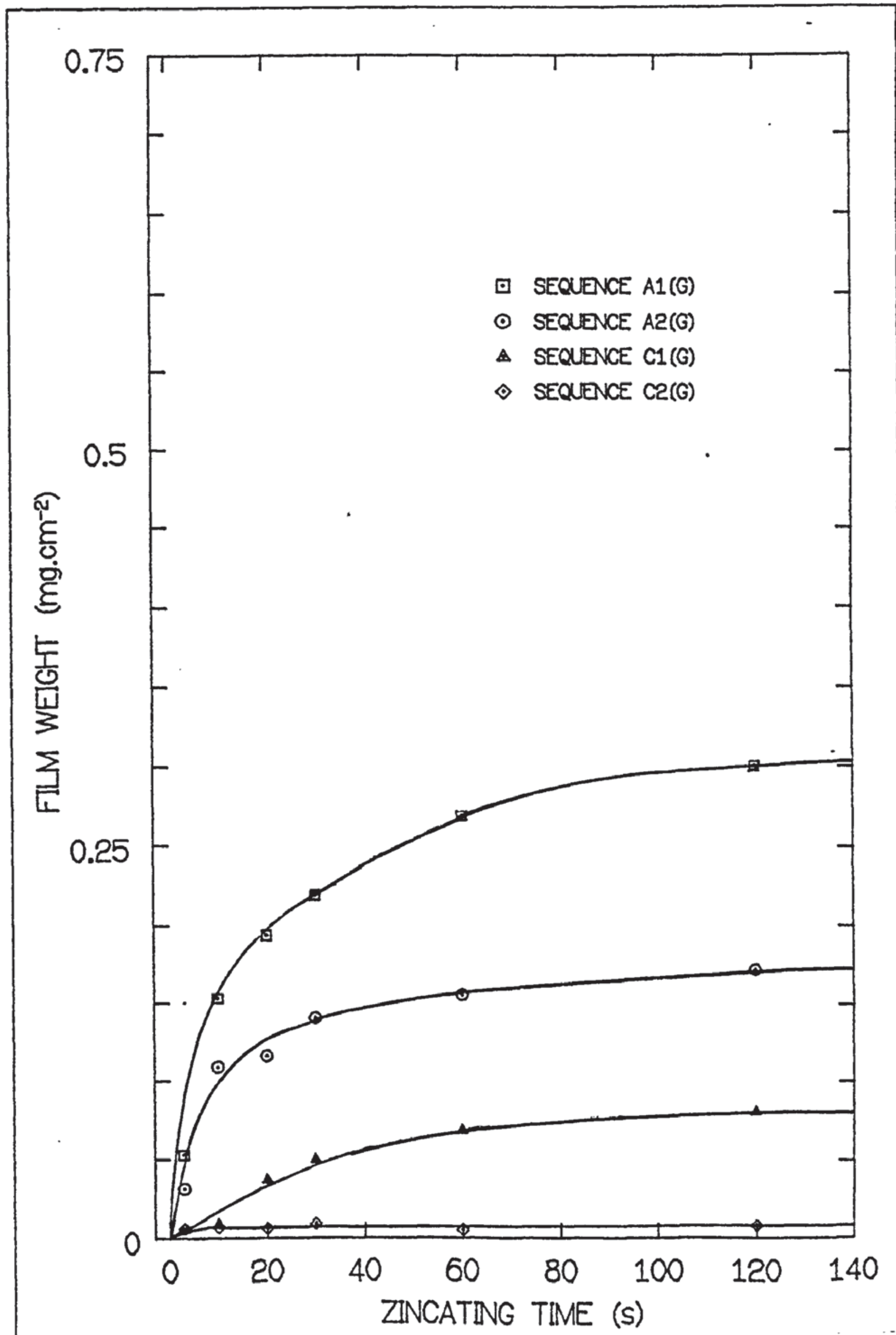

FIG. 32 Relationship between zincate time and film growth weight on AS15 using 'Bondal' solution for :

(a) Sequence $A 1(G)$ (b) Sequence A2 (G)

(c) Sequence $\mathrm{Cl}(\mathrm{G})$ (d) Sequence C2(G) 


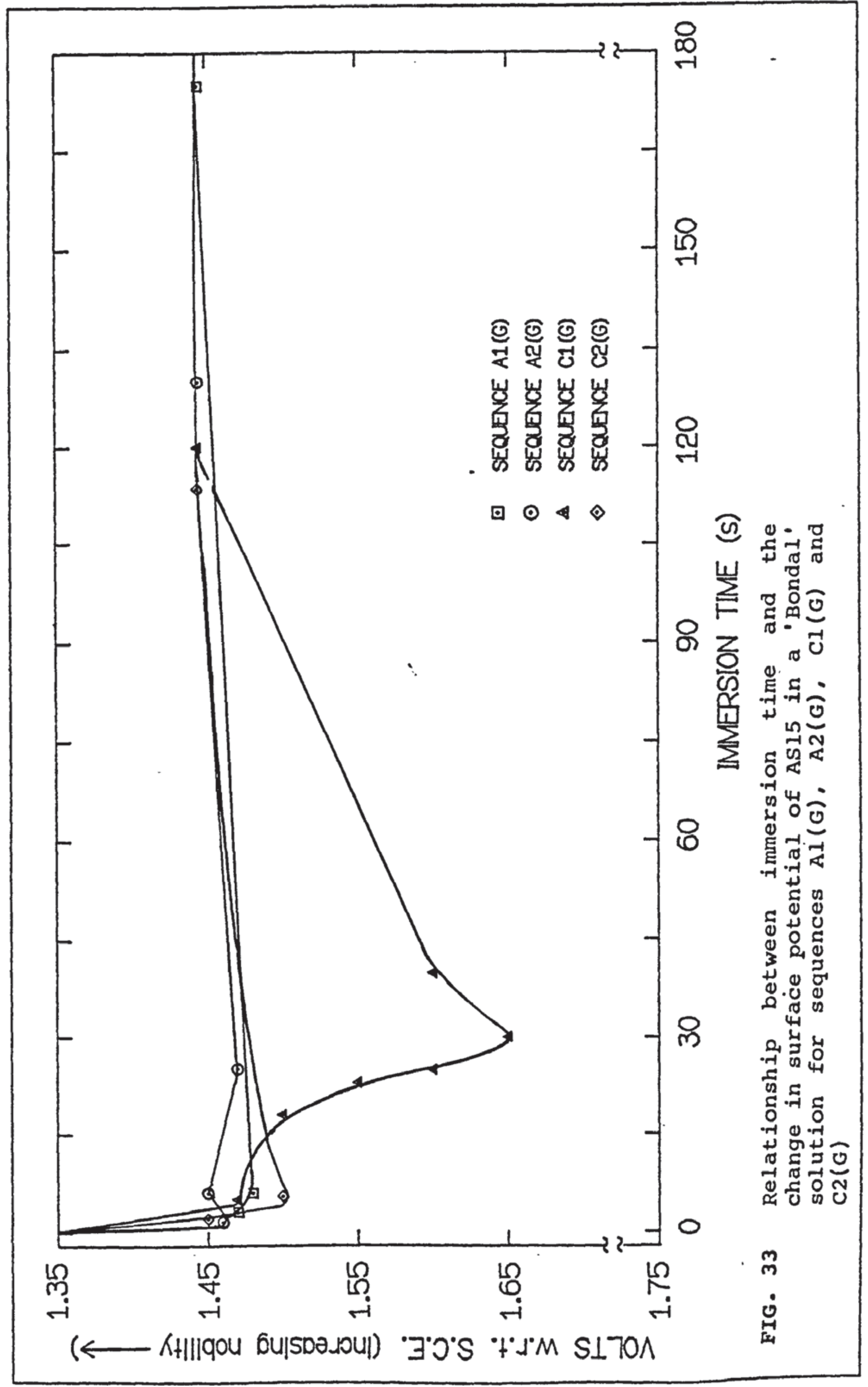


The peel adhesion values obtained by this pretreatment sequence are very low compared to the highest values obtained on SIC. The single immersion sequence $A I(G)$ produces better adhesion than the single immersion sequence Al on SIC. This must be due to the extra mechanical keying involved. 


\section{1 on S1C Aluminium}

The double brush treatments produce greater attack of the surface than the corresponding single pretreatments. This is due in part to the surface dissolution of aluminium that occurs during the formation of the first zincate film deposited. When this film is removed by stripping in acid, the chemical activity of the freshly exposed surface is more uniform and hence the subsequent zinc alloy films will be thinner and have superior properties when deposited onto this surface( 98$)$.

The degree of surface attack found in this investigation is much less than had been suggested in previous work, for the equivalent sequences(137). Golby and Dennis have shown a much finer dispersion of smaller etch pits using sequence Al, the non electrolytic immersion sequence, whereas in this investigation much larger etch pits were found. This variation is probably due to a difference in. substrate material. This could account for the differences at subsequent stages and the corresponding higher adhesion values obtained previously. The severity of the immersion pretreatment with respect to the brush mode can be explained in terms of time taken for completion of this stage. Both sequences are carried out electrolytically for 
the same time, 2 minutes. In the non electrolytic immersion sequence, $A I$, the whole surface is subject to a current density of $2 \mathrm{Adm}^{-2}$ for the whole treatment time. In the simple brush, $\mathrm{Cl}$ however, the only area of the substrate being etched at any particular instant is the area directly underneath the pad (approximately $100 \mathrm{~mm}^{2}$ ). Hence in any 2 minute period the actual cleaning time was only about 4 seconds per $100 \mathrm{~mm}^{2}$ area (with the panels used in this investigation). It should be emphasised that the current density in the brush pretreatment (approximately $100 \mathrm{Adm}^{-2}$ ) counteracts this time reduction to some extent and comparable results could be achieved with an increase in brushing time and/or an increase in area of pad contact.

The ideal monomolecular zinc alloy film, suggested by Bullough and Gardam(90) is not realised on hetrogeneous alloys, which contain such features as grain boundaries and intermetallics. These result, even after etching, in local differences in surface potential. Mechanical damage such as scratch lines, which result in stressed regions, can also lead to the formation of a non uniform zinc coating. Brushing with an abrasive pad, as in this investigation will produce scratch lines on the surface and hence preferential growth around these lines will occur. The nucleation and growth of the film is influenced by these local surface variations in potential due either to compositional differences in the substrate or mechanically induced stresses. Hence mechanisms other than a simple 
replacement reaction are involved in film growth.

The non electrolytic brush sequences $\mathrm{Cl}$ and $\mathrm{C2}$ result in coarse films which exhibit relatively slow surface coverage although growth is rapid. These films develop by the formation of rounded growth centres which possibly grow from nuclei already present in the initial monomolecular layer and preferential sites for nucleation such as around etch pits or scratch lines also exist. Initially the galvanic driving force varies in intensity across the surface. After prolonged treatment, growths then appear to develop over much of the remaining surface. An explanation of this could be that the sites which had previously been involved in the anodic reaction become sites for the cathodic reaction at a later time in the treatment period hence, are dynamic in nature. Normally there will be a slight delay before film growth is initiated, since it is necessary for oxide dissolution to occur. Even after pretreatment it is unlikely the whole surface will be oxide free, this again will influence film growth. As zinc alloy treatment increases, for the non electrolytic immersion sequences $A l$, growth of the film slows down after its rapid initial surge. Eventually the individual growth centres spread and coalesce to form a continuous deposit. This however is not the case with the non electrolytic brush sequence, where coalescence does not occur within the first two minutes of treatment. The double immersion treatment sequence A2 produced a film which is slower growing but 
very coherent and almost featureless, consistent with a film growing on a more uniform and less reactive surface(98). The double brush sequence, $C 2$, does produce a slower growing film, but individual growth centres are still observed after 2 minutes. The lack of coherency of the film produced by brushing is a consequence of the technique. Any tendency to grow across the surface could be counteracted by the brushing motion and hence redistribution of the zinc alloy film along lines parallel to the brush direction occurs.

The brush results discussed above were produced using the nylon-polypropylene pad which is quite an abrasive material. This pad could prove to be too abrasive for certain brush plating applications. Consequently, similar trials were carried out using 'selvyt' cloth, a much softer, less abrasive pad. In general, the trends shown in the results produced using the abrasive pad are followed by those from the softer material. However, it is evident from the results that for a similar zinc alloy application there is much less of the film on the slc surface when the 'Selvyt' is used. This is due to the nylon-polypropylene pad having a much more open structure than that of the 'Selvyt', this will obviously allow more of the zinc alloy solution to be present on the substrate surface, allowing growth to occur over a larger surface area. 
The peel test results obtained when using the 'Selvyt' are much lower than those found by using the nylonpolypropylene pad however, it should be noted that a level of adhesion has been achieved. ...This indicates that complete coverage of the surface by the zinc alloy film is not essential for adhesion to result. Adhesion between the zinc alloy film and the overlay will occur at the points where there is zinc. It may be that complete coverage will necessitate the formation of a thicker zinc alloy film which itself will have low strength hence, lower adhesion will result as failure will occur within the zinc alloy layer.

The electrolytic single brush films, Dl, are again coarse, however surface coverage and perpendicular growth are more rapid so that much greater film weights are produced for equivalent treatment times. The electrolytic double brush films were less coarse but again growth was rapid. This is shown by the obvious brush lines evident after only a short deposition time Fig. 18iih, whereas during non electrolytic treatment these lines were only evident after longer treatments.

It should be noted that the non electrolytic brushed pretreatment sequences $\mathrm{Cl}, \mathrm{C2}$, produce less continuous films than the non electrolytic immersion films, but have higher film weights. This suggests that there is a greater tendency for the immersion films to grow across the 
substrate rather than perpendicular to it. Higher film weights are also associated with unpretreated specimens ${ }^{-}$and so the brush pretreatment can be considered as a less efficient cleaning method than the immersion one. It is also true that brushing removes the depleted film of liquid from the growing surface therefore more rapid growth is likely.

The electrolytic sequences produce higher film weights than their corresponding non electrolytic treatments. This is because film growth no longer relies solely upon the differences in potential between the aluminium and the zinc alloy solution, since an external potential is applied. This external potential also sustains film growth, whereas in the non electrolytic case the driving force for film growth decreases as film thickness increases.

Potential - time measurements also show the two modes of zinc alloy film formation :

i) fast growing coarse films giving poor coverage

ii) slow growing fine films giving good coverage.

The rate of change of surface potential appeared to be a function of the rate of surface coverage with the film. This can be seen in Fig. 24b, with the marked difference in potential values between the sequences A2 and C2, during the initial 10 seconds of zinc alloy treatment. 
The adhesion between two different materials is determined by the extent of the chemical and mechanical bonding. - The presence of a zinc alloy film is no guarantee of satisfactory adhesion. While excess etching is undesirable a limited amount is useful since it removes surface layers weakened by mechanical deformation. Furthermore pitting can improve adhesion due to the increased mechanical keying(137). A certain minimum level of attack appears necessary if the immersion film produced is to have the characteristics required to result in a reasonable peel adhesion level. Examination of the failure surfaces following peel adhesion testing reveals that failure surface characteristics are influenced by adhesion level and pretreatment. Even when peel adhesion was low some of the substrate was pulled off with the electrodeposit during peeling. However, generally an increase in the amount of substrate detached is associated with an increase in adhesion value. This suggests that poor adhesion is not just due to lack of metallic bonding at the substrate/ coating interface but also failure within the surface layer of the substrate. This must be caused by weakening of the substrate owing to etching which suggests that there is a minimum degree of etching necessary for all good adhesion, but, that overetching should be avoided. - The distribution of etch pits is also important. The adhesion values, Table 5. confirm the results obtained from film weight and potential - time measurement in so far as the slower finer films which result from uniform surface chemical activity 
give the highest adhesion values.

The zinc alloy solution is obviously a complex one in which the alloying elements are reported to play a significant part by refining the growing film, slowing down growth and facilitating deposition onto certain alloys.

From general considerations of the nobility of copper, it would be expected that aluminium, when placed in a solution of copper ions, would suffer a rapid displacement reaction. Sites covered with copper would undergo only limited further reactions. This could provide a mechanism for limiting film growth however, a more complex situation exists here as zinc, nickel and iron are all codeposited. It seems reasonable to suppose that the initial layer of the 'zinc alloy' film is mainly copper.with some zinc, with the copper : zinc ratio falling as the film continues to grow. The initial deposition of copper will be rapid due to the high electrochemical driving force and the subsequent deposition of zinc will be slower due to a lower driving force. This is confirmed when reference is made to the film growth weight curves shown in 9.1 .1 where an initially high growth rate eventually slows down and by Auger Electron Spectroscopy (AES) carried out on a zinc alloy film by Monteiro and Ross(101).

The presence of nickel in the zinc alloy solution is reported to be beneficial in promoting the adhesion of 
nickel plated directly onto the zinc alloy immersion film(94). The proportion of nickel is claimed to increase with time and it is believed that the growing surface is gradually poisoned with nickel and it is this which eventually arrests film growth(94,97). Grain refinement is achieved by the iron which inhibits growth of acicular crystals from the uniform fine grained crystal matrix.

The effect and the necessity of the various addition agents upon the zinc alloy film may change when a brush application of the zinc alloy solution is carried out. Although it is very likely that copper will again initially displace the aluminium, the effect of the nickel and iron additions must be debated. As previously discussed, during immersion the proportion of nickel in the film increases hence, eventually stopping, or greatly reducing, film growth. However, by brushing the zinc alloy solution, disruption of the depleted layer of liquid at the growing surface occurs. This causes the composition of the solution at the surface to approach that of the bulk solution hence, it can be assumed that the film would contain relatively more zinc than nickel when brushed than when immersed. In the context of this investigation, overlay plating of bearings, the necessity for the film to contain nickel, in order to promote the adhesion of nickel electrodeposited onto the zinc alloy film is reduced, as no such deposition occurs, other than that necessary for peel testing. It is also possible that the inclusion of iron, 
to facilitate grain refinement is also unnecessary; as the agitation which results from the brushing motion will cause a certain degree of refinement to occur.

The main points of the above discussion can also be applied to the 'Alumseal' solution, as the film also contains nickel, copper and iron. The film composition results indicate that the 'Alumseal' deposit contains relatively more nickel than is present in the. 'Bondal' film. This suggests that the film growth arresting mechanism discussed above occurs to a greater degree with the 'Alumseal' film. This again is confirmed by the film growth weight results, where although initially the growth of the 'Alumseal' film is more rapid, the growth rate slows down after a shorter time. Generally, the peel adhesion results obtained when using the 'Alumseal' solution are higher than those when the 'Bondal' solution is used. This could be due to the lower proportion of copper being present in the 'Alumseal' deposit, as excess copper in the film gives rise to poor adhesion( 94 ).

\subsection{On AS15}

The use of the nitric acid desmut on the AS15 bearing shells is not recommended for two reasons :

i) The nitric acid will readily attack the steel backing which not only detracts from the aesthetic 
appeal of the bearings but the reaction that occurs produces nitric oxide which is rapidly oxidised to form dinitrogen tetraoxide $\left(\mathrm{N}_{2} \mathrm{O}_{5}\right)$ a red-brown gas that is toxic on inhalation.

ii) The degree of etching of the AS15 that occurs is much greater than has previously been reported for sic, due to the attack of the tin phase. It is obvious that the degree of etching will increase when the double sequences are used consequently, the reported benefits of the double treatments(98) cannot be utilized with this system. To obtain a degree of surface attack similar to that experienced with SlC, the brush or immersion application must be carried out for only very short periods. This would make the process a critical one, where the slightest error in application time, would cause a dramatic change in the final surface condition of the AS15 hence, alter the adhesion results.

When using the hydrogen peroxide - sulphuric acid desmut a lower degree of etching occurs than when nitric acid is used. This system also eliminates the problem encountered of the etching of the steel backing.

The initial zinc alloy film produced on the substrate by the brush aplication was similar to that obtained on S1C, with a number of rounded growth centres however, at the 
longer treatment times far more of the substrate remains apparently unaffected by the zinc alloy solution than is the situation on SIC. This is reflected in the film weight curves. It is somewhat surprising that a relatively low film growth rate is observed, as there is a high degree of surface activity present during the initial application. The potential-time curves for the unpretreated ASI5 is very similar to that after sequence $\mathrm{Cl}(\mathrm{G})$, suggesting that the cleaning involved is not very effective.

From the immersion sequences $A 1(G)$, $A 2(G)$ the resultant film weight curves are higher than those produced by brushing. This contradicts the earlier findings of the work on SIC and the results of the potential-time measurements. It is reasonable to assume that the higher surface activity of the brush sequences, particularly $\mathrm{Cl}(\mathrm{G})$, is associated with higher film weights however, this is clearly not the situation that is occurring here.

The peel adhesion value obtained for sequence $\mathrm{Cl}(\mathrm{G})$ is very low. This reflects the very poor degree of film coverage however, it should be noted that the lack of the zinc alloy film and the fact that adhesion is obtained indicates, as previously discussed for 'Selvyt' in 10.1 that the absence of complete coverage does not result in total adhesion failure. 


\subsection{Direct Plating Pretreatments (Sequence E)}

The results of the brush pretreatment of SIC and ASI5 have been shown, for the sequences prior to the zinc alloy application stage. The electron micrographs show that only a small degree of etching occurs. However, when the direct pretreatment sequence $\mathrm{E}$ is followed, a very different surface topography is observed. The SEM micrographs Fig. 34 show a large degree of etching of the ASI5 and of the slc, this indicates that the tin phase is not being selectively etched. The surface illustrates the crystallographic cubic etching, which is a characteristic of aluminium when it is etched by a halide ion, such as $\mathrm{Cl}^{-}$ when no passivation of the oxide film occurs. Far more mechanical keying of the subsequent overlays will be able to take place with this particular etched surface, than is possible with the zinc alloy pretreated substrates. However, it is possible that the extremely rough surface may be detremental to the fatigue properties of the bearing when in service, as the etch pits may be considered as sites to initiate fatigue cracks. Peel adhesion results obtained using this sequence, shown in Table 5 approach those of the single immersion sequence $A l$ on SlC. 

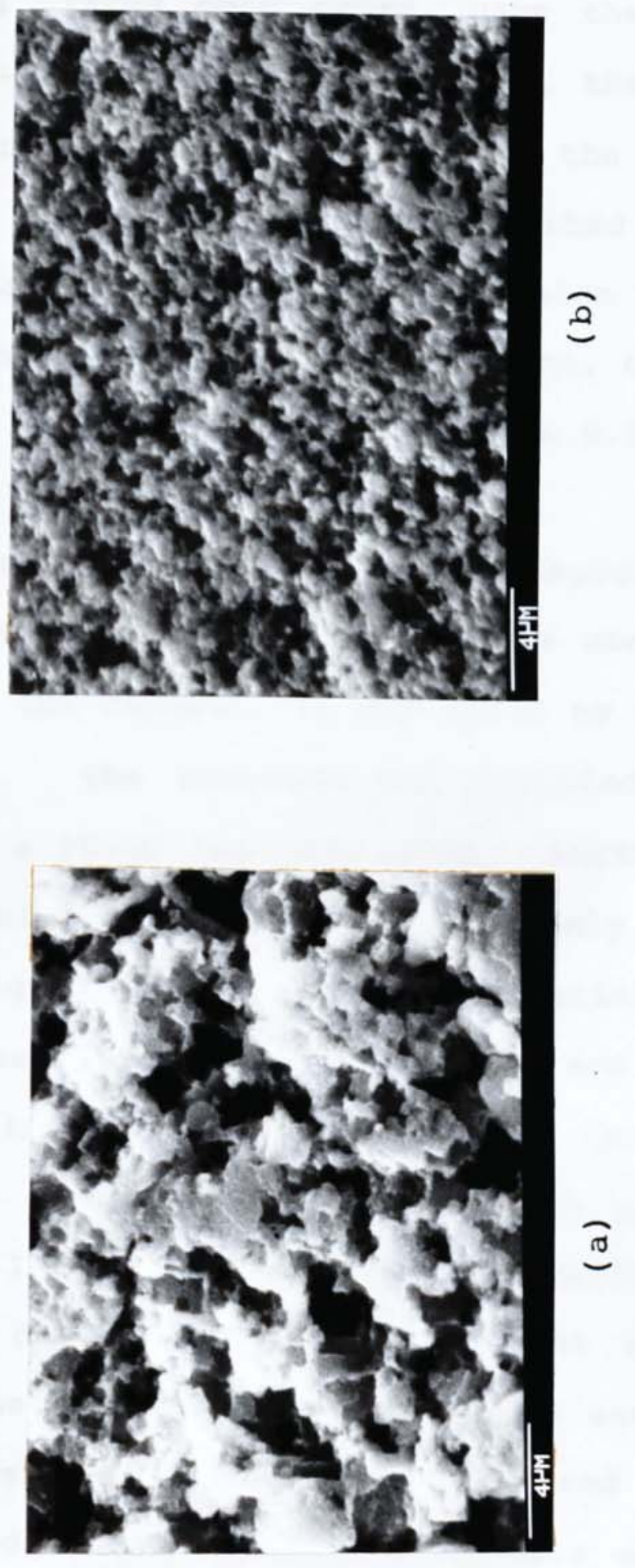

넝오

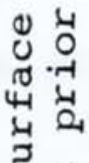

कि

๘)

4 近.

牙国

us

过

का

4 의

○्य

प्रत क

볼.

โี

느의

U.

西

क्ष

艎

है

ป็ํำ

ले 


\subsection{Lead-Tin Overlays}

The commercially obtained lead-tin alloy plating solution, when brush plated onto brass, gave the appearance of a sound semi-bright deposit. However, the appearance varied with plating voltage. In all cases the deposit adhered to the brass when cross-hatched scribed and peeled with adhesive tape. This level of adhesion occurred even when the brass had received no pretreatment, other than a simple degrease. The $\mathrm{pH}$ of the solution was 9.2 .

When examined in the SEM a fine deposit could be seen. However, when the EDXA attachment was used to quantitativeIy analyse the deposit, it was found to contain less than $5 \%$ of tin. The solution was supplied with the aim of depositing a 90:10 lead-tin alloy. Further solutions were obtained which again were found to only deposit 2-38 tin. As a consequence of the results obtained with the alloy solution, separate solutions of lead and tin were acquired and mixed in various proportions to obtain alloy plating solutions. These solutions were brush plated at different voltages. It can be seen from the results in Fig. 35 that a 108 tin deposit can be obtained at reasonable plating voltages (between 10-20V) to ensure a satisfactory plating rate. However, the solutions required to be relatively concentrated, $30 \mathrm{~V} / 0$ tin. The results also indicate that the 90:10 lead-tin alloy solution previously supplied, was in fact a $90: 10 \mathrm{v} / 0$ mixture of the two single metal 


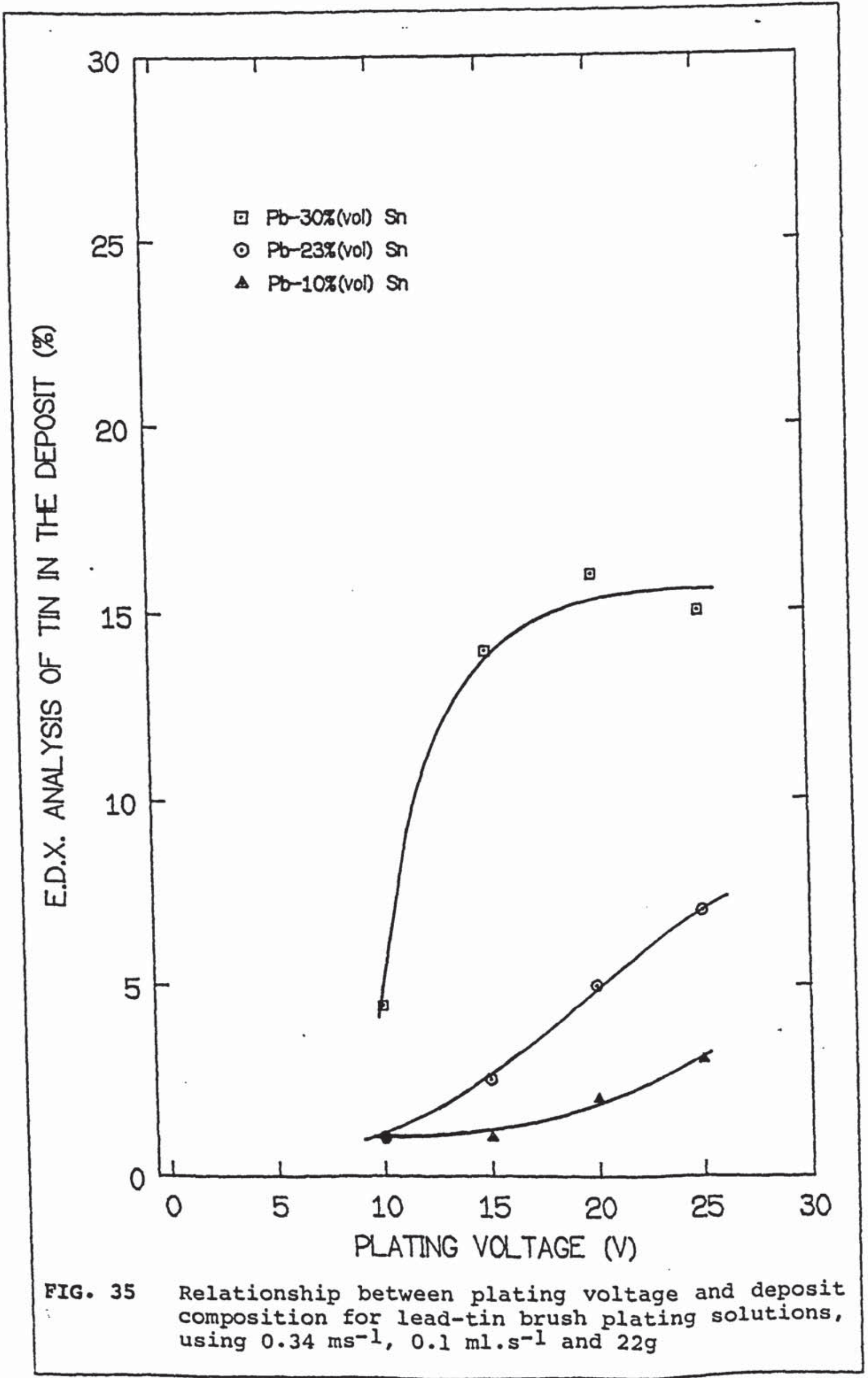


solutions which produce less than $5 \%$ tin in the deposit.

Calculations of the cathode current efficiencies for the lead and the tin single metal solutions were carried out, the results showed that lead had an efficiency of $75.6 \%$, while the efficiency for the tin solution was $81.4 \%$.

The commercially available lead-tin fluoborate solution was brush plated onto the ASI5 bearing shells at various plating voltages. The deposit was then analysed in the SEM and the results Fig. 36 , show that the deposit composition was far more consistant over a range of voltages than." deposits from the brush plating lead-tin solutions. However, there was practically no adhesion between the substrate and the coating for any of the brush pretreatment sequences. The solution had an efficiency of $63 \%$ at $5 \mathrm{~V}$.

11.2.1 Effect of Speed, Load and Solution Flow on Deposit Characteristics

A study of the effects of the various plating conditions, relative anode - cathode motion, anode load and solution. flow rate upon deposit characteristics was undertaken. Fig. 37 shows the effect of the plating variables on the deposit composition and efficiency for the lead-30\%/0 tin solution when using two different anode pad materials, nylon-polypropylene and 'Selvyt' cloth. The main points to note from the results are : 


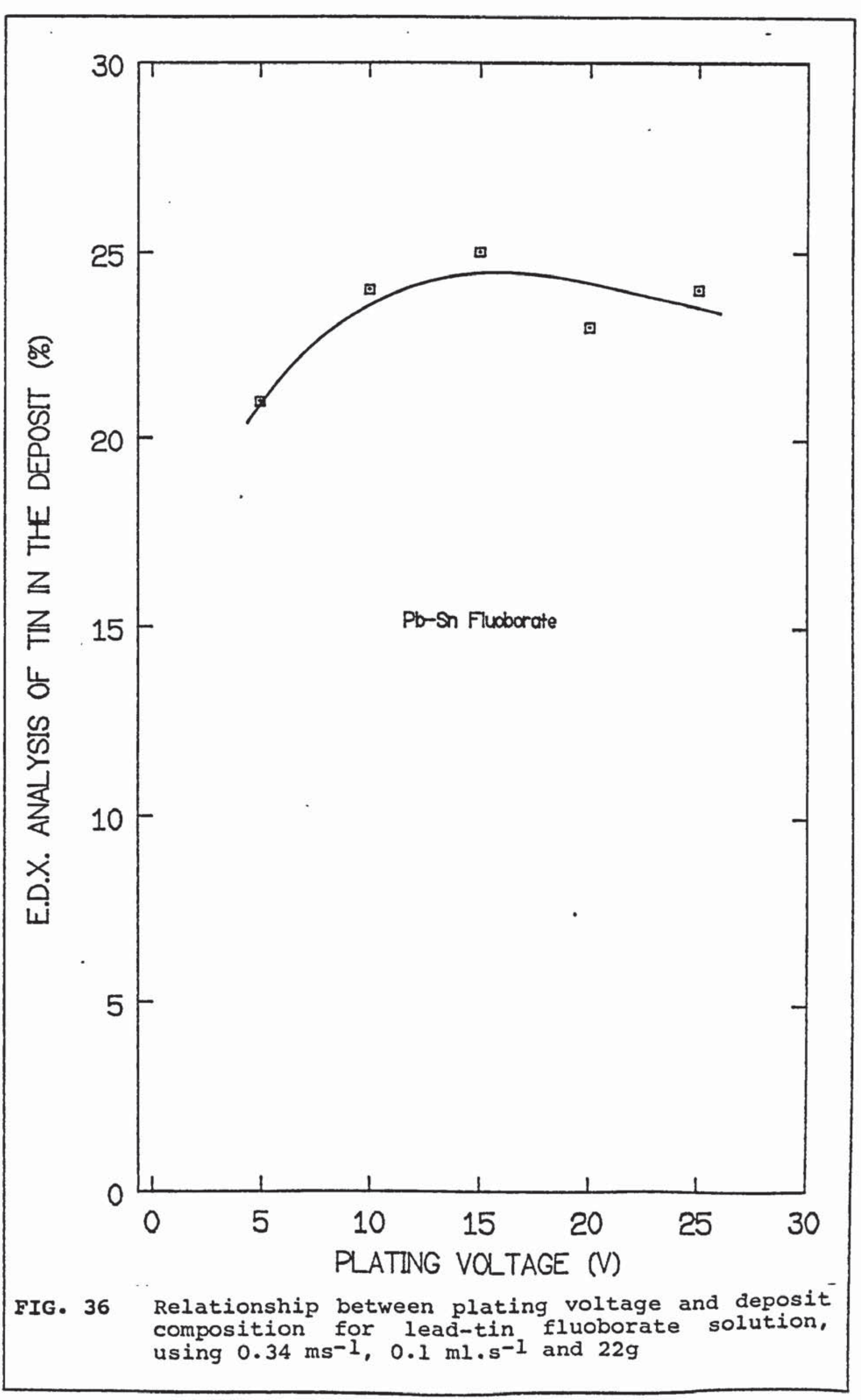




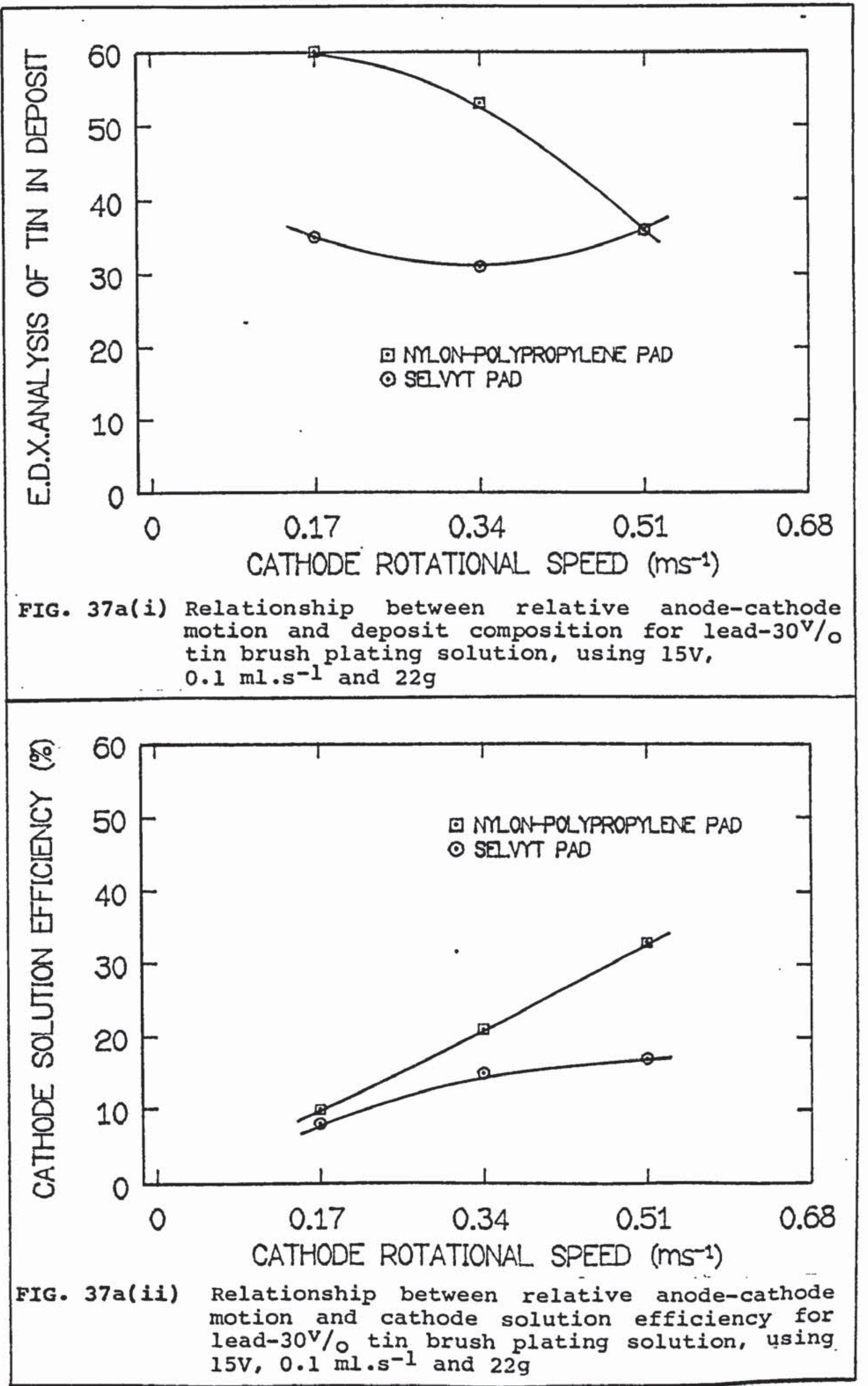




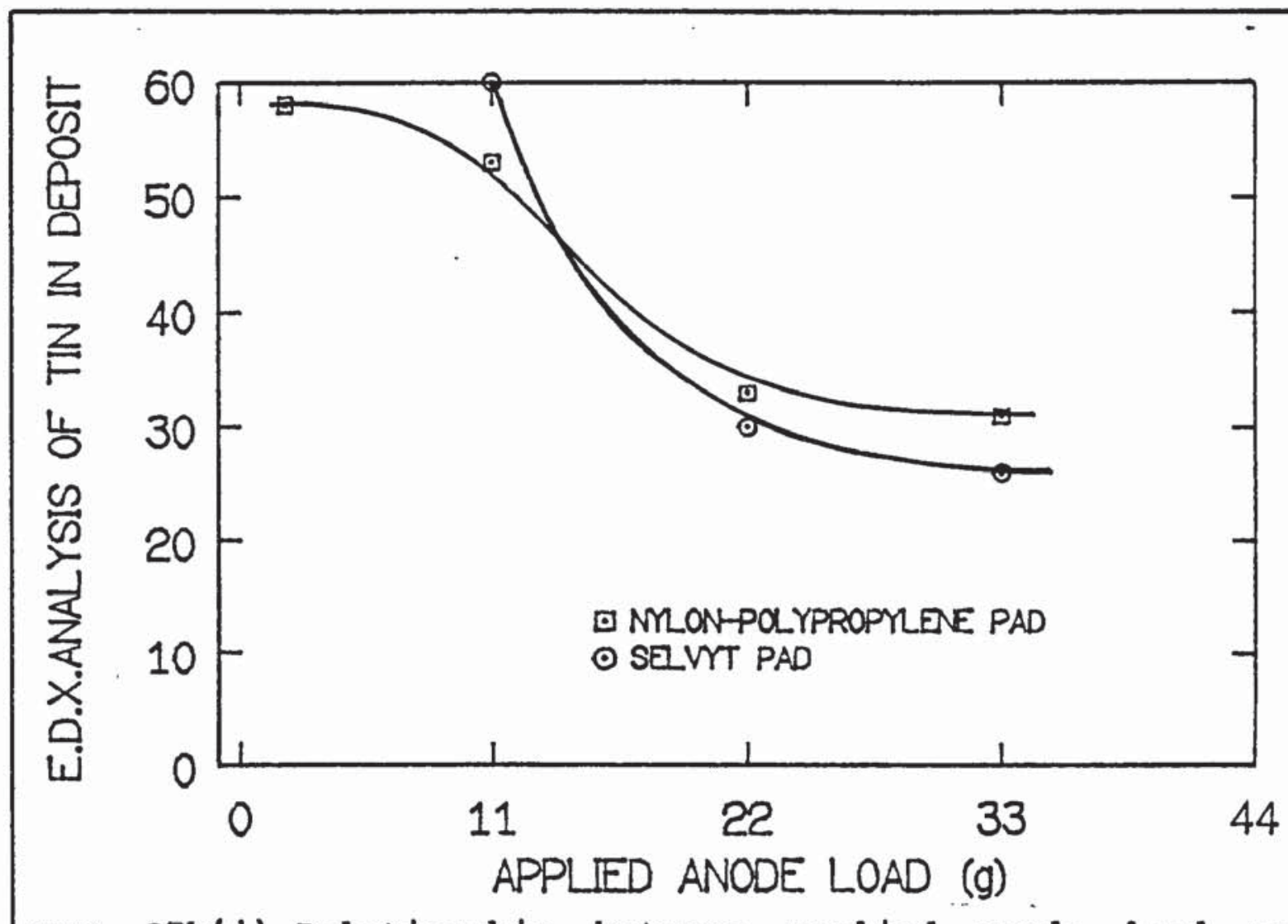

FIG. $37 b(i)$ Relationship between applied anode load and deposit composition for lead-30v/o tin brush plating solution, using $15 \mathrm{~V}, 0.34 \mathrm{~ms}^{-1}$ and $0.1 \mathrm{ml} \cdot \mathrm{s}^{-1}$

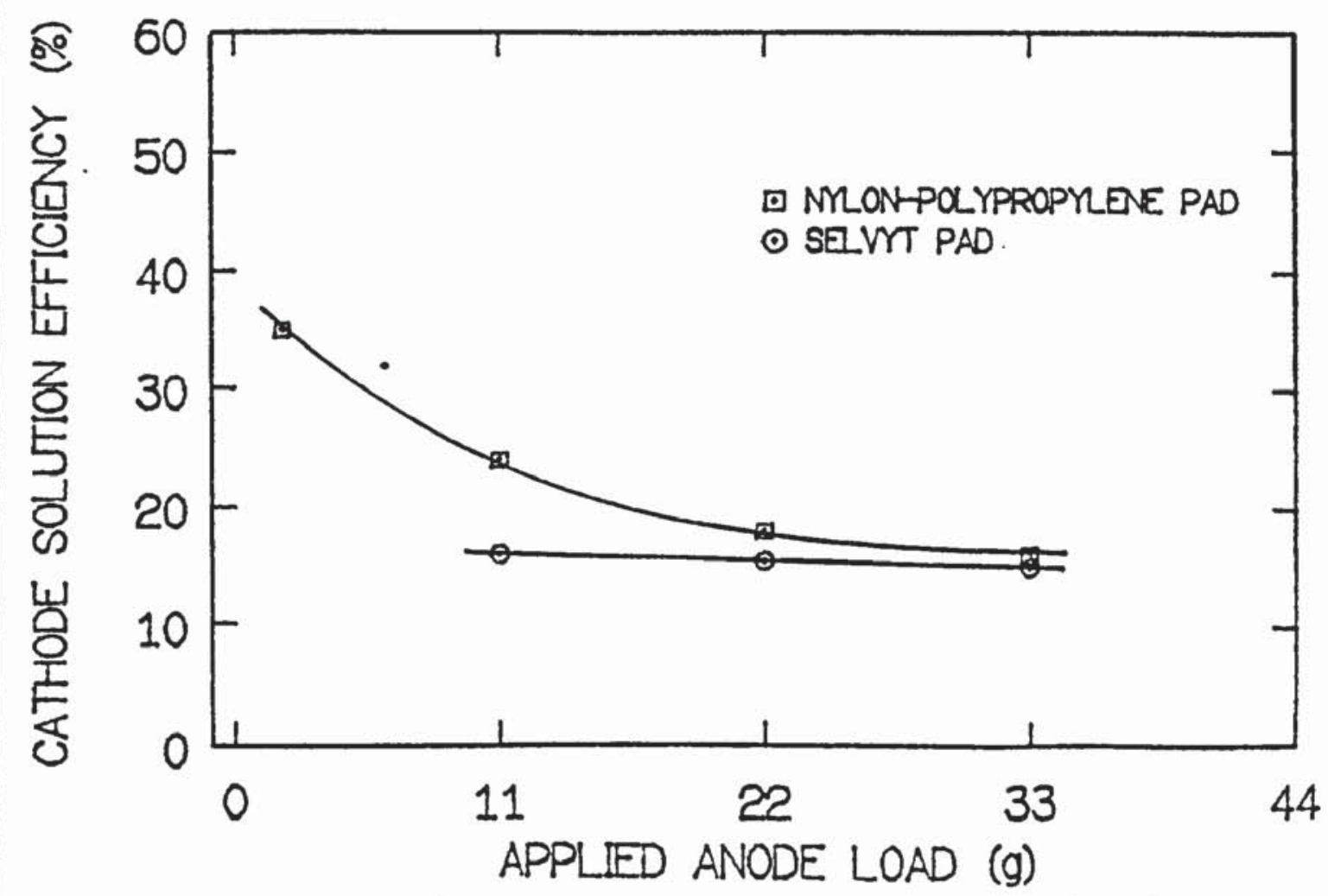

FIG. 37b(ii) Relationship between applied anode load and cathode solution efficiency for lead-30 $/ 0$ tin brush plating solution, using $15 \mathrm{~V}$, $0.34 \mathrm{~ms}^{-1}$ and $0.1 \mathrm{ml} . \mathrm{s}^{-1}$ 


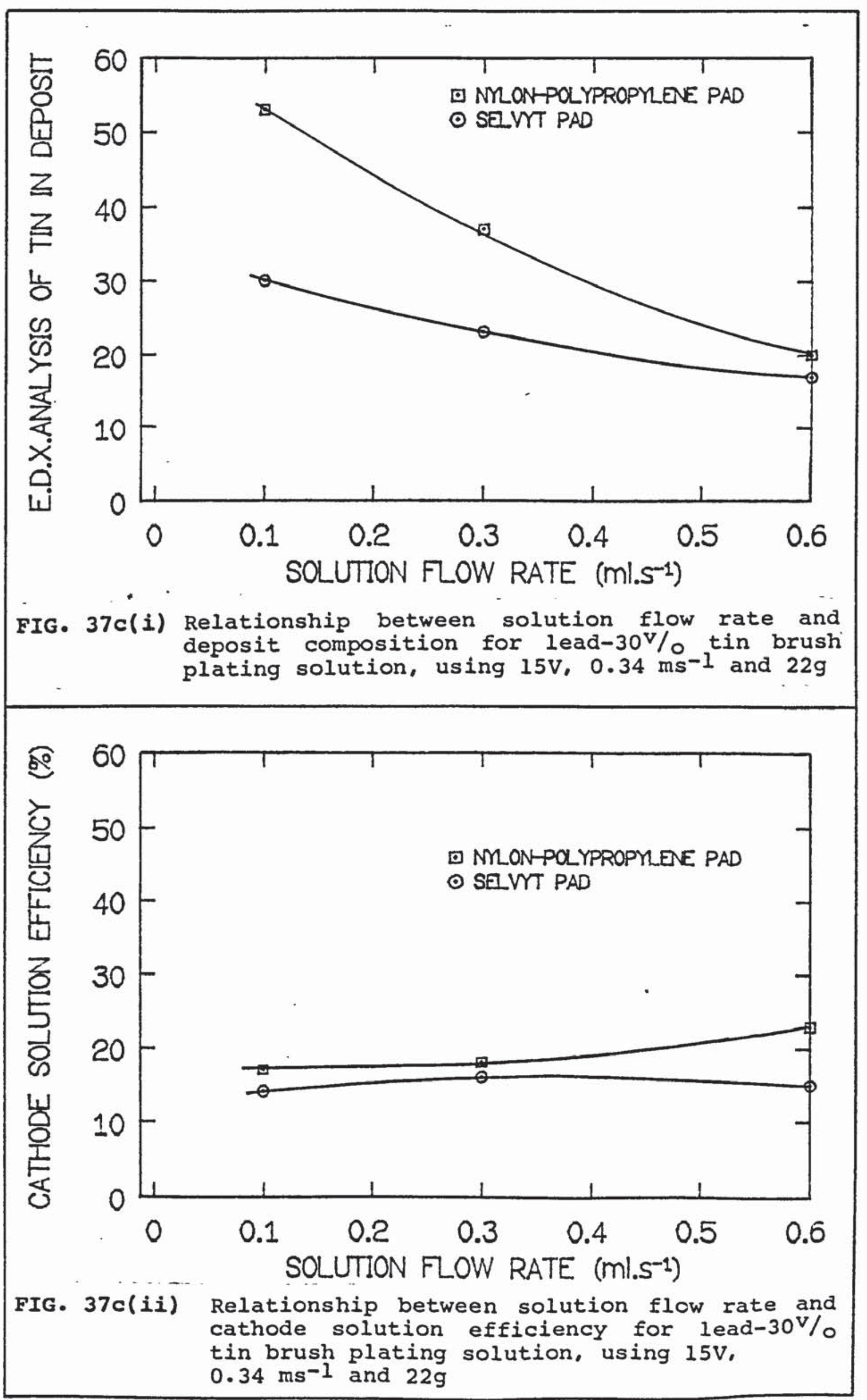


i) As the anode-cathode motion increases, the proportion of tin in the deposit decreases and the efficiency of the solution increases

ii) Increase in the solution flow rate causes the proportion of tin in the deposit to decrease and the efficiency to increase

iii) As the applied anode load is increased the proportion of $t$ in in the deposit decreases, the efficiency also decreases.

These trends are the same regardless of the anode pad material used. However, it has been found that in general the softer 'Selvyt' pad results in a lower amount of tin being incorporated in the deposit and lower efficiencies. This appears to contradict the overall result from Fig. 37 , where a lower proportion of tin results in relatively higher efficiencies. The efficiencies obtained here, are much lower than those for the commercial single metal solutions, previously mentioned, of over 708 .

It should be noted that the determination of deposit composition was carried out by using both the AAS and EDXA methods. The results were consistant and variation was approximately $0.2 \%$ 


\subsection{Tin-Cobalt Overlays}

Separate single metal brush plating solutions were obtained, mixed in varying proportions and brush plated onto a brass substrate. Deposition was carried out at $15 \mathrm{~V}$ for $0.1 \mathrm{Ah}$. The results can be seen in Fig. 38 and indicate a linear relationship between the proportion of cobalt in the solution and the amount of cobalt in the deposit. It can be assumed that the results deviate from this linear relationship after $75 \mathrm{v} / 0$ cobalt in the solution, as $100 \mathrm{~V} / 0$ cobalt will produce a $100 \%$ cobalt deposit.

The tin-cobalt deposit also varies with plating voltage. Fig. 39 shows how the two are related for the semiautomated brush plating operation when the following conditions are used, $0.2 \mathrm{Ah}, 75-25 \mathrm{~V} / \mathrm{O} \mathrm{Sn}-\mathrm{Co}$ solution, 0.34 $\mathrm{ms}^{-1}, 0.1 \mathrm{ml} . \mathrm{s}^{-1}$ solution flow and using 'Selvyt' as the pad material. The results indicate that an increase in the proportion of cobalt detected in the deposit is associated with increased plating voltage. Calculation of the efficiency of the tin and cobalt single metal electrolytes resulted in the tin having an efficiency of $81.4 \%$, while the cobalt was 70.48 efficient.

It is noticed during brush plating that when a hot stylus was placed into a beaker containing the tin-cobalt solution, subsequent precipitation occurred. However, 


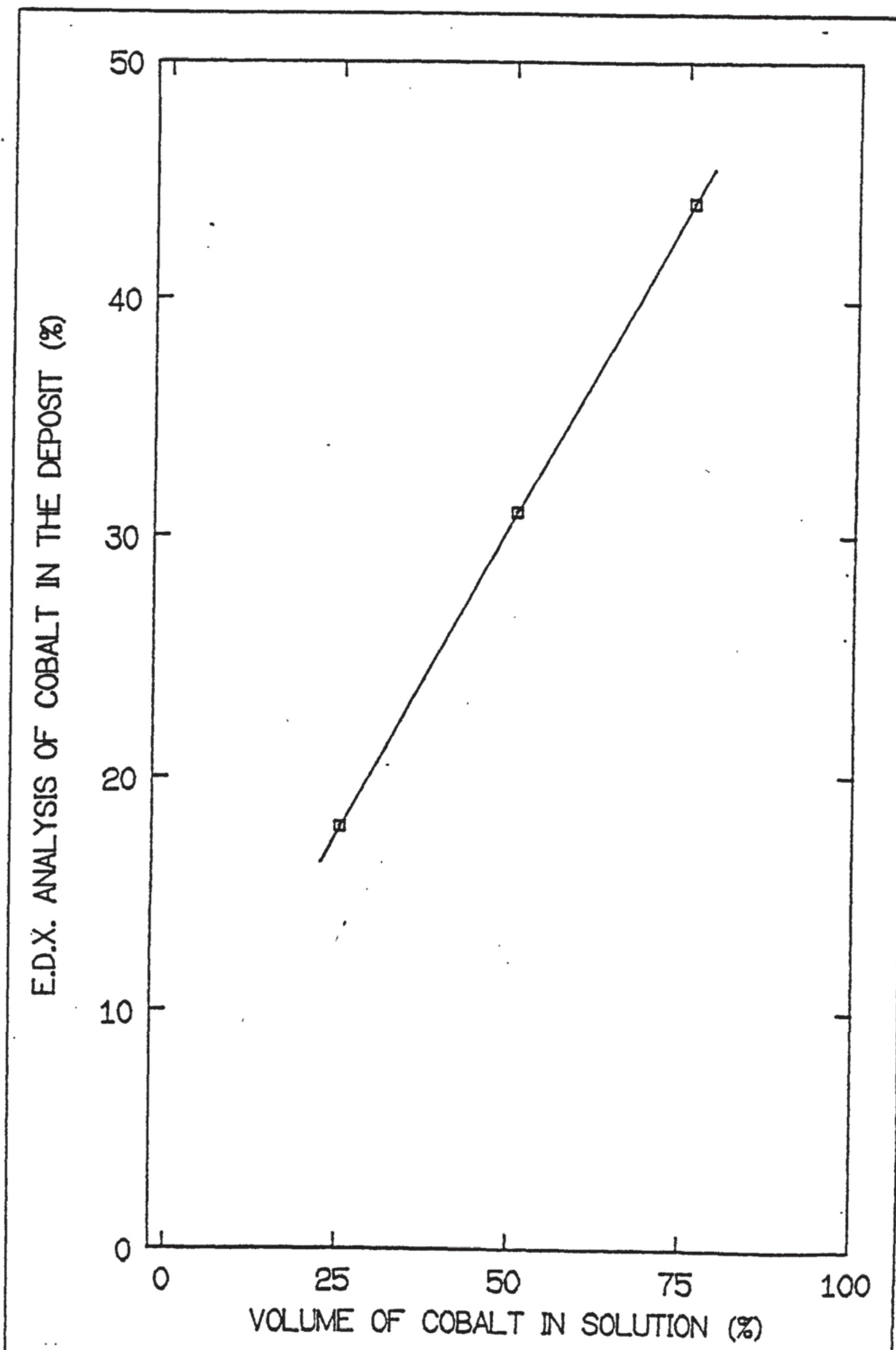

FIG. 38 Relationship between solution make-up and deposit composition for tin-cobalt brush plating solutions using $15 \mathrm{~V}, 0.34 \mathrm{~ms}^{-1} 0.1 \mathrm{ml}^{-1} \mathrm{~s}^{-1}$ and $22 \mathrm{~g}$ 


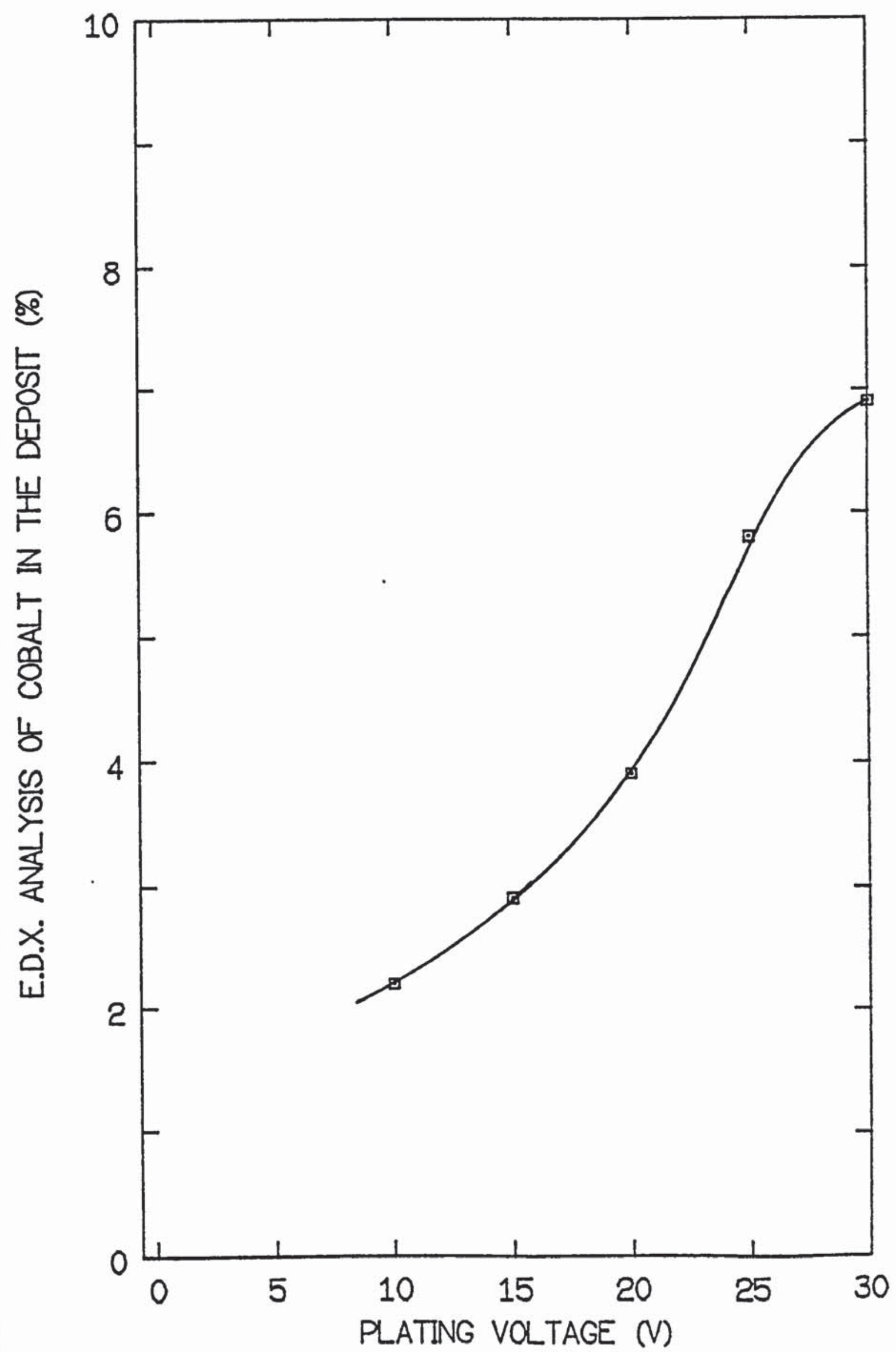

FIG. 39 Relationship between plating voltage and deposit composition for tin-25 $/ 0$ cobalt brush plating solution, using $0.34 \mathrm{~ms}^{-1}, 0.1 \mathrm{ml} \cdot \mathrm{s}^{-1}$ and $22 \mathrm{~g}$ 
coatings deposited from the solution containing the precipitate produced reasonable deposits, of similar composition to overlays produced prior to precipitation. Further investigation revealed that although noticed when a hot stylus was replaced into the solution, precipitation does occur in unused solution as well. The length of time taken to produce precipitation varies, depending on whether the solution is fresh or used, from approximately 1 hour for the used solution to 48 hours for the unused. Typical EDXA results are listed below.

New Solution

precipitate ( $\%$ )
Used Solution

Precipitate ( 8 ) si

$\mathbf{S}$

Cl

$\mathrm{Sn}$

Co

$$
0.17
$$$$
1.25
$$$$
0.75
$$$$
37.54
$$

60.29
0.20

0.10

0.68

30.66

68.36

The relationship between applied voltage and the amount of cobalt in the deposit for three of the Aston solutions has also been determined, Fig. 40. The results show that I solutions 1 and 2 are similar, but solution 4 produces less cobalt in the deposit for the same plating voltages. This is consistant with the solution make-up. The tin : cobalt ratio for solutions 1 and 2 is the same, but solution 4 contains relatively more tin than cobalt. 


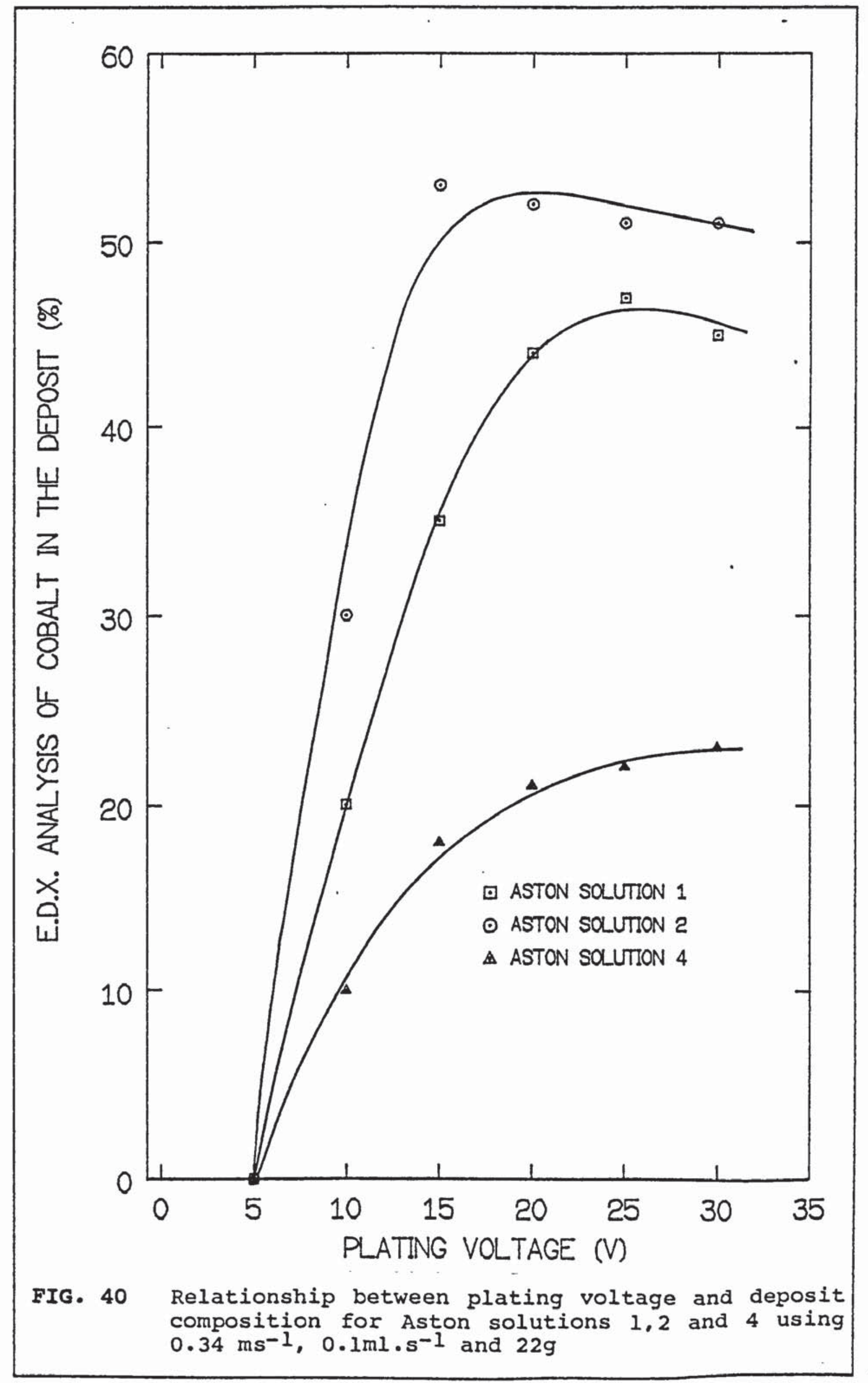


The choice of pad material affects the morphology of the overlay. This can be seen with reference to Fig. 41, where the nylon-polypropylene deposit is a much finer one compared to the deposit produced using the much softer pad.

The selection of pad material also has an effect on the alloy deposit composition, Fig. 42. under the same conditions the softer less abrasive pad material produces less cobalt in the deposit than the nylon-polypropylene pad. The deposit composition is also affected by the load applied by anode and the degree to, which solution replenishment occurs however; these effects will be reported later.

A selection of tin-25V/o cobalt overlay plated bearings were immersed in Medicinal White Oil, at $120^{\circ} \mathrm{C}$ for 24 hours. After cleaning, the bearings were scribed with a series of cross-hatched lines, attempts were then made to remove the overlay by application of adhesive tape. It was shown in all cases, that bearings plated using the zinc alloy pretreatment sequences $A l(G)$ and $C l(G)$, failed this adhesion test, the overlay being completely removed from the AS15 substrate. Bearings plated using the Direct sequence $E$, did not fail, as no overlay was removed. 


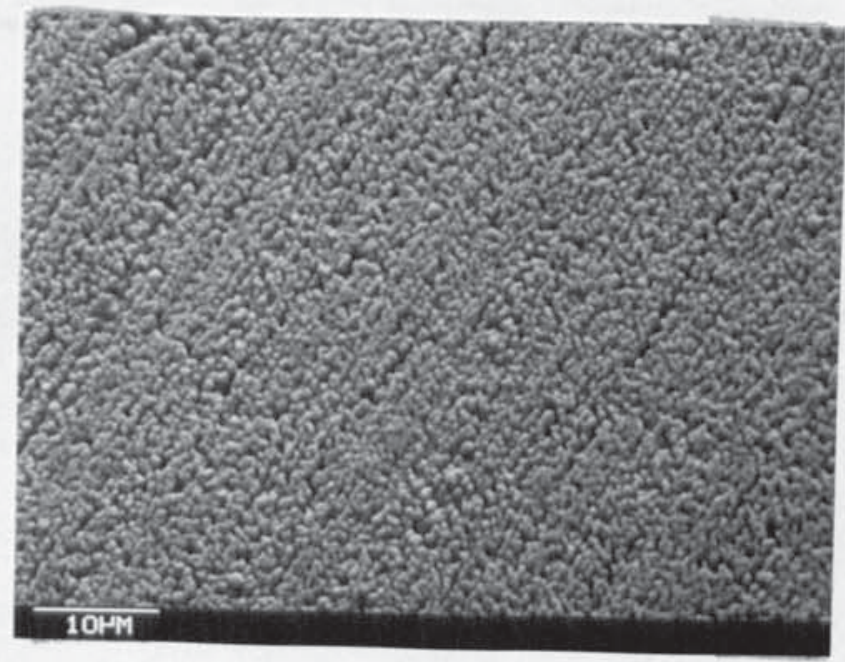

(a)

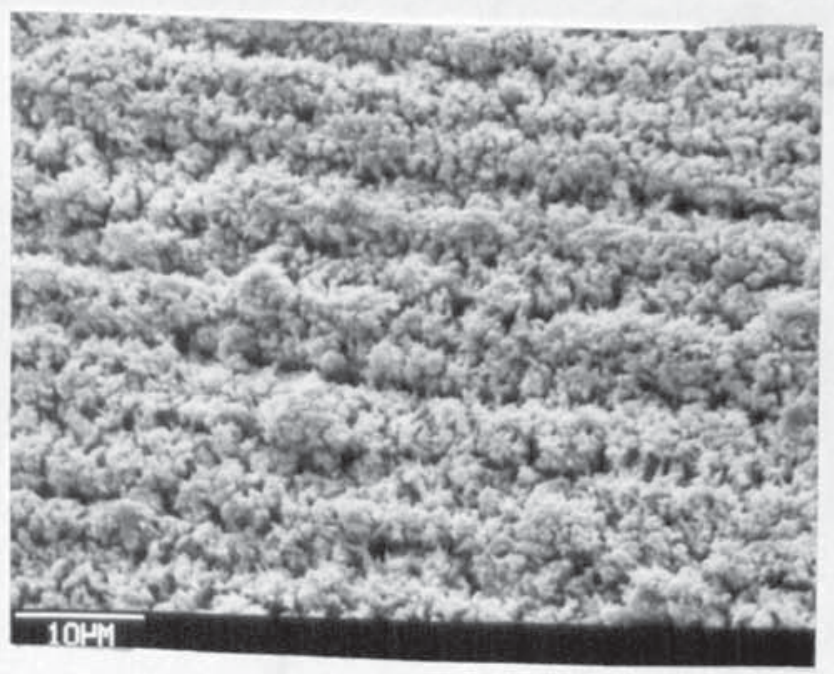

(b)

FIG. 41 Scanning electron micrograph showing the effect of the pad material on overlay morphology for

(a) nylon-polypropylene pad and (b) 'Selvyt' pad 


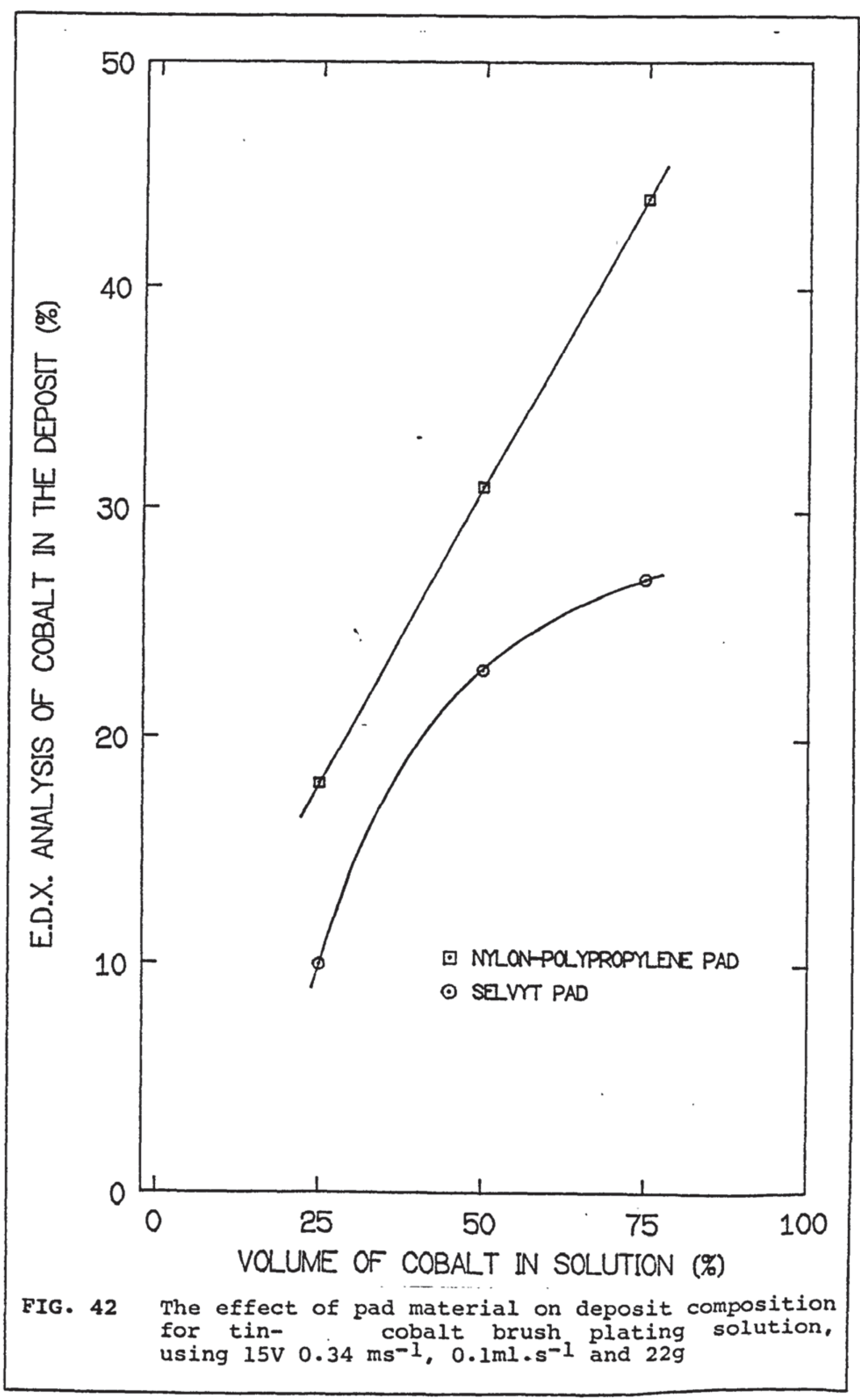




\section{Characteristics}

A study of the effects of these plating variables upon the deposit produced by the commercial $75 \mathrm{~V} / 025 \mathrm{~V} / 0$ tin-cobalt solution, Aston solution 3 and the effect of the pad material was carried out and the results shown in Figs. 43 and 44 .

The results show the same trends as those observed with the lead-tin solution 11.2.1, with an increase in anode-cathode motion, anode load and solution flow, all leading to a decrease in the proportion of the least noble metal in the deposit, in this case cobalt.

It should be noted that the analysis of deposit composition was determined by the EDXA attachment on the SEM, on the surface of the sample. This method is not an accurate indication of the deposit composition if there is any inhomogeneitywithin the coating, but will only give the average deposit composition over the depth of penetration of the electron beam ( $<2 \mu \mathrm{m})$. If the deposit composition changes through the thickness of the coating, it is obvious that the efficiency of the solution will also change. Therefore, the efficiencies quoted here are the calculated efficiencies using the total coating weight with the final deposit composition after 0.15 Ah plating. Calculations of the solution efficiency were carried out on thicker 


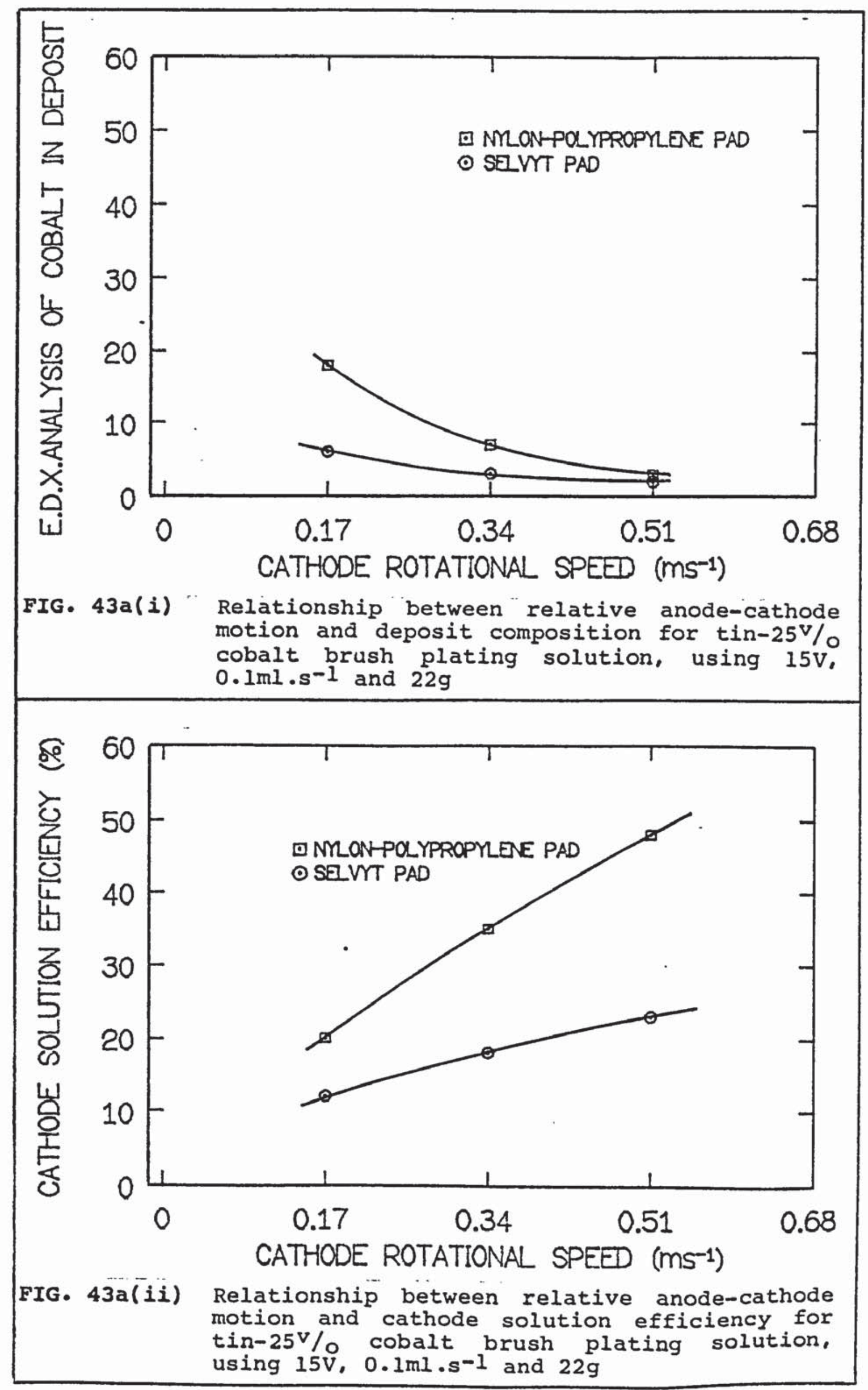




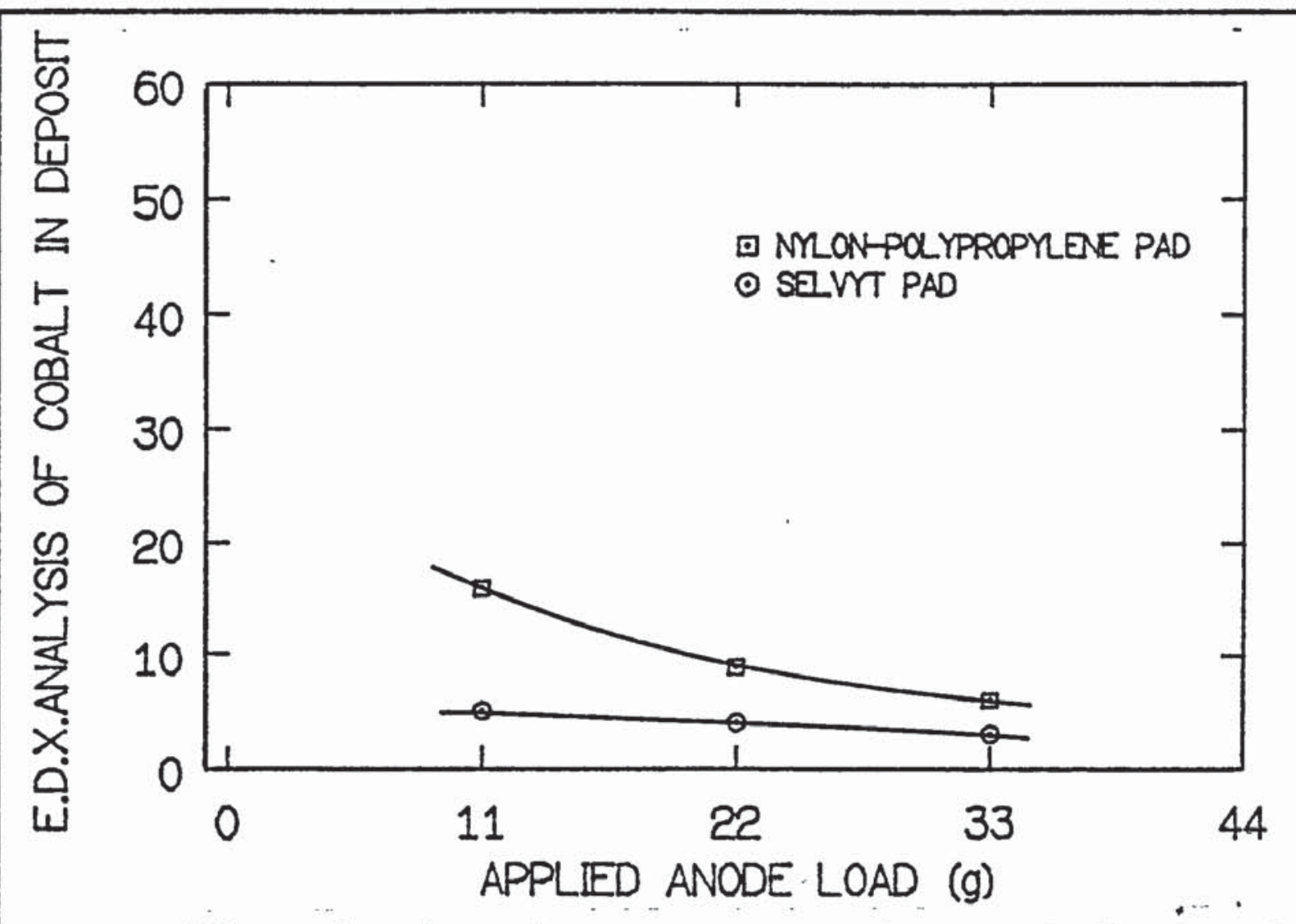

FIG. 43b(i) Relationship between applied anode load and deposit composition for tin-25 $/ 0$ cobalt brush plating solution, using $15 \mathrm{~V} 0.34 \mathrm{~ms}^{-1}$, $0.1 \mathrm{ml} \cdot \mathrm{s}^{-1}$

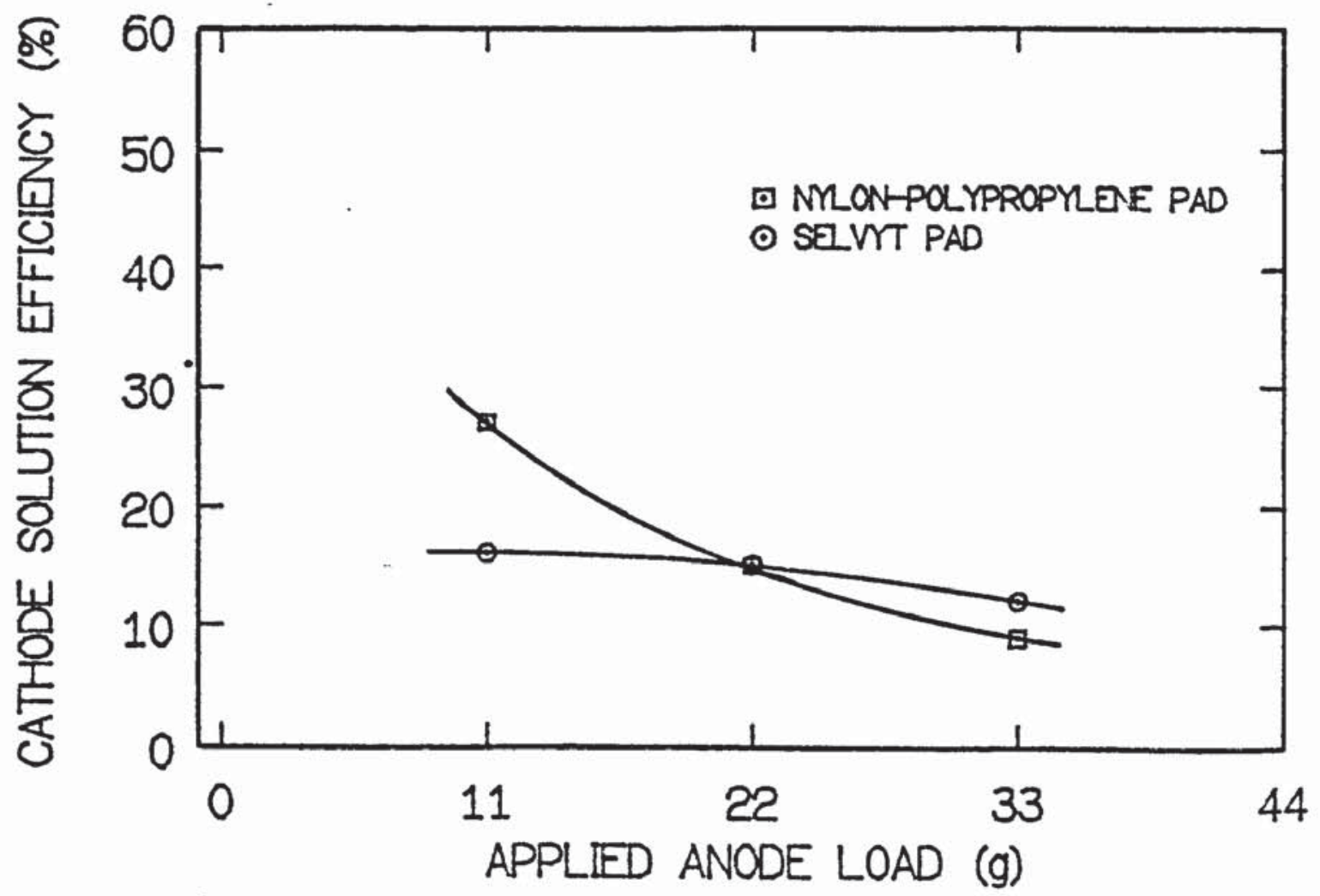

FIG. 43b(ii) Relationship between applied anode load and cathode solution efficiency for tin-25\% cobalt brush plating solution, using $15 \mathrm{~V}$ $0.34 \mathrm{~ms}^{-1}$ and $0.1 \mathrm{ml}^{-1} \mathrm{~s}^{-1}$ 


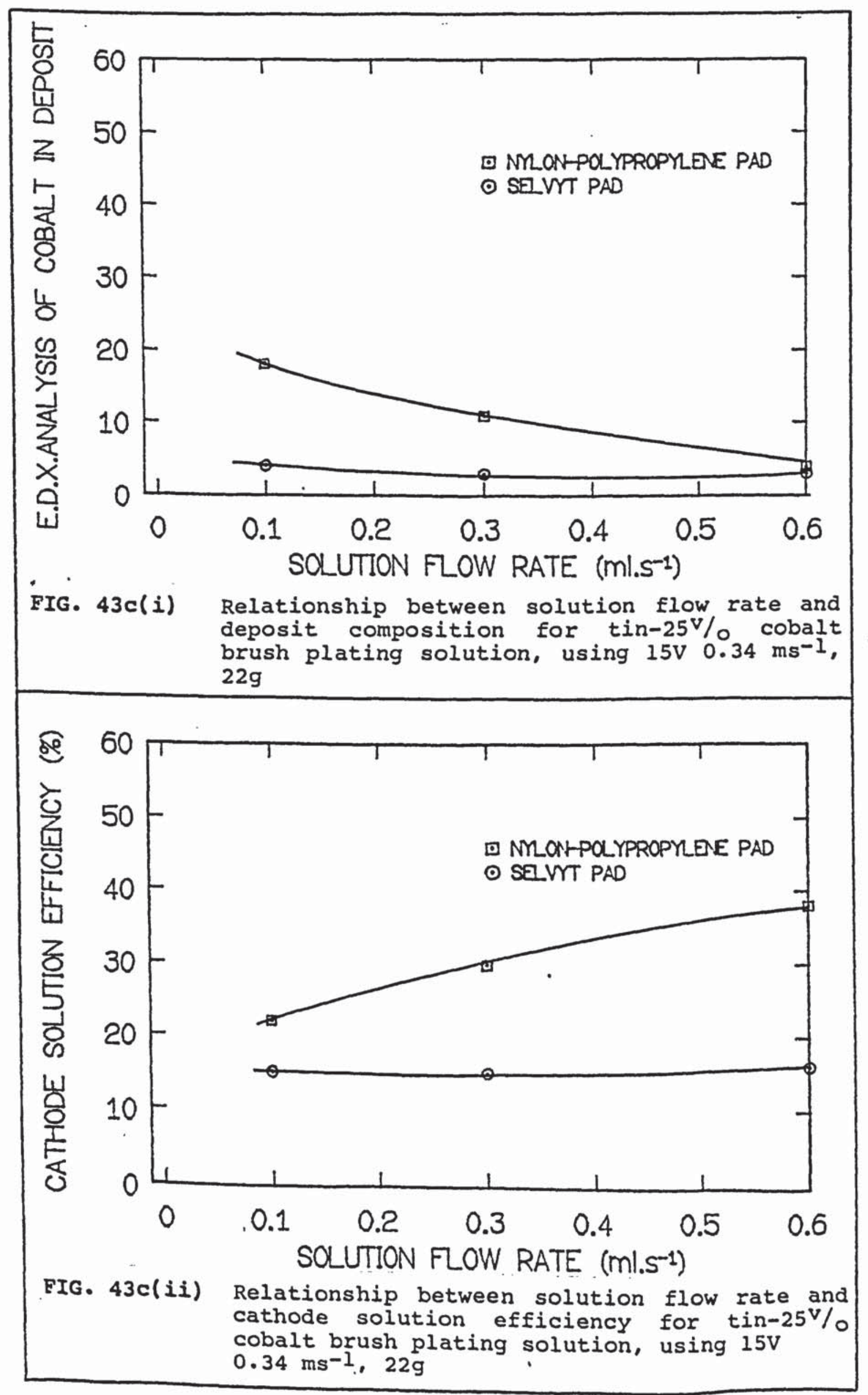




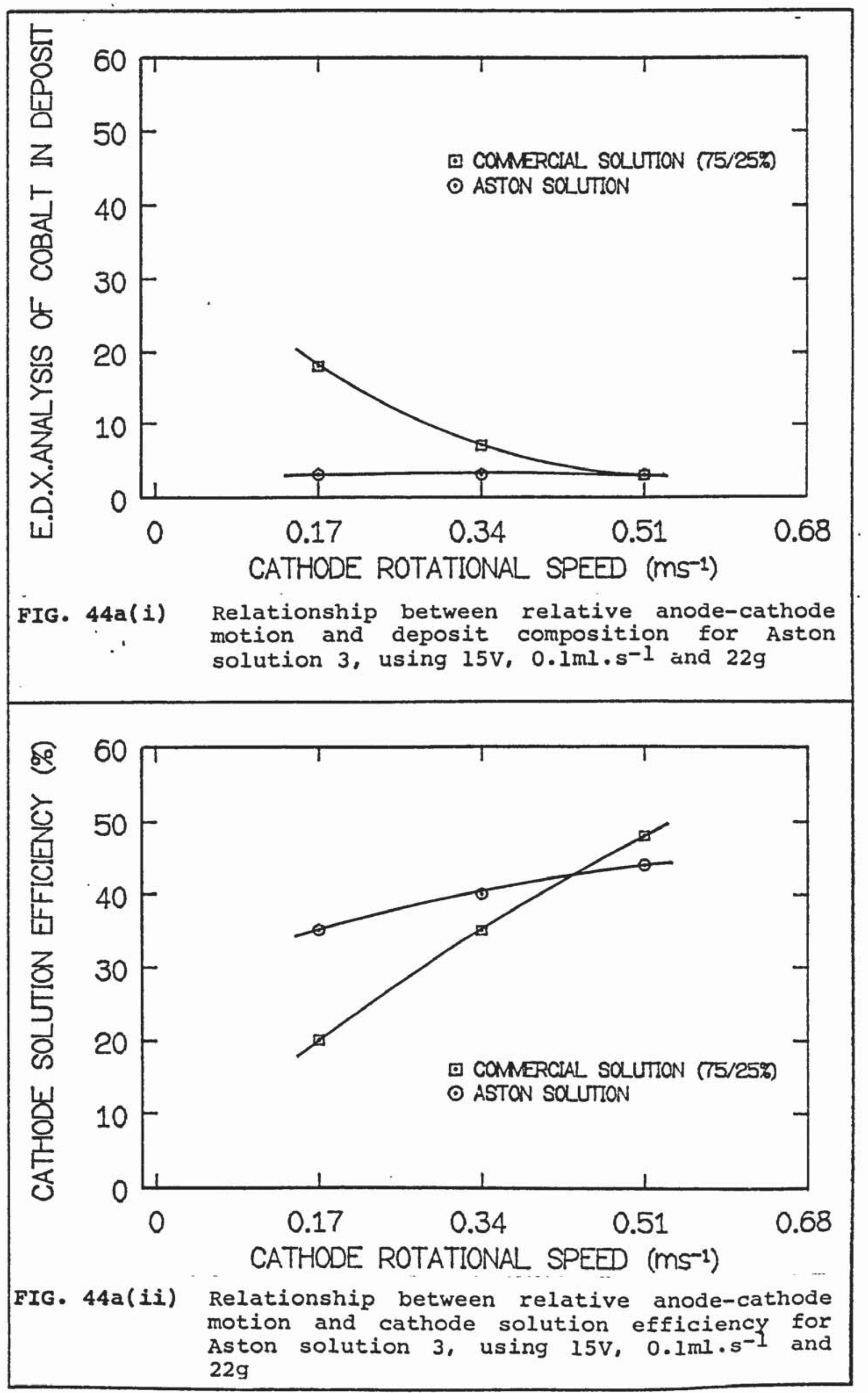




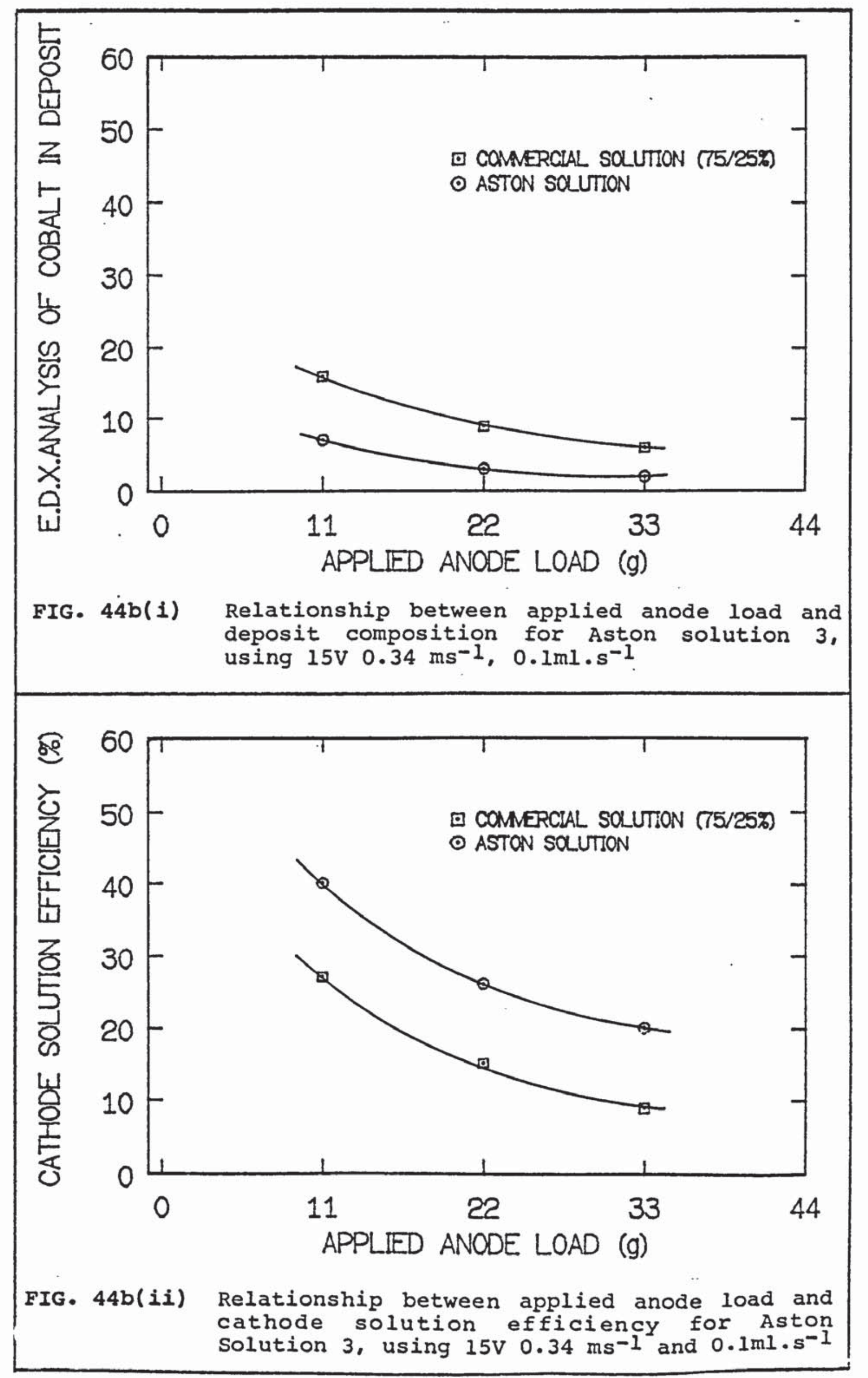




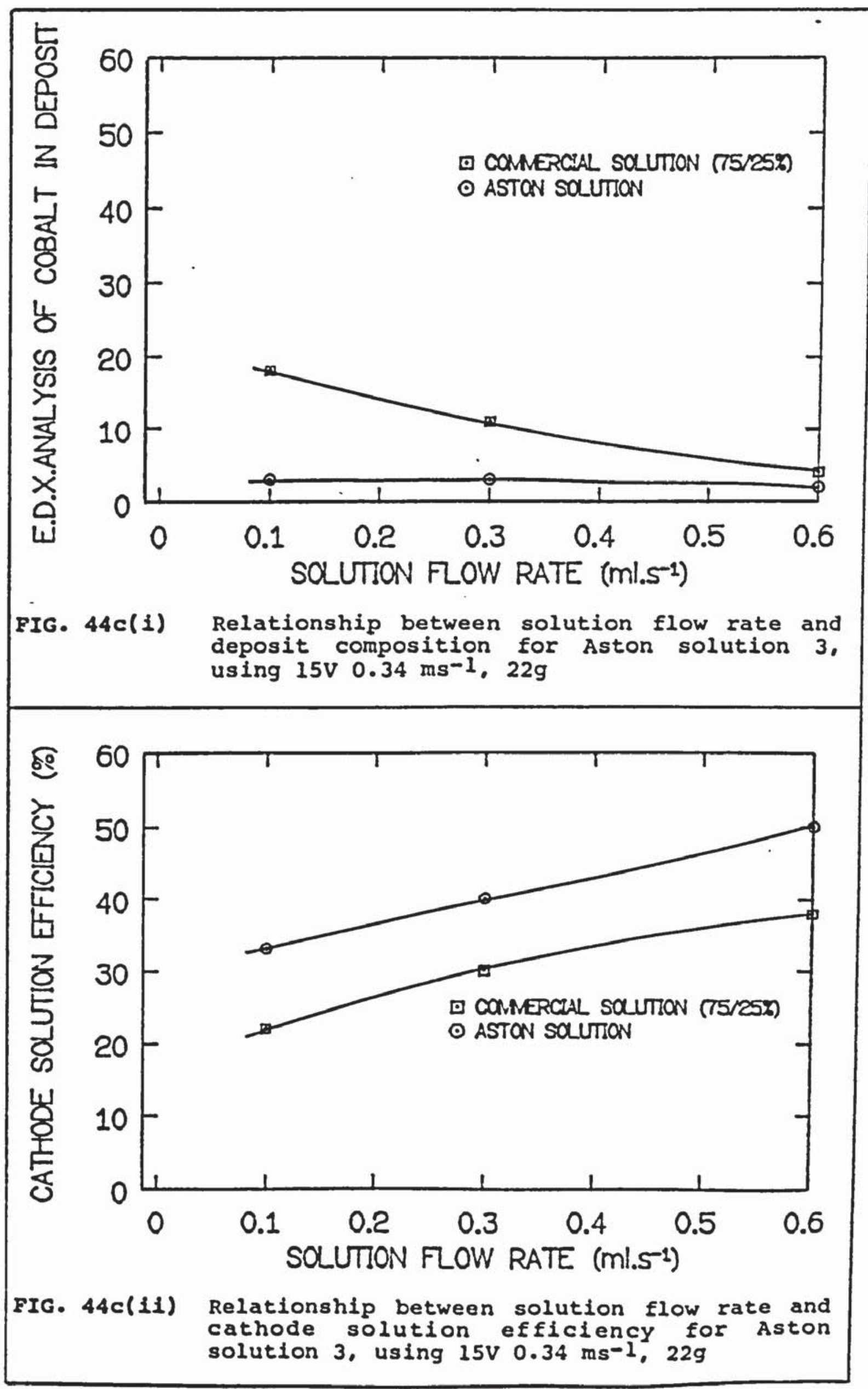


overlays after 0.6 Ah plating. The results for the efficiencies were higher, as the amount of cobalt detected by the EDXA was very low (refer to section 11.3.2). Although the actual values for efficiency differ, the trends evident in the results given here are the same.

When multiple regression analysis is carried out on the above results, Figs. 43 and 44 , including the results of similar experiments using lead-tin alloys, Fig. 37, the following equations relating the dependent and independent variables can be produced.

(a) Tin-25\% cobalt using a nylon-polypropylene pad.

$$
Y=44.12 X_{1}-0.46 X_{2}-12.55 x_{3}+37.48
$$

Correlation coefficient 0.8511

(b) Tin-25V/o cobalt using a 'selvyt' pad.

$$
Y=-11.77 x_{1}-9.09 x_{2}-1.98 x_{3}+10.02
$$

Correlation coefficient 0.9104

(c) Aston Solution 3

$$
Y=4.9510^{-5} x_{1}-0.23 x_{2}-2.78 x_{3}+8.72
$$

Correlation coefficient 0.9033 
(di) Lead-30V/o tin using a nylon-polypropylene pad.

$$
Y=-70.59 x_{1}-0.77 x_{2}-49.37 x_{3}+91.24
$$

Correlation coefficient 0.8961

(dii) $z=67.65 x_{1}-0.60 x_{2}+3.71 x_{3}+9.94$

Correlation coefficient 0.9519

(ei) Lead-30\%/。 tin using a 'selvyt' pad.

$$
y=2.94 x_{1}-1.55 x_{2}-39.48 x_{3}+72.02
$$

Correlation coefficient 0.9029

(eii) $z=.26 .47 x_{1}-4.5410^{-2} x_{2}+5.59 x_{3}+5.84$

Correlation coefficient 0.8978

where $Y$ is the percentage of alloying element in the deposit.

$\mathrm{z}$ is the cathode solution efficiency

$\mathrm{X}_{1}$ is the cathode rotational speed in $\mathrm{ms}^{-1}$.

$\mathrm{X}_{2}$ is the applied anode load in $\mathrm{g}$. 
$\mathrm{X}_{3}$ is the solution flow rate in $\mathrm{mls}^{-1}$.

The use of 9 data points and 3 independent variables produces the following correlation coefficients for various levels of significance.

$\begin{array}{ll}958 & 0.836 \\ 998 & 0.917\end{array}$

It can be seen that in all cases, the correlation of the derived equations have a significance greater than 958 and for (dii) the correlation is greater than 998 significant.

If consistant values for the independent variables $\left(x_{1} 0.34\right.$ $\mathrm{ms}^{-1}, \mathrm{x}_{2} 22 \mathrm{~g}, \mathrm{x}_{3} 0.1 \mathrm{ml}^{-1} \mathrm{~s}^{-1}$ ) are introduced into the above equations, the relative significance of each of the independent variables, upon either the deposit composition or the cathode solution efficiency, can be examined.

From these results, it is clear that for the majority of equations $(a, b, d i, d i i, e i i), x_{1}$, cathode rotation speed is the most significant independent variable and $x_{3}$, solution flow rate is the least significant. Only in the equation for Aston Solution 3, can any single independent variable $\left(x_{1}\right)$, be considered to be insignificant, with regard to predicting deposit compositions. 
It should be noted that for the tin-cobalt solutions, equations predicting cathode solution efficiency had been omitted, for the reason given above.

\subsubsection{Microstructure of Tin-Cobalt overlays}

Conventional optical microscopy of the tin-cobalt overlays indicated the presence of two distinct phases. Consequently an attempt was made to determine the composition of the 'light blue' phase, by using two techniques EDXA on the SEM and $\mathrm{x}$-ray diffraction. It was also quite obvious that the proportions and distributions of these two phases varied from sample to sample, depending upon the brush plating conditions and technniques used.

Attempts were made to analyse the 'light blue' phase using the EDXA attachment however, the two phases cannot be distinguished in the SEM consequently, accurate analysis by this technique was not possible. However, a position where the phase occurred was found optically, the same position was then found in the SEM. By carrying out a series of 'spot analysis' using the quantitative analysis program, the change in composition over an area was determined. Results indicate that the phase is cobalt rich, over $50 \%$ having been detected in one area. It was also noted that in the majority of overlays, the proportion of cobalt detected, decreased as the area of analysis was moved away from the substrate-coating interface and in some cases to 
practically zero at the surface. The results of this analytical method are shown in Figs. 45-47 for the majority of the fatigue tested bearings (refer to Chapter 13). Analysis was also carried out with the $75^{\mathrm{V}} / 0^{-25 \mathrm{~V} / 0}$ tincobalt brush plating solution plated at different voltages, i.e. different current densities and by increasing the temperature of the initial plating solution and anode to approximately $70^{\circ} \mathrm{C}$. During brush plating, the electrolyte often approaches its boiling point and temperature can fluctuate quite markedly however, it was postulated that by having an initially 'hot' system, the distribution of the cobalt would change, as there would not be a warming-up period. The reason for changing the plating voltage is quite obvious. The effects of these changes can be seen in Fig. 48. The plating voltage (current density) has a marked influence on the deposit composition. At lower voltages (low current densities): much less cobalt is found to be present in the deposit than at higher voltages (high current densities). The effect of starting the plating operation with an initially 'hot system' appears to 'flatten out' the decrease in cobalt found in the deposit, from a situation where the initial system is cold.

The observations from the optical micrographs and the EDXA analysis are confirmed by cobalt elemental line concentration profiles of the cross-sections. The point at which the 'light blue' phase appears, corresponds to the peaks of the concentration profiles. A selection of the 


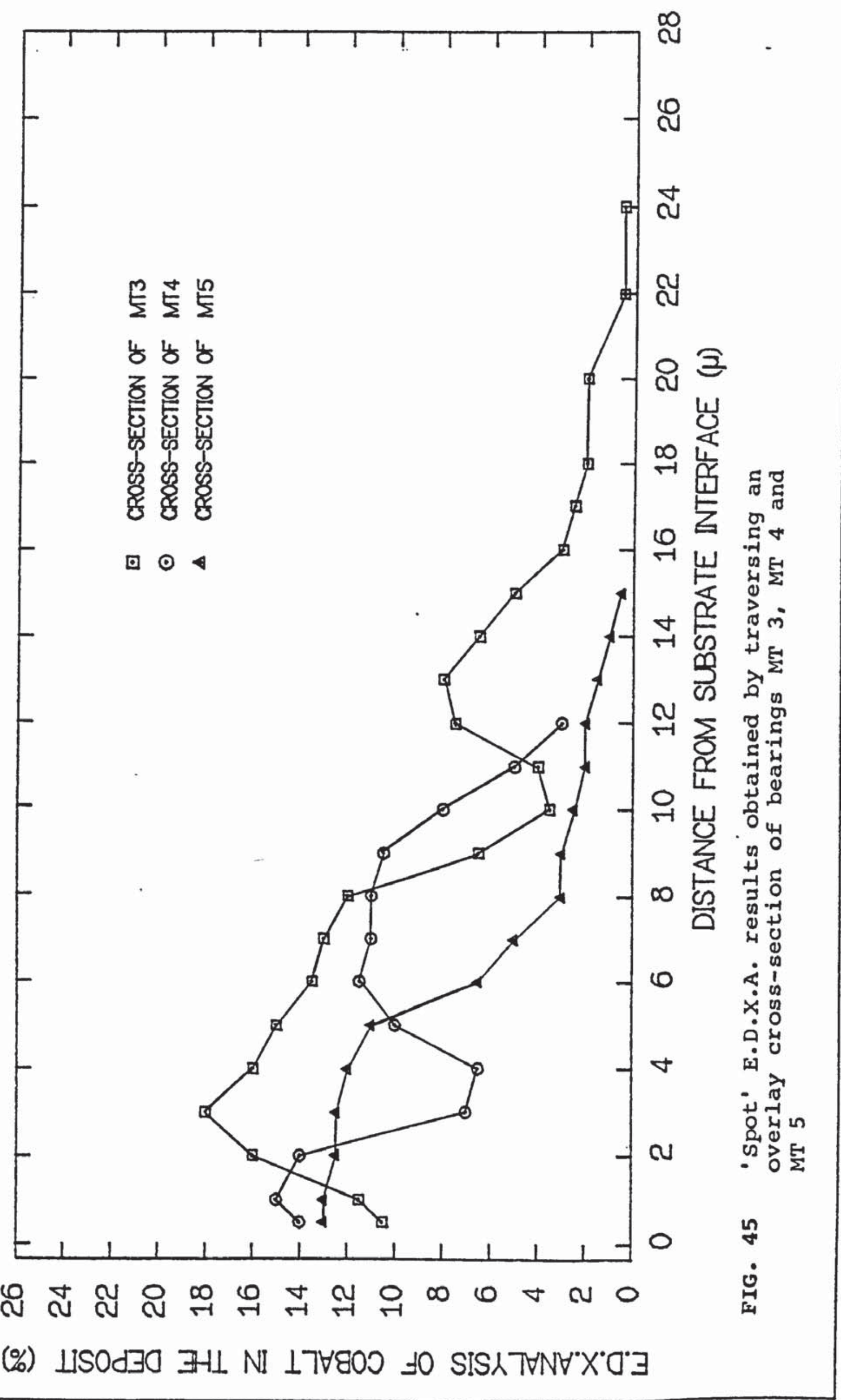




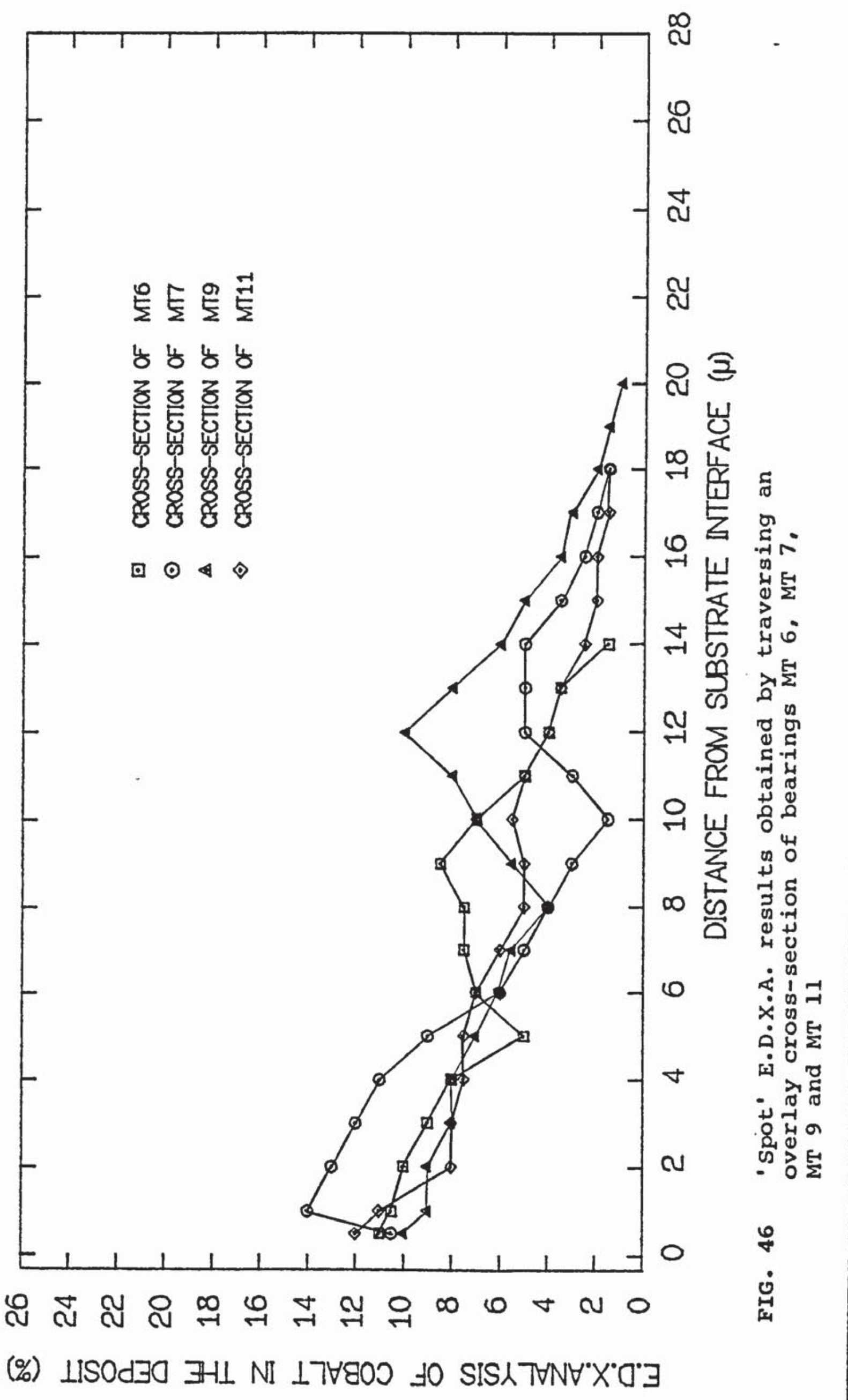




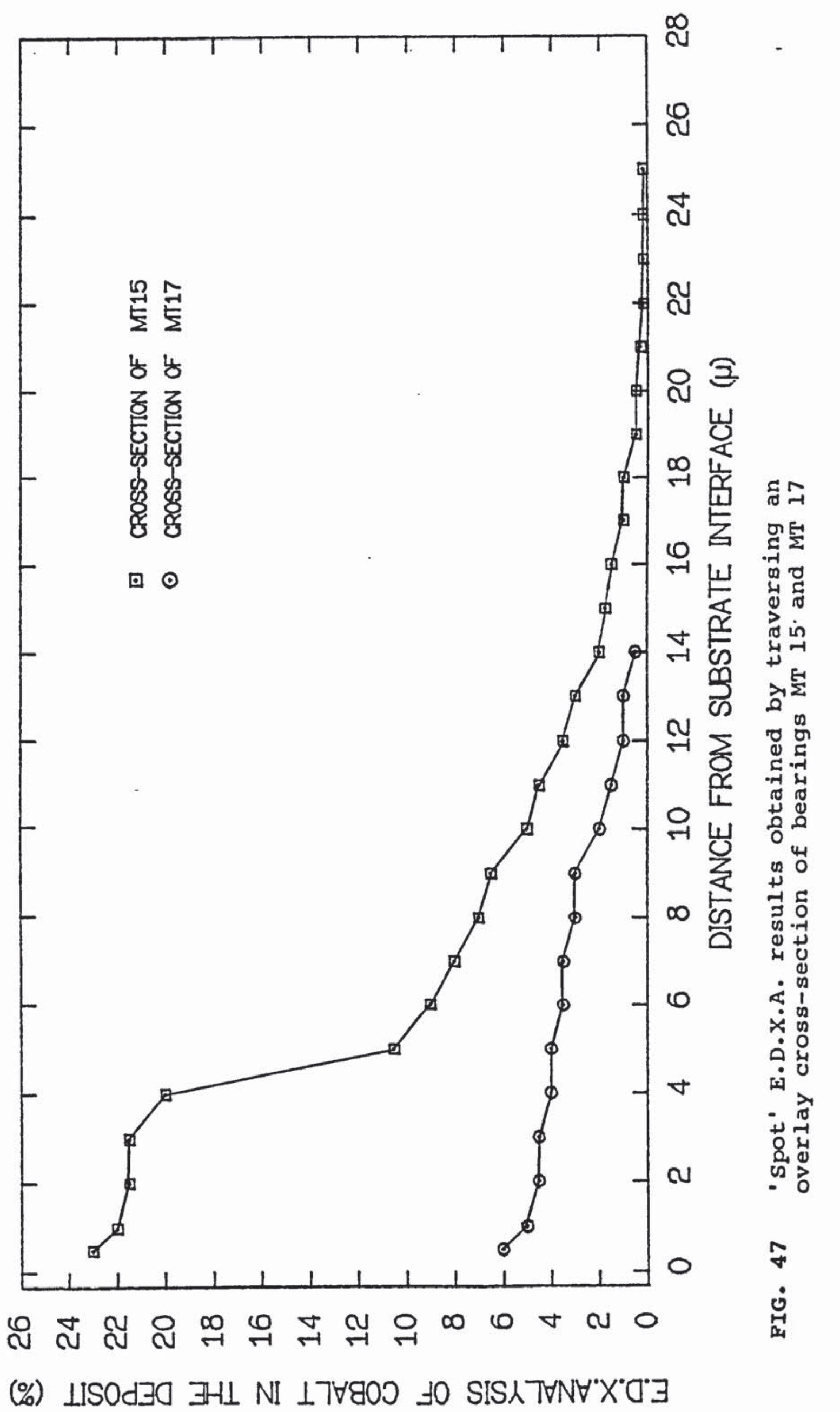




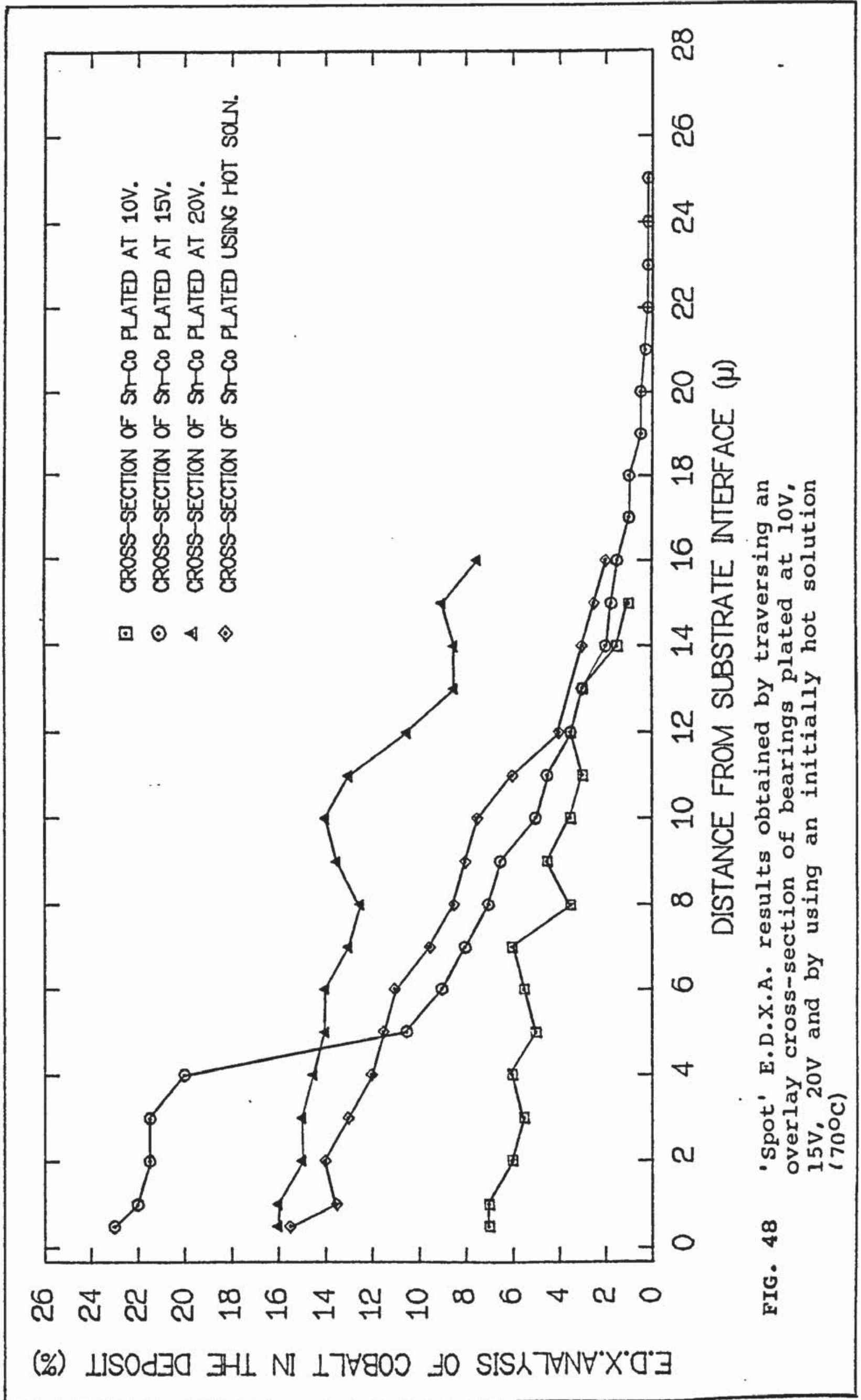


various phase distributions together with the line concentration profiles can be seen in Figs. 49-52.

A tin-cobalt plated bearing was placed in a heat-treatment furnace at $180^{\circ} \mathrm{C}$ for up to 100 hours. Periodically the bearing was removed, a section taken and then the bearing replaced. A cobalt line concentration profile was then produced. It appears from Fig. 53 that the effect of the 100 hour heat-treatment was to allow the cobalt to diffuse evenly throughout the overlay.

$\mathrm{X}$-ray diffraction of the various overlays has been carried out. The results indicate the presence of tin and a tincobalt intermetallic phase. Accurate indentification of the phases present has proved to be difficult, due to the fact that the possible phases involved $S n, \operatorname{co}, \cos n, \operatorname{CoSn} 2$ and $\mathrm{Co}_{3} \mathrm{Sn}_{2}$ all have similar 'd spacings'. However, the results appear to indicate the presence, in most of the tin-cobalt overlays examined, of $\mathrm{Sn}$ and $\mathrm{Co}_{3} \mathrm{Sn}_{2}$ (60 at $8,42.4$ wt $\mathrm{Co}$ ). Some overlays also produce peaks that correspond to the Cosn phase, although too few of these peaks are evident to enable positive identification to be made. Typical 'd spacings' together with the theoretical 'd spacings', for the phases involved, taken from the 'ASTM Powder Diffraction File' are presented in Table 6 . 


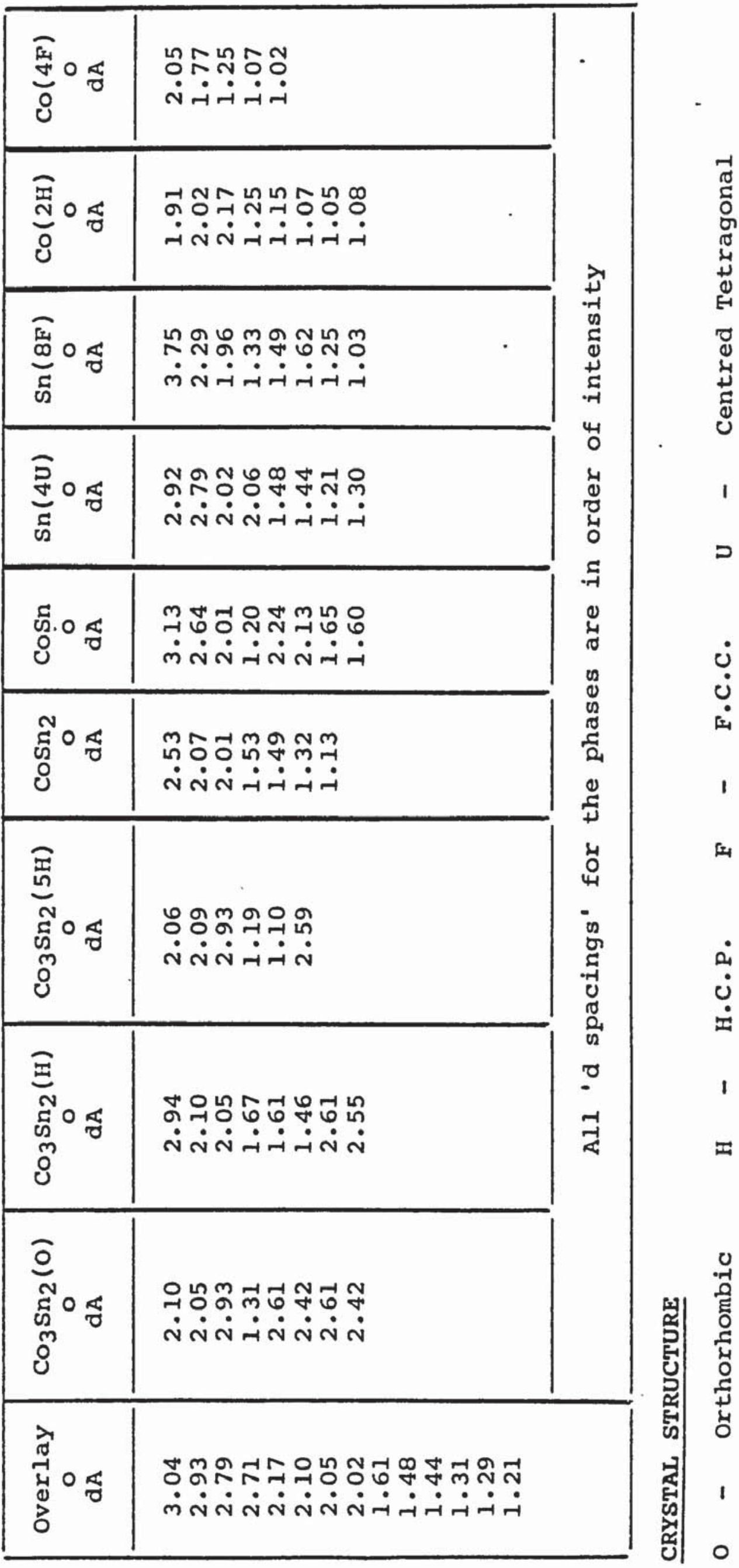



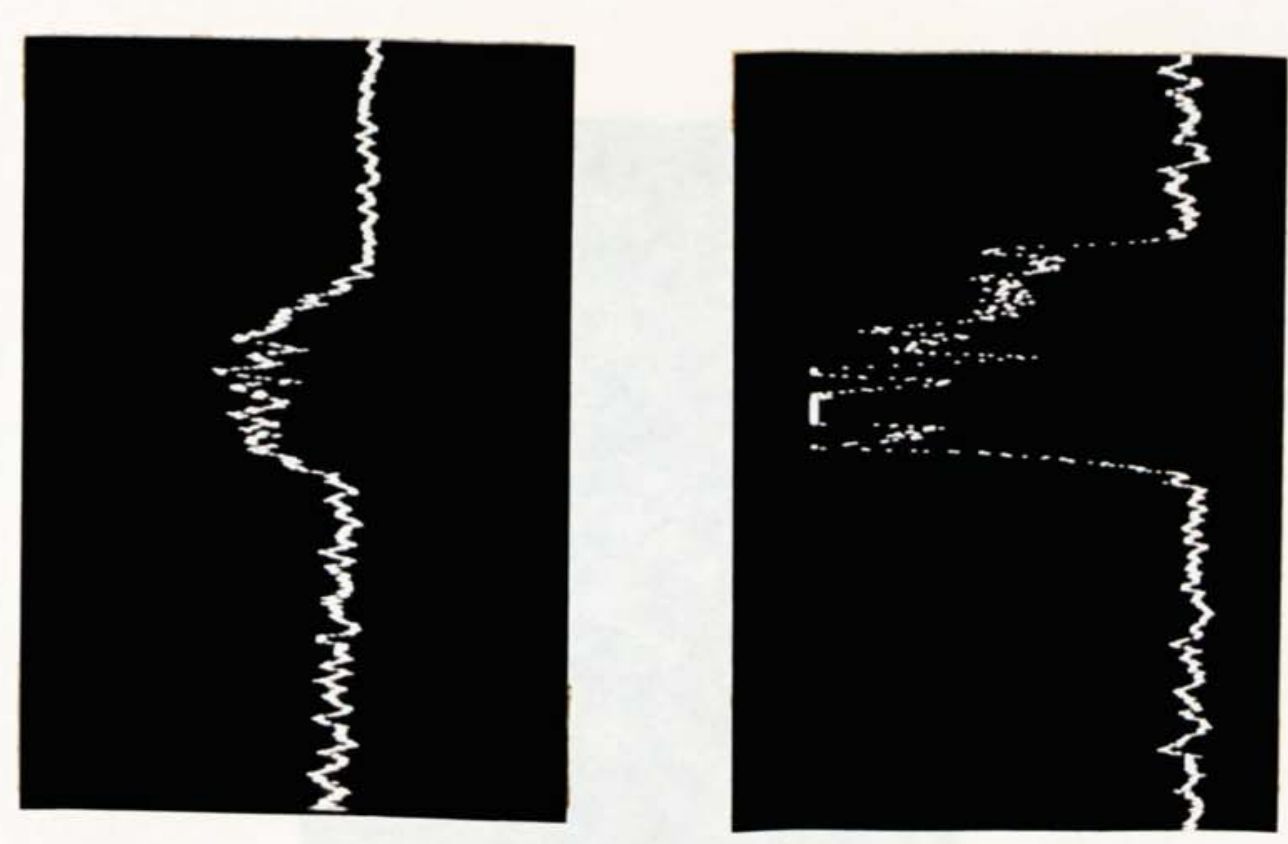

吾

مَ

$\pi$

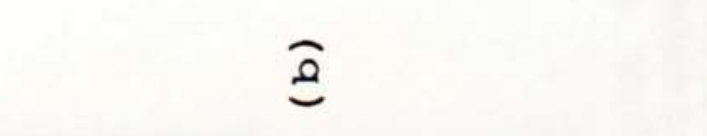

赵记

क्ष

다에

ชู

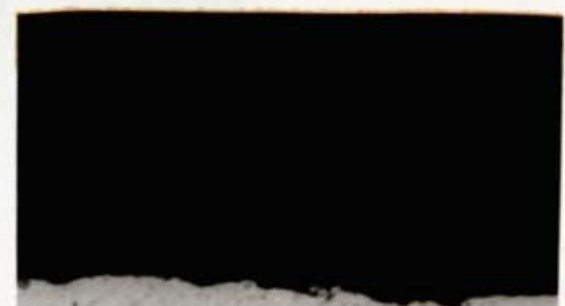

है

ชั

न 0

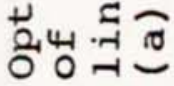
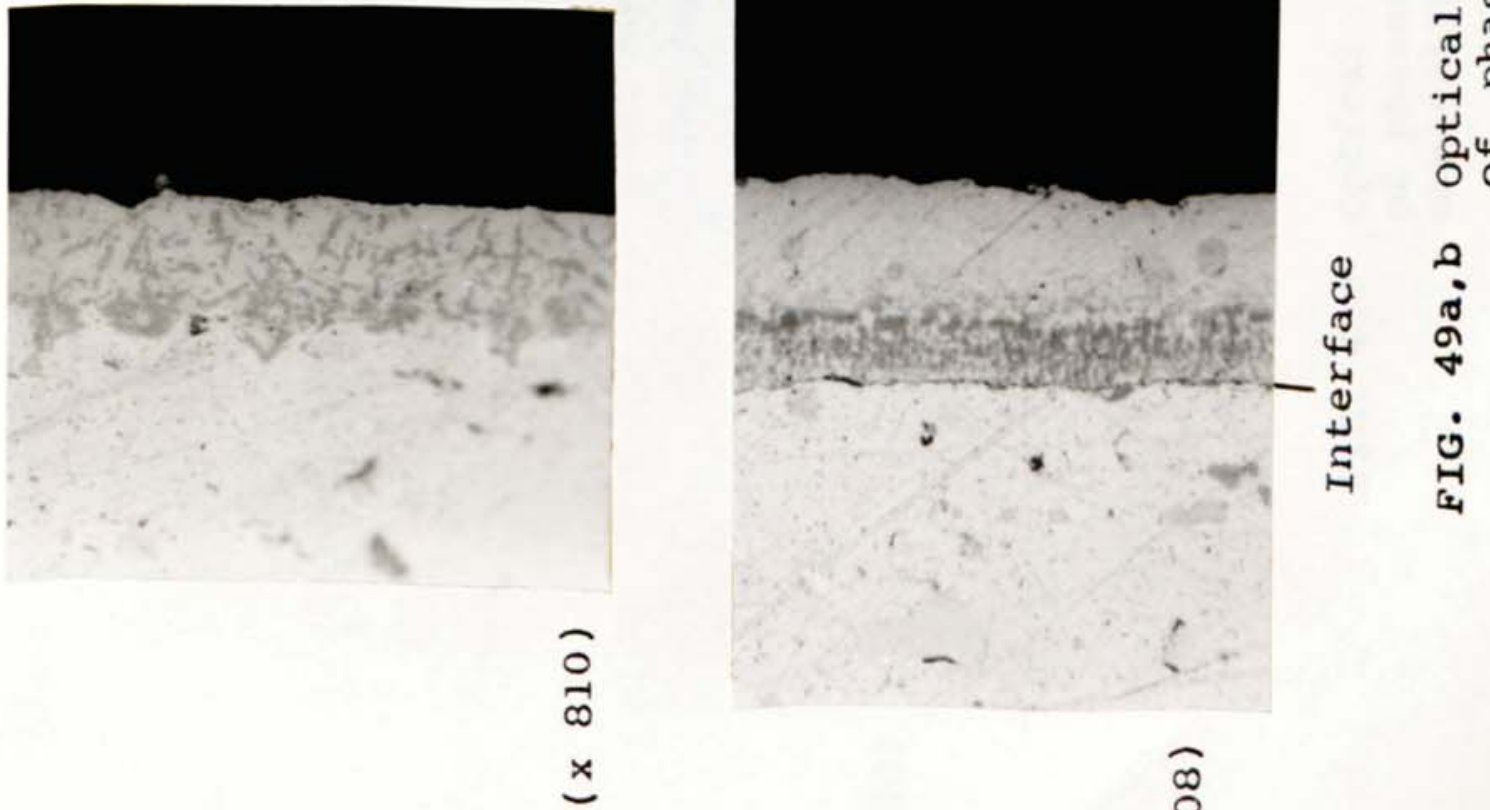

$\widehat{\infty}$
0
0
-1
$\times$ 


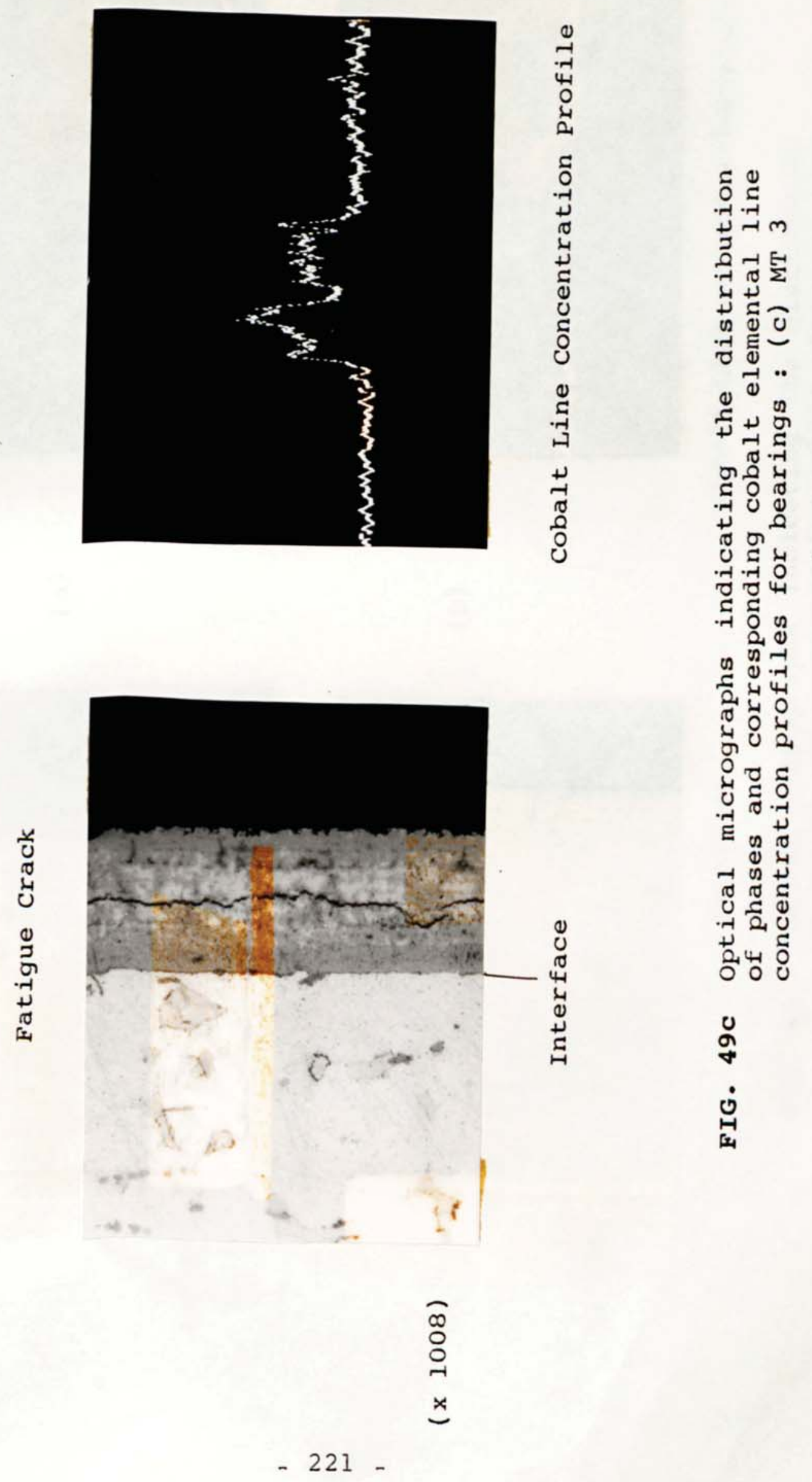



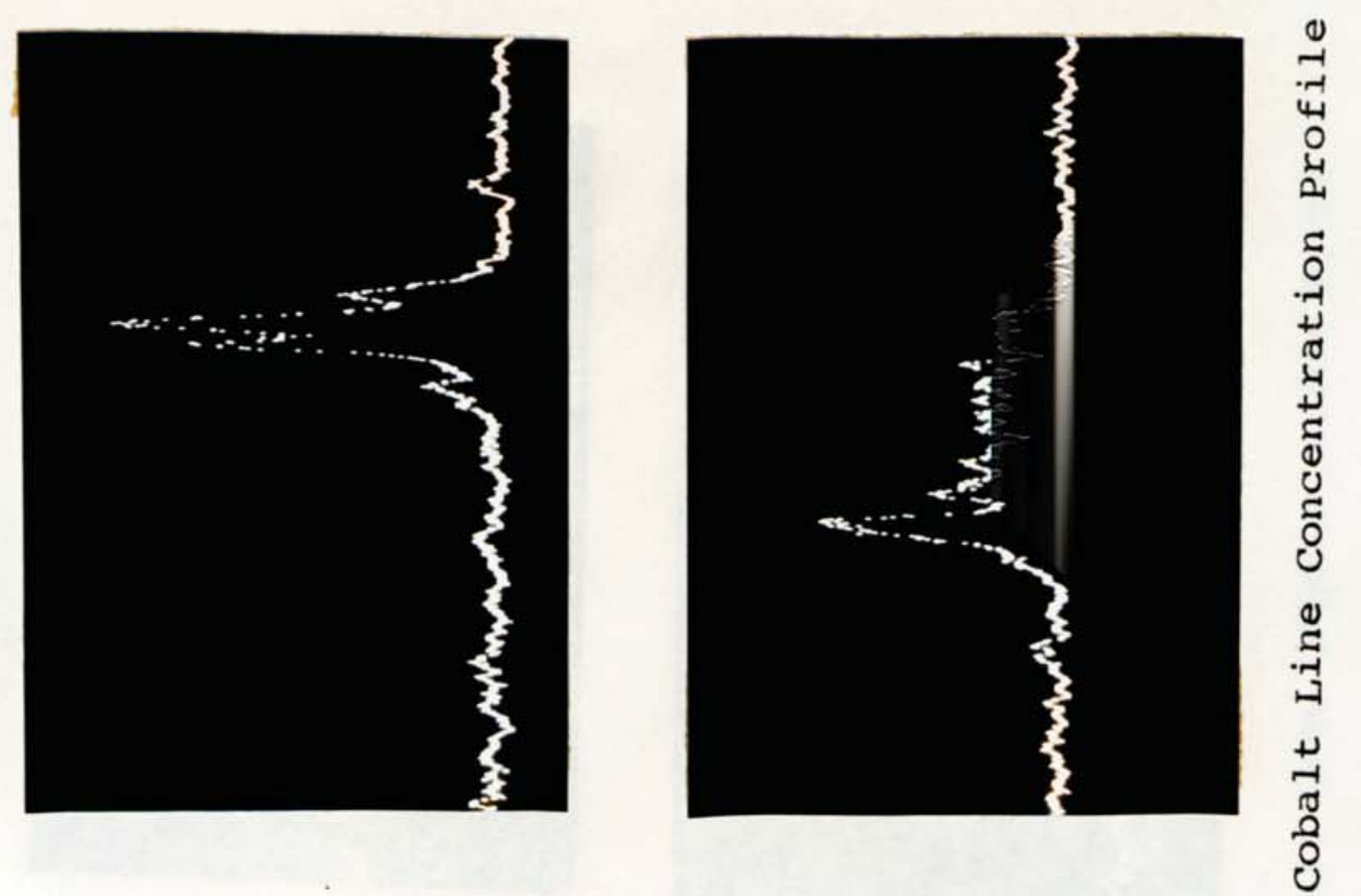

吾 舟出
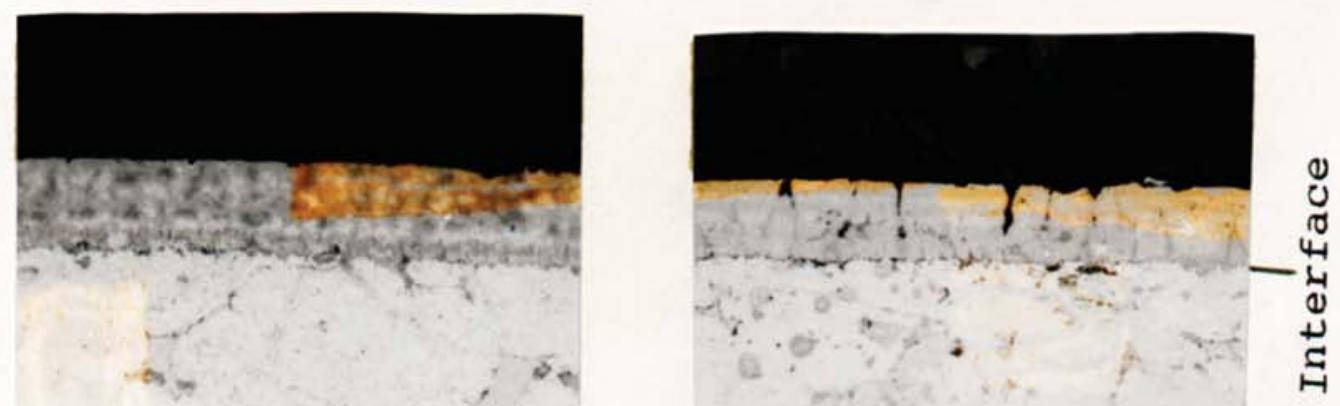
कूठ कू

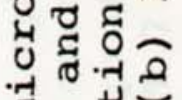
글 ¿

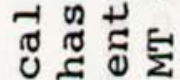
U ठํำ

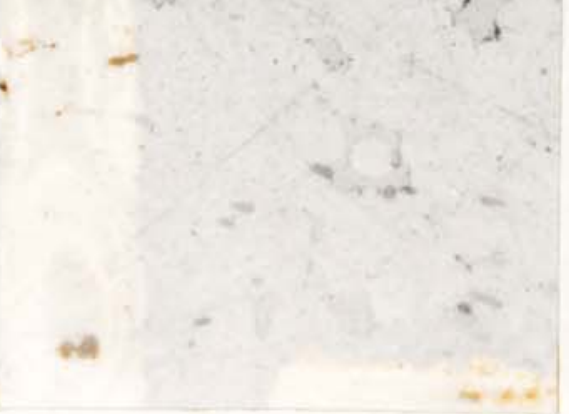

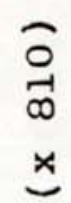

$\stackrel{+}{\mathrm{m}}$
$\stackrel{*}{ }$ 

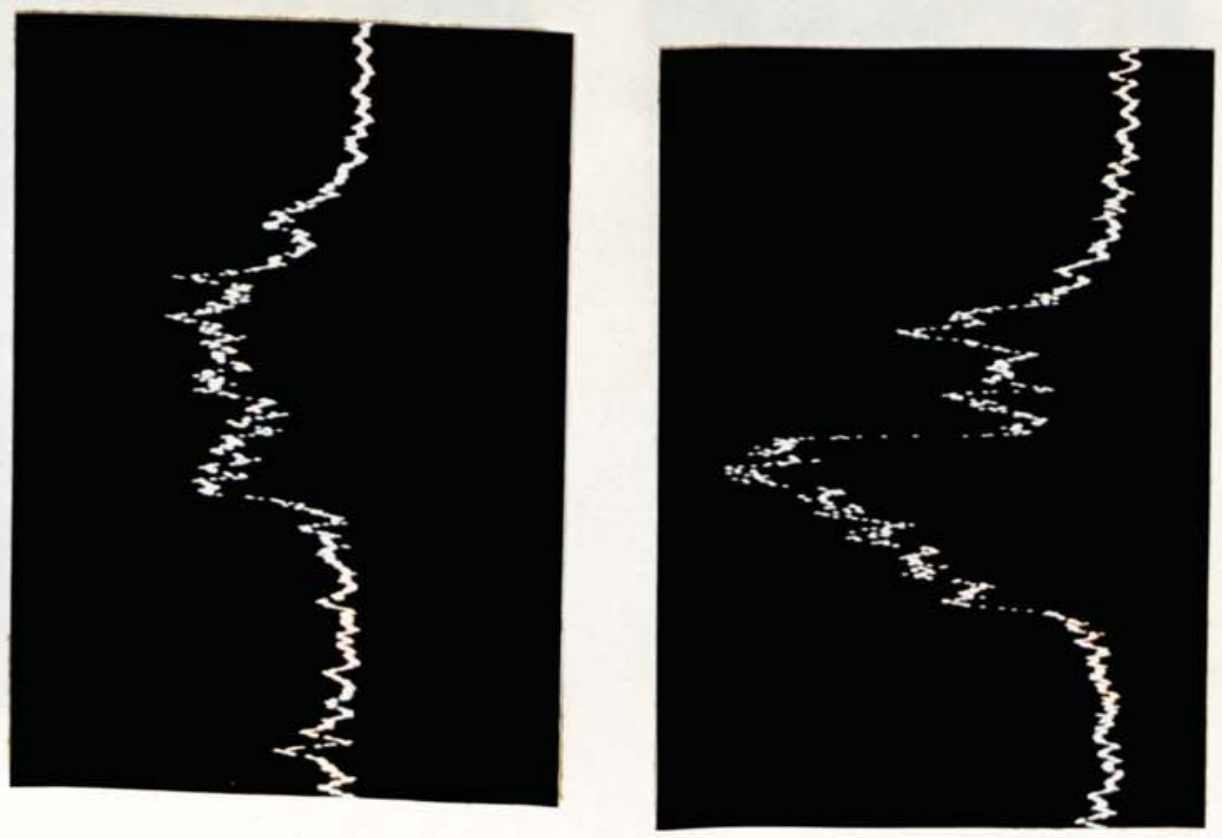

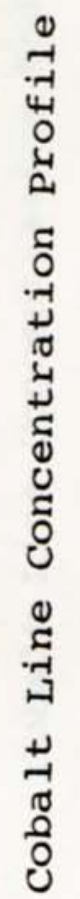

ธี ฮี

건

苟

룽

.

छ त्न

(1) क

†势

융

न 0

on

ชู

$\pi$

อ

नु

न

की
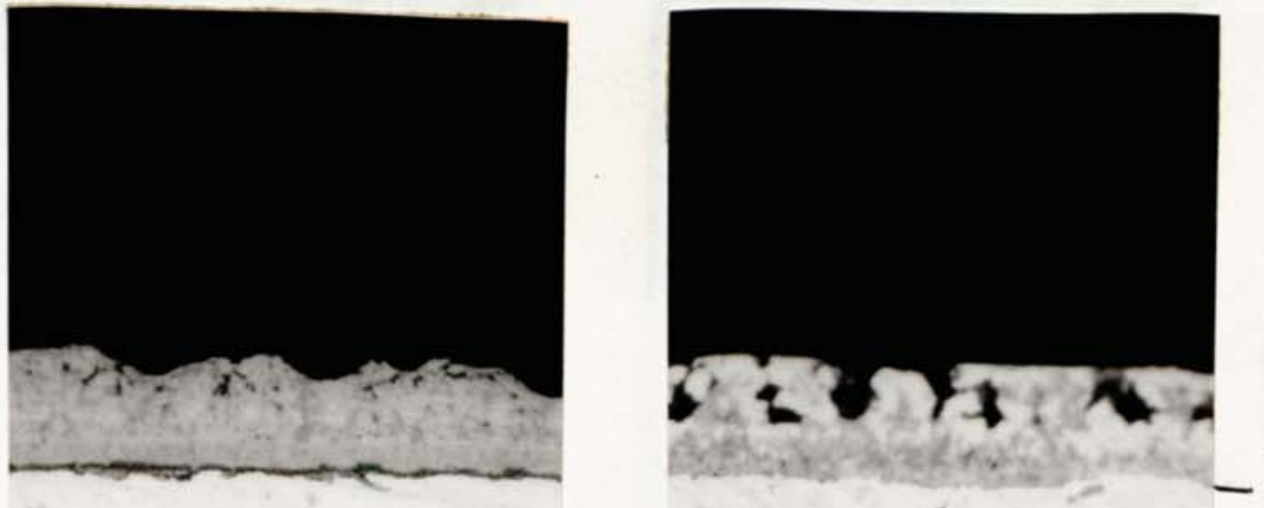

牙出 究 कूष 0 . ชูำ . of 6

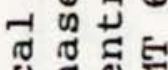
ช0 त 0 영

ㄱ.

in

ఏ్
0
0
$\times$ 

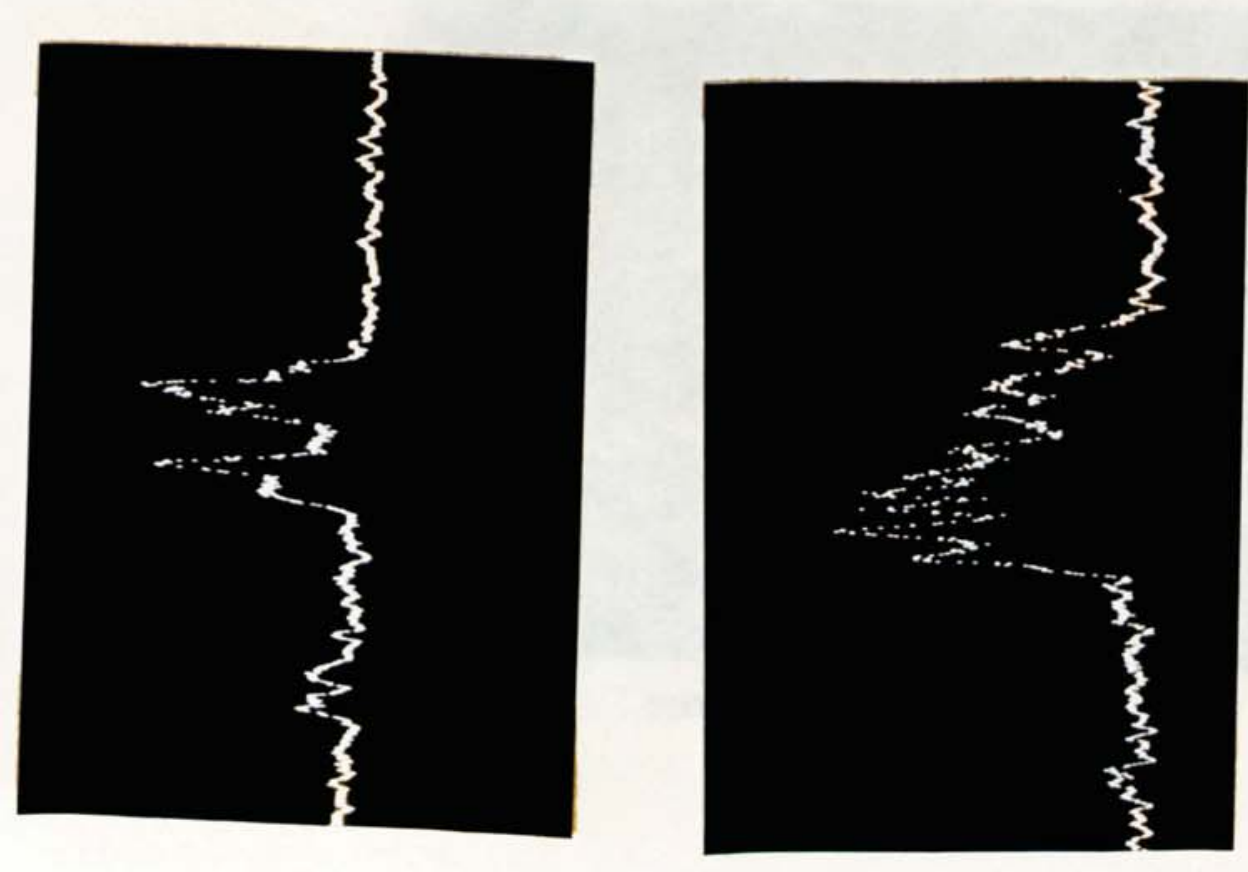

年

Ðี

걱

วิำ

究

(1) क त

નु ન

$+\quad 0$ व

त

ช

¿유

ف

\%

$\pi$

อ
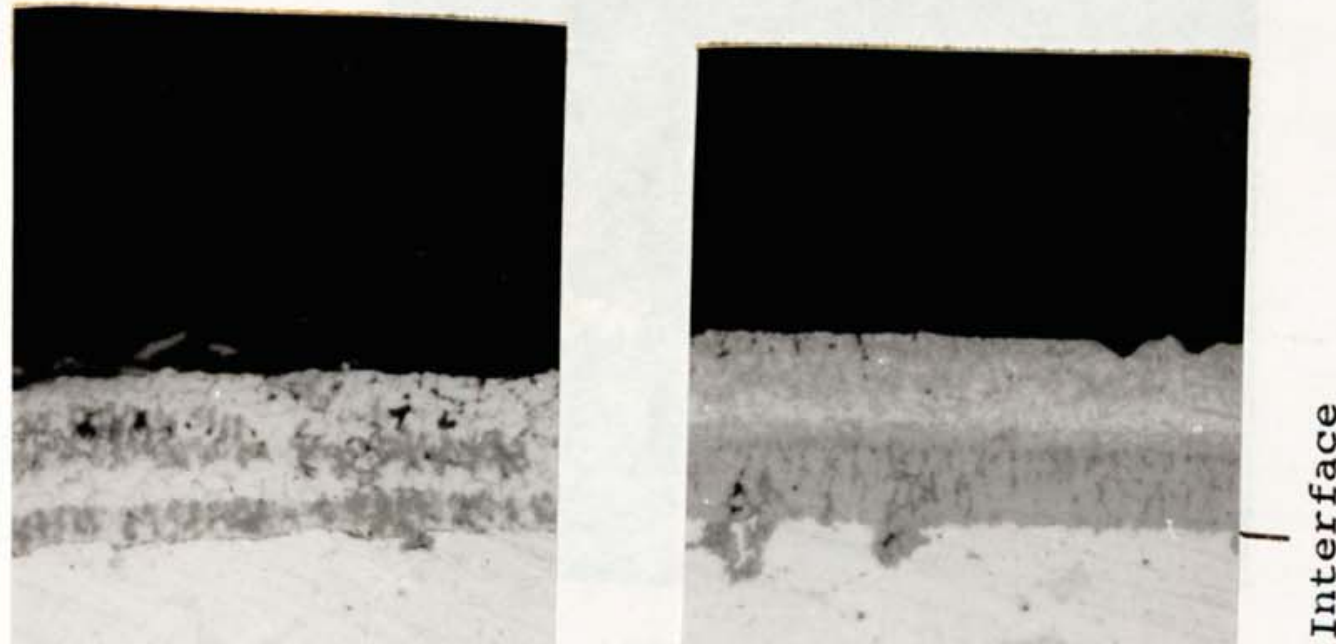

न- न

ชृ

नै ठี้ थ

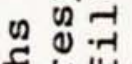

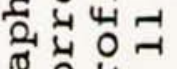

कू ठै

०ण ${ }^{\Sigma}$

อูป

E 0

(1) प्र०

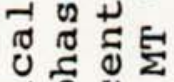

U

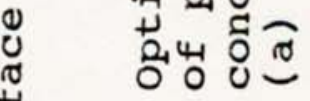

$\underset{0}{\infty}$

@્

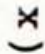




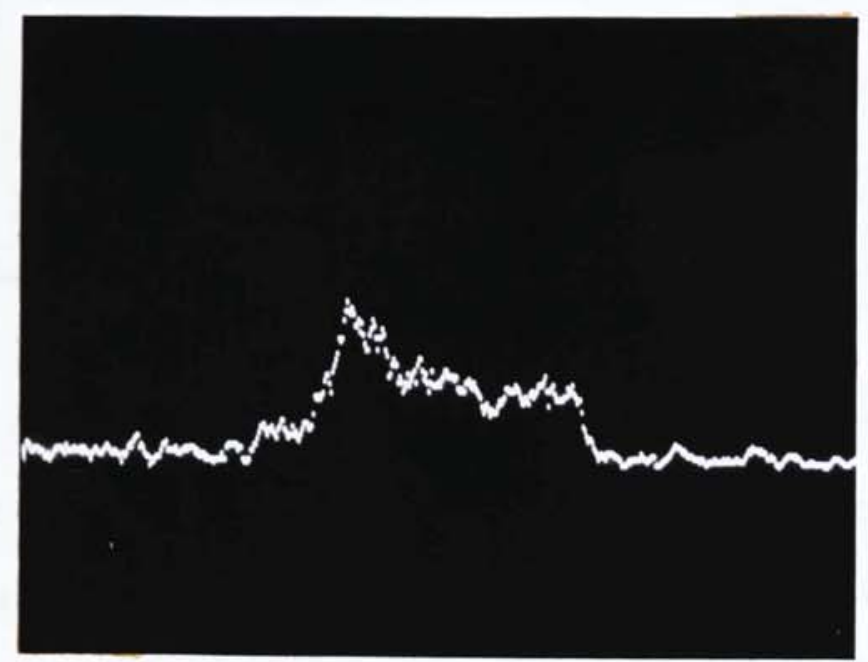

Unheat-treated

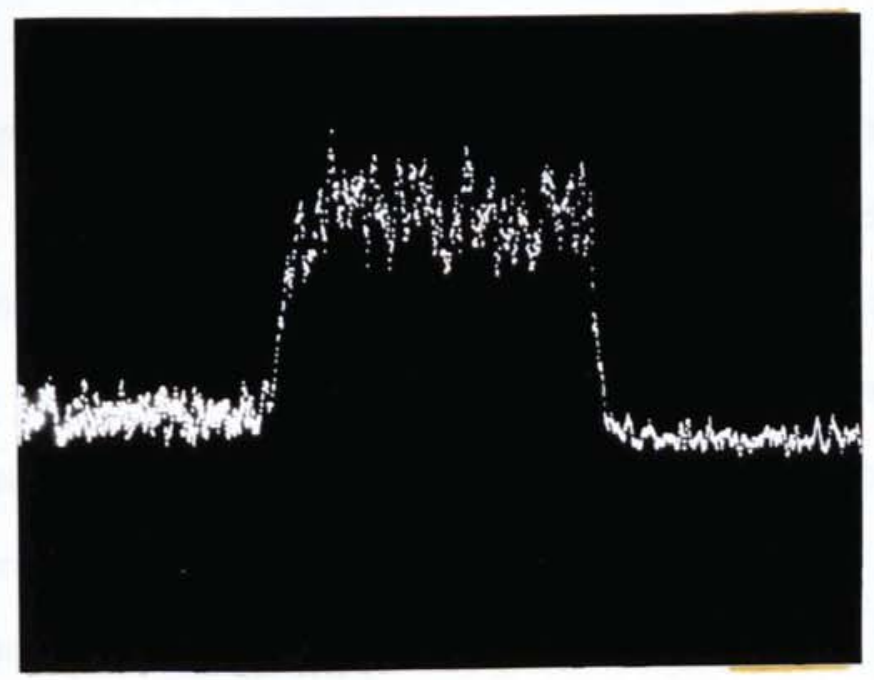

100 hours at $180^{\circ} \mathrm{C}$

FIG. 53 Cobalt elemental line concentration profiles of an overlay plated bearing (a) before and (b) after heat-treatment at $180^{\circ} \mathrm{C}$ for 100 hours 


\section{SHELIS}

\subsection{Direct Plating pretreatments}

The surface of both the ASI5 and SIC prior to overlay plating after pretreatment using sequence $\mathrm{E}$, resulted in a heavily etched surface, characteristic of the crystallographic etching of aluminium, which takes place when no passivation of the oxide film occurs. If the etching is carried out with no applied potential, the aluminium will go into solution,

$$
\mathrm{Al}+3 \mathrm{H}^{+} \longrightarrow \mathrm{Al}^{3+}+3 \mathrm{H}
$$

the chloride ion prevents passivation and the liberation of hydrogen causes agitation and keeps the surface clean of oxygen. The chloride present in the acid etchant attacks the weak spots in the aluminium film therefore, allowing aluminium to go into solution. This continues at a fast rate, until saturation of the solution close to the surface occurs. When the reaction slows down, there is then the possibility of some precipitation of chloride, hydroxide or oxide back onto the aluminium.

The 'white areas' evident in Fig. 34, particularly on AS15, are not sufficiently 'in focus' to be able to determine what they are. This may be for two reasons.

i) 'Charging' due to oxide, hydroxide or chloride 


\section{MISSING}

\section{PAGES}

NOT

AVAILABLE 
chloride solution is used(138).

Wasserman's hypothesis(111-113), that pretreatment sequence E converts the aluminium surface to a meta-stable aluminium hydride $\left(\mathrm{AlH}_{3}\right)$ is somewhat misleading. Hydrogen will be present at the aluminium surface and consequently, some of the hydrogen will diffuse into the aluminium lattice. However, no compound between the aluminium and the hydrogen will be formed, as aluminium hydride cannot be produced by direct interaction of aluminium and hydrogen(139). In the presence of aluminium alkyl, a reaction to form aluminium dialkyl hydride can occur. It is therefore," incorrect to state that the aluminium surface is electrochemically converted to form aluminium hydride.

\section{$12.2 \quad$ Lead - Tin Overlays}

The commercially supplied lead - tin alloy brush plating solution was only capable of producing a deposit that contained less than $5 \%$ tin, at reasonable plating voltages and not the $10 \%$ tin in the deposit as was the intention when the solution was purchased. It is apparent from the subsequent work on solution mixing of the lead and tin single metal solutions, that the supplied alloy solution contained $10 \%$ tin by volume. This indicates that commercial suppliers of brush plating solutions have little understanding of these alloy plating solutions. In discussions with the suppliers, it was intimated that for 
deposit compositions up to $20 \%$ tin, the ratio of lead and tin in the solution should be $1: 1$ ie equilibirium codeposition. With reference to Brenner(27), lead acts as the more noble metal and therefore deposits preferentially, providing that the tin content of the bath is less than 70\%. However, for the composition $70 \%$ tin $30 \%$ lead, the system is one of equilibrium codeposition. This confusion on behalf of the suppliers could easily have been rectified if they had simply analysed the deposits produced from the solution, this they admitted, they had failed to do.

The required 90:10 deposit can be achieved however, the solution requires a relatively high proportion of tin to be present in the solution. It is also evident that there is a large variation of deposit composition with respect to plating voltage, for this particular solution consequently, accurate control over plating voltage is necessary.

The lead - tin fluoborate solution allows much greater control over the deposit composition with respect to plating voltage than is possible with the 'brush solutions'. This is more beneficial for a commercial application however, the lack of adhesion with the pretreatments investigated would have to be improved. It is worth noting that the fluoborate solution when brush plated, produces a deposit that contains approximately $23 \%$ tin, but when the same solution is vat plated, at $4 \mathrm{Adm}^{-2}$ with no agitation, the deposit contains $17 \%$ tin. The 
increase in the proportion of tin in the deposit when brush plated, is to be expected of the regular plating systems, where an increase in current density results in a decrease in the content of the more noble metal in the deposit.

The study of the effects of the plating variables upon the deposit characteristics revealed the following points :

i) Increase in anode - cathode motion (ms-1), decreased the proportion of tin in the deposit, but increased the solution efficiency

ii) Increase in solution flow rate decreased the proportion of tin in the deposit, but increased the efficiency

iii) Increase in anode load decreased the tin in the deposit and also resulted in lower solution efficiencies.

In general these findings agree with those of other regular alloy plating systems(27), with tin functioning as the least noble metal.

The effect of agitation on the composition of the deposit, is due to the concentration changes which it produces at the cathode - solution interface. During alloy deposition, the cathode diffusion layer is depleted of metal ions and furthermore, the ratio of the concentration of the metals in the layer, differs from that in the bulk of the solution. Increased agitation of the system, in this case 
by increasing the rotation of the cathode, decreases the thickness of the cathode diffusion layer and not only results in an increase in the concentration of metal ions in the diffusion film, but also causes the metal ratio of the diffusion film to approach more closely that of the bulk solution. Hence, this favours an increase in the rate of deposition of that metal which is depositing preferentially. An increase in the rate of deposition of the preferentially deposited metal will give a corresponding increase in the solution efficiency.

The effect of introducing more solution into the plating system, by increasing solution flow rates, is to increase the rate of deposition of the more noble metal. This again follows diffusion theory for the regular plating systems. The greater the volume of solution available for deposition; the greater the reduction in diffusion film thickness. As discussed above, this allows the metal ratio of the film to approach that of the bulk solution, allowing the more noble metal to deposit preferentially, with a corresponding increase in solution efficiency.

The results obtained by increasing the pressure on the anode, appear to indicate that although the proportion of tin in the deposit decreases, as would be expected for an increase in agitation with the regular plating system, the cathode efficiency also decreases. This can be explained by the fact that the greater the load applied, the greater 
the scouring action. of the pad on the overlay. With very soft deposits, some of the coating is removed by the higher pad load. This removed deposit can be found either on the pad itself or in the used solution. Hence, increased anode load appears to lower the cathode solution efficiency, when this may not be the case.

The results obtained by using the 'Selvyt' pad follows similar trends to those discussed above however, there are obvious anomalies. If it were assumed that the 'selvyt' pad was less aggressive on the diffusion film than the nylon-polypropylene pad, the expected results would show a relative increase in the amount of tin being detected in the deposit. However, it is obvious from Fig. 37 that this is not the case, the 'selvyt' pad actually produces less tin in the deposit for the equivalent conditions. This suggests that the softer 'selvyt' pad is more abrasive towards the diffusion film i.e. producing more effective agitation. The more open structure of the nylonpolypropylene pad, allows more of the plating solution to be present at the substrate surface than the 'selvyt' hence, the 'Selvyt' produces effectively greater agitation. A further anomaly is that although the 'Selvyt' produces less tin in the deposit than the nylon-polypropylene, the corresponding solution efficiencies are also lower. This is probably as a result of a burnishing action of the 'Selvyt' pad. The nylon-polypropylene pad will effectively be in contact with a smaller surface area of the substrate, 
due to its open structure hence, more of the deposited coating can be removed by the 'selvyt' pad resulting in an apparantly lower efficiency.

It is also evident that the 'Selvyt' pad produces results with a lower variation of deposit composition between the two extremes of the variables tested, this obviously means that the system is more controllable.

The efficiencies which result from the alloy plating solutions appear to be much lower than either of the corresponding single metal electrolytes. This must be a consequence of the formation of complexes within the solution. As the compositions of the solutions are unknown, despite attempts to analyse them, no indication of the complexes involved can be given. However, this phenomenon of a reduction in cathode current efficiency upon the formation of complexes, is presented in detail by Dennis and Jones(24).

\subsection{Tin Cobalt overlays}

The results of the investigation into the relationship between both the proportion of cobalt in the solution and plating voltage, in relation to the amount of cobalt in the deposit follow similar trends to those of lead-tin, 12.2. The amount of cobalt in the deposit increases with plating voltage and the solution must contain a higher proportion 
of cobalt than will be present in the deposit. It should be noted that as with lead-tin, the proportion of metais in the solution is not a quantitative measurement but it is in fact only a comparison between the relative proportions of the single metal solutions mixed together. These results suggest that the tin-cobalt alloy solution is functioning as a regular plating system, with cobalt acting as the least noble metal. . This confirms the observations of Brenner (27).

The precipitation of the solution is an obvious problem in that the commercial potential of such solutions must be limited if there is only a short 'active life'. It is important therefore, that the occurrance of precipitation must be substantially delayed or eliminated completely. A reaction obviously occurs between the two stable single metal solutions when they are mixed, causing the precipitation.

It is however, not possible to identify which reaction is occurring and consequently, no possibly remedy can be given. However, generalisations are possible. In work on cobalt alloy solutions by Jones(140), the plating solutions used were adjusted to $\mathrm{pH} 1.5$ prior to the addition of the alloying elements. This avoided the formation of stable insoluble cobalt complexes. It is obvious that such a phenomenon could be occurring here, as the commercially available tin-cobalt solutions have near 
neutral $\mathrm{pH}^{\prime} \mathrm{s}$, whereas the single metal solutions have $\mathrm{pH}^{\prime} \mathrm{s}$ of 6.7 (tin) 1.5 (cobalt). It may therefore be more advantageous to use an acid tin solution rather than the alkaline solution used in this investigation.

With the solutions prepared at Aston, care was taken to reduce the $\mathrm{pH}$ to 1.5 as stated by Jones. . This resulted in the solutions being relatively stable. However, problems with these solutions were also encountered, most notably the oxidation of the stannous salt $\left(\mathrm{Sn}^{2+}\right)$ to the stannic form ( $\mathrm{Sn}^{4+}$ ) which is insoluble. This too must be avoided. It is known that the addition of ammonium fluoride allows a complex compound of tin $\left(\left(\mathrm{SnF}_{4}\right)^{2-}\right)$ to form $(141,142)$, which subsequently reduces the oxidation of the stannous salt. Additions of ammonium fluoride have been used for tincobalt alloy plating(143).

The results from the study of speed, load and solution flow confirm the observations that the solution is functioning as a regular plating system. The results follow similar trends to those already discussed in 12.2 for lead-tin.

It is quite obvious from Figs. 45-48 that in all cases the proportion of cobalt in the deposit decreased from the substrate - coating interface towards the substrate - air interface although, the final amount of cobalt varied from sample to sample. It is interesting to note that 'generally' the results from the 'spot analysis' agree with 
the optical micrographs and the cobalt elemental line concentration profiles. That is, where a band of the 'light blue' phase occurred a peak in the line concentration and a corresponding rise in the EDX Analysis resulted. It is evident from these results that any methods used to analyse the deposit composition are restricted by serious flaws in the techniques. Atomic Absorption spectrophotometry, when used to analyse the deposit, resulted in an average figure of the whole overlay, for the amount of cobalt present. For example, in the case of MT 5 , the A.A.S. result indicated 6.28 cobalt in the deposit, whereas the EDXA (cross-section) indicated that there was 138 cobalt at the interface and 0.58 cobalt at the surface. When the EDX analysis was carried out on the surface of the bearing, the analysis indicated that 1.58 cobalt was present, as this method 'averages out' the composition over the depth of penetration of the electron beam (approximately $1.5 \mu \mathrm{m}$ ) .

It is therefore important to ascertain which of the analytical methods have been used and to fully understand the implications that this has upon the deposit composition stated. It is almost meaningless to state that any of these tin-cobalt overlays 'have a specific composition'. This is not to say that the trends evident from experiments, such as the work relating to the plating variables and effect of plating voltage on the 'composition'are worthless. The trends are valid as the condition under 
which the tests were carried out were consistent. However, the solution efficiency results, as actual figures, are meaningless, as the calculation used to determine cathode efficiency, requires the use of the deposit composition. Consequently, the figures quoted are the efficiencies of the whole coating, calculated with the final deposit composition, measured by EDX analysis on the overlay surface.

Brush plating is an operation unlike conventional vat plating since many of the plating conditions can vary during'the plating operation. The three most important variables are :

Temperature

- varies from ambient to boiling in a few seconds as a result of the large current densities.

Current Density - varies as the anode - cathode gap changes.

Volume of Solution - if the solution is not pumped onto the pad or cathode surface, the stylus must be removed to allow solution replenishment to be carried out hence, the pad can contain excess solution or none at all. However, as the current technique used, pumps solution onto the cathode surface this situation does not arise. 
At the instant the anode pad is applied to the cathode, at the start of the plating operation, the temperature of the whole system is several degrees lower than even after one minute of plating. It is therefore obvious to assume that temperature has an effect on the distribution of cobalt throughout the deposit. By starting with an initially hot system, the 'heating-up' time will be reduced hence, any effect this has on the distribution of the cobalt will be noticed. From diffusion theory, an increase in temperature should give rise to an increase in the proportion of the more noble metal in the deposit, as the diffusion rate of the ions in solution is increased. This effectively decreases the thickness of the diffusion film. However, it can clearly be seen from Fig. 48, that the opposite effect occurs here.

The plating voltage (current density) has a marked influence on the deposit composition. From Fig. 48, it can be seen that at the lower voltages (lower current densities), much less cobalt is found in the deposit than at the higher voltages 15, 20V (higher current densities). This is consistant with previous findings. However, during the brush plating operation an increase in current is detected after a certain variable length of time for a constant voltage. This appears to represent an apparent increase in current density. From the results presented here, the increase in current should be associated with an increase in the amount of cobalt detected in the deposit. 
Figs. 45-48 show that this is clearly not the case. The increase in current is obviously associated with an increase in conductivity of the solution, probably due to an increase in solution temperature, increasing the diffusion rate. The rise in current may also be a consequence of the pad material becoming saturated with solution hence, reducing resistance and allowing it to conform more closely to the cathode surface. This would have the effect of increasing the area over which the pad is in contact with the substrate and the increase in current may not be associated with an increase in current density. At the extreme case the current density may be lowered.

Evidence of variations in alloy composition with thickness of deposit appear in the literature. However, most of the examples including those published by coats(144) and Henstock and Spencer-Timms(145) refer to compositional changes occurring in deposits of less than. lum in thickness. Two agencies may be responsible for these differences $(27)$ in conventional vat plating :

a) the nature of the initial cathode surface and

b) diffusion phenomenon.

To explain the effect of the nature of the cathode surface, it must be assumed that (i) the overvoltages of the deposition of the two metals differ for various substrate materials and (ii) the surface characteristics of the 
substrate which influences the overvoltages of deposition, must be propagated or reproduced by the deposit, if any differences of alloy composition occur after the initial few atom layers are deposited. ..The influence of the cathode surface on the electrodeposited alloys should only be effective through a limited thickness of deposit, probably less than l $\mu \mathrm{m}$. However, results published by Dennis and Jones(24) suggest that over relatively thick deposits, the substrate had an important influence on deposit composition.

The mechanism by which diffusion phenomenon, occurring in the cathode layer, may affect the composition of the initial deposit is relatively simple. It is based on the concentration changes that occur in the vicinity of the cathode during the first minute or two of plating and on the time required for the metal ion concentration at the cathode surface to reach a steady state. It is obvious, that the initial composition of the alloy deposit will be different to that after a steady state ion concentration has been reached, because the initial deposition is occurring from a solution of a higher metal ion concentration, than that at the steady state condition. According to diffusion theory, the high metal ion concentration favours the deposition of the preferentially. deposited metal. One method of eliminating this is by plating at pulsed potentials, this has produced level composition - thickness for nickel - 208 iron(146). 
It is difficult to apply the above discussion where the compositional changes cease after <lum of coating, to the present brush plating situation and thick deposits. It is obvious from the results presented in Fig. 45-48 that not only does the phenomenon occur over several microns of coating, the highest concentration of the less preferentially deposited metal is at the interface.

Work on conventional deposition of cobalt-molybdenum and cobalt-tungsten alloys by still(147) illustrated that a similar phenomenon was occurring. The maximum concentration of the alloying element was present at the substrate - coating interface and this decreased as the thickness of the coating increased. Still postulated that the compositional change was more noticeable at lower degrees of agitation, where a thickening of the diffusion film forms a shallow concentration gradient. The concentration of metal ions at the interface decreases with time, as the ions take longer to diffuse through the film, leading to a decrease of the alloying element in the deposit.

Clearly this hypothesis is not relevant to this investigation, as the high degree of agitation dramatically reduces the thickness of the diffusion film. The observations by still are also in opposition to the results of this investigation, where a decrease in agitation results in an increase in the proportion of the alloying 
element in the deposit.

It can also be seen from the optical micrographs particularly Figs. 50-52 and from the 'spot analysis' results Figs. 45-46 that a second cobalt rich band has occurred midway through the thickness of the coating. During the brush plating operations, for those overlays, the anode was removed from the cathode to enable visual examination of the overlay to occur. This suggests that when the anode was reapplied, a situation analogous to the initial plating situation occurs, causing the second cobalt peak.

It is important to determine the controlling factors associated with the distribution of the phases, as a coating which contains the cobalt phase evenly distributed will have vastly different properties to one where there is only a thin band at the interface, particularly in respect of the plain bearing requirements.

It is evident from the phase diagram produced by Lewkonja(148) and Nial(149) that three intermetallic phases of tin and cobalt are present at low temperatures. These are $\operatorname{CoSn}_{2}, \operatorname{CoSn}$ and $\mathrm{CO}_{3} \mathrm{Sn}_{2}$. The literature indicates that by a variation in electrolyte composition and plating conditions, any of the intermetallic phases can be produced. Tsuji and Ichikawa(150) claim a $\operatorname{CoSn}_{2}$ alloy to be deposited. This intermetallic phase was also predicted 
by Hemsley and Roper(55), from a mixed sulphate bath however, no evidence was presented. A bath capable of depositing $\cos n$ was developed by clarke et al(53). The conditions and solutions in this investigation combine to produce the $\mathrm{Co}_{3} \mathrm{Sn}_{2}$ phase. However, the possibility exists for the observed phase being a non-equilibrium one. Nonequilibrium phases can be produced by electrodeposition. one example of a non-equilibrium phase, produced by electrodeposition is NiSn. 
The production of overlay plated bearings suitable for fatigue testing can be divided into four distinct groups :

1) Manual brush plating

2) Semi-automatic brush plating, 1 pair of bearings plated using a small anode pad.

3) Semi-automatic brush plating, 1 pair of bearings plated using a large anode with a 'Selvyt' pad

4) Semi-automatic brush plating, 3 pairs of bearings (4 dummy bearings), large anode with a 'Selvyt' pad.

A summary of all the results of the fatigue test is shown in Table 7.

\subsection{Manual Brush Plating}

13.1.1 AlA (Sequence Cl, Sn-Co overlay from 75:25 solution)

Bearing AlA failed by fatigue at $62 \mathrm{MPa}$. From the crosssection it appears that the fatigue cracks did not propagate to the AS15 substrate. There also appear to be areas where cavities have formed without visible fatigue cracks, Fig. 54. This suggests that either;

a) the cracks have not propagated perpendicular to the surface or

b) the fatigue cracks, in some cases, initiate within the overlay itself. 


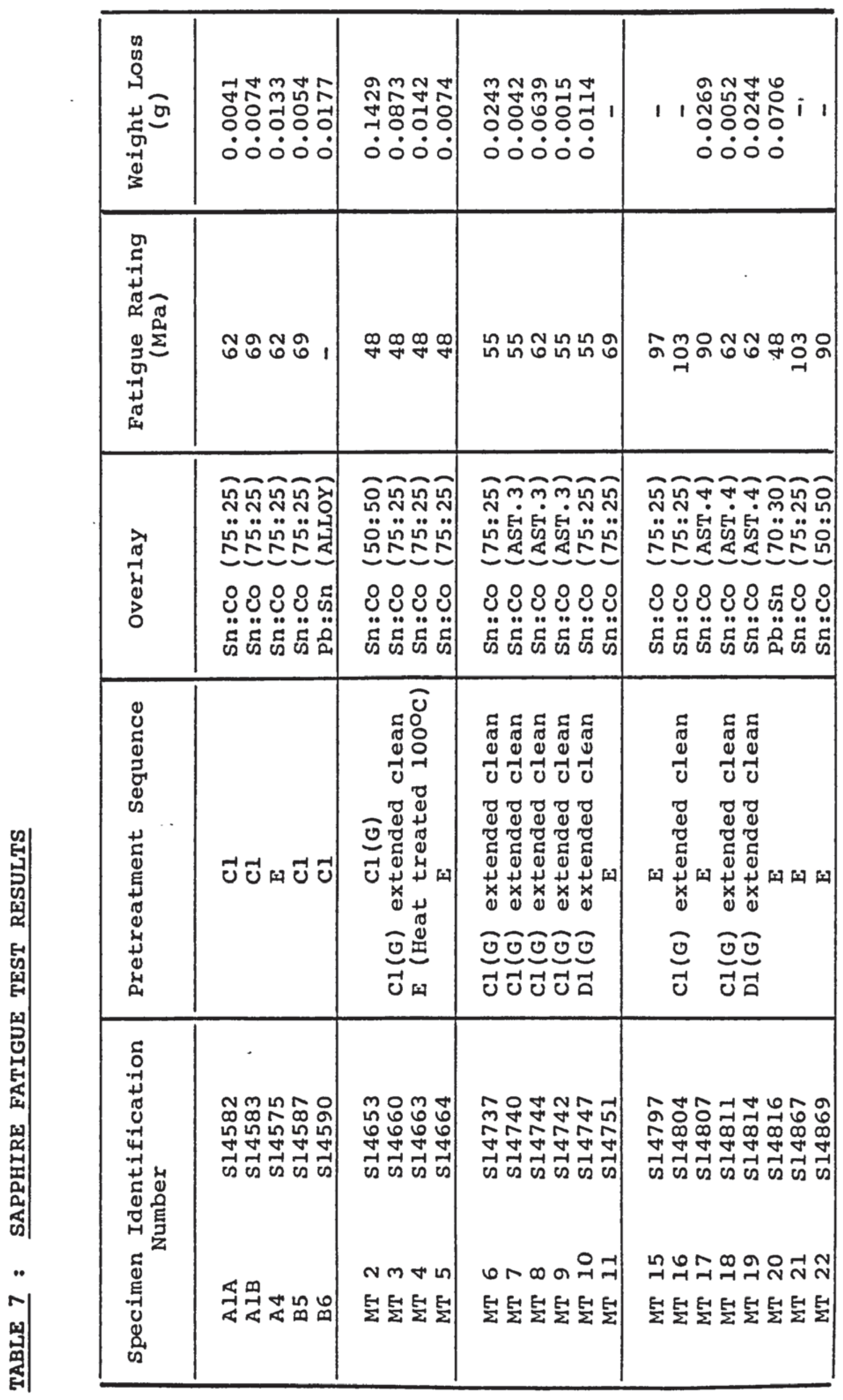



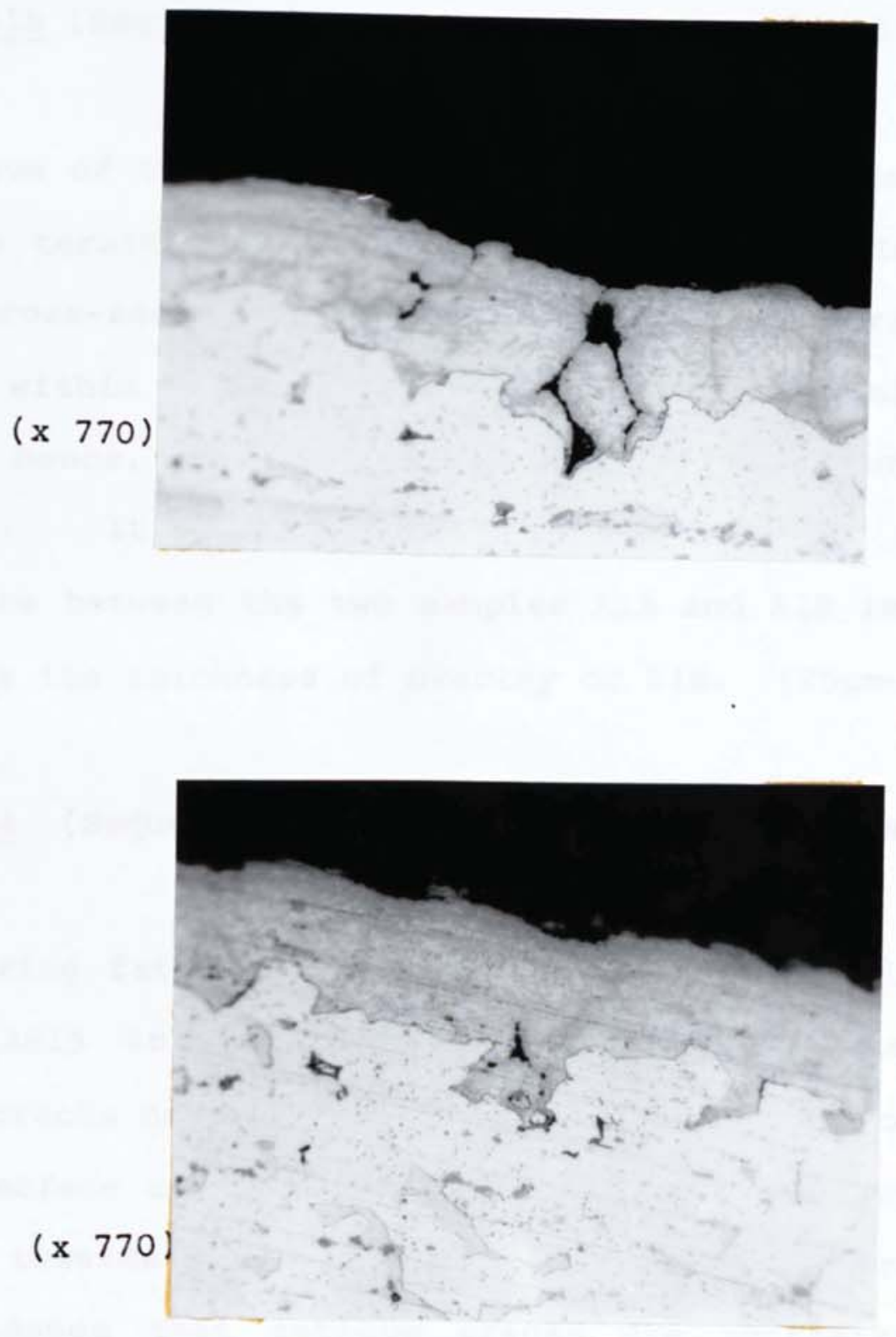

FIG. 54 Optical micrographs of bearing AlA showing cavities within the overlay 
There also appears to be a relatively even distribution of the phases within the overlay.

13.1.2 $\mathrm{AlB}$ (Sequence $\mathrm{Cl}$, Sn-Co overlay from 75:25 solution)

No fatigue of the overlay was noted at $69 \mathrm{MPa}$ however, the test was terminated due to adhesion failure. Examination of a cross-section revealed that fatigue cracks were present within the overlay although, not visible on the surface hence, fatigue failure would have subsequently occurred. It is interesting to note that the only difference between the two samples $A 1 A$ and $A 1 B$ is that $A 1 A$

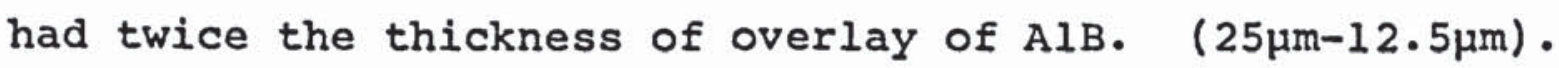

13.1.3 A4 (Sequence $\mathrm{E}, \mathrm{Sn}$-Co overlay from 75:25 solution)

This bearing fatigued at $62 \mathrm{MPa}$, with catastrophic failure of the AS15 in some areas, Fig. 55. In general, the fatigue cracks have propagated from the overlay towards the AS15 interface and then proceeded via the tin particles in the AS15 towards the steel backing material. There is also some evidence that fatigue cracks are initiated at the overlay-AS15 interface.

13.1.4 B5 (Sequence $\mathrm{Cl}$, Sn-Co overlay from 75:25 solution)

The test was terminated at $69 \mathrm{MPa}$ due to fatigue occurring at the edge of the bearing. The weight of overlay removed during the 80 hour test was less than in the case of $A 1 B$. 

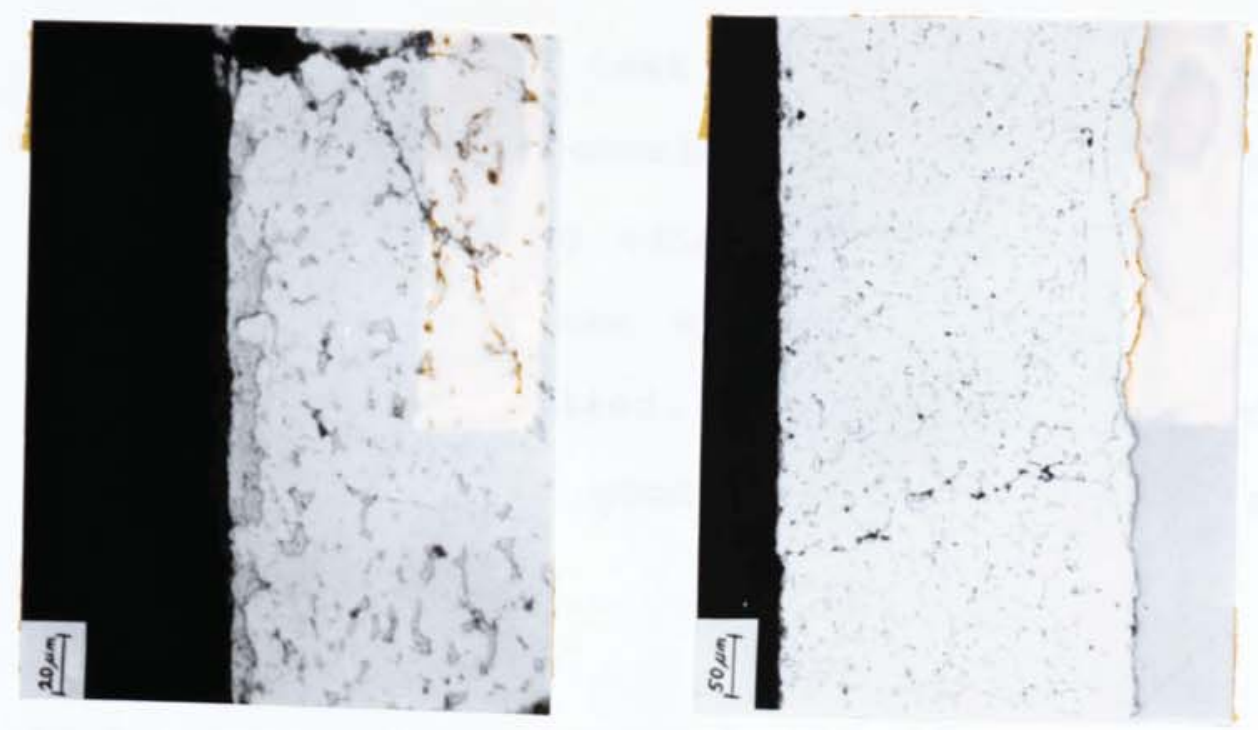

0
.4
3
0
0
0
3

离

出

on 0

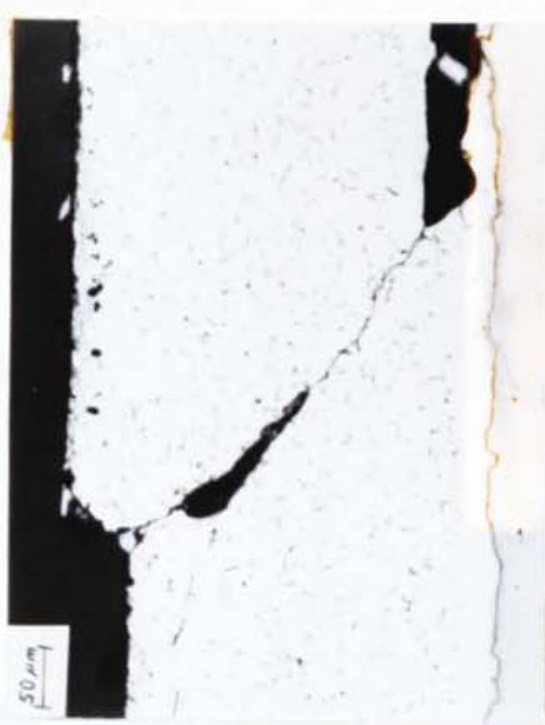

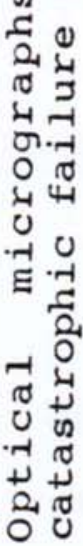

กี

ن. 
This is probably due to a greater area of overlay being removed as a result of adhesion failure of AlB.

13.1.5. B6 (Sequence $\mathrm{Cl}, \mathrm{Pb}-\mathrm{Sn}$ overlay from commercial alloy solution)

After 20 hours the test was stopped. Fatigue had not occurred, but the overlay had been stripped from the substrate, indicating adhesion failure. This bearing was pretreated in the same way as B5 except that a lead-tin overlay had been applied. This suggests that the lead-tin overlays are not as good when brush plated, as the tincobalt.

\subsection{Semi - Automatic Brush Plating (Small Anode)}

13.2.1 MT 2 (Sequence $\mathrm{Cl}(\mathrm{G}), \mathrm{Sn}$-Co overlay from $50: 50$
solution)

The fatigue properties of this coating system and pretreatment could not be assessed as the test was terminated after 20 hours at $48 \mathrm{MPa}$. Adhesion failure was the cause. No fatigue of the coating was noted. The weight loss resulting from this test is much higher than other bearings, indicating that much of the overlay had been removed. It is also evident from Fig. $49 \mathrm{~b}$, that the 'light blue' phase is present at the interface. 
13.2.2. $\mathrm{MT} 3$ (Sequence $\mathrm{Cl}(\mathrm{G})$ extended clean, Sn-Co overlay from 75:25 solution)

It is obvious from this test result, that the different solution composition used for MT 2, was not the cause of the adhesion failure, as again the test was stopped at 48 MPa. However, the amount of coating removed in this case was less than for MT 2, possibly as a result of the extended clean MT 3 received in the pretreatment stage. Many fatigue cracks are visible on the cross-section, although few propagate to the AS15 lining. The cracks appear to terminate half way through the overlay and then proceed horizontally. The distribution of phases is such, that a cobalt rich band appears close to the substrate coating interface, Fig. 49c. This may have some influence on the propagation of fatigue cracks.

\subsubsection{MT 4 (Sequence $\mathrm{E}\left(100^{\circ} \mathrm{C}\right) \mathrm{Sn}-\mathrm{Co}$ overlay from $75: 25$ solution)}

Fatigue occurred at the edges of the bearing and at this point the overlay has been removed. In the centre of the bearing however, no fatigue cracks are visible. The crosssection Fig. 50a, revealed that there are two bands of the 'light blue' phase present. 


\subsubsection{MT 5 (Sequence E, Sn̈-Co overlay from 75:25 solution)}

This bearing failed at $48 \mathrm{MPa}$, in a similar manner to MT 4. The overlay of MT 5, Fig. 50b unlike MT 4, only denoted the presence of one band of the 'light blue' phase.

It should be noted that although all four bearings tested in this section failed at $48 \mathrm{MPa}$, some interesting observations can be made. It can be seen from Fig. 56 that the appearance after the testing of the bearings, indicate that the condition of MT 5 in superior to that of MT 4 and MT 4 in superior to MT 3, with MT 2 being inferior to all three. This is reflected in the weight loss data obtained during the fatigue test, which is presented in Fig. 57. This indicates that an increase in the pretreatment cleaning sequence of MT 3 as opposed to MT 2 increases the adhesion level of the coating. The direct pretreatment sequence $E$ produces a surface that allows more mechanical keying of the overlay hence, increasing the adhesion level.

\subsection{Semi - Automatic Brush Plating (Large Anode 'Selvyt'} Pad)

13.3.1 MT 6 (Sequence $\mathrm{Cl}(\mathrm{G})$ extended clean, Sn-Co overlay from $75: 25$ solution)

overlay bond failure occurred at the edge of the bearing at $55 \mathrm{MPa}$. The bond failure is evident from the cross-section 


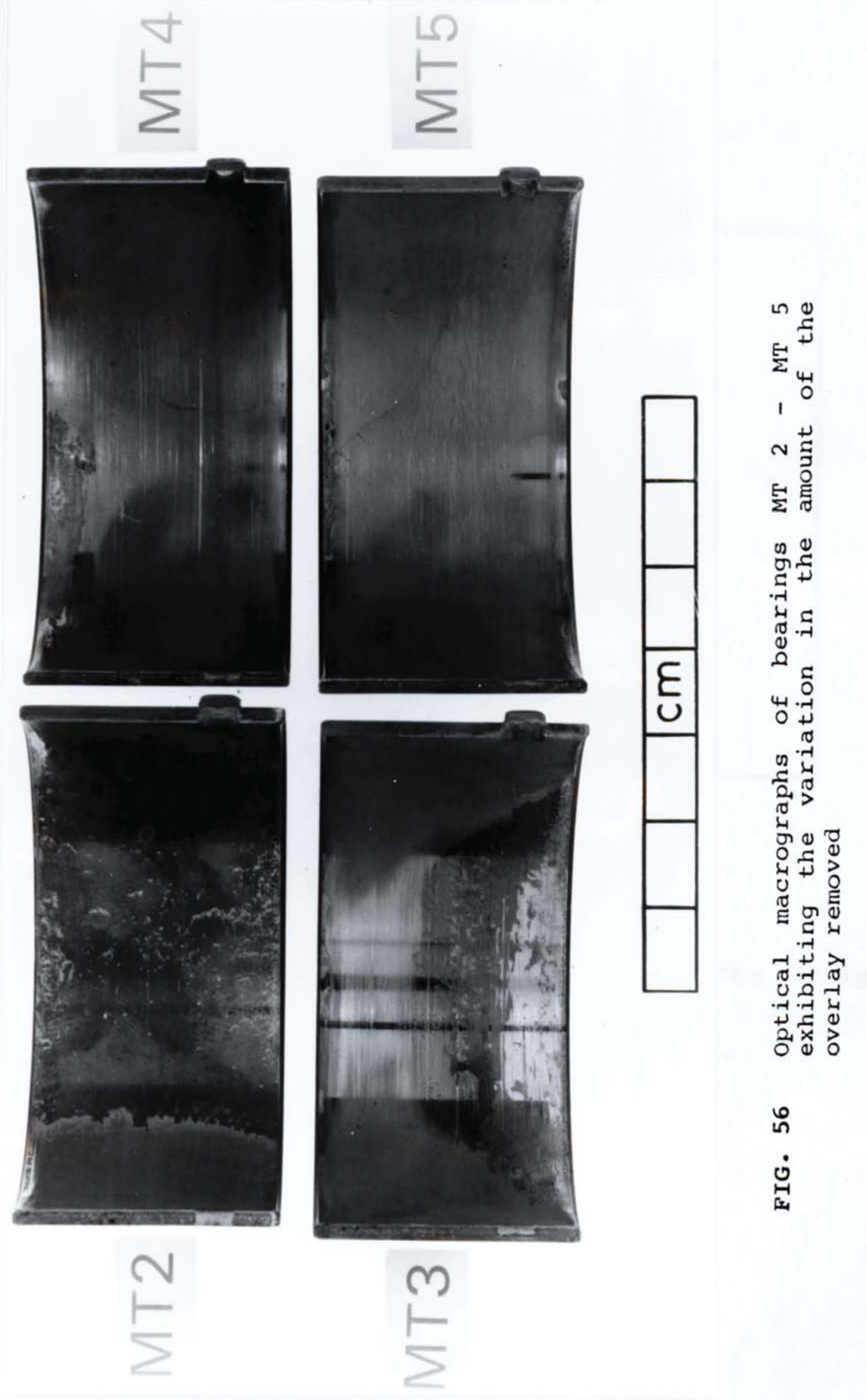




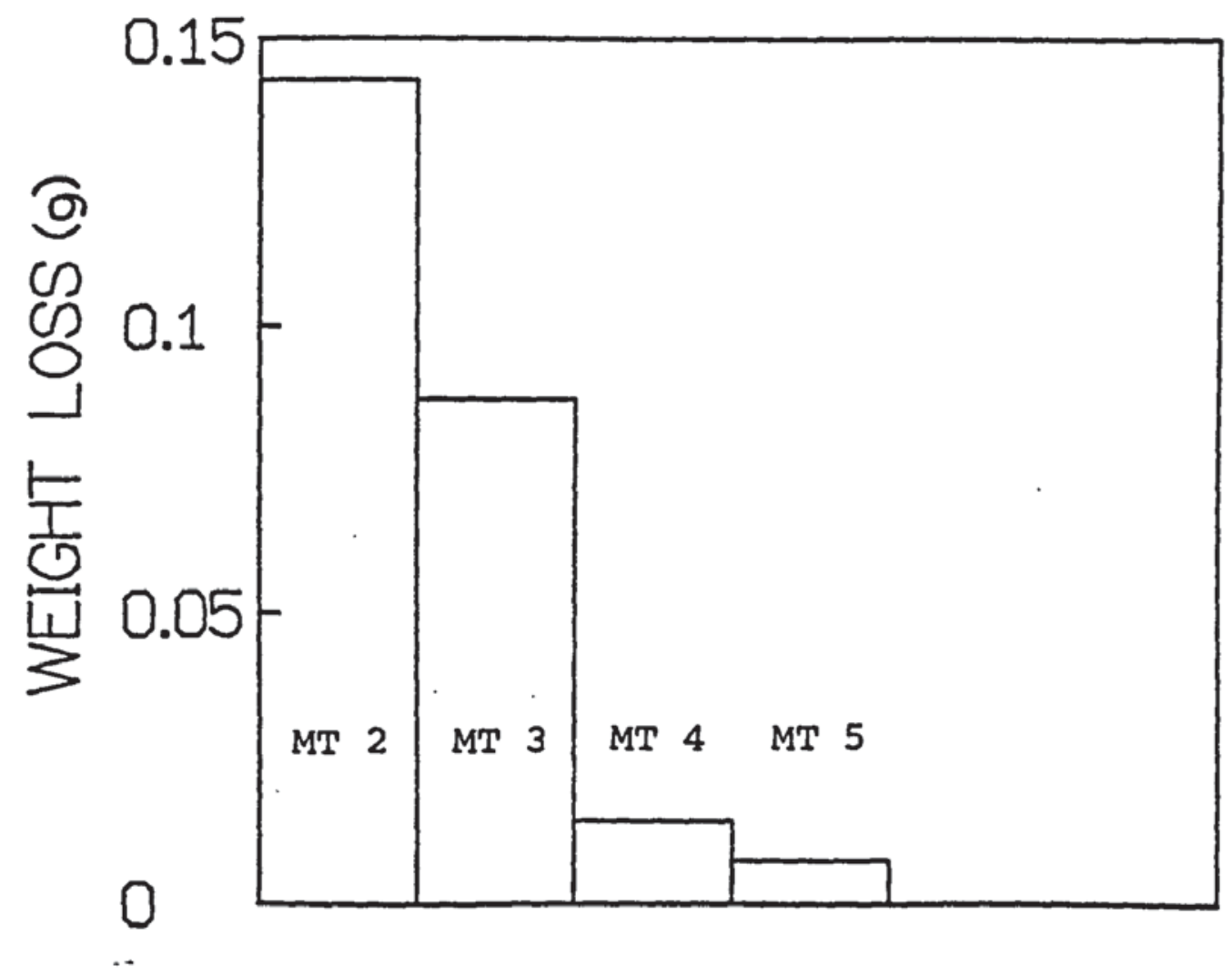

FIG. 57 Weight loss data obtained during the fatigue tests of bearings MT 2 - MT 5 
taken from the bearing after testing. It can be seen in Fig: 5la, as a dark line between coating and substrate. Some fatigue cracks are present, indicating that if adhesion had been satisfactory, fatigue failure would have subsequently occurred. The 'light blue' phase is distributed throughout the overlay, but appears to be in a greater concentration at the interface.

13.3.2 MT 7 (Sequence $\mathrm{Cl}(\mathrm{G})$ extended clean, Sn-Co overlay from Aston solution 3)

Fatigue occurred at $55 \mathrm{MPa}$ at the edge of the bearing, with no evidence of fatigue in the centre. This suggests that if the susceptibility of the bearing to fatigue at its edge could be eliminated, the overlay would be able to withstand higher loads before failure.

13.3.3 MT 8 (Sequence $\mathrm{Cl}(\mathrm{G})$ extended clean, Sn-Co overlay from Aston solution 3)

MT 8 failed at $62 \mathrm{MPa}$ by fatigue at the bearing edge and by adhesion failure.

13.3.4 MT 9 (Sequence $\mathrm{Cl}(\mathrm{G})$ extended clean, Sn-Co overlay from Aston solution 3)

'Due to MT 7 and 8 failing by preferential fatigue at the edges of the bearings, $1.5 \mathrm{~mm}$ was machined away allowing the remainder of the overlay to be tested without premature 
edge fatigue.

overlay bond failure occurred in a small region in the centre of the bearing at $55 \mathrm{MPa}$.

The cross-section Fig. 52a, again showed the presence of two 'light blue' bands, similar to MT 7, Fig. $51 \mathrm{~b}$.

13.3.5 MT 10 (Sequence DI(G) extended clean, Sn-Co overlay from $75: 25$ solution)

overlay fatigue at the bearing edge caused the test to be terminated at $55 \mathrm{MPa}$.

$13.3 .6 \mathrm{MT} 11$
$\begin{aligned} & \text { (Sequence } \mathrm{E}, \mathrm{Sn}-\mathrm{Co} \text { overlay from } 75: 25 \\ & \text { solution) }\end{aligned}$

The test stopped at $69 \mathrm{MPa}$ at which point the overlay had been completely removed and fatigue of the ASl5 had occurred. Since the overlay was in good condition at 62 MPa, overlay bond failure was suspected. The cross-section does show some evidence of fatigue although none of bond failure. However, voids can be observed close to the interface, Fig. 52b. The two phases appear to be distributed throughtout the overlay, with the greatest concentration of the 'light blue' phase at the interface.

13.4 Semi - Automatic Brush Plating ( 3 Pairs of Bearings)

It is evident, from the fatigue test results of the previous two sections, that preferential fatigue occurs at 
the bearing edge. This tendency to fatigue must be eliminated before an accurate assessment of the overlay performance and adhesion of the coating can be made. Upon closer examination of the brush plating technique used in sections 13.2 and 13.3, the following observations were made. The pad used was only slightly larger than the length of the bearing and when attached by means of rubber bands to the anode tended to bow. This caused a variation, although only slight, in the anode - cathode gap across the bearing length. There are two possible effects of this :

a) When a light anode pressure is applied.

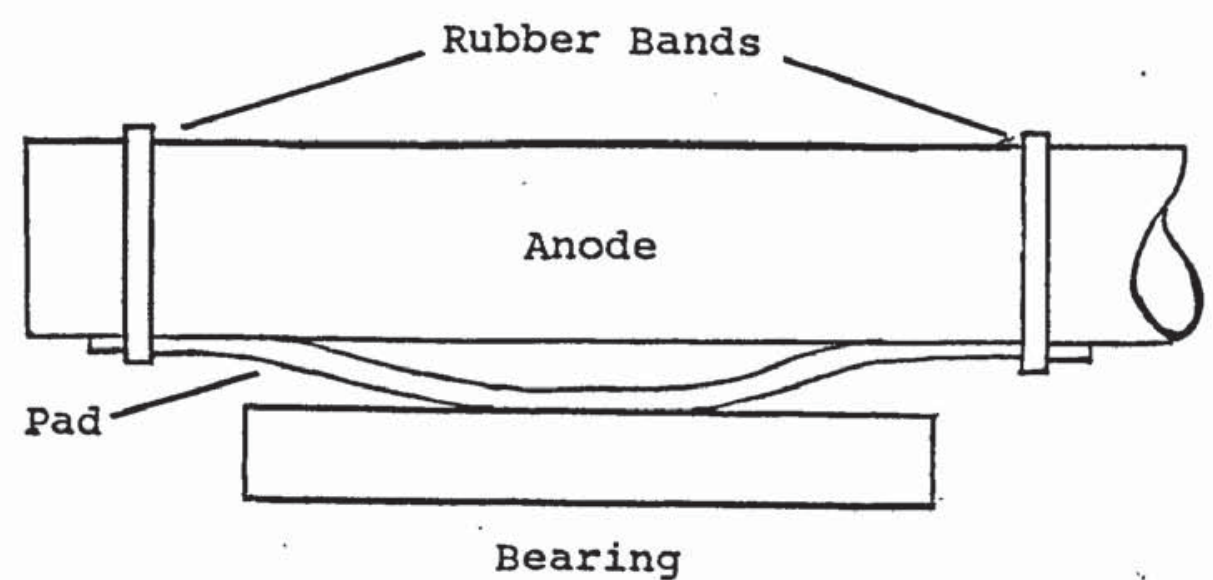

b) When a heavy anode pressure is applied.

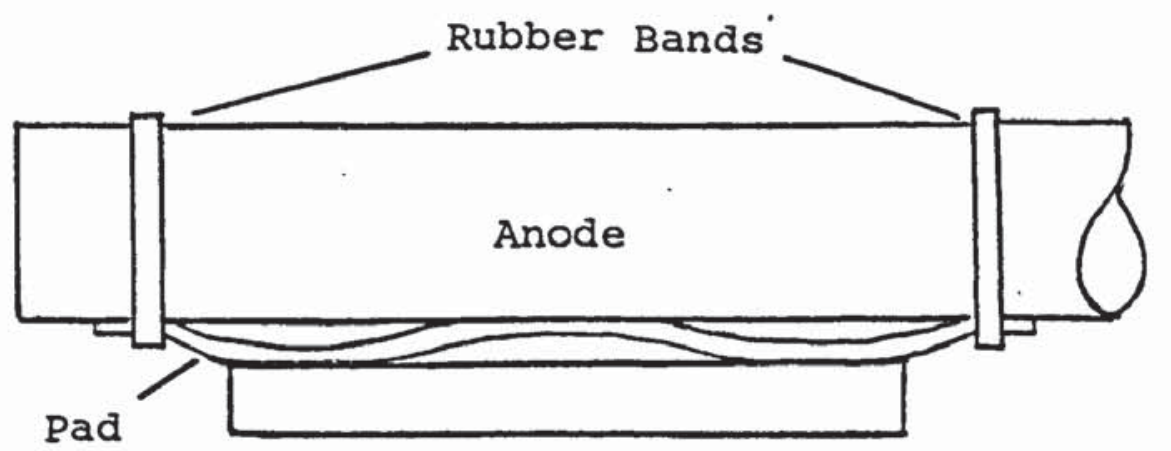

Bearing 
With reference to Fig. 1, it is obvious that an excessively high degree of anode - cathode motion can cause stréssed deposits to be produced, whereas a high current density can give rise to burned deposit. It is quite possible that either or both of these situations are occurring at various points across the bearing during a single plating operation. An extreme example of the variation in deposit quality from edge to centre can be seen in Fig. 58. To eliminate the variation in the anode - cathode gap that existed in sections 13.2 and 13.3 , several changes were made to the plating technique.

a) A multiple bearing holder was constructed, this allowed 3 pairs of bearings to be housed in a cylinder. The cylinder was then placed in the turning head, Fig. 15 .

b) A larger pad was used to enable all 3 pairs of bearing to be plated at the same time.

c) The outer four bearings were classed as 'dummy bearings' and discarded after plating.

The system described above allowed the central pair of bearings to be plated with a constant anode - cathode gap.

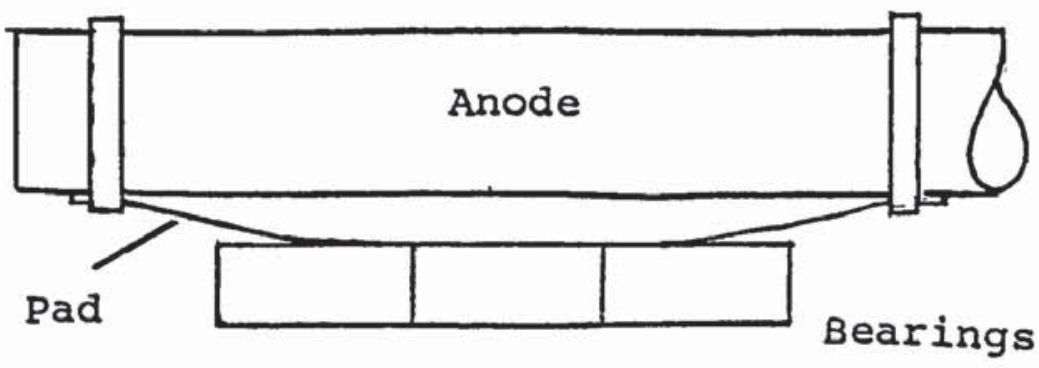




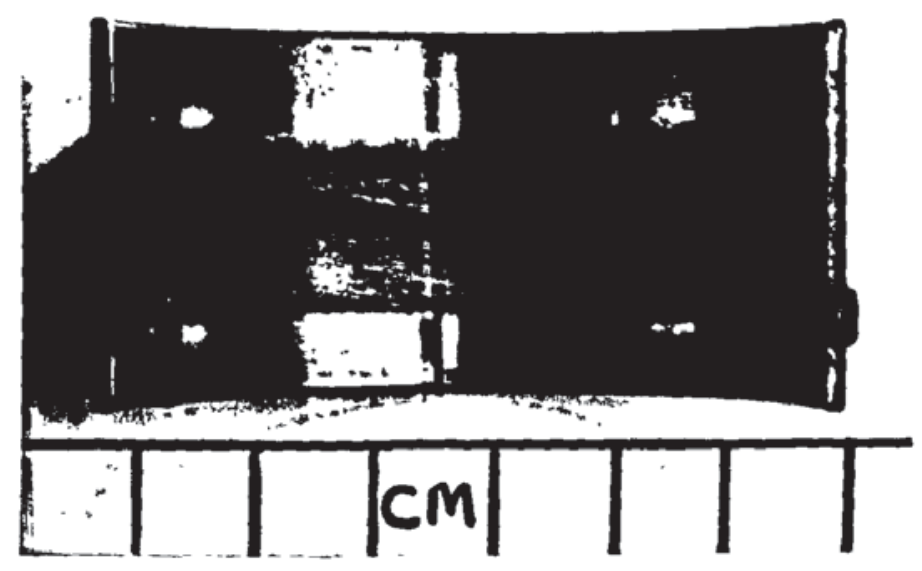

FIG. 58 optical macrograph of bearing exhibiting the variation of overlay deposit quality from edge to centre 
13.4.1 MT 15 (Sequence E, Sn-Co overlay from 75:25 solution)

The bearing fatigue test was terminated at $97 \mathrm{MPa}$ due to fatigue of the ASI5 lining. The overlay itself was still in good condition, with no evidence of fatigue, Fig. 59a. The cross-section Fig. 59b indicated the presence of the 'light blue' phase at the substrate/coating interface.

13.4.2 MT 16 (Sequence $\mathrm{Cl}(\mathrm{G})$ extended clean, Sn-Co overlay from $75: 25$ solution)

The bearing seized at $103 \mathrm{MPa}$, probably due to Asl5 lining fatigue. This result to some degree confirms that of MT 15 in that the overlay can withstand high fatigue loads.

13.4.3 MT 17 (Sequence E, Sn-Co overlay from Aston solution 4 )

The overlay fatigued at $90 \mathrm{MPa}$. The cross-section revealed that there was some evidence of fatigue of the overlay and fatigue of the ASI5 lining, without overlay fatigue being observed, Fig. 60 .

13.4.4 MT 18 (Sequence $\mathrm{Cl}(\mathrm{G})$ extended clean, Sn-Co overlay from Aston solution 4)

The bearing failed after 20 hours at $62 \mathrm{MPa}$, either due to overlay fatigue or bond failure. This result indicates 

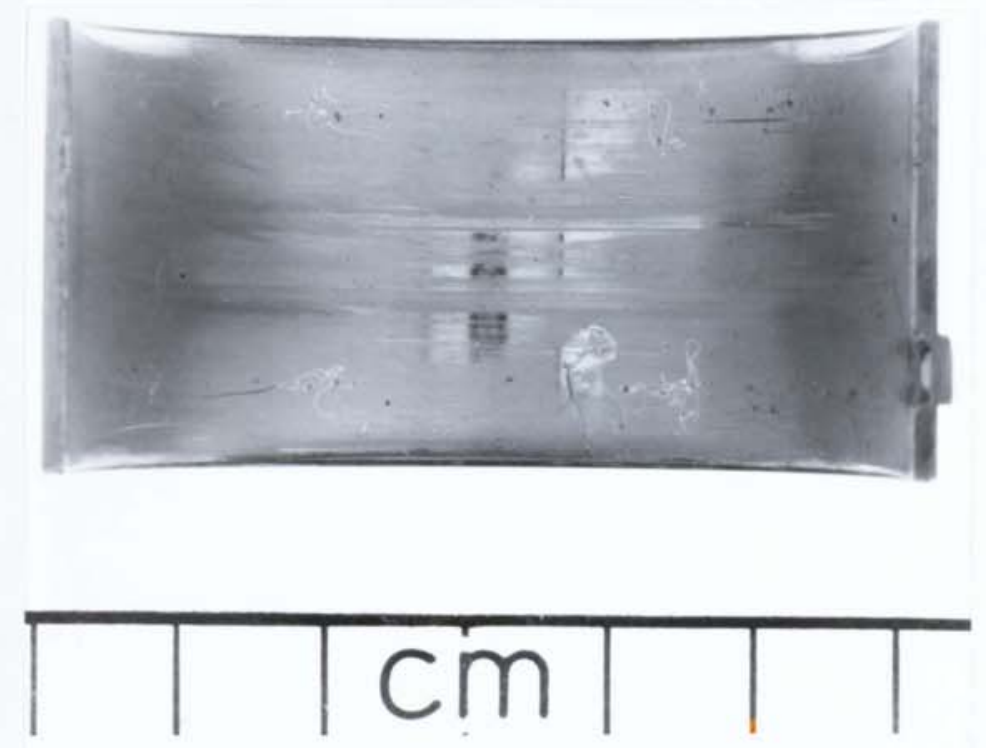

FIG. 59a Optical macrograph of bearing MT 15 after
Sapphire fatigue testing, showing no evidence of
fatigue

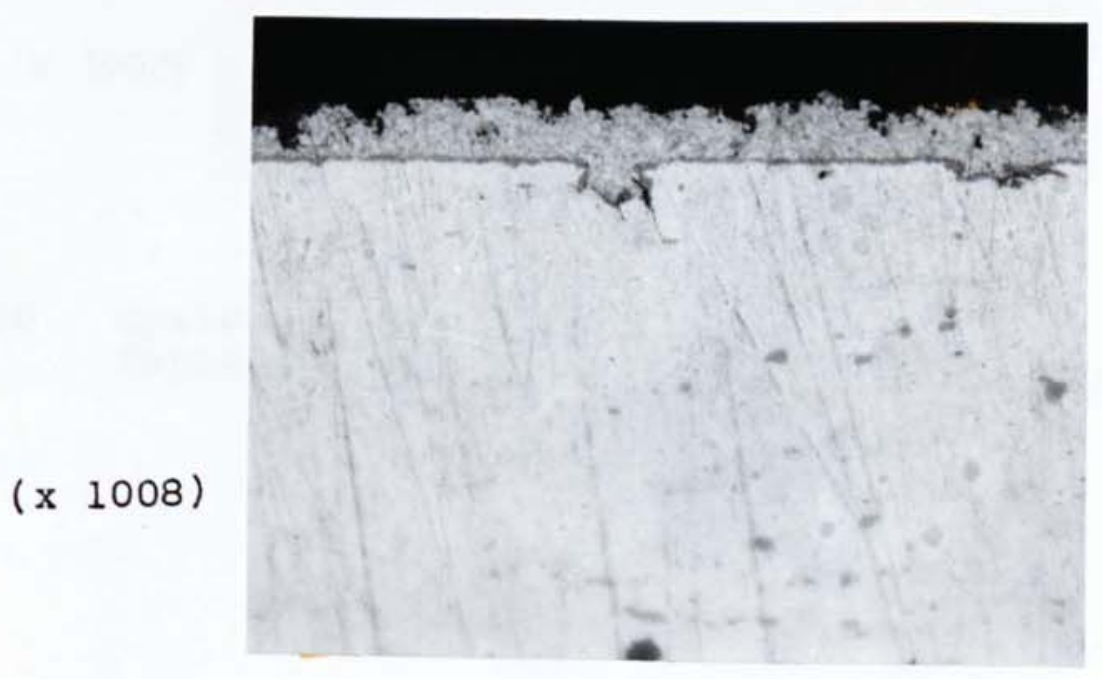

FIG. 59b optical micrograph of bearing MT 15 after Sapphire fatigue testing indicating the presence of a 'light blue' phase at the substrate-coating interface 


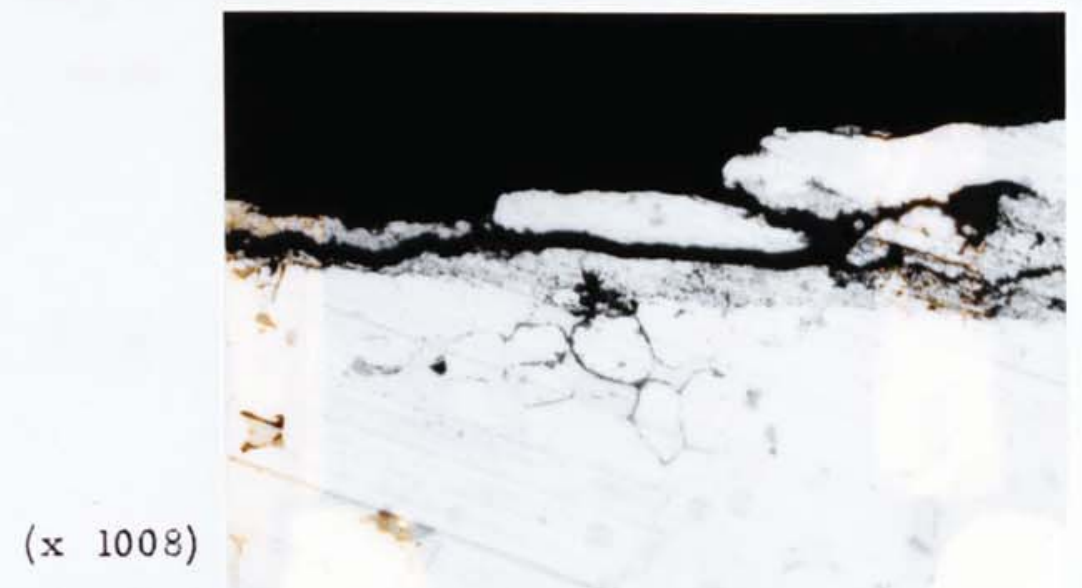

FIG. 60 Optical micrograph of bearing MT 17, exhibiting fatigue of the ASls lining 
that the zinc alloy pretreatment sequences, in this case $\mathrm{Cl}(\mathrm{G})$, are more variable in the degree of adhesion that can be achieved, than the direct sequence $E$.

13.4.5 MT 19 (Sequence DI(G) extended clean, Sn-Co overlay from Aston solution 4)

This is a similar result to MT 18 however, some areas have fatigue cracks propagating into the lining while other areas show no evidence of fatigue. There are also fatigue cracks that run parallel to the interface within the overlay.

13.4.6 MT 20 (Sequence $\mathrm{E}, \mathrm{Pb}-\mathrm{Sn}$ overlay from 70:30 solution)

The overlay was completely removed from the loaded area after 20 hours at $48 \mathrm{MPa}$, probably due to a poor bond. This result, using exactly the same pretreatment sequence as MT 15, confirms with B6 that while reasonable results have been achieved with tin-cobalt overlays, only poor results have been obtained when using lead-tin.

13.4.7 MT 21 (Sequence E, Sn-Co overlay from 75:25 solution)

This bearing is a copy of MT 15 and failed at $103 \mathrm{MPa}$ at which point the overlay had been removed and the Asl5 lining had fatigued. 
13.4.8 MT 24 (Sequence $\mathrm{E}, \mathrm{Sn}-\mathrm{Co}$ overlay from 50:50 solution)

The test was terminated at $90 \mathrm{MPa}$. The overlay, was worn in the loaded areas, but had not fatigued although, the AS15 lining had failed. 
Fatigue of plain bearings occurs because the crankshaft loads that are transmitted through the oil film vary considerably with crank angle(128) and at the current rotational speeds, act on an element of the bearing surface for a few milliseconds. If the existance of these load contours was not so fleeting they would be less steep, since the oil pressures would have more time to equalize. In the region of the densest packing of these contours, there is a concentration of shear stress and it is in this plane in which the fatigue crack first occurs. Work carried out on bearings without overlays(128) suggests that these cracks propagate as plain cracks towards the alloy steel bond, but then turn and run parallel to the bond when still in the alloy. It is known that a consequence of using an overlay, is an apparent increase in the fatigue strength of the underlying bearing material although, fatigue of the overlay usually occurs at a lower load than for the lining material(116). The overlay tends to cushion the lining by lowering the specific load experienced(117). However, no references to the effect and propagation of the fatigue cracks within the overlays has been found in the literature.

From the fatigue results obtained during this investigation, Table 7, there does appear to be some correlation between the pretreatment sequences employed, 
brush plating technique, overlay material and the fatigue results. There appears to be two main reasons for the failure of the bearings when Sapphire fatigue tested :
a) Adhesion failure, although the overlay contained fatigue cracks.
b) Fatigue failure.

Adhesion Failure was most evident for bearings MT 2 - MT5, plated using the semi - automatic technique with a small anode. Both zinc alloy and direct pretreatment sequences were used. It is evident from Fig. 56, that although all four bearings failed after the same time and at the same load, some bearings have less of the overlay removed than others. This indicates that some of the bearings have greater adhesion than others. MT 2 had most of its overlay removed hence, considered to have the lowest adhesion value. This bearing was pretreated using sequence $\mathrm{Cl}(\mathrm{G})$, that is using the hydrogen peroxide - sulphuric acid desmut. It is obvious from the results discussed in Chapter 10, that the degree of etching for this pretreatment prior to zinc alloy application is less than for $\mathrm{Cl}$ where nitric acid is used. .This probably indicates why this particular bearing failed, whereas bearings AlA, $\mathrm{AlB}$ and B5 did not fail by adhesion when $\mathrm{Cl}$ was used. MT 3 was pretreated in the same way as MT 2 except that it had an extended clean, that is an extra alkaline cleaning stage. This obviously improves the adhesion from that of 
MT 2 however, it is still lower than AlA, AlB and B5. The reasons why nitric acid cannot be used in a production process were given in 10.2 .

The direct plating sequence $E$, again improves on the adhesion level of MT 3. This is due to the extent of the mechanical keying that occurs as a result of this pretreatment sequence, as opposed to the zinc alloy ones. It is interesting to note that when a directly plated bearing was subjected to a heat - treatment at $100^{\circ} \mathrm{C}$, recommended by Wasserman(112) in his hypothesis to allow the electrodeposit to bond directly to the aluminium by converting the meta - stable aluminium hydride to a metal to metal bond, the amount of overlay removed was greater than when no heat - treatment was carried out MT 5 . An increase in the adhesion level was achieved, ie fewer bearing failures, with sequence $\mathrm{Cl}(\mathrm{G})$ by increasing the anode size. This effectively increases the area of the pad in contact with the substrate and consequently for the two minute sequence, the effective cleaning time per unit area was increased, resulting in greater adhesion. It should be noted that in neither of the bearings, where the zinc alloy solution was applied electrolytically, MT 10 and 19, did adhesion failure occur.

From the peel adhesion results, Table 5, it would be reasonable to assume that the brush pretreatments would not be able to produce satisfactory adhesion and that the 
conventional immersion sequences are far superior. However, the majority of the fatigue results indicate that satisfactory adhesion for this particular environment can be achieved by the brush treatments.

All fatigue tests were carried out on bearings pretreated by the single brush sequences as opposed to the double brush. From the peel test results Table 5, it may be considered to be more advantageous to use the double brush sequences. However, the simpler single sequences were considered to be of more commercial interest, providing that satisfactory adhesion could be achieved when fatigue tested.

The two lead - tin overlay plated bearings tested $\mathrm{B} 6$ and MT 20 both resulted in adhesion failure although, both were pretreated by sequences used to successfully plate tin cobalt overlays. These results, together with the total failure of the lead - tin fluoborate solution to produce a deposit with any adhesion, suggests that the bonding mechanism between the lead - tin and the ASI5 is unsatisfactory.

Fatigue Failure The direct sequence $E$ has no obvious detremental effect upon the fatigue properties of the bearings, when compared to the zinc alloy sequences. It was suggested in 11.1 that the deep angular etch pits may be considered as sites capable of initiating fatigue cracks 
hence, premature failure would occur. It may be more accurate in view of the results in Table 7 , to consider. the surface after pretreatment to be similar to that of an aluminium surface that has been glass - bead peened. This process has been used to reduce the probability of fatigue cracking(113).

For bearings MT 2 - MT 8 whether they failed by adhesion or fatigue, the areas that initially failed were at the edge of the bearing. Once fatigue or adhesion failure occurs in one area of the bearing surface, the test is terminated. As in the case of MT 2 - MT 8 premature failure at the bearing edge occurred hence, the actual fatigue rating of the overlay could not be evaluated. This problem was eliminated by a refinement to the plating technique detailed in 13.4. Hence, the fatigue ratings of MT 15 - MT 24 can be considered as accurate representations of the plating technique and the overlays used.

The results of MT 15, MT 16, MT 21 and to some extent MT 24. show that the tin - cobalt overlay used can withstand relatively high fatigue loads, higher infact than the AS15 lining itself. This was demonstrated by MT 15 where the test result indicated that the overlay was still in good condition although, the ASl5 had fatigued. The significance of this result can be put into perspective with reference to previously published fatigue ratings Fig. 6. The AS15 lining material has a fatigue range of 90-103 
MPa. Conventionally deposited lead - $10 \%$ tin has a rating of approximately 76 - $85 \mathrm{MPa}$. These results suggest that the $75 \mathrm{v} / 0$ tin $25 \mathrm{v} / 0$ cobalt overlay would be able to withstand higher fatigue loads than the rating indicates. Hence, a stronger more fatigue resistant lining could be used, without the possible consequence of the overlay failing, which would increase the possibility of the shaft being scoured by debris.

Further work however, is necessary to evaluate the corrosion resistance, seizure characteristics, optimum thickness and diffusion properties of the overlay.

The results of MT 15 and MT 16 also indicate that both pretreatment sequences used $\mathrm{E}$ and $\mathrm{Cl}(\mathrm{G})$ respectively have an adhesion level, that can satisfactorily withstand these high test loads. However, it was shown by the corrosion tests performed on the tin - cobalt overlay plated bearings, that immersion of the zinc alloy pretreated sample in hot oil, allowed the overlay to be subsequently removed by the application of adhesive tape. This was not the case with the directly plated bearings. The immersion in oil at $120^{\circ} \mathrm{C}$, caused the zinc alloy film and the tin in the high tin containing overlay to form an intermetallic phase, which consequently reduced the adhesion of the overlay. 
The cross-sections of the tested bearings revealed four distinct modes of fatigue crack initiation and propagation.

$i$ ) Initiation of the fatigue crack at the overlay surface. This propagates as a plane crack towards the coating - substrate interface. This mode of propagation was found in all bearings tested.

ii) Initiation at the overlay surface and propagation to some point within the overlay where the crack turns and runs parallel to the lining, in a manner analogous to that of the fatigue cracks in nonoverlay plated white metal bearings(128). This type of crack was only evident in the overlays that had a band of $\mathrm{CO}_{3} \mathrm{Sn}_{2}$ close to the interface. It appears from Fig. 49c that the fatigue crack propagates along the interface between the $\mathrm{Co}_{3} \mathrm{Sn}_{2}$ band and the tin rich band, that is along the surface between the harder and softer areas of the overlay. As a load is applied to the overlay, it is obvious that more deformation of the softer area will occur with respect to the relatively harder area. ...This will eventually cause a void to be formed between the two layers, allowing the crack to continue.

iii) Initiation within the overlay. Evidence of this type of crack formation is most noticible in the bearings where the distribution of the two phases is 
relatively even. There are two possible causes of this type of initiation.

a) The fatigue crack is initiated at a point below the surface where the shear stress is at a maximum although, Stobo and Lloyd(128) suggest that in the case of plain bearings, the maximum stress is at the surface.

b) The presence of the evenly distributed $\mathrm{CO}_{3} \mathrm{Sn}_{2}$ phase can be interpreted as a series of relatively hard particles in a softer matrix. Under the action of a rapidly alternating load the softer matrix will deform to a greater extent than the relatively harder $\mathrm{Co}_{3} \mathrm{Sn}_{2}$ phase hence, after several million such encounters, it is possible that a void is formed at the interface between the $\mathrm{CO}_{3} \mathrm{Sn} 2$ and the softer matrix, causing a preferential fatigue crack initiation site to be developed.

It is also evident from Fig. 54, that during propagation, larger voids occasionally occur within the overlay. The path of the fatigue crack may be obstructed by the relatively harder $\mathrm{Co}_{3} \mathrm{Sn}_{2}$ phase. Eventually the crack is forced around the interface between the two phases, in a manner similar to that discussed in (ii) above. A section of the overlay could then be removed during polishing. 
iv) The fatigue crack initiates at the overlay - lining interface. Only MT 17 showed any evidence of this type of fatigue. However, if as suggested for MT 15. that although the overlay is in good condition, the AS15 lining had fatigued, this type of fatigue crack mode would be expected to occur more often. It is unfortunate that in the bearings with the higher fatigue rating, the Asl5 lining fatigued too much to allow any examination to occur.

From all the information obtained so far, some generalizations can be made. The pretreatment sequences, both $\mathrm{Cl}(\mathrm{G})$ and $\mathrm{E}$ performed satisfactorily in a number of bearings and it can be assumed that under the right conditions no adhesion failures would occur. It may be worth noting that sequence $E$ appears to be more controllable than $\mathrm{Cl}(\mathrm{G})$, in terms of adhesion level that is, less likely for failure to occur. The lead - tin overlays have proved to be unsatisfactory in terms of adhesion and it may be assumed that the fatigue rating of this overlay is lower than that obtained by using tin cobalt.

It appears that the most satisfactory results were obtained when the tin - cobalt overlay contained a band of $\mathrm{Co}_{3} \mathrm{Sn}_{2}$ close to the interface. This would give the overlay increased strength, while the relatively softer tin based coating would impart excellent compatability, 
conformability and embeddability in a manner analogous to the steel backing and aluminium alloy lining in unplated bearings.

The effect of prolonged heating of the bearing, that is under service conditions, shown by the diffusion results indicate that eventually the $\mathrm{Co}_{3} \mathrm{Sn}_{2}$ phase will be more evenly distributed throughout the overlay. This too may be advantageous. Initially, the softer overlay is required for the initial running - in period however, the slightly harder overlày which would result after diffusion, would have beneficial effects in relation to the fatigue properties. 
1. A study of the various means of applying the zinc alloy film has shown the following :

a) The double treatments, both brush and immersion, resulted in hịgher peel adhesion and lower fịlm weights than their corresponding single versions, on SIC.

b) The electrolytic sequences resulted in hịger fịlm weịghts and hịgher peel adhesion values than their corresponding non electrolytic ones.

c) Immersion treatments resulted in higher peel adhesion values and lower film weights than theịr correspondịng brush versịons.

d) The nylon-polypropylene pad has a more open structure than 'Selvyt' hence, allowing more of the zinc alloy solution to reach aluminium surface, resulting in lower film growth weights and lower peel adhesion values.

e) The use of nịtrịc acịd on ASl5 (Al-20\% $\mathrm{Sn}-1$ \% $\mathrm{Cu}$ ) results in the tịn phase beịng readily attacked hence, the surface of the alloy, prior to the application of the second zincate film, has a 
higher activity than prior to the first application.

f) The use of a hydrogen peroxide/sulphuric acid desmut on AS15, results in a similar etch pattern, to that obtained when using nitric acid on SIC.

g) Using a hydrogen peroxide/sulphuric acid desmut results in the double treatments giving higher film weights and peel adhesion values than the corresponding single ones, but lower results than obtained on SIC.

2. The direct pretreatment sequence $\mathrm{E}$, was used to successfully overlay plate bearings for fatigue testing. Some oxide will be present on the alloys, prior to overlay plating, but this does not greatly inhibit adhesion, due to the mechanical keying that occurs.

3. Both the lead-tin and tin-cobalt brush plating solutions, have been shown to be examples of regular codeposition systems.

4. The use of 'Selvyt' as the pad material, results in lower proportions of the alloying element in the deposit. This suggests that the softer 'selvyt' is 
more aggressive towards the diffusion film, than the nylon-polypropylene pad, causing a greater degree of agitation to occur.

5. Satisfactory adhesion for fatigue testing could not be attained with lead-tin brush plated deposits.

6. The tin-cobalt overlays can withstand relatively high fatigue loads, higher than the Asl5 lining itself. To gain maximum benefit, the overlay should be deposited onto a more fatigue resistant lining material.

7. The corrosion and subsequent lack of adhesion, of the tin-cobalt overlays, experienced using the zinc alloy pretreatments, has been eliminated when the direct pretreatment sequence is used.

8. Four modes of fatigue crack initiation and propagation have been identified.

a) Initiation at the overlay surface, the crack then turns and runs parallel to the lining when still in the overlay.

b) Initiation at the overlay surface and propagation as a plane crack towards the lining. 
c) Initiation within the overlay.

d) Initiation at the overlay-lining interface.

9. In summary, it can be concluded that this investigation, using a direct (brush) plating technique has been used to successfully eliminate the nickel strike and the zinc alloy film. This reduces corrosion problems encountered by high tin containing overlays. The tin-cobalt alloy overlay developed, has proved to be superior in fatigue tests, to current overlays, superior even to the bearing lining used in this investigation. The brush plating procedure, has been developed to a multi-bearing, semi-automatic technique, which can be easily fully automated. 
Further work must involve the production of brush plating equipment on a larger scale, to enable a greater number of bearings to be plated by a fully automated technique. The design of the equipment and the material selection must be considered, particularly for the anode and the turning head sample holder. The sample holder should be manufactured, or coated, with a material that allows electrical contact between the substrate and the holder, but must also be resistant to the corrosive media used, most notably the hydrochloric acid cleaning solution and the water used to rinse the system between the various stages. The inert anode, must be manufactured from a material that will withstand the conditions encountered during plating, but not be exorbitantly priced, in order that it can be used for a production process. The use of graphite, as in this investigation, is limited due to the deterioration of the binding agent when used for prolonged times, at high current densities. It would also be advantageous to feed the plating solution through the anode, in which case this must also be considered in design and material selection.

The equipment should be designed to enable greater control over the plating variables involved to be achieved. It is important to determine the controlling factors, associated with the distribution of the phases found when using tincobalt overlays. A coating which contains the $\mathrm{CO}_{3} \mathrm{Sn}_{2}$ phase evenly distributed, will have vastly different properties 
to an overlay that contains only a thin band of $\mathrm{Co}_{3} \mathrm{Sn}_{2}$ at the substrate-coating interface, particularly in respect of plaịn bearịng requịrements. It may also be advantageous, to investigate the variation in hardness between the tin phase and the $\mathrm{CO}_{3} \mathrm{Sn}_{2}$ phase by the use of an 'ultramicrohardness' technịque.

Tịn-cobalt overlays have been shown to be capable of wịthstanding hịgher fatigue loads, than the lining materịal onto which they have been deposited. It is therefore, important to deposit similar overlays onto a stronger, more fatịgue resịstant lịnịng material, such as AS78 (Al-118Si$18(\mathrm{C})$, to asses fully the limiting properties of the overlay.

A fundamental study to establish the failure modes, of all overlays, in plain bearings should be undertaken. In particular the effects of fatigue, on the failure of tincobalt overlays, with respect to the effects of the dịstrịbution of $\mathrm{CO}_{3} \mathrm{Sn}_{2}$.

Stable and relatively inexpensive brush plating solutions, capable of depositing sound coatings over a wide range of current densities, must be developed. The addition of ammonium fluorịde, reducing the oxidation of stannous tin to stannic tịn may be sufficient. The solution should also be relatively easy to maintain as large volumes would be required for successful, commercial operation of such a brush plating facility. 
1. RUBINSTEIN, M. "hịgh speed Selective (Brush) Plating" Gold Plating Technology Bulletịn Number 1001974.

2. HUGHES, H.D. "Practical Brush Plating"

Trans. Inst. Met. Fin. 1956, 33, 424-429.

3. MAITLAND, D.W. and DEITSH, M.J. "Selective Plating" A.S.M. Metals Handbook 9 th Edịtion Volume 5 p.292299

4. KUSHNER, J.B. "A Simplified manual of modern Brush Plating"

J.B. Kushner Electroplatịng School. Evansville, Indiana U.S.A. 1950.

5. RUBINSTEIN, M. "Brush Plating Now Practical" Materịals and Methods 1954, 40(6), 98-102

6. RUBINSTEIN, M. "Metal put-on tool solves complex aircraft maintenance problems"

Selectron organisation Commercial Lịterature 1972

7. "The Dalic Process"

Metadalic Ltd.. Poyle Estate, Blackthorne Road, Colnbrook, Bucks.

8. RUBINSTEIN, M. and OGDEN, E.S. "Brush Plating" Proceedings of the Institute of Metal Finishing Annual Technical Conference, Blackpool, England, May 1979 .

9. RUBINSTEIN, M. "Selectịve Platịng on Alumịinium and Selective (Brush) Anodising"

Met. Fịnishịng (N.Y.) 1982, 80(3), 53-58 
10. BAINBRIDGE, W.W. "Selective Plate Your Moulds to Reduce Corrosion"

Selectron organisation Commerical Literature. Reprinted from plastics Technology, 1967.

11. GROSHART, E. "Brush Plating Techniques" Metal Finishing Guidebook 1981.

Published by Metals and Plastics Technology Inc. N.J. U.S.A.

12. RAPIDS, F.R. "Method of Gold Plating"

U.S. Patent $3755089(26-8-73)$

13. RAPIDS, F.R. "Method of Electroplating"

U.S. Patent $4067781(10-1-78)$

14. UHLIG, H.H. "Corrosion and Corrosion Control" Published by J. Wiley and Sons. New York, 1963.

15. DENNIS, J.K. and SUCH, T.E. "Nickel and Chromium Plating"

Published by Butterworths London 1972.

16. POTTER, E.C. "Electrochemistry-principles and Applications"

Published by cleaver-Hulme Press, London, 1981.

17. KENDRICK, R.J. and WATSON, S.A. "Proceedings of the Symposium on Sulphamic Acid and its Electrometallurgical Applications".

Milan, May 1966 .

18. WATSON, S.A. "Applications of Nickel Electroforming in Europe"

Plating 1975, 62, 851-861.

19. HART, A.C. "High Speed Electroplating- A review on the subject"

Trans. Inst. Met. Fin. 1977, 55, 65-69. 
20. GABE, D.R. and ROBINSON, D.J. "High speed Electrodeposition of Copper from Conventional sulphate Electrolytes"

Trans. Inst. Met. Fin. 1970, 48, 35-42.

21. WESLEY, W.A., SEllERS, W.S. and ROEHL, E.J. "Electrodeposition of Nickel at High Current Density"

Proc. Am. Electroplaters Soc. 1949, 36, 79-92.

22. SAFRANEK, W.H. and LAYER, C.H. "Fast Rate Electrodeposịtion"

Trans. Inst. Met. Fin. 1975, 53, 121-125

23. EISNER, S. "An Ultra High speed Plating Process Utịlịsing Small Hard Partịcles"

Trans. Inst. Met. Fin. 1973, 51, 13-16.

24. DENNIS, J.K. and JONES, D. "Brush Platịng" Surfiace Technology 1981, 12, 57-73.

25. HUGHES, H.D. "Practical Brush Platịng"

Trans. Inst. Met. Fin. 1956, 33, 424-429.

26. RUBINSTEIN, M. "Selectịve (Brush) Plating, A put-on tool"

Met. Fịnịshịng (N.Y.) 1981, 79(10), 73-78.

27. BRENNER, A. "Electrodeposition of Alloys" Published by Academic Press Inc. New York, U.S.A. 1963.

28. LOWENHEIM, F.A. "Electroplatịng"

Published by McGraw-Hill Inc. New York, U.S.A. 1978.

29. GABE, D.R. "Electrodeposited Decorative and protective Coatings" Electroplatịng and Metal Finishịng 1972, 25(10), 1021 . 
30. KROHN, A. and BOHN, C.W. "Electrodeposition of Alloys : 1965-1970" Plating 1971, 58, 237-241.

31. ROOKSBY, H.P. "The Structure of Speculum Electrodeposits"

J. Electrodep. Tech. Soc. 1950, 26, 119-124.

32. RAUB, E. and SAULter, F. "Der Aufbau galvanischer Legierungsnied-erschlaege XII"

Metalloberflache 1957, 11(8), 249-252:

33. ROOKSBY, H.P. "An X-ray Study of Tin-Nickel Electrodeposits"

J. Electrodep. Tech. Soc. 1951, 27,153-160.

34. SMART, R.F. and ROBBINS, D.A. "The Structural Stability of Tin-Nickel Electrodeposits"

Trans. Inst. Met. Fin. 1960, 37, 108-109.

35. GROFF, J.F. "Process of Electroplating" U.S. Patent 1364051 (1920).

36. CHANDLER, C.H. "Plating" U.S. Patent 1373488 (1921).

37. BLUM, W. and HARING, H.E. "The Electrodeposition of Lead-Tin Alloys"

Trans. Am. Electrochem. Soc. 1921, 40, 287-304.

38. DuROSE, A.H. and HUTCHINSON, D.M. "Influence of Operating Variables on Composition of Electrodeposited Lead-Tin Alloys"

Plating 1953, 40, 470-476, 630-632:

39. WILD, F. "Fluoborates in Plating"

Electroplating and Metal Finishing 1960, 13(9), 630632 . 
40. CAMPBELL, F. and VON FRAUNHOFER, J.A. "Some Uses of Pyrophosphates in Metal Finishing II"

Surface TEchnology 1977, 5, 235-254.

41. VON FRAUNHOFER. J.A. "The Electrodeposition of Lead" Published by Academic Press London, 1979.

42. SREE, V., VAID, J. and RAMA CHAR. T.L. "Electrodeposition of Lead and Lead-Tin Alloys from Pyrophosphate Baths"

J. Electrochem. Soc. Japan 1958, 26(4-6E), 78-85 (Overseas Edition).

43. RAMA CHAR, T.L. and VAID, J. "Electrodeposition of Tin-Lead Alloys from the Pyrophosphate Bath"

Met. Finishing (N.Y.) 1961, 12, 44-49.

44. PIONTELLI, R. and GIULATTO, A. "The Electrodeposition of Metals from Solutions Based on Aminosulphonic Acid and its Salts"

Cemicae Industeria 1939, 21(8), 478-491.

45. PIONTELLI, R. and CANONICA, L. "Alloy Deposition from Sulphate Baths"

Proc. 3rd. Int. Conf. on Electrodeposition 1947, 121-125.

46. CLIFTON, F.L. "Electrodeposition"

U.S. Patent 2489523 (1949).

47. DuROSE, A.H. "Lead-Tin Alloy Plating"

U.S. Patent 2460252 (1949).

48. INDIRA, K.S.A AND UDUPA, H.V.K. "Suphamate Baths for Lead and Lead-Tin Alloy Deposition"

Met. Finishing (N.Y) 1971, 69(1), 94-101.

49. DUPONT DE NEMOURS, E.T. and CO. "Procedure for the Electrolytic preparation of Coatings consisting essentially of Tin"

German Patent 670403 (1939) 
50. JENNISON, H.C. and BRADLEY, J.C. "Method of Inhibiting the Formation of Blackspots on Tinned Copper"

U.S. Patent 2336615 (1946).

51. IRELAND, J. and PARKINSON, N. "Improvements in the Electrodeposition of Metals"

G.B. Patent 661154 (1951)

52. SREE, V. and RAMA CHAR. T.L. "Tin-Cobalt Alloy plating from the Pyrophosphate Bath"

Bull. India Sect. Electrochem. Soc. 1960, 9, 13-14.

53. CLARKE, M., ELBOURNE, R.G. and MACKAY, C.A. "An - Electrodeposited Bright Tin-Cobalt Intermetallic Compound CoSn"

Trans. Inst. Met. Fin. 1972, 50, 160-163.

54. THOMAS, J.H. and SHARMA, S.P. "An XPS/AES study of Films of Electrodeposited Tin-Cobalt Alloy"

$\mathrm{J}$. of Vac. Sci. and Technology 1978, 15(5), 17061711 .

55. HEMSLEY, J.D.C. and ROPER, M.E. "Tin-Cobalt Alloy plating from a Sulphate Electrolyte"

Trans. Inst. Met. Fin. 1979, 57, 77-80.

56. SPANCHAK, M.J.D. and O'GRADY, J. "Tin-Cobalt Alloy Electrodeposits"

proceedings of the Institute of Metal Finishing Annual Technical Conference, 1983.

57. SAFRANECK, W.H. "The Properties of Electrodeposited Metals and Alloys : A Handbook"

Published by American Elsevier New York 1974.

58. ENDICOTT, D.W. and KNAPP, J.R. "Electrodeposition of Nickel-Cobalt Alloy : Operating Variables and physical properties" Plating $1966,53(1), 43-60$. 
59. MCFARLEN, W.T. "Electroformed Nickel-Cobalt Alloy Deposits"

plating 1970, 57(1), 46-50.

60. ZENTNER, V. "Electrodeposited and Electroless Magnetic Alloys for Computers"

Plating 1965, 52(9), 868-872

61. BRENNER, A., COUCH, D.E. and WILLIAMS, E.K. "Electrodeposition of Alloys of Phosphorous and Nickel or Cobalt"

Plating 1950, 37, 36-42, 161-164.

62. TURNS, E.W. and HILDEBRAND, J.F. "Electroforming Refractory Metals and Alloys"

Proc. Am. Electroplaters Soc. 1964, 51, 150-163.

63. WEIL, R. and READ, H.J. "The Structure of Electrodeposited Metals"

Met. Finishing (N.Y) 1955, 53(12), 60-64.

64. NEWMAN, R.C. "The Lattice spacing of Thin Electrodeposits of Cobalt and Nickel in a Copper Single Crystal"

Proc. Phys. Soc. $1956(B), 69(4), 432-440$.

65. GaIGALAS, K.I., BODNEVAS, A.I. and MATulis, J. "The Effect of Plating Bath Variables on the Structure Transformations of Electrodeposited Cobalt"

Lietuvos TSR Mokslu Akad. Darbai Seriia B, 1968, $55(4), 59-68$.

66. GODDARD, J. and WRIGHT, J.G. "The Effect of Solution $\mathrm{pH}$ and Applied Magnetic Field on the Electrodeposits of Tin Single Crystal Films of Cobalt"

Brit. J. App. Phys. 1964, 15(7), 807-814.

67. SARD, R., SCHWARTZ, C.D. and WEIL, R. "Deposition Modes of Cobalt from Sulphate-Chloride Solutions" J. Electrochem. Soc. 1966, 113(5), 424-428. 
68. CARDONA, I and CAVALLOTTI. P. Electrochim Metal (Politec. Milan) 1966, I(3), 364.

69. ANON, The Brass World and Platers Guide 1913, 9, 29.

70. WEST, E.G. "Electroplating on Aluminium"

J. Electrodep. Tech. Soc. 1946, 21, 211-266.

71. JONKIND, J.C. "Experience With Plating on Aluminium" Trans. Inst. Met. Fin. 1967, 45, 155-160.

72. TRAVERS, W.J. "Plating on Aluminium"

Trans. Am. Electroplating Soc. 1939, 75, 201-206.

73. TRAVERS, W.J. "Preparation of Anodised Aluminium for Plating"

Proceedings of the 30 th Annual Conference of the American Electroplaters Soc. 1942, 29, 119-12.

74. BUNCE, B.E. "Production Plating of Aluminium and Its Alloys Using the Phosphoric Acid Anodising Pretreatment"

Electroplating and Metal Finishing 1953, 6(9), 317323.

75. ECKERT, G.

Metallwaren Industrie und Galvano Technic. 1932, 30, 81 .

76. WORK, H.J. "Practical problems Involved in Commercial Electroplating on Aluminium"

J. Electrodep. Tech. Soc. 1933, 8(7), 1-15.

77. DuMOND, T.C. "Chromium is Directly Plated on Aluminium by a New Process"

Materials and Methods 1950, 32(4), 56-57.

78. WORK, H.K. "Electroplating on Aluminium and its Alloys"

Trans. Am. Electrochem. Soc. 1928, 53, 361-387. 
79. WITHERS, T.C. and RITT. P.E. "Firm Adherent Plating of Aluminium"

Met. Finishing (N.Y) 1958, 56(1), 53-57.

80. LOBO, L.J.V., KINNERKAR. P.S., GANU, IG.M. and ROY. D.L. "Electroless Plating of Metals on Aluminium" Electroplating and Metal Finishing 1969, 22(9), 2126.

81. HEIMAN, S. "Deposition of Metals on Aluminium by Immersion from Solutions Containing Fluoborates" J. Electrochem. Soc. 1949, 95(5), 205-225.

82. WERNICK, S. and PINNER. R. "The Surface Treatement and Finishing of Aluminium and its Alloys" Published by R, Draper Ltd. London. 1972.

83. $M$ and $T$ CHEMICALS LTD. "Stannate Coating Bath and Method of Coating Aluminium With Tin" U.S. Patent 3274021 (1966).

84. $M$ and $T$ CHEMICALS LTD. "Tin Electrodeposition Process"

U.S. Patent 3346468 (1967).

85. M and T CHEMICALS LTD. "Plating Metal" G.B. Patent 1080291 (1968).

86. M and T CHEMICALS LTD. "Tinning of Aluminium" G.B. Patent 1087054 (1968).

87. M and T CHEMICALS LTD. "Electroplating" G.B. Patent 1109676 (1968).

88. M and T CHEMICALS LTD. "Chromium Plating" G.B. Patent 1110412 (1968).

89. M and T CHEMICALS LTD. "Immersion Plating" G.B. Patent 1110770 (1968). 
90. BUllough, $W$ and GARDAM. G.E. "The Quantitive Adhesion of Nickel Electrodeposited onto Aluminium Alloys"

J. Electrodep. Tech. Soc. 1947, 22, 169-186.

91. LASHMORE, D.S "Immersion Coatịngs on Alumininium" Platịng and Surface Finishịng 1980, 67(1), 37-42.

92. LASHMORE, D.S. "Thịn zịnc Films on Alumịinu" J. Electrochem. Soc. 1980, $127(3), 573-578$.

93. KELLER, F. and zELLEY. W.G. "Condịtionịng Alumịium Alloys for Electroplating"

J. Electrochem. Soc. 1950, 97, 143-151.

94. SUCH, T.E. and WYSZYNSKI. A.E. "An Improvement in the Zincate Method for Plating Aluminium"

Platịng 1965, 52, 1027-1034.

95. BENGSTON, H. "Methods of Preparation of Aluminium for Electrodeposition"

Trans. Electrochem. Soc. 1945, 88, 307-324.

96. W. CANNINGS and CO. LTD. "Electroplating on Alumịịum and Its Alloys."

G.B. Patent 1007252 (1965).

97. WYSZYNSKI, A.E. "An Immersion Alloy Pretreatment for Electroplatịng onto Alumịnịum."

Trans. Inst. Met. Fịn. 1967, 45, 147-154.

98. KORPIUN, J. "Electrodeposition on Alumininum and its Alloys"

U.S. Patent. 2142564 (1939).

99. SAUBESTRE, E.B. and MORICO, J.L. "Dilute Zịncating Solution for plating on Aluminium"

Platịn 1966, 53(7), 899-904. 
100. KAMPERT, W.P., COCHRAN, W.C. and BAKER, F.W. "Zincate Films on Aluminium"

American Electroplaters Society 65 th Annual Technical Conference. June 1978.

101. MONTEIRO, F.J. and ROSS, D.H. "A Study of Modified Alloy Zịcate Pretreatments for Platịng on Alumịnịm Part II".

Trans. Inst. Met. Fin. 1985, 62, 155-159.

102. ATKINSON, J.T.N. "Acịd Copper Platịng on Aluminium" J. Electrochem Soc. 1958, 105(1), 24-27.

103. ATKINSON, J.T.N. "Novel Process for plating Nịckel onto Alumịinium Alloys"

Platịng 1960, 47(5), 509-512.

104. FAUST, C.L., SCHAER., G.R. and SEMONES, D.E. "Electroplatịng Chromịum Dịrectly onto Alumininium". Plating 1961, 48(6), 605-612.

105. EISEN-U METALLDIENST (VIENNA) 1959, 25, 8.

106. WORK, H.K. "Electroplating on Alumịịm from Cyanịde Solutịons"

Trans. Am. Electrochem. Soc. 1931, 60, 53-57.

107. ASADA, T. "Method of Electroplating Nickel on an Alumịnịm Article"

U.S. Patent. 3515650 (1970).

108. FYFE, R. "Commercial Methods of Depositing Nickel and Chromịm"

Metal Industry 1950, 77, 300-302.

109. WALlBANK, A.W. "The Platịng of Alumịnịm Articles as a Production Process"

J. Electrodep. Tech. Soc. 1952, 28, 209-217.

110. RUBINSTEIN, M. "Platịng Aluminịum Without Tanks" Modern Metals 1969, 25(3), 64-69. 
111. WASSERMAN, A. "Dịrect Electroplating on Aluminium" Products Fịnịshịng (Cịncịnati) 1978, 42(5), 48-52.

112. WASSERMAN, A. "Dịrect Plating of Alumịịu" American Electroplaters Soc. Symposium on plating Difficult to Plate Metals. New Orleans U.S.A. 1980.

113. WASSERMAN, A. "Dịrect Plating of Aluminium" Platịng and Surface Finịshịng 1982, 69(2), 58-60.

114. DUCKWORTH, W.E. and FORRESTER, P.G. Proceedings of the Institute of Mechanical Engineers Conference on Lubrication and Wear. London 1957.

115. PERKINS, C.A. and CAMPBELL, B.D. "The Effects of Dịesel Engịne Development on Crankshaft Bearịng Performance." The Glacịer Metal Co. Ltd. London LB 433/78.

116. PRATT, G.C. "Materials for Plaịn Bearings" International Metallurgical Review 1973. Institute of Metals London.

117. EASTHAM, D.R. and CROOKS. C.S. "Platịng for Bearing Applịcations"

Trans. Inst. Met. Fin. 1982, 60, 9-13.

118. SEMLITSCH, M. "Comparative Mịcroanalysis Investigations of Complex Friction Bearings by Means of AAS, XRD and EPMA."

Mikrochim. Acta. 1970, IV, 157-169.

119. TIN RESEARCH INSTITUTE "Tin in Plaịn Bearings" Publication Number. 595.

120. BEEBE, A.H., ROTHSCHILD, B.F. and Le BRASSE, G.J. "Overlay Platịng of Steel Backed Aluminịum Lịned Sleeve Bearings"

Proc. Am. Electroplaters Soc. 1956, 43, 164-171. 
121. BEEBE, A.H. "Electrodeposition of lead Alloys onto Alumịnium Lịned Steel Backed Engịne Bearịngs"

American Electroplaters Soc. Syposium on Plating Dịfficultt to Plate Metals, New Orleans U.S.A. 1980.

122. PUGH, B. "Frịctịon and Wear"

Published by Newnes-Butterworth. London 1973.

123. CzIChOS, H. "Faịlure Crịteria in Thin Film Lubrication-The Concept of the Failure surface" Tribology 1974, 7(1), 14-20.

124. WATERHOUSE, R.B. "Fretting Corrosion" Publịshed by Pergamon Press London 1981.

125. PRATT. G.C. "Wear of Plaịn Bearịngs" Trịbology 1969, 2(8), 3, 162-165.

126. GARNER, D.R., JAMES, R.D. and WARRINER, J.F., "Cavitation Damage in Engine Bearịgs."

A.S.M.E. Energy Technology Conf. New orleans U.S.A. Feb. 1980 .

127. MCNAUGHTAN, D.J. "The Improvement of White Metals for Severe Servịce."

J. Inst. Met. 1934, 55, 33-47.

128. STOBO, J.J. and LLOYD, K. "The Fracture of Plain Bearịgs"

Metals Forum 1979, 2(4), 205-211.

129. WILSON, W.H. "A Test Machịne for Assessing the Fatigue Properties of Impulsịvely Loaded Plaịn Bearings ."

Proc. Inst. Mech. E. 1968, 182(3G), 129-131.

130. REYNOLDS, 0 "On the Theory of Lubrication and Its Application to B. Tower's Experiments"

Phịl. Trans. Roy. Soc, 1886, 177(1), 157-234 
131. TOWER, B. "First Report on Friction Experiments" Proc, Inst. Mech. E. a) 1883, 11, 632-659.

b) $1884,1,29-35$.

132. TOWER, B. "Second Report on Friction Experiments" Proc. Inst. Mech. E. 1885, 1, 58-70.

133. British Petroleum Company. "Lubrication Theory and Application."

Published by B.P. Trading Itd. London 1969.

134. MARTIN, F.A. and 'GARNER, D.R. "Design of Plain Bearings"

"Industrial Tribology." Jones and Scott. Eds. Published by Elsevier Scientific Co. 1983.

135. DENNIS, J.K. and TIPPING, P. "A Study of Factors Affecting peel Adhesion of Electroplated Coatings on ABS and Polypropylene"

Electroplating and Metal Finishing 1974, 27(11), 916.

136. GOLBY, J.W., DENNIS, J.K. and WYSZYNSKI, A.E. "Factors Influencing the Growth of Zinc Immersion Deposits on Aluminium and its Alloys"

Trans. Inst. Met. Fin. 1981, 59, 17-24.

137. GOLBY, J.W. and DENNIS, J.K. "A Study of the Effect of pretreatment procedures on Plating of Aluminium Alloys"

Surface Technology 1981, 12(2), 141-155

138. BAKISH, R., KORNHAAS, R.J. and BORDERS, E.Z., "Etching of Hard Aluminium Foil"

Electrochem Tech. 1968, 6(5-6), 192-194.

139. COTTON, F.A. and WILKINSON, G.

Advanced Chemistry. Published by $J$. Wiley and Sons. New York U.S.A. 1980. 


\section{Aston University}

Pages removed for copyright restrictions. 